\title{
MASTER
}

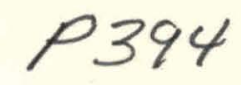

\section{L2-3 PRE-LOCE MANEUVER CORE SAFETY ANALYSIS}

S. A. Atkinson/D. G. Satterwhite

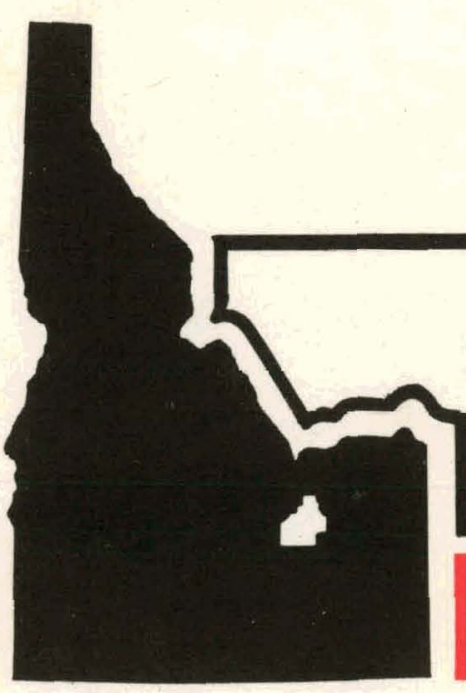

\section{$\prod_{>} E \boldsymbol{E} \Sigma \boldsymbol{G}$ Idaho, Inc.}

This report was prepared as an account of work

sponsored by the United States Government. Neither the

United States nor the United States Department of

Energy, nor any of their employees, nor any of their

contractors, subcontractors, or their employees, makes

any warranty, express or implied, or assumes any legal

liability or responsibility for the accuracy, completeness

or usefulness of any information, apparatus, product or

process disclosed, or represents that its use would not

infringe privately owned rights.

\section{DEPARTMENT OF ENERGY}




\section{DISCLAIMER}

This report was prepared as an account of work sponsored by an agency of the United States Government. Neither the United States Government nor any agency Thereof, nor any of their employees, makes any warranty, express or implied, or assumes any legal liability or responsibility for the accuracy, completeness, or usefulness of any information, apparatus, product, or process disclosed, or represents that its use would not infringe privately owned rights. Reference herein to any specific commercial product, process, or service by trade name, trademark, manufacturer, or otherwise does not necessarily constitute or imply its endorsement, recommendation, or favoring by the United States Government or any agency thereof. The views and opinions of authors expressed herein do not necessarily state or reflect those of the United States Government or any agency thereof. 


\section{DISCLAIMER}

Portions of this document may be illegible in electronic image products. Images are produced from the best available original document. 


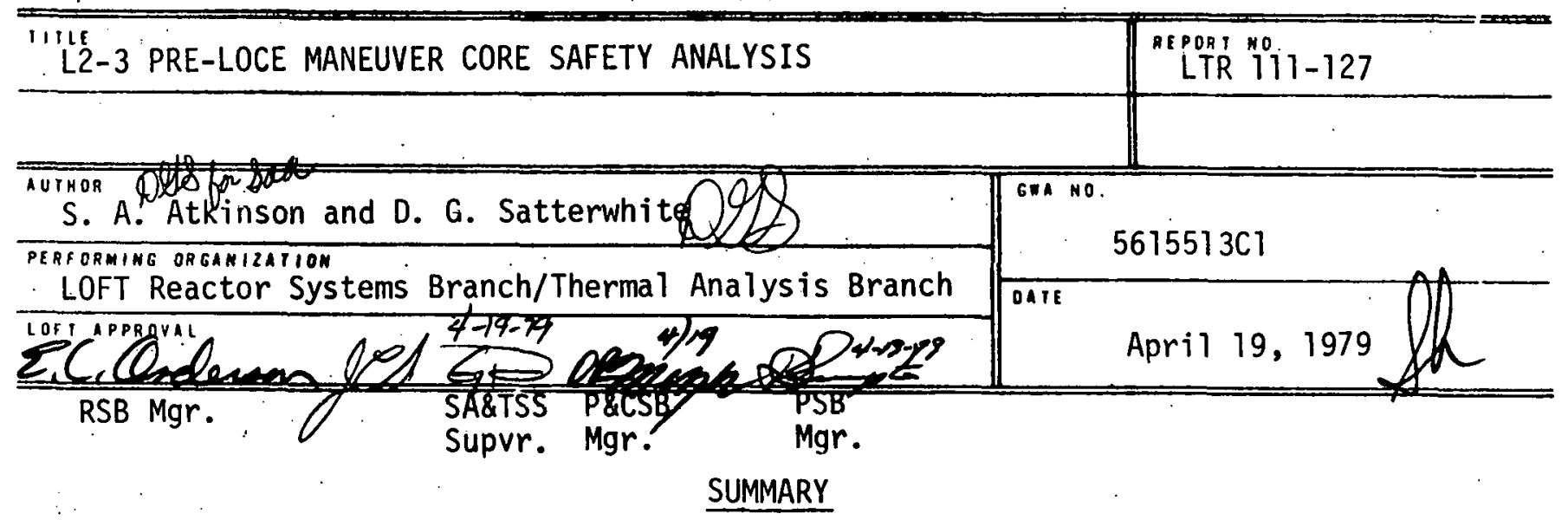

This report summarizes the core safety analyses and reactivity control analyses that have been done to support safe operation of the LOFT reactor in the LOCE pre-blowdown (or pre-LOCE) operating mode (Operating Mode 8) for the L2-3 nuclear loss of coolant experiment. This report also summarizes safety analyses done to support LOFT operation in other operating modes (Modes 5, 6, and 7) with changes in operating conditions or assumptions due to requirements for safe operation of the L2-3 test (changes from conditions or assumptions for previous safety analyses for those operating modes). The analyses discussed herein do "not include analyses for potential loss of coolant accidents, or for accidents during the LOCE blowdown mode (Mode 9), or for potential radiation releases during LOCE operation. These latter analyses are discussed in:

(1) "L2-3 Blowdown Scoping Experiment Safety Analysis (ESA)", C. H. Cooper, (November 27, 1978).

(2) "L2-3 Test Experiment Safety Analysis (ESA)", J. L. Plum, (to be published).

This report and the ESA reports above provide the core safety analysis to support LOFT operation for the L2-3 test.

\section{DISPOSITION OF RECOMMENDATIONS}

No dispositton required. 
THIS PAGE

WAS INTENTIONALLY

LEFT BLANK 


\section{CONTENTS (contd:)}

Page

5. Limiting Faults.............. 83

5.1 Rod Ejection Accident . . . . . . . . . . . 83

5.2 Steam Line or Feedwater Line Rupture . . . . . . . 85

5.2.1 Steam Line Rupture at Full

\begin{tabular}{l} 
Pre-LOCE Power . \\
5.2.2 Maximum Cooldown Accident . . . . . . $\quad 85$ \\
\hline.
\end{tabular}

5.3 Rapid Loss-of-Flow from Both Primary Coolant Pumps . 87

6. Accident Analysis Conclusions ............ 87

VI. MODE 5, 6, AND 7 ANALYSIS FOR L2-3 OPERATION . . . . . . . 93

1. Operation With Reduced Nominal Pressure . . . . .. . . 93

2. L2-3 Mode 7 Operation With Revised Scram Curve . . . . 98

3. L2-3 Xenon Effects on Mode 7 Operation . . . . . . . . 99

4. Miscellaneous L2-3 Mode 7 Analyses ......... 101

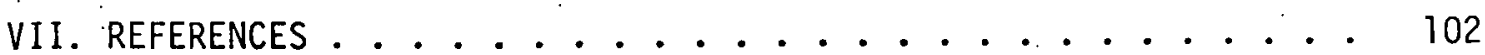


CONTENTS (contd.)

Page

\section{TABLES}

II-1 L2-3 MODE 8 LIMITING CONDITIONS FOR OPERATION BASED ON L2-3 MODE 8 ANALYSIS BOUNDS ......... . 4

II-2 L2-3 MODE 8 SAFETY LIMITS BASED ON L2-3

MODE 8 STEADY-STATE ANALYSIS ............ 8

II-3 L2-3 PPS TRIP SETPOINTS - MODE 8 FINAL VALUES . . . 10

III-1 THERMAL-HYDRAULIC ANALYSES DAMAGE CRITERIA . . . . . 14

III-2 L2-3 COBRA MODEL RADIAL POWER FACTORS . . . . . 28

III-3 COMPARATIVE COBRA IIIC CALCULATIONS FOR EFFECT OF SPACER GRID LOSS COEFFICIENT EQUATION ERROR . . . . . . . 31

III-4 COMPARATIVE FRAPT CALCULATIONS FOR EFFECT OF INSTANT DENSIFICATION ASSUMPTION FOR A SLOW REACTIVITY INSERTION TRANSIENT . . . . . . . . . . . 33

$\begin{array}{ll}\text { IV-1 } & \text { L2-3 MODE } 8 \text { SAFETY LIMIT ANALYSIS RESULTS THOT } \ldots \ldots \\ & \left(\text { OFF-NOMINAL) }=613^{\circ} \mathrm{F} \ldots \ldots \ldots\right.\end{array}$

$\begin{array}{ll}\text { IV-2 RECOMMENDED } L 2-3 \text { PPS TRIP SETPOINTS - } \ldots \ldots \text {........ } 42 & 42\end{array}$

IV-3 SUMMARY OF MODE 8 COOLDOWN REACTIVITY ANALYSIS $\ldots \ldots 48$

IV-4 DIFFERENTIAL 3 -ROD SCRAM WORTHS ......... 50

IV-5 3-ROD SCRAM REACTIVITY WORTH VS. TIME ....... 51

IV-6 SCENARIO FOR DIFFERENTIAL ROD WORTH CALCULATIONS . . . 54

IV-7 RESULTS OF DIFFERENTIAL ROD WORTH CALCULATIONS FOR CRWA . 55

$V-1$ INITIAL CONDITIONS FOR L2-3 TRANSIENT ANALYSIS .... 63

V-2 LIMITING CONDITIONS FOR L2-2 CRWA ANALYSES ..... 65

VI $-3 \quad$ FINAL LIMITING CRWA ANALYSIS RESULTS FOR L2-3 $\ldots \ldots \ldots 6$

$\begin{array}{lll}V-1-A & \text { L2 }-3 \text { CRWA PARAMETRIC SIUUY RESULTS EFFECT OF } \\ & \text { RAMP RATE }(P / A=2.60) \ldots \ldots \ldots\end{array}$

$V-4-B \quad$ L2 -3 CRIA PARAMETRIC STUDY RESULTS EFFECT OF
MODERATOR AND DOPPLER COEFFICIENTS $(P / A=2.60) \ldots 70$

V-4-C L2-3 CRWA PARAMETRIC STUDY RESIII.TS EFFECT OF P/A AND POWER TRIP. ................... 71

V-5 L2-3 MODE 8 ACCIDENT ANALYSIS SUMMARY . . . . . . 88 


\section{CONTENTS (contd.)}

Page

\section{FIGURES}

II-1 POWER CHANNEL TRIPS AND BOUNDS VS. MEASURED P/A ... 5

II -2 LCO FOR L2-3 MODES PCS LOOP FLOW ......... 6

II-3 L2-3 MODE 8 REACTOR POWER SAFETY LIMIT $\ldots \ldots \ldots$

III-1 COBRA-III MODEL OF $1 / 8$ SEGMENT OF LOFT CORE FOR DNB ANALYSIS ............. 23

1II-2 COBRA-IIIC MODEL OF LOFT CORE CENTRAL ASSEMBLY FOR TRANSIENT DNB ANALYSIS . . . . . . . . . . 24

II I-3 HOT PIN POWER PROFILE FOR L2-3 SAFETY ANALYSES $\cdots \cdots 25$

IV-1 SCRAM REACTIVITY INSERTION COMPARISONS ...... 53

IV-2 PARTITION POWER AXIAL PROFILES

FOR INVERTED XENON ANALYSIS ............. 59 


\section{INTRODUCTION}

This report summarizes the core safety analyses and reactivity control analyses that have been done to support safe operation of the LOFT reactor in the LOCE pre-blowdown operating mọde (operating Mode 8) for the L2-3 nuclear loss-of-coolant experiment (LOCE). LOCE pre-blowdown operation (also referred to as pre-LOCE operation) is primarily that period of operation prior to the initiation of the blowdown portion of the LOCE when the reactor is in steady-state operation at the desired initial test conditions, i.e., operating at the power level and low flow condition necessary to obtain the test conditions for maximum linear heat generation rate (MLHGR) and core enthalpy rise $(\triangle H)$. Pre-LOCE or Mode 8 operation also includes the low flow maneuver, when the low flow trippoint has been decreased to the Mode 8 value, and flow is being decreased while temperature is being increased to desired test values. Feactor power is assumed to be near the desired test value prior to initiation of the low flow maneuver.

The analyses discussed herein do not include analyses for potential loss-of-coolant accidents (LOCA's) during L2-3 Mode 8 operation, accidents during the LOCE blowdown (Mode 9), or analyses for potential radiation releases during LOCE operation. These analyses or studies are scoped by References [1], [2], and [3].

This report also summarizes safety analyses done to support LOFT operation in Modes 5, 6, and 7 (zero power physics testing, startup, and power range operation, respectively) with changes in operating conditions or assumptions due to some specific requirements for safe operations of the L2-3 test. (The changes are changes from conditions or assumptions for previous safety analyses for these operating modes.) Examples are analyses and studies done to support operation with LOFT nominal PCS pressure reduced by 93 psi to 2169 psia in order to gain safety maryin fur L2-3 Mode 8 operation. 
The potential accidents and other safety considerations are much the same as for the L2-2 pre-LOCE core safety analysis [9]. However, the L2-3 power leve1 is 50\% higher than for L2-2; therefore, the safety margins are significantly less. Because of this, the conservative approach used for L2-2 Mode 8 analyses to determine operating limitations, trippoints, and safety Tinits could not be used for L2-3. The L2-3 safety requirements thus become more numerous and leave less operating margin. 


\section{SUMMARY OF ANALYSIS RESULTS AND CONCLUSIONS}

1 .

Mode 8 Analysis - Steady-state and transient safety analyses were performed for potential L2-3 LOCE pre-blowdown (Mode 8) operating conditions to establish the margins of safety and required operational bounds for L2-3 Mode 8 operation. The thermal-hydraulic criteria for judging the acceptability of the steady-state and transient analyses are discussed in section III.1. The criteria used is the Damage Criteria of the LOFT Technical Specifications.

The steady-state analyses are discussed in Section IV.1. The transient analyses are discussed in Section $V$. Off-nominal limits for the reactor PCS parameters and other operating bounds were determined from the steady-state and transient analyses either as required bounds in order that the Damage Criteria could be met, or as reasonable conditions necessary for doing a core safety analysis. These resulting analysis bounds, or limiting conditions for operation (LCO's), are listed in Table II- I. These LCO's are not allinclusive. Not included are those analys is bounds which are unchanged from the analysis bounds (or assumptions) used for power range or L2-2 safety analyses (i.e.., valve response times, opening and closing rates, relief valve set pressure, etc.).

High reactor power is 1 imited by the shutdown reactivity analyses performed in Section IV.4.1. A peak to core average (P/A) of 2.3 will satisfy the constraint of $41.7 \mathrm{MW}$ (off-nominal high power) and allow the L2-3 LOCE requirement of $12 \mathrm{~kW} / \mathrm{ft}$ to be attained.

The low reactor power bound is a bound used to keep the consequences of high reactivity rate control rod withdrawal accidents (CRWA) within the Damage Criteria.

The hot leg temperature bound, high pressure bound, maximum measured $P / A$, and boron concentration 1 imit are all required for satisfactory mitigation of CRWA's. The control rod position bounds are needed so that $P / A$ will not exceed 2.60 , and for the scram reactivity insertion assumptions. The 
TABLE II-1

L2-3 MODE 8

\section{LIMITING CONDITIONS FOR OPERATION}

BASED ON L2-3 MODE 8 ANALYSIS BOUNDS

Reactor Power (high)

Reactor Power (low)

Loop Flow (low)

Hot Leg Temperature (high)

PCS Pressure (high)

(Reactor outlet)

PCS Pressure (10w)

(Reactor outlet)

Control Rod Position

Measured Peak-to-Core average power ratio

Boron Concentration in the PCS

Steam Flow Control Valve stroke time
Power must be controlled to $\leq$ nominal $+2.5 \mathrm{MW}$. Nominal power $=90.23 /(P / A) \overline{M W}$ where $P / A$ is the measured peak to core average power ratio (maximum relative power). This condition is satisfied if indicated power is held below the top control band plotted in Figure II-1.

Power must be controlled to $>$ nominal - $3.5 \mathrm{MW}$. This condition is satisfied Twith an extra margin of $1 \mathrm{MW}$ ) if indicated power is held above the bottom control band plotied in Figure II-l.

Loop flow must be above a flow calculated as $[3.390 /(P / A)]-0.125 \mathrm{Ml} \mathrm{bm} / \mathrm{h}$. This low flow bound is plotted in Figure II- 2 .

$\leq 673^{\circ} \mathrm{F}(100 \mathrm{p}$ flow $\leq 3.0 \mathrm{Mlbm} / \mathrm{hr})$.
$\leq 600^{\circ} \mathrm{F}(100 \mathrm{p}$ flow $>3.0 \mathrm{Mlbm} / \mathrm{hr})$.

Pressure $\leq 2257$ psia

(2219 psia indicated).

Pressure $\geq 2081$ psia

51 to 57 inches indicated withdrawn

$2.3 \leq P / A \leq 2.60$

Greater than or equal to $500 \mathrm{ppm}$ (measured).

SFCV stroke time shall be within 17 to $40 \mathrm{~s}$.

Note: A11 values are true value except CRA position which is indicated. 


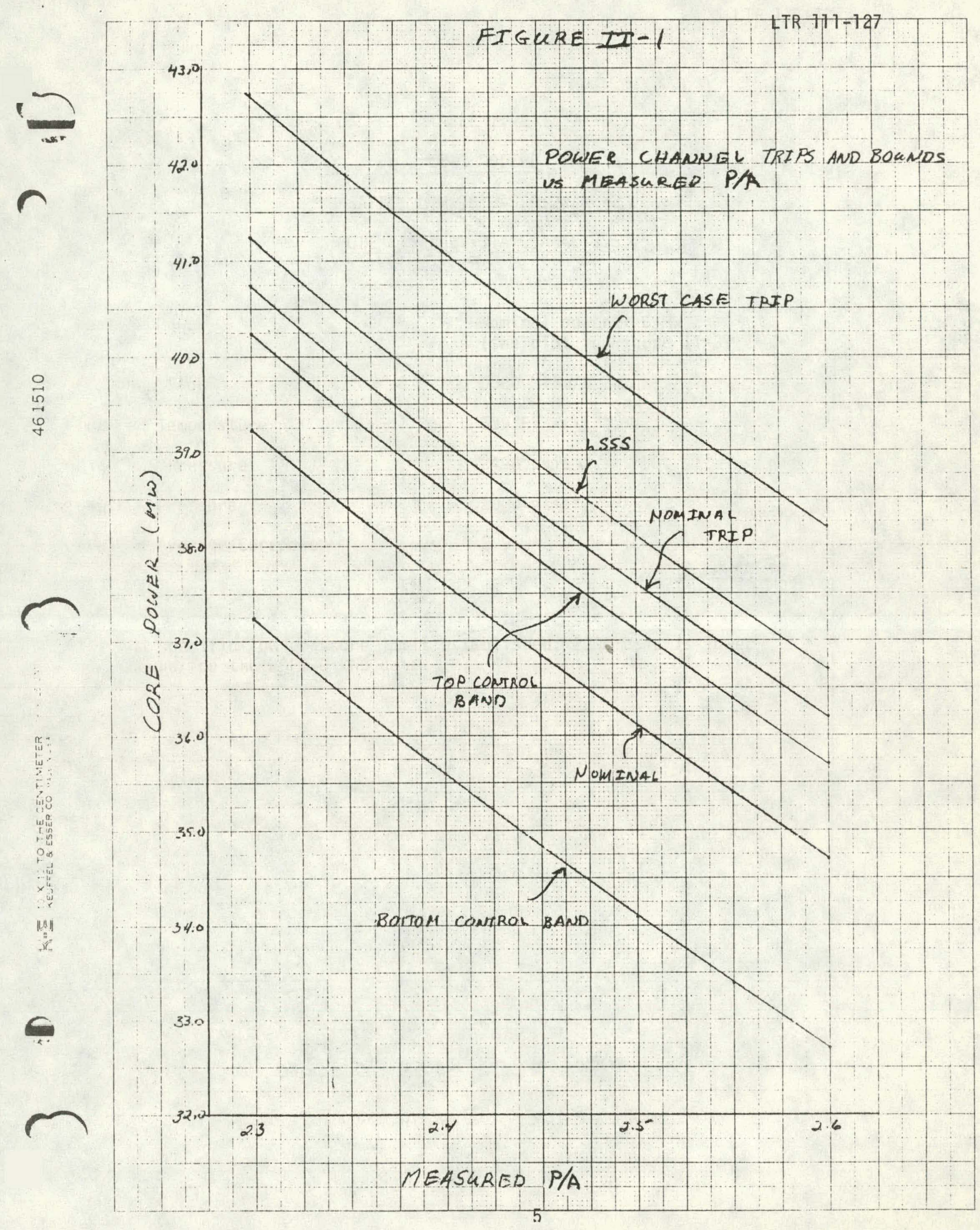


FICURE II-2

LCO FOR L2-3 MOOES

PCS LOOP FLOW

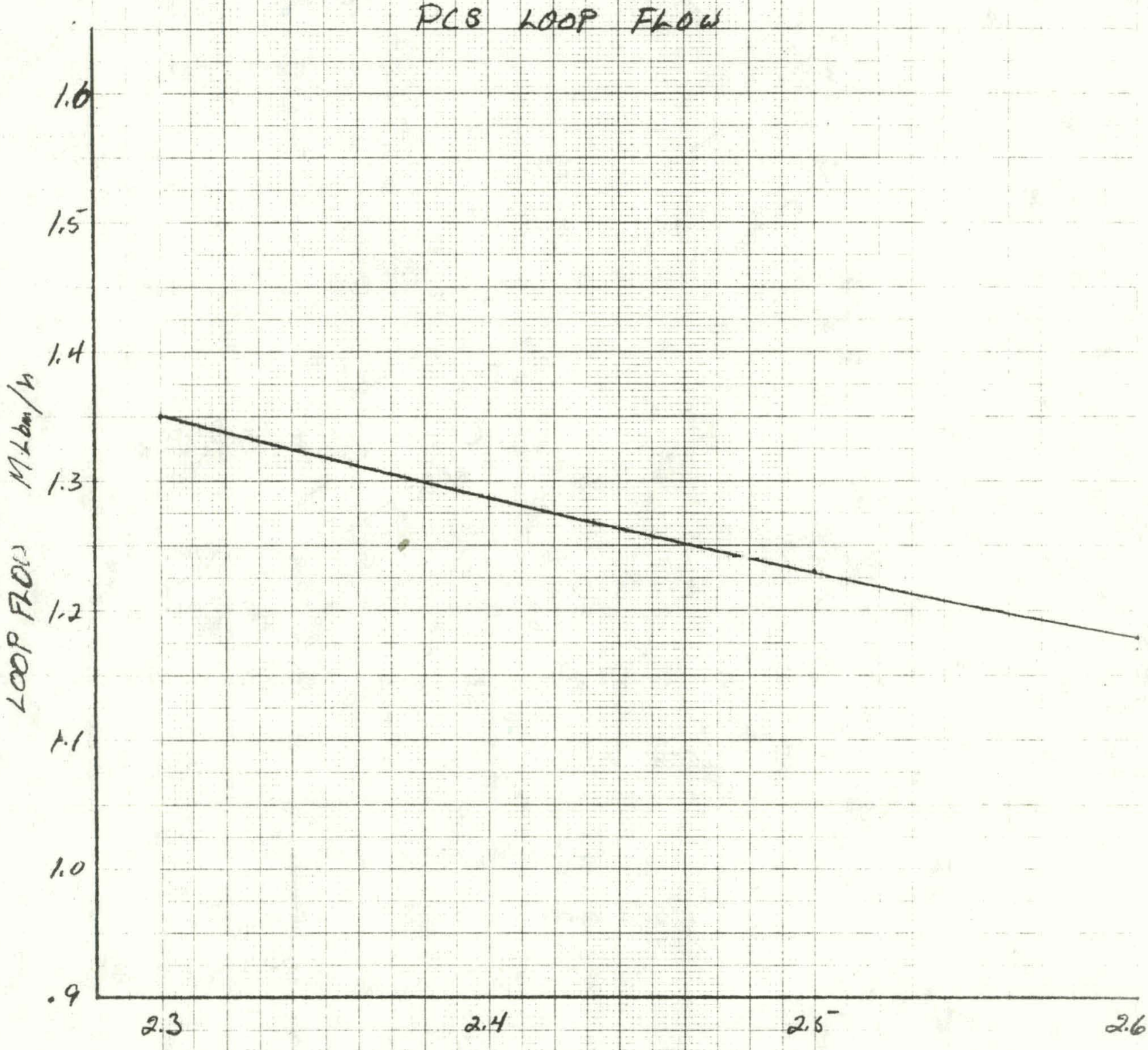

MEASURED PEAK TO CORE

AVERAGE POWER RATIO 
boron concentration bound of $500 \mathrm{ppm}$ is limited by the assumptions for the development of the high bounds for the L2-3 moderator feedback coefficient (see Appendix $\mathrm{A}-5$ ). The 1 imit on high operating pressure was also required for the determination of steady-state limits (safety limits) that satisfy Damage Criteria A.

The bound for low pressure results from the analysis for the loss of steam load accident.

The steady-state analyses established the safety limits for steady-state L2-3 Mode 8 operation that are 1isted in Table II-2. See Section IV. 1 for a discussion of the assumptions and analyses for determining these safety limits.

Steady-state analyses also determined that flow instability was not likely for L2-3 operation at worst-case values of the reactor thermalhydraulic parameters $[36]$.

The L2-3 LOCE pre-blowdown (pre-LOCE) accident analyses demonstrate that the consequence 1 imit of Damage Criteria $A$ is satisfied for all accidents but one. Since the accident consequences are only required to meet the 1 imits of Damage Criteria B or $\mathrm{C}$, then the safety margins for these accidents are acceptable. The one accident for which Damage Criteria $A$ is not satisfied is the rod ejection accident. The consequences of a rod ejection do, however, meet the limits of Damage Criteria $C$ with significant margins which is acceptable for this limiting fault. The accident analyses are discussed in Section $V$. As discussed in the previous section, the accident analyses herein do not include LOCA's or accidents during the LOCE blowdown.

The PPS trippoints required for L2-3 safety are discussed in Section IV.2. Table II-3 lists the final trippoints as established by the L2-3 Mode 8 transient analyses and discussed in Appendix A-3. These trippoints are, in some cases, slightly more conservative than those required by the analysis in Section IV.2. Figure II-1 plots the trippoint requirements for the reactor power trip as a function of $P / A$. All other trippoints are single valued for L2-3 operation. 


\section{TABLE II-2}

\section{L2-3 MODE 8}

\section{SAFETY LIMITS BASED ON L2-3}

\section{MODE 8 STEADY-STATE ANALYSIS}

Reactor Power

PCS Loop Flow

Hot Leg Temperature

High PCS Pressure

Low PCS Pressure

Peak to Average Corepower

\author{
iNominal power +6 MW \\ (see plot in Figure II-3) \\ $0.80 \mathrm{MT} \mathrm{bm} / \mathrm{h}$ \\ $639^{\circ} \mathrm{F}$ \\ 2490 psia \\ 2000 psia* \\ 2.9
}

* No specific low pressure limit established; 2000 psia is lower bound for the LOFT-3 DNB data. 
FIGURE $\mathbb{I}-3$

$\angle 2-3$ NODE 8

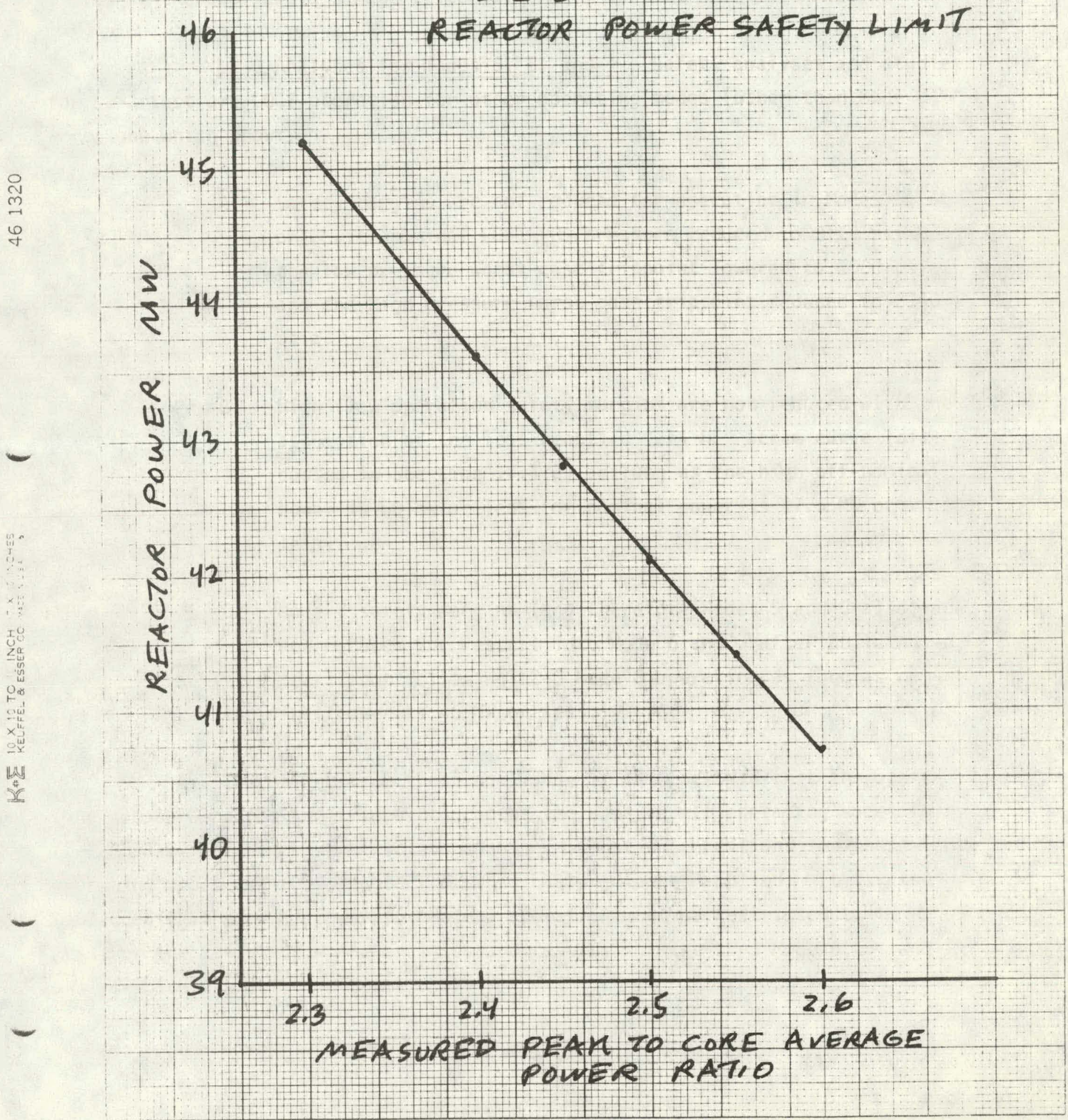


TABLE II-3

L2-3 PPS TRIP SETPOINTS - MODE 8

FINAL VALUES $(c)$

\begin{tabular}{|c|c|c|c|c|}
\hline & $\begin{array}{l}\text { Nomina } 1 \\
\text { Trip } \\
\text { Setpoint } \\
\end{array}$ & $\underline{\text { LSSS }}$ & $\begin{array}{c}\text { Worst- } \\
\text { case } \\
\text { Trippoint } \\
\end{array}$ & $\begin{array}{c}\text { Time } \\
\text { Constant } \\
\text { (s) } \\
\end{array}$ \\
\hline High average power ${ }^{(a)}(M W)$ & $\begin{array}{r}\text { (Nomina } 1+1.5 \text { ) } \\
\text { (These are }\end{array}$ & $\begin{array}{l}\text { (Nominal }+ \\
\text { plotted in }\end{array}$ & $\begin{array}{l}\text { 2) (Nominal + } \\
\text { Figure II-1) }\end{array}$ & 3.5) 0.25 \\
\hline Peak Power & NA & NA & NA & NA \\
\hline High Hot Leg Temperature $\left({ }^{\circ} \mathrm{F}\right)$ & 613 & 615 & 617 & 18 \\
\hline PCS Loop Flow $(M 1 \mathrm{bm} / \mathrm{h})$ & 1.25 & 1.20 & 1.06 & 1.0 \\
\hline High Pressure $\underset{(p s i g)}{(p s i a)}(b)$ & $\begin{array}{l}2282 \\
2269\end{array}$ & $\begin{array}{l}2312 \\
2299\end{array}$ & $\begin{array}{l}2340 \\
2327\end{array}$ & 1.0 \\
\hline Low Pressure $\underset{(p s i a)}{(p s i g)}(b)$ & $\begin{array}{l}2058 \\
2046\end{array}$ & $\begin{array}{l}2028 \\
2016\end{array}$ & $\begin{array}{l}2000 \\
1988\end{array}$ & 1.0 \\
\hline $\begin{array}{c}\text { Reflood Assist Bypass } \\
\text { valve (\% open) }\end{array}$ & 5 & 8 & 10 & 0.10 \\
\hline
\end{tabular}

(a) Nominal power $=90.23 /(P / A)$

(b) For conservatism, the high pressure channel uses $1 \mathrm{~atm}=13 \mathrm{psia}$, and the low pressure channel uses $1 \mathrm{~atm}=12$ psia.

(c) Development and determination of these final values is discussed in Appendix A-3. 
Conclusions from the transient analyses are discussed in Section V.6. The conclusions are much the same as those for the L2-2 core safety analysis. Reactivity or power increase accidents are the most 1 imiting type of accident for L2-3 Mode 8 operation (including the loss of steam load accident). As was shown for the L2-2 core safety analyses, the accident consequences are worst (lowest MDNBR) for analyses with the maximum assumed measured $P / A$. The slow power rise accidents were a particular problem for the L2-3 safety analyses. Considerable parametric study was required before the analysis and trippoint bounds could be defined which would result in satisfactory mitigation of these transients. The lowest value of MDNBR (other than for the high energy rod eject accident) was 1.150 for a CRWA or maximurn boron dilution with a ramp rate of reactivity insertion of $0.7 \times 10^{-4} \mathrm{\Delta p} / \mathrm{s}$.

Analyses for CRWA's and the loss of steam load accident showed that the use of Damage Criteria $A$ or $B$ for evaluation of the accident consequences was not significantly different. A case was not found for these slow transients for which the concequence limit for Damage Criteria $A$ could be exceeded (MDNBR > 1.14) without also exceeding the consequence 1 imit for Damage Criteria B (peak clad surface temperature, PCST > 1650 $\mathrm{F}$ ). This may be largely due to the many conservative assumptions used in the FRAPT4 LOFT fuel pin analysis, as well as the practice of forcing the fuel pin surface into DNB any time the probability for DNB exceeds $5 \%$.

Reactivity controls and considerations for L2-3 pre-LOCE operation are discussed in Section IV.4. The potential effects of Xenon on the safety of L2-3 pre-LOCE operation is discussed in Section IV.4.5. The discussions in these sections conclude that certain limitations must be imposed for safe reactor operation. In Mode 7 , the maximum power must be 1 imited to 1 es 5 than the $46 \mathrm{MW}$ due to the Xenon inversion effect resulting from a Mode $8 \mathrm{scram}$. The Mode 8 maneuver is limited in that Hot Leg Temperature must be less than $600^{\circ} \mathrm{F}$. (off-nominal) for PCS loop flows greater than $3.0 \times 10^{6} \mathrm{lbm} / \mathrm{hr}$. With these limitations it is concluded that with the suggested controls on boron concentration and control rod position, LOFT can be operated safely in the L2-3 pre-LOCE evolution. 
The conclusion of the steady-state and accident analyses is that the LOFT reactor can be operated safely at L2-3 LOCE pre-blowdown (Mode 8) conditions within the analysis envelope assumed, and with reactor trippoints within the assumed worst-case trippoints, since the analysis results demonstrate that the consequences of L2-3 Mode 8 operation will satisfy the consequence 1 imits of the applicable damage criteria.

.2. L2-3 Analyses for Modes 5, 6, and 7 - Safety analyses and studies for L2-3 test pre-LOCE operation for other operating modes (other than Mode 8) were done which show:

A. Safety margins are not reduced for operation in Modes 5, 6, or 7 with nominal LOFT PCS pressure reduced to 2169 psia, the low pressure worst-case trippoint lowered to 2000 psia, and the high pressure worst-case trippoint reduced to 2340 psia.

B. High flow operation safety margins are not reduced with the assumption of the less reactive "214 HF" scram curve (discussed in secc tion IV.4.'Z) as long as the high off-nominal power is $50 \mathrm{MW}$ or less (or nominal power is $47.5 \mathrm{MW}$ or less).

C. Mode 7 safety margins (and therefore Modes 5 and 6 also) are not reduced for restart into Mode 6 and 7 after building in peak Xenon following L2-3 Mode 8 operation as long as nominal power is $46 \mathrm{MW}$ or less.

Therefore, from these analyses, it is concluded that the operating pressure bounds and trippoints can be the same in all operating modes for L2-3 Mode 8 operation. Restriction on other operating conditions for those operating modes are not changed from what has previously applied. It is also concluded that nominal power for Mode 7 operation must be restricted to $46 \mathrm{MW}$ or less for the L2-3 test. The analyses and results for the L2-3 Mode 5, 6, and 7 analyses are discussed in Section VI. 


\section{ANALYSIS ASSUMPTIONS AND MODELS}

1. Analys is Criteria - L2-3 pre-LOCE steady-state and accident analyses are required to demonstrate that the consequences of accidents, operational transients, or normal steady-state operation within allowable bounds are predicted to be within the consequence levels of the damage criteria specified in the LOFT Technical Specifications (Specifications 3.13.3 and 4.13.3). Normal pre-LOCE operation (including operational transients) is required to satisfy the consequence levels of Damage Criteria A. Accident analyses demonstrate that the consequence levels of the damage criteria that correspond to the accident probability (or event category) are satisfied. These consequence levels are: Damage Criteria B for Incidents of Moderate Frequency, Damage Criteria $C$ for Infrequent Incidents, and Damage Criteria D for Limiting Faults. Essentially, for the purposes of core thermal-hydraulic analyses, the consequence levels of the damage criteria are as listed in Table III-1.

Steady-state and operational transient analyses discussed in Sections. IV and $V$ demonstrate that consequence levels (a) and (b) of Damage Criteria $A$ are satisfied, or the analyses define the limits within which consequence levels (a) and (b) are satisfied. FSAR, zero power, and power range safety analyses [3][15][18] determined that consequence level. (a) of Damage Criteria A was satisfied for operation at normal LOFT flow rates (otherwise referred to as "high" flow) if the minimum DNBR (MDNBR) is $\geq 1.13$ when using the LOFT-1 DNB (or CHF) correlation [4]. The LOFT-1 correlation was based, however, on data for channel mass fluxes greater than $0.75 \mathrm{Mlbm} / \mathrm{h}-\mathrm{ft}^{2}$. The channel mass fluxes for the low flows desired for LOCE preblowdown operation are below the data bound for the LOFT-1 correlation. Additional DNB data for a simulated LOFT fuel bundle was collected recently at Columbia University for mass fluxes from $0.33 \mathrm{Mlbm} / \mathrm{h}-\mathrm{ft}^{2}$ to $0.60 \mathrm{Mlbm} / \mathrm{h}-\mathrm{ft}^{2}$. The data for mass fluxes of $0.38 \mathrm{Mlbm} / \mathrm{h}-\mathrm{ft}^{2}$ and greater was added to the LOFT-1 data, and a new LOFT DNB correlation was developed. The results of the analysis for the new DNB correlation (the LOFT-3 correlation) are reported in Appendix A-1, and discussed in more detail in Reference [22]. The MDNBR for greater than a 95\% probability at a $95 \%$ confidence level that DNB will not occur on the hot fuel pin using the LOFT-3 correlation is a MDNBR $\geq 1.14$. 
TABLE III-1

\section{THERMAL-HYDRAULIC ANALYSES DAMAGE CRITERIA}

Damage

Criteria

A

$B$

C

D

\section{Consequence Levels}

(a) The minimum DNBR shall be greater than that value required for a $95 \%$ probability at a 95\% confidence level that DNB will not occur on the hot fuel pin.

(b) The fuel rod centerline temperature shall not reach the melting temperature at the hot spot. Fuel melting occurs at $5080^{\circ} \mathrm{F}$ at $\mathrm{BOL}\left(5062^{\circ} \mathrm{F}\right.$ at $2000 \mathrm{EFPH}$ ).

(a) The maximum temperature at the fuel cladding outer surface shall be less than $1650^{\circ} \mathrm{F}$.

(a) The maximum fuel cladding temperature sha 11 not exceed $2200^{\circ} \mathrm{F}$.

(b) Fuel damage shail not result in more than 244 fuel rods exceeding an outside cladding temperature of $1900^{\circ} \mathrm{F}$.

(c) The total oxidation of the cladding shall nowhere exceed 0.17 times the total cladding thicknes 3 before oxidation. As used therein, the total oxidation means the total thickness of cladding metal that would be locally converted to oxide if all the oxygen absorbed by and reacted with the cladding locally were converted to stoichiometric zirconium, dioxide.

(d) Average fuel pellet enthalpy at the hot spot shall not exceed $280 \mathrm{cal} / \mathrm{g}$ in any fue $1 \mathrm{rod}$ during reactivity-initiated events.

(No thermal hydraulic limits are specified. However, usually attempt to satisfy Damage Criteria C.) 
In addition to the consequence levels (a) and (b) of Damage Criteria $A$, the steady-state performance objective reported in Section 4.1.2.3.3 of the FSAR ${ }^{[6]}$ that "Hydrodynamic instability shall not occur during normal operation and operational transients" needs to be demonstrated. The potential for hydrodynamic instability and the assurance that instability will not occur for L2-3 pre-LOCE operation is discussed in Section IV.1.

The steady-state analyses discussed in Section IV. 1 were done to demonstrate that the above criteria are satisfied for normal pre-LOCE operation for L2-3 test conditions with one or more core thermal-hydraulic parameters equal to or exceeding the worst-case trippoint for that parameter while all other sensitive thermal-hydraulic plant parameters are at their off-nominal values. The steady-state analyses also defined at what value of the sensitive thermal-hydraulic plant parameters the limit of Damage Criteria $A$ is reached. These steady-state analyses define the bounds for steady-state L2-3 Mode 8 operation. These bounds or limits meet the intent of 10 CFR 50.36 for safety limits as illustrated in the 1968 Guide to the Content of Technical Specifications [23].

2. Analysis Assumptions - Desired L2-3 test operating conditions are as specified in the EOS ${ }^{[24]}$. The primary requirements are:

Maximum Linear Heat Generation Rate (MLHGR) $12 \mathrm{~kW} / \mathrm{ft}(39.4 \mathrm{~kW} / \mathrm{m})$

Core Differential Temperatures $\quad 64.5^{\circ} \mathrm{F}\left(35.8^{\circ} \mathrm{C}\right)$

To obtain the $64.5^{\circ} \mathrm{F}$ core $\Delta \mathrm{T}$, the specified core enthalpy rise (for a $617^{\circ} \mathrm{F}$ hot leg temperature, $2264.6 \mathrm{psia}$, and $1.44 \mathrm{Mlbm} / \mathrm{h}$ loop flow) is specified as $88.07 \mathrm{BTU} / 1 \mathrm{bm}$.

The $L 2$ test series EOS ${ }^{[24]}$ specifies that reactor power and flow will be adjusted to obtain the specified MLHGR and $\Delta H$ as a function of the peak-tocore average power ratio ( $P / A)$ determined using the TIP system. The process by which the TIP measurements are used to construct the core power distribution and $P / A$ is described in Reference [47]. Power is then adjusted according to the equation $[24]$ :

$$
P_{L}=7.519 \frac{M L H G R}{P / A} M W \text {, where MLHGR }=12 \mathrm{~kW} / \mathrm{ft} \text {. }
$$


Flow will be adjusted to obtain the specified $\Delta H$ according to the equation ${ }^{[24]}$ :

$$
\ddot{M}=\frac{P_{L}}{\Delta H}(3.413) M T b m / h .
$$

Therefore, reactor power and loop flow will be a function of the core power $P / A$ determined by the TIPS program. For $\Delta H=88.07 \mathrm{BTU} / 1 \mathrm{bm}, \dot{M}=3.502 /(\mathrm{P} / \mathrm{A})$. However, as has been indicated, the final test conditions necessary to achieve acceptable accident analysis consequences are different than specified in the E0S ${ }^{[24]}$. For the final allowable test conditions $\left(609^{\circ} \mathrm{F}\right.$ hot leg temperature, and 2169 psia) the $\Delta H$ corresponding to a $64.5^{\circ} \mathrm{F}$ core $\Delta T$ is $86.31 \mathrm{BTU} / 1 \mathrm{bm}$. For this $\Delta H$, $\dot{M}=3.568 /(P / A)$. The original specified $\Delta H$ was used for determining the loop flows assumed for the $L 2-3$ core safety analyses. Therefore assumed flows are conservative for the final allowable test conditions.

The control rod assembly position (CRP) is specified as $54( \pm 0.5)$ in. withdrawn. At 54 inches withdrawn, $P / A$ is predicted to be 2.40 for equilibrium Xenon conditions (see Appendix.A-3). However, the CRP bounds desired for operational flexibility are 50 to 58 inches withdrawn. Since $P / A$ increases as control rods are inserted, then $P / A$ could be greater than 2.40. A study for the potential values of $P / A$ for $L 2-3$ operation is in Appendix A-2. From Appendix A-2, the predicted $P / A$ for $C R P^{*}=50$ inches is 2.57. As discussed in the Appendix, the agreement between TIP-determined and predicted $P / A$ is usually within $1 \%$, and almost always within $3 \%$. $A P / A \geq 2.65$ would envelope operation for L2-3 with a CRP as low as 50 inches and allow for a $3 \%$ difference between measured and predicted $P / A$. However, since operation significantly below CRP $=56$ inches ( 54 inches withdrawn) is not intended, the safety analyses were based on a maximum measured (TIP-determined) $P / A$ of 2.60. This maximum measured $P / A$ envelopes potential operation at a $C R P=52$ inches with a $4 \%$ margin, and still envelopes the expected $P / A$ for $\mathrm{CRP}=50$ inches with a margin $>1 \%$. The maximum measured $P / A$ during the $L 2-2$ maneuver was 2.44 as compared to a predicted P/A of 2.43. Note that these CRP's are actual positions, and a comparison of indicated rod withdrawal to these values will need to consider the accuracy of the indication $( \pm 1$ inch indication error plus 2 inch displacement of rod tips above fuel bottom for 0 inches withdrawn).

* Control Rod Position refers to actual position of poison tips above fuel bottom. 
The measured P/A may also be less than the predicted 2.40, especially if CRP > 56 inches. The safety analysis for L2-2 demonstrated that analyses for the highest assumed $P / A$ was always limiting since the higher measured $P / A$ results in the lowest test-specified loop flow ${ }^{[10]}$. Therefore, only a few analyses were done for a $P / A$ less than 2.40 (at $P / A=2.37$ ) to verify the L2-2 conclusion. As for L2-2, a higher assumed P/A is found to be most limiting for L2-3 safety analyses.

The values for off-nominal (ON) operating conditions (used in the analysis) are estabiished according to the equations:

High Reactor Power:

Low Loop Flow:

High Hot Leg Temperature:

Pressure:
$P_{\text {ON }}=P_{\text {NOM }} \pm 2.5 \mathrm{MW}$ (10W reactọr power has been set to $P_{\text {NOM }}-3.5$ giving a $-2 \mathrm{MW}$ control band)

Allows for $a+1 \mathrm{MW}$ control band, a $1 \mathrm{MW}$ calorimetric power measurement accuracy, and a 0.5 MW neutron power channel accuracy.

$\dot{M}_{O N}=[3.327 /(P / A)]-0.125 \mathrm{Mlbm} / \mathrm{h}$ (based on $T_{\text {HOT }}=617^{\circ} \mathrm{F}$ nominal)

Off-nominal flow is established as $0.125 \mathrm{Mlbm} / \mathrm{h}$ (channel accuracy including indicator) less than the low-flow alarm point (at 95\% nominal flnw).

Nominal $\mathrm{T}_{\text {Hot }}+4^{\circ} \mathrm{F}$

Allows for $+2^{\circ} \mathrm{F}$ control band and a $2^{\circ} \mathrm{F}$ channel accuracy (including indicator).

Nominal \pm 88 psia

Allows for a +50 psi control band, and a 38 psi total indication accuracy. 
The safety analyses are initiated from off-nominal bounds, unless initiation from within the control bands will result in more severe consequences. The nominal and off-nominal conditions for power and flow as a function of assumed measured $P / A^{\prime}$ 's used in L2-3 safety analyses are:

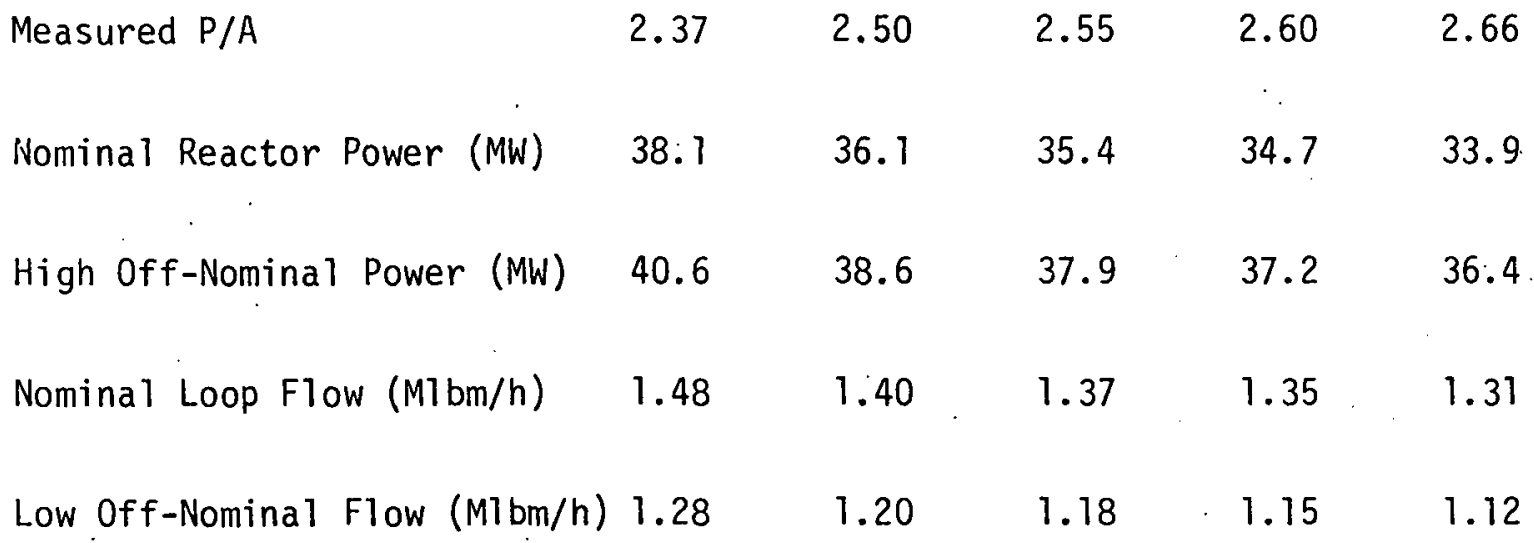

Initial steady-state and transient analyses for L2-3 Mode 8 determined that Damage Criteria A (a LOFT-3 MDNBR $\geq 1.14$ ) could not be satisfied at the high pressure limit (at $2440 \mathrm{psia}$ ). Also, parametric studies indicated that the largest single gain in safety margin (increase in MDNBR) could be obtained by lowering the pressure. A subsequent study was done of the effect of pressure on MDNBR as calculated by the LOFT-3 correlation, and the pressure effect on the critical heat flux (CHF) as seen in the LOFT DNB test data for low (L2-3 off-nominal) flows. This study, in Appendix A-4, concluded that LOFT nominal pressure (as determined at the reactor outlet) should be lowered from 2262 psia to at least 2169 psia. This decrease in pressure lowered the off-nominal high pressure to $2257 \mathrm{psia}$, and appeared to be worth approximately a $4 \%$ increase in MDNBR. Subsequent safety analyses were performed with these reduced pressures.

The assumed hot leg temperature ( $T_{\text {hot }}$ ) was varied in the safety analyses to determine a value for which the applicable damage criteria could be satisfied. The range of values of $\mathrm{T}_{\text {hot }}$ used were $606^{\circ} \mathrm{F}\left(602^{\circ} \mathrm{F}\right.$ nominal) to $627^{\circ} \mathrm{F}$ $\left(617^{\circ} \mathrm{F}\right.$ nominal).

The reactor trippoints for L2-3 reactor power and low flow can be a function of measured $P / A$. However, for the assumed trips for the safety 
analysis, only the reactor power trip was varied. The assumed low flow trip was based on the value that would be required for the worst-case trip for a measured $P / A$ of 2.66 . The assumed worst-case trippoints for the safety analyses were:

$\begin{array}{ll}\text { High Reactor Power } & \begin{array}{l}\text { Variable, but not less than } \\ \text { nominal }+3.5 \mathrm{MW}\end{array} \\ \text { Low Loop Flow } & 1.01 \mathrm{Ml} \mathrm{bm} / \mathrm{h} \\ \text { High Hot Leg Temperature } & \text { Nominal }+8^{\circ} \mathrm{F} \\ \text { High Pressure. } & 2340 \mathrm{psia} \\ \text { Low Pressure } & 2000 \mathrm{psia} \\ \text { RABV Opening } & 10 \% \mathrm{full} \text { open }\end{array}$

The assumed time constants for the trips were the same as used for the L2-2 safety analyses with the exception of the time constant for the $T_{\text {hot }}$ trip. Initial analyses for the control rod withdrawal accident determined that the damage criteria could not be satisfied with a $40 \mathrm{~s}$ time constant for the $T_{\text {hot }}$ trip. An investigation into the assumed time constant determined that with a modification to the thermal wells (addition of a thermal conducting compound inside the thermal wells) a 15 time constant should be attainable. This time constant was then used for most final safety analyses. The limiting accident for a hot leg temperature trip, a slow control rod withdrawal accident was analyzed with a hot leg trip constant of $18 \mathrm{~s}$ which corresponds to the limit given in the LOFT Technical Specifications. The assumed trip time constants were:

$\begin{array}{ll}\text { Reactor power } & 1.0 \mathrm{~s}[0.25 \mathrm{~s} \\ & \text { LOFT Technical } \\ \text { Loop flow } & 1.0 \mathrm{~s} \\ \text { Hol Leg Temperature } & 15 \mathrm{~s} \text { and } 18 \mathrm{~s}\end{array}$


Pressure

RABV Opening

Loss of PSMG Field
1.0

0.10

0.10 delay time

A $7 \%$ uncertainty was assumed for the local power distribution at the hot fuel pin given a TIP-determined in-core power distribution. Bases for the $7 \%$ uncertainty are discussed in Appendices A-2 and A-3. This power uncertainty is considered reasonable in that the power distribution measurement. uncertainty in typical nuclear power reactors is less than $5 \%[25]$. The section on analysis models discusses how the power distribution uncertainty is applied.

The maximum and minimum values for moderator and Doppler reactivity feedback coefficients as used for the safety analyses were redefined for L2-3 operating conditions. The spread between the FSAR maximum and minimum values was considered excessive. Measured data for the coefficients from LOFT zero power physics tests and power range physics tests were used to define reasonable, but still bounding; limits. The moderator density and Doppler reactivity feedback coefficients used for L2-3 safety analyses are:

\section{Maximum $\quad$ Minimum}

Moderator Density Coefficient $\left(\Delta \mathrm{p} / 1 \mathrm{bm} / \mathrm{ft}^{3}\right)$

$6.5 \times 10^{-3} \quad 2.6 \times 10^{-3}$

Doppler Coefficient

$-1.08 \times 10^{-5}-0.44 \times 10^{-5}$

$$
\left(\Delta \rho /{ }^{\circ} \mathrm{F}\right)
$$

A discussion of the test-measured coefficients and how they were used to derive a spread in the coefficient values for $L 2-3$ is in Appendix A-5.

Two scram curves were assumed for the L2-3 Mode 8 analyses. Most analyses were done using the "10/26 LF" scram curve (scram reactivity vs time) as used for the L2-2 Mode 8 safety analysis [11]. A conservative determination of 
the scram reactivity for L2-3 operating conditions was made after most L2-3 accident analyses had been done. Onty those accidents whose consequences are most susceptable to change due to a change in the rate of negative reactivity insertion following a scram were re-analyzed with the new scram curve. As is discussed in Section $V$, the consequences of L2-3 accident analyses are not significantly changed by use of the new scram curve. The scram reactivity assumption for L2-3 operation is compared to the 10/26 LF scram curve in Figure IV-1, and is discussed in Section IV.4.2. Also discussed in Section IV.4.2 is the revised scram reactivity assumption for power range operation (Modes 6 and 7).

3. Analysis Models - The accident analyses were in all but one case based on the plant response to those accidents predicted using the LOFT hybrid computer model. The LOFT hybrid computer model is the same as used for the FSAR analyses as described in References [26], [27], and [28]. There has been hybrid model changes made in which some former analog calculations were changed to digital calculations to improve calculational precision, but otherwise the LOFT model is the same as for the FSAR analyses. Assumptions specific to the L2-3 hybrid computer analyses for specific accidents are discussed in Section $V$.

Analyses for the rod ejection accident were performed using the LOFT rod ejection RELAP4 model ${ }^{[29]}$ with modifications [16]. This RELAP 4 kinetics model is the same as used for the FSAR, zero power physics testing, power range testing, and the L2-2 Mode 8 safety analyses, except that initial conditions have been changed to those for L2-3 operation. The "10/26 LF" scram curve was used for the L2-3 rod ejection accident arialyses, with a $0.25 \mathrm{~S}$ delay. Although the L2-3 scram curve is worth slightly less than the "10/26 LF" scram curve in the first 1.5 seconds after scram (see Figure IV-1) the rod eject accident is terminated by fuel Doppler feedback. Therefore, the consequences of the rod ejection accident are not significantly affected by the scram assumption.

The calculations for steady-state and transient DNBR's used the COBRA IIIC computer code to solve for the thermal hydraulic response in the LOFT reactor fuel bundles. A subroutine in the LOFT versions of COBRA IIIC calculate the DNBR's in the coolant channels using the LOFT-3 DNB correlation (see Appendix $A-1)$. The steady-state analyses and the analyses for the limiting transients 
used the LOFT 1/8th core model. The COBRA LOFT $1 / 8$ th core model and the model assumptions are basically the same as was used for the steady-state FSAR analyses as described in the FSAR ${ }^{[5]}$ and in LTR 1111-38[21]. A cross-section of the $1 / 8$ th core model used for LOFT is in Figure III-T. The LOFT small core model, representing 1/8th of the center or " $A$ " fuel assembly and not containing the more exact representation of the cross flow interfaces (thus being more conservative), was used for the non-limiting transients. The LOFT small core COBRA model and model assumptions are basically the same as used for the FSAR transient analyses as described in LTR $1111-38^{[21]}$. Figure III-2 shows a crosssection of the small LOFT core model. Differences in the L2-3 COBRA analyses from the model assumptions used for the FSAR are discussed in the following paragraphs.

The COBRA model assumptions for power distribution and power distribution uncertainties for the L2-2 core safety analyses were discussed in detail in Appendix A-4 of LTR $111-116^{[12]}$. This discussion is attached to this report as Appendix A-6 for ease of reference. For L2-3 as for L2-2 the axial power distributions chosen for safety analyses were chosen for a flatter profile and a peak further up the channel. Appendix A-6 discusses the conservatism inherent in using a flatter power distribution, and how use of prurile will a high radial pcak to average power $\left(F_{\wedge H}\right)$ achieves this purpose. (For a given total $P / A$, a hot pin power distribution with a high $F_{\Delta H}$ will therefore have a low axial peak-to-average power ratio $\left(F_{A X}\right)$ or a flatter axial power profile since $\left.P / A=F_{\Delta H} F_{A X}\right)$. A study of power distributions determined that seldom was $F_{\Delta H}>1.60$. Therefore, $F_{\Delta H}=1.60$ was assumed for the L2-2 analyses. A study of the L2-2 experience and the relationship of pre-test $P D Q$ predictions to TIP-determined power distributions is in Appendix A-2. In Appendix A-2 it was concluded that $F$ operation. Therefore, the axial profile for $P D Q$ run $L 1012[30]$ wilh a $P / A$ of 2.59 between 24 and 27 inches (axial channel height) and a radial peaking factor of 1.57 for a control rod position (CRP) of 50.6 inches above fuel bottom was chosen for the safety.analyses. The radial peaking was increased to 1.58 to obtain a total $P / A=2.60$. The L2-3 predicted power distribution, in Appendix $A-3$, for a CRP of 54 inches, has a peak only 21 to 24 inches up the channel, and an $F_{\Delta H}=1.51$. The L2-3 P/A $=2.60$ axial power profile used. in the safety analyses is plotted in Figure III-3. The predicted radial power distribution in the core was used for the L2-3 analyses. This distribution is input into the COBRA model normalized to the value for the hot pin (pin number 13 in Figure III-1 and III-2). 
Center of core

(3) Externol T/C

(6)

(10)-(9) 6 (8)

(15) (14) 913 (12) (11) Fuel Rod

$15{ }^{14}{ }^{14} 13$ I2 I11

CRA Guide Tube

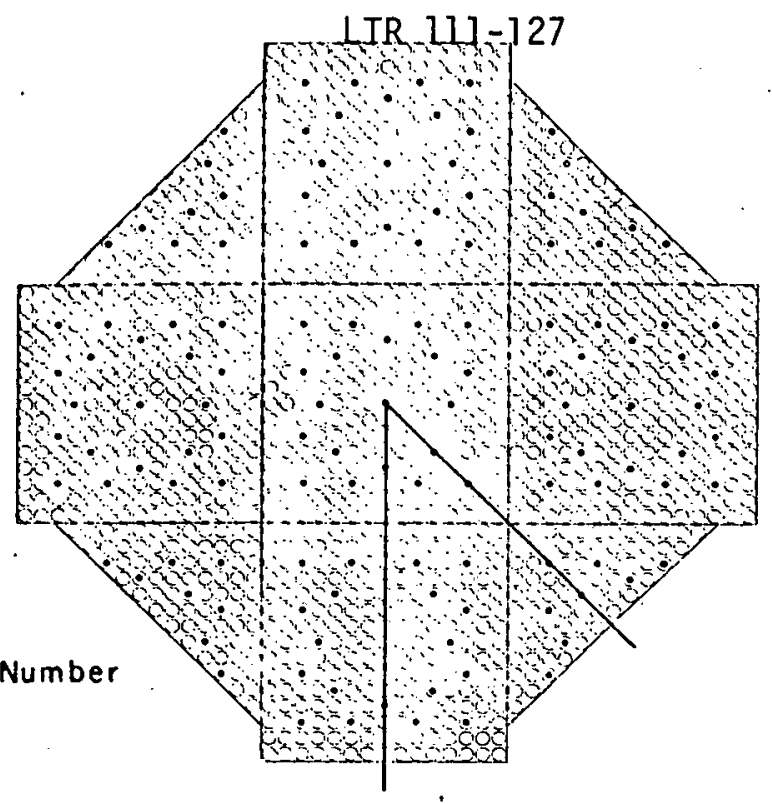

$\left.121 I_{20}{ }_{19} I_{18} I_{17}\right]_{16}$

(28) (27)-(26)-(25)-(23) (22)

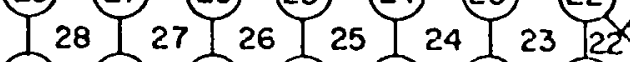

(36)-(35)-(34)-(33)-(32)-(30)-(29)

Subchonnel Number

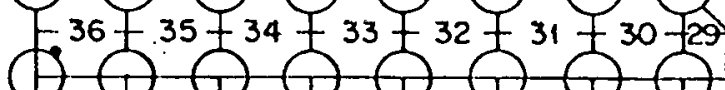
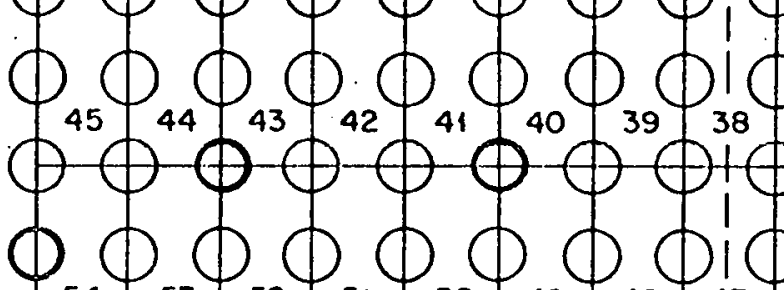

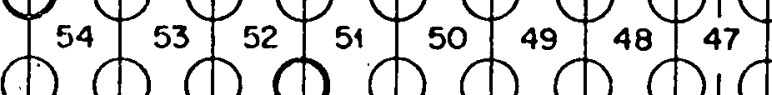
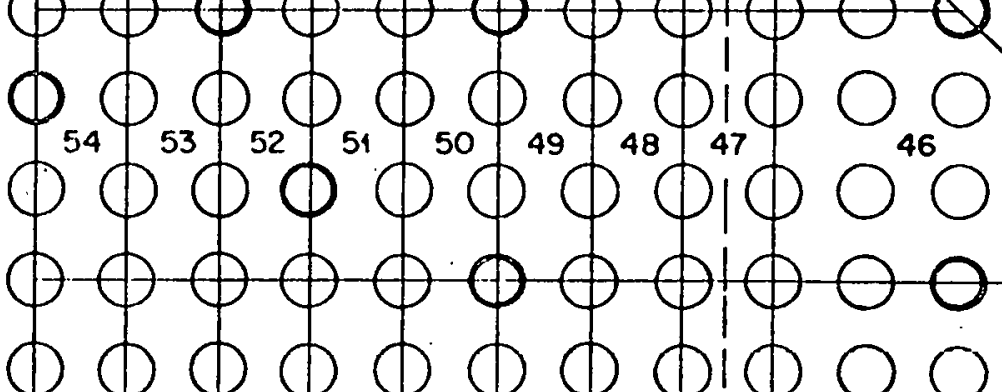

46

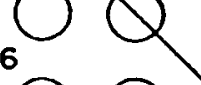

0000

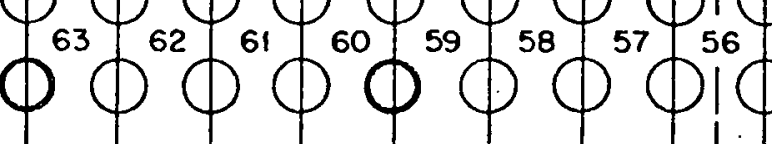

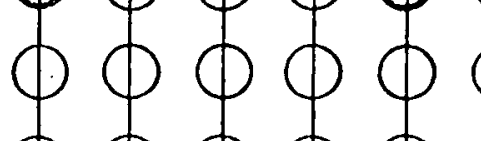

$\phi$ o.

$\phi 000$

$\phi 000$

$\rightarrow 0$

$\bigcirc \odot 0$

0000

○ф०
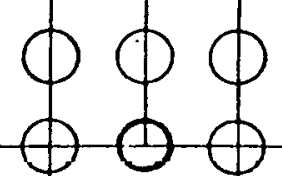

(1.

00000

$\mathrm{O}_{55} 0000$

$\mathrm{O}^{55} \mathrm{O} 0 \mathrm{O}$

$\circ \circ \mathrm{O}$

ANC $-B-5333$

Figure III-1 COBRA-III Model of $1 / 8$ Segment of LOFT Core for DNB Analys is 


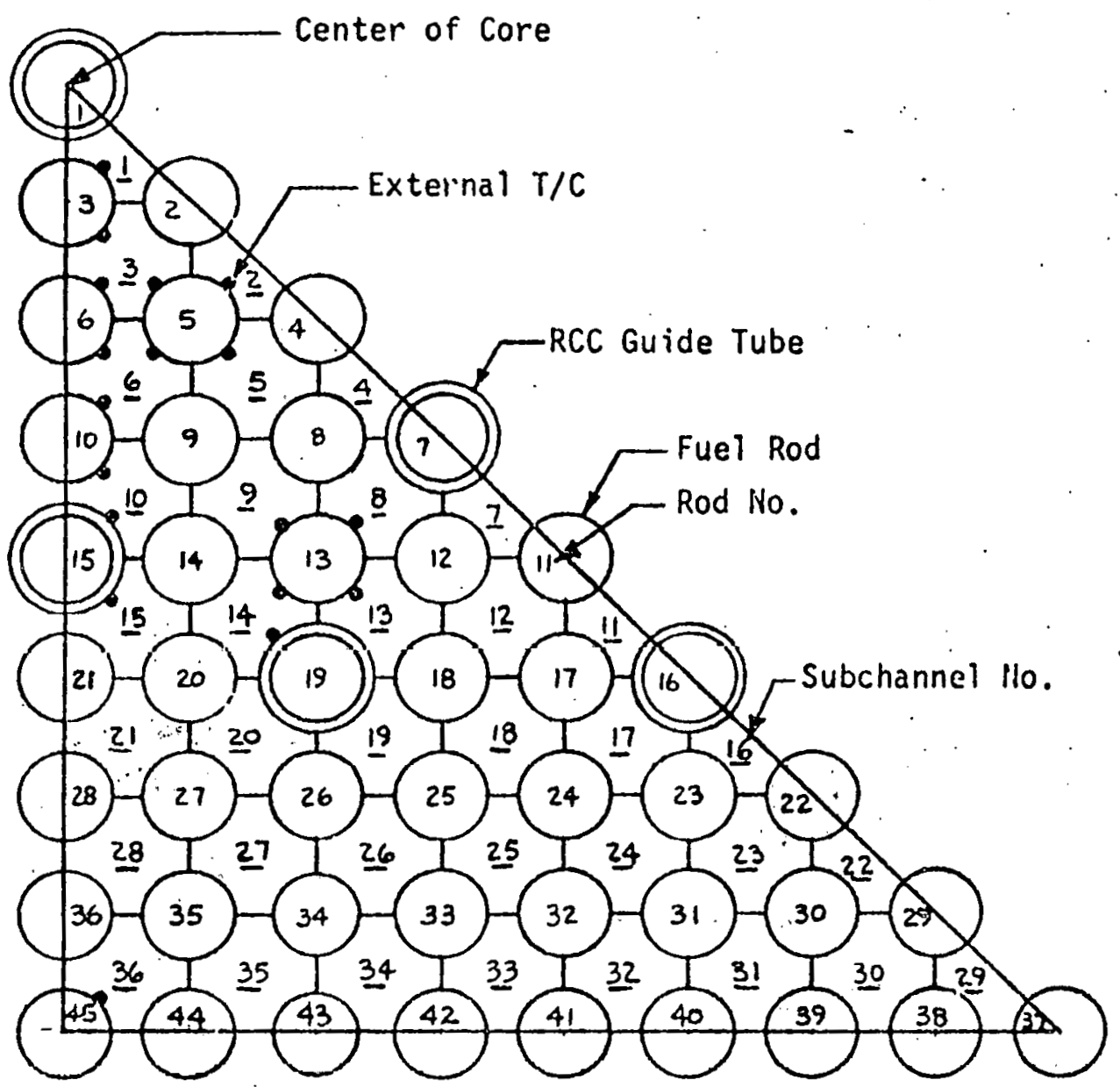

Figure III-2 COBRA-IIIC Model of LOFT Core Central Assembly for Transient DNB AnaTys is 

(

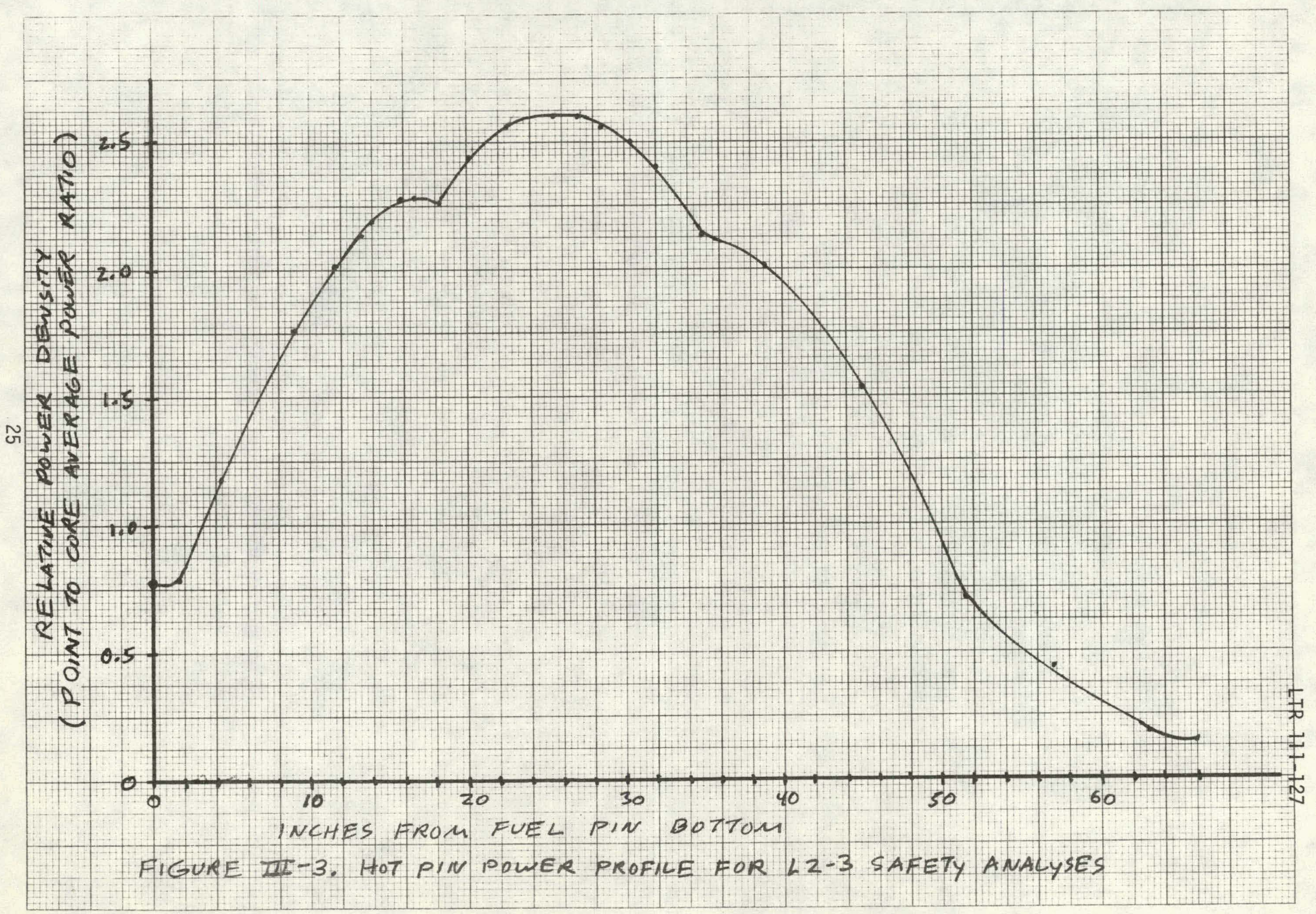


Appendix A-6 discussed how the uncertainties on the local power distributions were input into the COBRA mode1 for the L2-2 analyses. The power distribution uncertainty is applied to all fuel pins surrounding the hot channel, as is the densification factor. The engineering hot spot factor is applied to the hottest pin adjacent to the hot channel. The same procedure was used for the L2-3 analyses. However, the L2-3 model differed in two respects from that used for the L2-2 analyses. These differences were:

A. The engineering hot spot factor was redefined using statistical methods. The redefined engineering hot spot factor was based on a margin of three standard deviations from the mean for the same fuel pellet density and enrichment data that was used to develop the previously-used engineering hot spot factor. The new engineering hot spot factor is a 1.026 multiplier applied to the hottest fuel pin adjacent to the hot channel. A discussion of the derivation of this redefined hot spot factor is in Appendix A-7.

B. The hot fuel pin in the core (pin number 13) is not moved to position 20 adjacent to the hot channel (channel 15). Figures III-1 and III-2 show these locations in the LOFT core. As stated in LTR 1111-38[21], "Uncertainties in the prediction of the power profile are accounted for in the COBRA-II analysis by assuming that the hottest rod in the core is adjacent to the subchannel with the limiting DNB ratio (subchannel 15)". This was accomplished in the LOFT model by setting the normalized radial power factor for rod (or fuel pin) 20 to 1.0. But for L2-3 operation, operating power is set as a function of the measured $P / A$ whereas for power range operation, power is independent of $P / A$ as long as the limitations on minimum control rod position are satisfied. For L2-3 operation, the local power distribution uncertainty is taken to be $7 \%$, an uncertainty that is greater than would be provided by setting the radial power factor for rod 20 to 1.0 (which increases the rod 20 power by $2.3 \%$ ). Therefore, the rod 20 radial fower factor is left as predicted by PDQ, but then a 7\% 1ocal uncertainty factor (a 1.07 multiplier) is applied to al1 three rods surrounding channel 15 (rods 14, 20, and 21). As a result of this approach, rod 14 becomes the hottest rod since it has a larger radial power factor than rod 20 .

The resulting three power uncertainties are input in the COBRA models as multipliers to the radial power factors obtained from PDQ (which were 
normalized to the radial power ratio for the $P D Q$ hot fuel pin, or pin 13). The three uncertainty multipliers as modeled for the L2-3 COBRA analyses are then:

A. Engineering hot spot factor (1.026). Applied only to the hottest fuel pin adjacent to channel 15 (pin 14).

B. Local power uncertainty factor (1.07). Applied to pins 14, 20 , and 21 .

C. Densification factor (1.011). Applied to pins 14,20 , and 21 .

The radial power distribution for PDQ run $L 1027^{[31]}$ (the power distribution used for FSAR and power range safety analyses for a control rod position of 50 inches above the bottom was used for the L2-3 safety analyses. The normalized radial power factors for this case are listed for the hot pins in Table III-2. Also listed in Table III-2 are the corresponding radial power factors for PDQ case L1012, the low flow case used for the L2-3 axial power profile. As seen in Table III-2, use of the $L 1027$ radial power distribution may be slightly conservative, but not significantly so.

$$
P D Q \text { run } L 1058^{[30]} \text { with } P / A=2.44, F_{\Delta H}=1.534 \text {, and a peak between }
$$
24 and 27 inches up the channel were used for the COBRA analyses for measured $P / A=2.50$ and 2.55. For these analyses, the radial peaking was increased to 1.57 and 1.60 , respectively. Tables of the axial and radial power factors used for the L2-3 COBRA analyses are in Appendix A-8.

A low conductance (for heat conduction across the fuel pellet to cladding gap) of $750 \mathrm{BTU} / \mathrm{h}-\mathrm{ft}^{2} \mathrm{-}^{\circ} \mathrm{F}$ was assumed for COBRA analyses for all accidents except power increase accidents. For power increase accidents, the gap conductance was assumed to have a conservatively high value of $10,000 \mathrm{BTU} / \mathrm{h}-\mathrm{ft}^{2}-{ }^{\circ} \mathrm{F}$. For other than power increase accidents, the small conductance tends to hold up the heat generated in the fuel and release it later in the transient when the thermal-hydraulic conditions are more severe (lower flow, higher coolant temperature). The high conductance offers very little resistance to heat flow out of the fuel, and therefore for a power increase accident, it results in maximum heat flux when the power is highest with a minimum transient hold-up of the heat. For slow power increase 
TABLE III-2

\section{L2-3 COBRA PIODEL RADIAL POWER FACTORS}

\begin{tabular}{|c|c|c|c|}
\hline $\begin{array}{l}\text { COBRA } \\
\text { P IN } \\
\text { NUMBER } \\
\end{array}$ & $\begin{array}{c}\text { NORMAL IZED } \\
\text { FACTORS } \\
\text { FROM PDQ LT027 }\end{array}$ & $\begin{array}{c}\text { NORMALIZED } \\
\text { FACTORS } \\
\text { FOR PDQ L1012 } \\
\end{array}$ & $\begin{array}{c}\text { L2-3 NORMALIZED } \\
\text { FACTORS WITH } \\
\text { MULTIPLIERS }\end{array}$ \\
\hline 13 & 1.0 & 1.0 & 1.0 \\
\hline 14 & 0.998 & 0.997 & 1.108 \\
\hline 20 & 0.977 & 0.976 & 1.057 \\
\hline 21 & 0.973 & 0.971 & 1.053 \\
\hline
\end{tabular}


transients, as for steady-state calculations, the value of the gap conductance in the COBRA model makes little difference.

During the development of LOFT models for use with the COBRA IV-I computer code, it was determined that the predictions for channel mass flux were significantly different from the predictions obtained using COBRA IIIC for slow transients. COBRA IIIC predicted significantly more flow diversion out of the hot channel, and thus predicted significantly smaller values for mass flux and DNBR. The COBRA IV results appeared reasonable, since it predicted results close to those obtained using a steady-state assumption. For slow power rise transients, such as boron dilution or slow control rod withdrawal accidents, a pseudo-steadystate solution approach should be reasonable and conservative.

An investigation for possible reasons or causes for this discrepancy determined that the equation for calculating the spacer grid (or spacer blade) loss coefficients in the COBRA LOFT model was in error. The equation, as it existed in the COBRA III model was:

$$
C D=C D+K(\operatorname{Re})^{r}
$$

This equation was added to COBRA to make the spacer loss coefficient (CD) a function of Reynolds number (Re). For the LOFT fuel bundle, CD is initially set to zero, and $r=-0.142$. As a result of the above equation, upon every axial flow solution iteration, $C D$ was increased by an increment equal to $K(R e)^{r}$. Therefore, the spacer loss coefficients were continually increasing through the transient. As a result, the axial flow restriction continually increases. Since the Reynolds number exponent is negative, the increase in the coefficient is greater in the channels with less flow, particularly in the hot channel (channel 15 in the COBRA model). This results in increased flow diversion out of the hot channel as the transient progresses. The correct equation for spacer loss coefficient is:

$$
\operatorname{CDS}=\operatorname{CDI}+K(\operatorname{Re})^{r}
$$

where CDI has an initial constant value set by the user (equal to zero for LOFT). This corrected equation for the spacer grid loss coefficient was used for the final analyses for the limiting L2-3 transients. 
Since the error in the loss coefficient equation increases the flow resistance in the hot channel relative to most other channels in the LOFT fuel bundle, then results obtained in analyses with the error should be conservative (a higher flow resistance results in lower mass flux in the channel, higher quality, and lower DNBR). The conservatism of analyses with the error in COBRA was shown by comparative calculation for different type of transients. One of these transients, the loss of both PCS pumps without a flywheel-assisted coastdown, is considered to be the type of accident for which the loss coefficient equation error would have the least effect (or possibly a non-conservative effect) because of the rapid change in the flow forcing function at the inlet to the channels. As seen in the results of the comparative COBRA calculations in Table III-3 for this accident, al though the effect of the error on MDNBR is small, it still remains a conservative effect. Appendix A-9 contains more discussion on the correction of the spacer grid loss coefficient equation in COBRA III.

The FRAP-T4 ${ }^{[20]}$ computer code was used to calculate fuel and clad temperatures for those transients for which the probability for DNB on the hot pin exceeded 5\% (MDNBR < 1.14). The results of the FRAP calculations were then compared to the consequence 1 imits of Damage Criteria $B$ or $C$ (whichever was applicable). For the final L2-3 Mode 8 transient analyses, a FRAP analysis was done only for the rod ejection accident.

Transient channel flow and enthalpy histories from the COBRA IIIC calculations are used as input for the FRAP analysis. The FRAP model for LOFT is a single (hot) pin in a single channel, whereas a fuel pin in the LOFT core is flanked by four open channels in the COBRA model. The FRAP coolant history input option used for the LOFT safety analyses is to:

A. Input the inlet and outlet plenum enthalpy history.

B. Input the core average pressure history.

C. Input an average channel mass flux history. (For LOFT safety analysis, the mass flux history at the point of MDNBR in the hot channel is used as the channel mass flux input.) 
TABLE III-3

COMPARATIVE COBRA IIIC CALCULATIONS FOR

EFFECT OF SPACER GRID LOSS COEFFICIENT EQUATION ERROR

$0.1 \times 10^{-4} \Delta p / s$

Reactivity Increase

$0.5 \times 10^{-4} \Delta \mathrm{p} / \mathrm{s}$

Reactivity Increase

With Loss Coefficient

Equation Error

Mass Flux e

Point of MDNBR

$M 7 \mathrm{bm} / \mathrm{h}-\mathrm{ft}^{2}$

$$
2.0 \times 10^{-4} \Delta \mathrm{s} / \mathrm{s}
$$

Reactivity Increase

Loss of Steam Load

Two Pump Lass Without

Flywheel Coastdown
With Corrected Loss

Coefficient Equation

Mass Flus a

Point of MDNBR

$\mathrm{MI} \mathrm{bm} / \mathrm{h}-\mathrm{ft}$ ? $\quad$ MDNBR

0.512

MDNBR

1.131

0.600

1.174

0.513

1.109

0.601

1.151

0.444

1.098

0.591

1.154

0.481

1.120

0.607

1.156

0.400

1.175

0.412

1.179 
The hot pin axial power profile and the average linear heat generation rate history for the hot pin are input to FRAP. These inputs are the same as for the COBRA calculations. A radial power profile in the fuel pin is input as described in Figure 7 of Reference [21].

The LOFT instant densification model is used for FRAP analyses for the hot fuel pin. The instant densification model is described in Reference 32. In this model, the fuel pellet diameter is decreased initially (before the start of the analysis) to a densified diameter. The densified diameter of the fuel pellet was calculated according to the equation recommended by Reference [33]. This assumption of instant densification results in use of an initial pellet diameter of 0.3603 inches $(9.15 \mathrm{~mm})$, instead of the nominal pellet diameter of 0.3659 inches $(9.29 \mathrm{~mm})$. Therefore, the LOFT FRAP model uses a high assumption for diametrical gap width $(0.33 \mathrm{~mm}$ instead of the nominal $0.19 \mathrm{~mm})$. Pellet mass and fuel content are considered constant. Therefore, the use of the instant densificiation assumption results in the calculation of high initial fuel temperatures and high latent energy in the fuel pellet. This initial condition will result in the calculation of high clad temperatures during a transient after the surface heat transfer state goes into film boiling. The effect of the instant densification assumption can be, seen in the results of two FRAP calculations for a slow power transient in Table III-4. Use of instant densification dimensions results in $270^{\circ} \mathrm{C}$ higher fuel centerline temperature and $66^{\circ} \mathrm{C}$ higher maximum clad temperature than would be calculated using the nominal pellet dimensions. For rapid transients with high peak powers (such as for a rod ejection), the difference may be less.

A hot spot factor of 1.05 is applied to the linear heat generation rate for the LOFT FRAP fuel pin model. The development of this hot spot factor is discussed in Reference [32]. The FRAP hot spot factor includes the effect on local power of:

A. Fuel pellet stack shortening due to instant densification. The amount of stack shortening, and the resulting increase in linear heat rate, i.s calculated from an equation recommended in Reference [33]. The resulting hot spot factor (multiplier) is 1.024 for a $24 \%$ decrease in stack height. 
TABLE III-4

COMPARATIVE FRAPT CALCULATIONS FOR EFFECT

OF INSTANT DENSIFICATION ASSUMPTION

FOR A SLOW REACTIVITY INSERTION TRANSIENT

With Instant

Densification

Fuel Pellet Diameter (mm)

Fuel-to-clad diametral gap width (mm)

Maximum Fuel Centerline Temperature

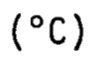

$\left({ }^{\circ} \mathrm{F}\right)$

Maximum $\mathrm{Cl}$ ad Temperature

$\left({ }^{\circ} \mathrm{C}\right)$

1083

1982

$\left({ }^{\circ} \mathrm{F}\right)$

Peak $\mathrm{Clad}$ Surface Temperature

$\left({ }^{\circ} \mathrm{C}\right)$

1059

1939
With Nominal

Pellet

9.29

0.19

2008

3646

1017

1863

994

1822

Hot spot was forced into film boiling at $29 \mathrm{~s}$.

Maximum temperatures occurred at approximately $35 \mathrm{~s}$.

Reactor scram was at $34.4 \mathrm{~s}$. 
B. Power spiking due to pellet-to-pellet gaps resulting from fellet densification. Although this would be a local (axial point) effect, the 1.026 hot spot factor is applied to the entire fuel pin.

C. Fuel pellet stack thermal expansion in response to densification. This results in a decrease in linear heat rate. The combination of this effect with the stack shortening effect of densification results in a net hot spot factor of 1.011 for densification fuel stack shortening (as used in the COBRA model).

D. Fuel enrichment tolerance (a hot spot factor of 1.0125).

The fuel pellet density tolerance is included in the input fuel density used in the LOFT FRAP model. The above FRAP input assumptions are the same as used for previous FSAR related LOFT FRAP analyses [7], for the zero power physics testing safety analysis ${ }^{[17]}$, and L2-2 Mode 8 safety analysis [13]. FRAP T4, Mod. 004 , version 6/23 was used such that surface heat transfer could be forced into film boiling at times and axial locations input to the code. 
IV. L2-3 OPERATIONAL AND REACTIVITY LIMITS

1. Steady-State Analyses and Safety Limits - Steady-state calculations were done using COBRA IIIC and the LOFT $1 / 8$ th core model to define safety limits for L2-3 Mode 8 operation. The analysis method was to set all the serlsitive thermal-hydrautic parameters except one to their off-nominal or a more limiting value (more limiting for determining DNBR), then to vary the remaining parameter until either:

(a) MDNBR $=1.14$,

(b) a physical limit is reached,

(c) a limit of analysis validity is reached, or

(d) as a minimum, the limiting worst-case trip level for that parameter is reached or exceeded.

The sensitive reactor thermal-hydraulic parameters are:

(a) Peak-to-core average power ratio $(P / A)$. This value is held constant at its maximum measured value.

(b) Reactor power.

(c) PCS loop flow (or core flow).

(d) PCS temperature. This value is defined by specifying the hot leg temperature.

(e) PCS pressure. This value is defined by specifying the reactor outlet pressure.

The off-nominal values for the sensitive parameters were calculated according to the equations in Section III.2. 
Early COBRA calculations for desired L2-3 test conditions had indicated that it may not be possible to meet Damage Criteria A (MDNBR $\geq 1.14$ ) at limiting steady-state values (worst-case trip values) of the sensitive thermal-hydraulics parameters (see Appendix B-2). These calculations were for $\mathrm{P} / \mathrm{A}=2.43,40.6 \mathrm{MW}, 1.04 \mathrm{M} 1 \mathrm{bm} / \mathrm{h}, 625^{\circ} \mathrm{F} \mathrm{T}_{\text {Hot }}$, and $2440 \mathrm{psia}$. Subsequent calculations for a maximum P/A of 2.66 determined that MDNBR was only 1.17 for all off-nominal conditions ( $36.4 \mathrm{MW}, 1.12 \mathrm{Mlbm} / \mathrm{h}, 631^{\circ} \mathrm{F}$, and $2350 \mathrm{psia}$ ) and that MDNBR > 1.14 at worst-case power $(37.4 \mathrm{MW})$ or worst-case pressure (2440 psia). Therefore, the conditions for L2-3 Mode 8 operation needed to be modified from those specified as nominal in the L2 EOS in order to meet Damage Critera $A$ at steady-state operation limits, and to meet Damage Criteria $B$ for incidents of moderate frequency.

The change that accomplished the greatest gain in MDNBR with what appeared to be a minimum impact on test objectives was to decrease the nominal operating pressure of LOFT. A study for a decrease in LOFT operating pressure and its influence on DNBR is in Appendix A-4. The suggested nominal pressure decrease was from 2262 psia to 2169 psia, which would increase the steady-state MDNBR by approximately $4 \%$. This decrease in nominal operating pressure lowered the high off-nominal pressure from 2350 psia and allows for a decrease in the worst-case high pressure trip to less than 2400 psia. Therefore, the steadystate limits are based on a 2169 psia nominal reactor outlet pressure for LOFT. In addition, the maximum measured peak-to-core average power ratio ( $P / A)$ was decreased to 2.60 (see Section III.2 for a discussion of P/A assumptions). With these two changes the MDNBR for all off-nominal conditions was increased from 1.17 to 1.24 . Transient analyses for control rod withdrawal accidents and the loss of steam load accident determined that an additional modification to L2-3 initial conditions was required. The hot leg temperature was subsequently decreased to $613^{\circ} \mathrm{F}$ off-nominal. The results of the L2-3 Mode 8 steady-state limit analysis are tabulated in Table IV-l for $613^{\circ} \mathrm{F}$ high off-nominal $T_{\text {Hot }}$. The steady-state analysis results are discussed further in Appendix B-1.

The reactor power safety limit was determined for a maximum measured peak-to-core average power ratio $(P / A)$ of 2.60 . The steady-state and transient analyses have consistently shown that the lowest values for MDNBR are 
TABLE IV- I

L2-3 MODE 8 SAFETY LIMIT ANALYSIS

RESULTS. THOT

\begin{tabular}{|c|c|c|c|}
\hline Parameter & Safety Limit & Limit Criteria & Comments \\
\hline Reactor Power & $\begin{array}{l}\text { Nominal power } \\
+6 \mathrm{MW}\end{array}$ & MDNBR $\geq 1.14$ & $\begin{array}{l}\text { Calculated } \\
1 \text { imit was } \\
41 \text { NW for } \\
P / A=2.60\end{array}$ \\
\hline $\begin{array}{l}\text { Hot Leg } \\
\text { Temperature }\end{array}$ & $639^{\circ} \mathrm{F}$ & $\begin{array}{l}\text { Saturation at the } \\
\text { reactor outlet for } \\
\text { low off-nominal } \\
\text { pressure }=2050 \text { psia }\end{array}$ & $\begin{array}{l}\text { MDNBR > } 1.18 \\
\text { with pres- } \\
\text { sure = } \\
2257 \text { psia }\end{array}$ \\
\hline PCS Loop Flow & $0.8 \times 10^{6} 1 \mathrm{bm} / \mathrm{h}$ & $\begin{array}{l}\text { Lower } 1 \text { imit of the. } \\
\text { LOFT-3 correlation } \\
\text { (mass flyx of } \\
0.4 \times 10^{6} 1 \mathrm{bm} / \mathrm{h}-\mathrm{ft}^{2} \text { ) }\end{array}$ & MDNBR > 1.24 \\
\hline $\begin{array}{l}\text { High PCS Pressure } \\
\text { (Reactor outlet) }\end{array}$ & 2490 psia & MDNBR $\geq 1.14$ & \\
\hline $\begin{array}{l}\text { Peak to Average } \\
\text { Core Power }\end{array}$ & $2: 9$ & Analysis limit & $\begin{array}{l}\text { PiA modified by } \\
\text { uncertainties }\end{array}$ \\
\hline
\end{tabular}

off-nominal conditions assumed were:

$\begin{array}{ll}\text { P/A (measured) } & 2.60 \\ \text { Reactor Power } & 37.2 \mathrm{MW} \\ \text { Hot Leg Temperature } & 613^{\circ} \mathrm{F} \\ \text { PCS Loop Flow } & 1.15 \times 10^{6} 1 \mathrm{bm} / \mathrm{h} \\ \text { PCS Pressure } & 2257 \mathrm{psia}\end{array}$


obtained for the highest assumed measured peaking. This result is to be expected since for any measured $P / A$, power is adjusted to obtain the specified nominal maximum 1 inear heat generation rate (MLHGR) of $12 \mathrm{~kW} / \mathrm{ft}$. With a higher measured $P / A$, power is lowered to obtain the specified MLHGR. Therefore, to obtain the specified core differential temperature, flow must be lowered. Therefore, for a high measured $P / A$, the core is operated with the specified MLHGR, but with a lower core flow, which results in a more severe thermal-hyraulic condition in the hot channels. Thus, the power safety limit of $41 \mathrm{MW}$ for $P / A=2.60$ is limiting for all $P / A \leq 2.60$ since the low off-nominal flow for $P / A=2.60$ is a minimum for a $11 P / A \leq 2.60$. This safety $1 \mathrm{imit}$ is more than $6 \mathrm{MW}$ above the nominal power for $P / A=2.60$ (34.7 MiW), or $18 \%$ above nominal power. Since the nominal power for $P / A=2.60$ is a minimum for all $P / A \leq 2.60$, then the power safety limit can be conservatively defined as nominal $+6 \mathrm{MW}$ for all $P / A \leq 2.60$.

The steady-state hot leg temperature was limited by reactor outlet saturation conditions. The minimum saturation temperature is $639.3^{\circ} \mathrm{F}$ for a low off-nominal reactor outlet pressure of $2050 \mathrm{psia}$. As seen in Table IV-1, MDNBR is still > 1.18 with a $639.3^{\circ} \mathrm{F} \mathrm{T}_{\text {Hot }}$ off-nominal power, and a high offnominal pressure of $2257^{\circ}$ psia. For the 2050 psia pressure that is corsistent with the $639.4^{\circ} \mathrm{F}$ saturation temperature, MDNBR $>1.31$. Hot leg temperature is limited by saturation because of the potential increase in the probability for hydraulic instability when the reactor exit temperature reaches saturation.

The analysis for a limit on flow was limited by the lower limit for the DNB data upon which the LOFT-3 DNB correlation is based, that is a loca] mass flux at the point of MDNBR of $0.40 \mathrm{Mlbm} / \mathrm{h}-\mathrm{ft}^{2}$ (see Appendix A-1). For P/A = 2.60 and L2-3 off-nominal conditions (an off-nominal $T_{\text {Hot }}=613^{\circ} \mathrm{F}$ ), this mass flux limit will occur at a loop flow of $0.69 \mathrm{Ml} \mathrm{bm} / \mathrm{h}$. However, below $0.80 \mathrm{Mlbm} / \mathrm{h}$ loop flow, the hot channel changed from channel.15 to channel 14 (channel 14 has less flow at these conditions in the region of peak power). Aisc, at loop flows less than $0.80 \mathrm{Ml} \mathrm{bm} / \mathrm{h}$, the inlet temperature has to be significantly less than $500^{\circ} \mathrm{F}$ in order to maintain a $613^{\circ} \mathrm{F} T_{\text {hot }}$ and the core $\Delta T$ for high off-nominal power. Therefore, the safety limit has been defined as $0.80 \mathrm{Ml} \mathrm{bm} / \mathrm{h}$ for 
L2-3 conditions and $613^{\circ} \mathrm{F}$ high off-nominal $T_{\text {hot }}$. At these conditions, MDNBR > 1.24 , and the mass flux at the point of MDNBR is $0.509 \mathrm{Mlbm} / \mathrm{h}-\mathrm{ft}^{2}$. For the same flow rate, if $P / A<2.60$, reactor power would be higher, $\Delta T$ would also be higher, and inlet temperature would therefore be less. Since MLHGR does not change, then MDNBR for cases where $P / A<2.60$ and flow not changed should be equal to or greater than that for $P / A=2.60$. A comparative calculation for $P / A=2.66$ and $P / A=2.37$ with $T_{\text {Hot }}=621^{\circ} \mathrm{F}$ (see Appendix $B-1$ ) show that while the MDNBR for 2.37 is less than that for 2.66, the difference is not significant. Therefore, the low flow safety limit is single valued for all $P / A \leq 2.60$.

Initial steady-state calculations for L2-3 conditions determined that the MDNBR 1 imit may be approached at the LOFT high pressure limits. For $\mathrm{P} / \mathrm{A}=2.60$ and $\mathrm{T}_{\text {Hot }}=621^{\circ} \mathrm{F}, \mathrm{MDNBR}=1.14$ at $2400 \mathrm{psia}$, a pressure 1ess than the worst-case trip level used for FSAR analyses (2440 psia). For a $613^{\circ} \mathrm{F}$ high offnominal $T_{H o t}$ and $P / A \leq 2.60$, the high pressure safety 1 imit (where MDNBR $=1.14$ ) was determined to be 2490 psia.

No low pressure safety 1 imit was defined for L2-3 operation, since the LOFT- 3 correlation predicts an increase in MDNBR at low flows as pressure is decreased. This behavior was examined by reviewing the LOFT-3 DNB data for low flow, and found to be supported by the LOFT-3 data. A discussion of the pressure dependence of the LOFT-3 low flow DNB data is in Appendix A-4. Therefore, the only low pressure safety limit for L2-3 Mode 8 is what might be implied by the low pressure data 1 imit for the LOFT-3 correlation of by the L2-3 Mode 8 low pressure worst-case trip, that is a limit of 2000 psia for both considerations. It should be noted, that the no penalty of a statistical nature is incurred by the use of this $1 \mathrm{imit.}$

In conclusion, the L2-3 Mode 8 steady-state analysis has established the following steady-state or safety 1 imits:

\section{L2-3 MODE 8 STFADY STATE SAFETY LIMTTS}

Reactor Power

PCS Loop Flow
Nominal +6 MW

$0.80 \times 10^{6} \mathrm{lbm} / \mathrm{h}$ 
Hot Leg Temperature

High. PCS Pressure $639^{\circ} \mathrm{F}$

2490 psia

Analysis for the hot fuel pin peak centerline temperature (PCT) for the FSAR demonstrated that PCT does not reach melting temperature for the fuel pellet unless reactor power exceeds full reactor power, that is at a maximum Linear Heat Generation Rate (MLHGR) greater than $22 \mathrm{~kW} / \mathrm{ft}^{[35]}$. Although the analysis for PCT was for normal or "high" flow, steady-state PCT is relatively insensitive to channel flow. The major portion of the temperature rise from the coolant channel to fuel center is across the clad-to-fuel gap and through the fuel pellet $i$ tself. Flow rate only influences the film temperature rise from the bulk coolant to the clad surface, which is not significant unless DNB is exceeded. Therefore, since L2-3 operation is only at a MLHGR of $12 \mathrm{~kW} / \mathrm{ft}$, the steady-state $\mathrm{PCT}$ will not approach melting temperature.

A calculation for PCT, and the peak cladding surface temperature (PCST), was made using the FRAP-T4 computer code in conjunction with some of the accident analyses for L2-3 pre-LOCE operation. The calculation was for initial off-nominal conditions of:

Power

Loop Flow

$\mathrm{P} / \mathrm{A}$

MLHGR
36.4

$1.12 \mathrm{MT} \mathrm{bm} / \mathrm{h}$

$12.9 \mathrm{~kW} / \mathrm{ft}$ (not including hot spot multipliers)

A calculated steady-state PCT was $4496^{\circ} \mathrm{F}$, with a value for PCST of $662^{\circ} \mathrm{F}$. Therefore a large margin exists from fuel pellet melting, which requires a temperature of $5080^{\circ} \mathrm{F}$ at $\mathrm{BOL}$, or $5075^{\circ} \mathrm{F}$ at $200 \mathrm{EFPH}{ }^{[35]}$. 
Note that if flow is increased during Hode 8 operation, core differential temperature will decrease and core inlet temperature will increase, changing the MDNBR. An anlysis for L2-2 test conditions [14] showed that such an increase in flow during Node 8 operation will result in an increase in safety margin (MDNBR increases). Based on that result, the calculation was not performed for L2-3 Mode 8 analysis.

A.study for the potential for hydrodynamic instability during LOFT operation for the L2-3 test has been performed [36]. This analysis indicates that thermal-hydrodynamic flow instabilities are not expected to occur for nominal test conditions, or for operation at worst-case type conditions for the L2-3 test. The instability study shows that static instability, due to a significant change in two-phase conditions and a large change in flow resistance, will not occur at L2-3 worst-case operating conditions (reactor exit bulk boiling will not occur, and the degree of boiling in the channels will not sufficiently change the core pressure drops to cause instability). The potential for dynamic instability was studied by comparing LOFT operating conditions for the L2-3 test to operating conditions for a reference PWR which had been shown to be dynamically stable. With regard to dynamic instability, LOFT operation for L:2-3 compared favorably with the reference PWR. Differences in geometry and operating parameters between LOFT and the PWR generally tend to make LOFT more stable. LOFT's larger pressure drop in the upper vessel structure, and the greater core inlet subcooling in LOFT are exceptions. But, the study shows that the 1 arger pressure drop in the upper structure of LOFT is not sufficient to result in instability. Also, the study shows as long as the core is protected from CHF (DNB), which the above steady-state analysis results denuristrate, then the greater core inlet subcooling in LOFT will not cause instabilities.

2. L2-3 Pre-LOCE Trip Limits - Recommended reactor trippoints for L2-3 LOCE pre-blowdown (Mode 8) operation (Table IV-2) are developed in Appendix A-3 (with exception of Reflood Assist Bypass). These recommended trippoints, are based on the possible operating range of power and flow as based on the core power distribution measured by the TIP system and defined by a $T_{H o t}=609$ nominal 
TABLE IV-2

RECOMMENDED L2-3 PPS TRIP SETPOINTS - MODE 8 (APPENDIX A-3)

High average power (M
$2.3 \leq P / A \leq 2.6$

Peak Power

High Hot Leg Temperature

PCS Loop Flow $(M i b m / h)^{(b)}$

High Pressure (psia) $\operatorname{(psig)}^{(c)}$

Low Pressure (psia) (psig) $^{(c)}$

Reflood Assist Bypass Valve (\% open)

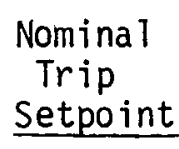

Nomina $7+1.5$

$$
\text { Worst- }
$$

case

LSSS

Trippoint

Nominal+2 Nominal+3.5

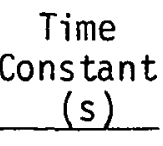

0.25

NA

NA

613

615

617

18

1.25

1.20

1.06

1.0

2282

2312

2340

1.0

2269

2299

2327

2058

2028

2000

1.0

2046

2016

1980

5

8

10

0.10

(a) Nominal power $=90.23 /(P / A)$

(b) The recommended flow trippoints for the L2-3 evolution are based on the following equations (for $M l b m / h$ ) with $P / A=2.60$ and core $\Delta H=86.31 \mathrm{Btu} / \mathrm{lbm}$ :

$$
\begin{aligned}
\text { Nominal flow } & =3.568 /(P / A) \\
\text { Nominal frip } & =3.247 /(P / A) \\
\text { LSS } & =[3.247 /(P / A)]-0.05 \\
\text { WCT } & =[3.211 /(P / A)]-0.175
\end{aligned}
$$

(c) For conservatism, the high pressure channel uses $1 \mathrm{~atm}=13$ psia, and the low pressure channel uses $1 \mathrm{~atm}=12 \mathrm{psia}$. 
resulting from the transient safety analysis. Trippoints were established by considering the required operating bands, PPS trip accuracies, trip setpoint allowances, and drift allowances, and adding or subtracting these as required to obtain the trippoints. The trippoints in Appendix A-3 provide operational margin and still satisfy the trip requirements of the L2-3 transient analyses (for Mode 8).

The steady-state and accident analyses for L2-3 LOCE pre-blowdown (pre-LOCE) operation were done with assumed worst-case trippoints (WCT) equal to or more severe (further away from nominal) than those in Appendix A-3. These analyses, discussed in Sections IV.I and $V$ of this report, show that LOFT can be operated safely (the applicable damage criteria are satisfied) with the worst-case trippoints and trip instrumentation time constants listed in Table IV-2.

All loss of flow accident analyses used a loop low flow WCT equal to or less than $1.01 \mathrm{Mlbm} / \mathrm{h}$. It has been shown that this low flow trip can be single valued even though the nominal and off-nominal loop flows must vary with measured $P / A$.

Although the safety analysis showed that the power trip margins from nominal may be increased for lower values of measured $P / A$, the final recommended power trips in Appendix A-3 is a WCT = nominal $+3.5 \mathrm{MW}$.

The hot leg temperature trippoints are 1 imited by the $613^{\circ} \mathrm{F}$ limit established for high off-nominal $T_{\text {Hot }}$ for the transient analyses. A $18 \mathrm{~s}$ hot leg temperature trip time constant is required for satisfactory mitigation of slow control rod withdrawal accidents (CRWA) from less than nominal power. These transients are tripped by high hot leg temperature.

The high pressure WCT of 2340 psia is required for satisfactory consequences of the CRWA's and the loss of steam load accident (which is tripped on high pressure).

The low pressure trip is only actuated for a steamline break accident, pressure control failure, or a control rod drop accident. As the 
steaml ine break accident is worsened by an earlier reactor trip, and the results of an analysis with an instant trip signal were used for the cooldown analysis, then the analysis does not define a limit on the low pressure trip. The analysis for a failure of the automatic pressure control system, an accident which would have actuated a low pressure trip, is shown to result in satisfactory results down to pressures significantly less than 2000 psia. The consequences of the control rod drop accident (Section V.3.3) were shown to be acceptable with a 2000 psia WCT. The consequences may still be acceptable without a trip (as they were for the L2-2 analysis ${ }^{[37]}$ ). However, a low pressure trip is still desired to limit the period of operation with an adverse perturbation of the power distribution in the core.

The worst-case trippoint assumed for opening of the reflood assist bypass valves (RABVs) was 10\% of the full open area, the same as used for power range testing analyses [18]. The RABV opening accident analysis, discussed in Section V.3.11, determined that a $10 \%$ open trip was acceptable (Damage Criteria A was satisfied). Therefore, the RABV open worst-case trippoint and the associated RABV trip setpoints remain the same as for power range testing operation. A $0.10 \mathrm{~s}$ time constant, as assumed for power range testing safety anaiyses[2]], was allowed for by adding a $0.10 \mathrm{~s}$ scram cielay to the hybrid simulation.

The peak power trip is not applicable to L2-3 pre-LOCE operation since CRA's are constrained to 50 to 58 inches withdrawn, a range in which the peak power trip is not effective because the high power trip will provide earlier protection (will trip the reactor at a lower power).

The minimum required trip allowances for instrument accuracy, drifl, cuntrol bands, etc.; are discussed in Appendix A-3. Using the allowances in Appendix $A-3$, and applying them to the worst-case trippoints discussed above, the trippoints in Table IV-2 are established for L2-3 Mode 8 operation. The low flow trip setpoints (for a worst-case trippoint of 1.06 $\mathrm{M} / \mathrm{bm} / \mathrm{h}$ ) are those associated with a $\mathrm{P} / \mathrm{A}$ of 2.60 using the relationships for flow and flow trips as a function of $P / A$ given in Table IV-2. The values are in 
units of $10^{6} \mathrm{lbm} / \mathrm{h}$ (or $\mathrm{Ml} \mathrm{bm} / \mathrm{h}$ ) of $100 \mathrm{p}$ flow. These relationships were based on a nominal $\mathrm{T}_{\text {hot }}$ of $609^{\circ} \mathrm{F}, 2169$ psia pressure, and on L2-3 core $\Delta \mathrm{H}$ of $86.31 \mathrm{BTU} / 1 \mathrm{bm}$ for a specified test differential temperature of $64.5^{\circ} \mathrm{F}$.

3. Reactivity Control Limits - The requirement for PCS boron concentration (minimum concentration limit) for reactivity control for L2-3 LOCE Pre-blowdown (Mode 8) operation is the same as the requirement for operation in Modes 6 and 7, that is a minimum boron concentration 1 imit of $100 \mathrm{ppm}$ (for shutdown margin considerations). This minimum boron concentration limit for Mode 8 is based on an extension of the cooldown reactivity analys is perforned for Modes 6 and $7^{[34]}$ (see Section IV.4). The analysis ${ }^{[34]}$ assumed a minimum PCS boron concentration of $100 \mathrm{ppm}$ in order to maximize the positive reactivity insertion due to moderator reactivity feedback during a moderator cooldown. A boron concentration of less than $100 \mathrm{ppm}$ could result in greater positive reactivity insertions than used in the cooldown analysis, and thus, the requirement for PCS boron concentrations of greater than or equal to $100 \mathrm{ppm}$ is established for Mode 8 operation (Section $I I$ establishes a higher value).

The required shutdown reactivity to prevent criticality during a steam line rupture accident or single rod ejection accident while in Modes 2 through $4^{[34]}$ is not affected by Mode 8 operation and must be adhered to for operations in Modes 2 through 4. In Section IV.1, it is shown that the Mode 4 shutdown reactivity requirement is satisfied for the nonreactivity accident entries from Mode 8 for CRA positions greater than 50 inches withdrawn.

For Mode 8 operation, the control rod assembiy bank position is limited to positions between 50 and 58-inches withdrawn. The control rod position limits stem from the following sources:

A. Prevention of radical rod motions which could result in core power distributions outside the bounds assumed for the Mode 8 safety analyses.

B. Ensuring adequate scram shutdown reactivity to prevent recriticality in the event of a steam line rupture accident. 
C. Ensuring that the scram reactivity insertion rate used for the Mode 8 safety analyses is a limiting value.

D. Ensuring that the maximum positive reactivity insertion rate assumed for the Mode 8 control rod withdrawal accident safety analyses is a bounding value.

E. Ensuring that the maximum positive reactivity insertion assumed for the Mode 8 single control rod ejection accident is a bounding value.

An additional consideration is limiting the effects that Mode 8 operations can have on the safety analyses previously performed for other reactor operational modes, specifically Modes 6 and 7. This is an especially important consideration because recovery from scrams while in Mode 8 will be via Modes 6 and 7, not Mode 8. Discussions in Section IV.4 wili address reentry into Modes 6 and 7 following Mode 8 operation. That the Mode 8 control rod assembly position limits satisfy each of the five items described above is demonstrated in the discussions that follow.

4.

\section{L2-3 Mode 8 Reactivity Considerations}

4.1 Shutdown Reactivity Considerations - The cooldown reactivity analyses for Modes 6 and $7^{[34]}$ were extended to Mode 8 operations to demonstrate that the lower limit of control rod assembiy position (50 inches withdrawn) provides sufficient shutdown reactivity after scram to:

A. Prevent recriticality during a steam iine rupture accident with coincident equipment failure resulting in a single stuck rod, and

B. Satisfy the Mode 4 shutdown reactivity requirement for planned or inadvertent (nonaccident) entries into Mode 4 via scram from Mode 8 . 
Two cooldown analyses using data and techniques developed in Reference 34 were performed to specify operating limitations that ensure conformance to the above requirements. Initial conditions and results appear in Table IV-3. The high power used corresponds to a P/A of 2.3 thus imposing a lower limit on allowed range of $P / A$.

A cooldown reactivity analysis was performed to demonstrate that the Mode 4 shutdown reactivity requirements are satisfied for planned or inadvertent (nonaccident) entries into Mode 4 via reactor scram from Mode 8 . However, for the Mode 8 analysis rod scram worth was evaluated at a boron concentration of $100 \mathrm{ppm}$ versus the conservative $1500 \mathrm{ppm}$ leve ${ }^{[34]}$. This was done to remove the extreme conservatism which results when assuming $100 \mathrm{ppm}$ boron for determining moderator reactivity feedback while assuming 1500 ppm boron for determining rod scram worth. Using a boron concentration of $1500 \mathrm{ppm}$ for calculating both scram worth and moderator reactivity feedback would have resulted in greater shutdown margins than those determined by using the $100 \mathrm{ppm}$ boron concentration for both scram worth and moderator reactivity. Results of the cooldown analysis are given in Table IV-3 for a scram and cooldown to $535^{\circ} \mathrm{F}$. As can be seen, the shutdown reactivity requirement of Mode $4^{[34]}$ (9\% $\Delta p$ shutdown reactivity) is satisfied for the nonaccident entries from Mode 8 for initial control rod positions equal to or greater than 50 inches withdrawn.

A cooldown reactivity analysis for a Mode 8 steam line rupture was performed to demonstrate non-recriticality for the 1 imiting accident specified in Reference 34 . As can be seen from Table IV-3 the initial conditions allowable in Mode 8 by other safety analyses had to be modified to assure nonan upper bound for off nominal high hot leg temperature $\left(T_{H}\right)$ while PCS flow is above $3.0 \mathrm{Mlbm} / \mathrm{hr}$. A conservative bound for off-nominal high $T_{h}$ is $600^{\circ} \mathrm{F}$ for flows greater than $3.0 \mathrm{Mlbm} / \mathrm{hr}$. The use of these limitations assure criticdlily will not occur for a steamline rupture with a resulting $225^{\circ} \mathrm{F}$ cooldown for Mode 8 operations with control rod positions equal to or greater than 50 inches wi thdrawn.

4.2 Scram Reactivity Considerations - Appendix A-10 provides 3-rod bank differential worths used in generating the Mode 8 3-rod scram reactivity 
TABLE IV-3

SUMMARY OF MODE 8 COOLDOWN REACTIVITY ANALYSIS

Demonstration of

Mode 4 Shutdown

Compliance

613

41.7

4.0

2100
Non-recritical ity from Cooldown

613

41.7

3.0

2100

$p$ (psia)

Cooldown to $535^{\circ} \mathrm{F} \Delta \mathrm{T}$ Cooldown $=225^{\circ} \mathrm{F}$

$\Delta \rho$

Doppler

$.97 \%$

$.98 \%$

$\Delta \rho$

Moderator

$5.12 \%$

$8.67 \%$

$\Delta p$

Rod Scram

$15.24 \%$

$9.69 \%$

$\Delta \rho$

Mode 4

$9.00 \%$

$\Lambda \rho$

Shutdown

$0.15 \%$

$0.04 \%$

$\Delta \rho \quad=$ Reactivity insertion due to cooling fuel to average initial Doppler Moderator temperature

$\Delta \rho=$ Reactivity insertion due to cooling moderator and fuel from Moderator average initial temperature to final temperature

$\Delta \rho \quad=\quad$ Reactivity insertion due to either 3-rod or 4-rod scram, as Rod Scram appropriate, from 50-inches withdrawn

$\Delta \rho=$ Required shutdown reactivity for Mode 4

Mode 4

$\Delta \rho_{\text {Shutdown }}=\Delta \rho_{\text {Rod Scram }}{ }^{-\Delta \rho_{\text {Doppler }}}{ }^{-\Delta \rho}$ Moderator ${ }^{-\Delta \rho}$ Mode 4 
insertion rate. The control rod differential worth analysis was performed using the LOFT core physics one-dimensional PDQ 07 model (described in Section 3.4 of Reference 18). As reactivity insertion rate is most important in terminating fast transients, initial conditions were chosen to conservatively minimize the initial rate. The conditions accomplishing this are:

A. Largest power to flow ratio (neglecting radial redistribution effects of at-power operation)

B. Xenon free condition

C. Highest core inlet temperature

D. Maximum control rod withdrawal

E. Single stuck rod remaining at initial bank position

Table IV.4 presents the 3-rod differential worths based on the above conditions for both Modes 7 and 8 . The axial range of the worth data are activc control rod tip positions from 34 inches to 60 inches above active fuel bottom. This range is adequate to demonstrate conservative termination of all fast transients. The remainder of the axial rod motion range is then conservatively calculated using "10/26 HF" data developed for Mode 7 analys is [18]. The technique for performing this operation is detailed in Reference [9]. It should be noted that a blending of data occurs at the 35 inch position but the resulting integral worth is still very conservative.

Rod drop times computed ${ }^{[18]}$ for a 58-inch withdrawn initial scram position were used to convert the differential rod worth data of Table IV-4 to the scram reactivity worth insertion data shown in Table IV-5. These data, designated the "214 HF" and "213 LF" scram curves, represent conservative scram reactivity insertions for Mode 7 and Mode 8 operations.

Many Mode 8 safety analyses did not use the "213 LF" scram curve. The curve used was the "10/26 LF" curve developed for the L2-2 safety analysis. 
TABLE IV-4

DIFFERENTTIAL 3-ROD SCRAM WORTHS

Position*

(inches)

61

59

57

55

53

51

49

47

45

43

41

39

37

35

33

31

29

27

25

23

21

19

17

15

13

11
9 $\mathrm{d} \rho / \mathrm{dh}(\% \Delta \rho /$ inch $)$

\begin{tabular}{cccc}
\hline $\mathrm{A}$ & \multicolumn{1}{l}{$\mathrm{B}$} & $\mathrm{C}$ & $\mathrm{D}$ \\
\hline .0076 & .0068 & .0141 & .0127 \\
.0115 & .0104 & .0209 & .0188 \\
.0152 & .0137 & .0266 & .0240 \\
.0186 & .0168 & .0312 & .0281 \\
.0214 & .0193 & .0342 & .0308 \\
.0257 & .0231 & .0392 & .0353 \\
.0330 & .0297 & .0490 & .0441 \\
.0385 & .0346 & .0550 & .0495 \\
.0440 & .0396 & .0605 & .0545 \\
.0500 & .0450 & .0662 & .0596 \\
.0568 & .0511 & .0726 & .0653 \\
.0646 & .0581 & .0799 & .0719 \\
.0726 & .0653 & .0870 & .0783 \\
.0803 & .0723 & .0937 & .0817 \\
& .1147 & & .1257 \\
& .1468 & & .1562 \\
&. .735 & & .1793 \\
& .1990 & & .2010 \\
& .2262 & & .2262 \\
& .2515 & & .2515 \\
& .2690 & & .2690 \\
& .2861 & & .2861 \\
& .3341 & & .3341 \\
& .3993 & & .3893 \\
& .3907 & & .3907 \\
& .3400 & & .2500 \\
& .2504 & &
\end{tabular}

Case A: 3-rod differential worths from Appendix A-10, Mode 8 conditions.

Case B: Final corrected differential worths used to generate scram curve. Conservatism factor of .9 has been applied.

Case C: 3-rod differential worths from Appendix A-10 Mode 7 conditions.

Case D: Same as B except for Mode 7.

* Axial position of poison tip of control rod bank above fuel bottom. 
TABLE IV-5

3-ROD SCRAM REACTIVITY WORTH VS. TIME

Time (s)

0.000

0.075 .

0.160

0.245

0.331

0.417

0.503

0.589

0.672

0.753

0.830

0.905

0.977

1.050

1.127

1.211

1.265

1.336

$1: 403$

1.514

1.590

1.710
Position (inches withdrawn)*

58.000

57.858

57.364

56.519

55.330

53.804

51.951

49.783

.47 .313

44.555

41.525

38.239

34.713

30.966

27.012

22.999

20.676

18.004

15.816

12.858

71.195

9.068
Case I

Worth $\% \Delta \rho$

$0.0000 \quad 0.0000$

$-0.0023$

$-0.0012$

$-0.0107$

$-0.0059$

$-0.0208$

$-0.0147$

$-0.0526$

$-0.0292$

$-0.0906$

$-0.0512$

$-0.1429$

$-0.0826$

$-0.2106$

$-0.1251$

$-0.3026$

$-0.1858$

$-0.4326$

$-0.2752$

$-0.5974$

$-0.3951$

$-0.8037$

$-0.5542$

$-1.0629$

$-0.7658$

$-1.4180$

$-1.0806$

$-2.0295$

$-1.6564$

$-2.8388$

$-2.4572$

$-3.3985$

$-3.0170$

$-4.1112$

$-3.7297$

$-4.7439$

$-4.3623$

$-5.7870$

$-5.4054$

$-6.4474$

$-6.0659$

$-7.2383$

Case I - Mode 8 Scram Curve "214 HF"

Cáse II - Mode 7 Scram Curve "213 LF"

* These data are reported to more significant figures than are physically meaningful to facilitate checking of computer data. For CRA axial position above fuel bottom add 2 inches to given value. 
However, accidents most 1 ikely to be effected by the less conservative "10/26 LF" were reanalyzed using the "213 LF" curve. The analysis using the "213 LF" scram showed no significant changes in consequences due to the new scram curve. Figure IV-1 displays the relationship of the reactivity insertion rates obtained with the two curves. Also included for comparison purposes is the high flow "817" curve used in the L2-2 safety analysis and the "214 HF" Mode 7 scram curve. All curves must be used with a scram delay time of .05 seconds or greater.

In conclusion, the control rod position limits of 50 to 58 -inches withdrawn for Mode 8 operations provide a sufficient reactivity insertion rate to satisfactorily terminate accident transients.

4.3 CRWA Reactivity Insertion Rate Considerations - The control rod position limits of 50 to 58-inches withdrawn for Mode 8 operation result in conditions that ensure the reactivity insertion rate resulting from a continuous CRA withdrawal accident is bounded by the maximum value assumed for the L2-3 pre-LOCE (Mode 8) safety analyses. The maximum insertion rate used for the Mode 8. CRWA safety analyses was $8 \times 10^{-4} \Delta \rho / \mathrm{sec}$ (see Section V.2.2). For a maximull: CRA withdrawal rate of 29 inches/min (assuming accident conditions), the 1 imiting differential rod worth is

$$
\left(8 \times 10^{-4} \Delta \rho / \mathrm{sec}\right)\left(\frac{1 \mathrm{~min}}{29 \text { inches }}\right)\left(\frac{60 \mathrm{sec}}{\min }\right)=0.166 \% \Delta \rho / \text { inch. }
$$

Calculations of differential rod worths were performed using the one-dimensional PDQ07 model of the LOFT core (see Section IV.4.2) to demonstrate that acceptable differential rod worths would occur even under extreme operating conditions. The case that was analyzed is described in Table IV-6. Results of the analysis are provided in Table IV-7. As can be seen by examination of these data, none of the calculated differential worths exceed the $0.166 \% \Delta \mathrm{o} /$ inch 1 imit, and, in fact they are well below the limit $(0.126 \% \Delta \rho /$ inch is the maximum calculated differential rod worth for rod tip positions of 50 to 66-inches above fuel bottom). Therefore, the maximum reactivity insertion rate used for the Mode 8 CRWA safety analyses is bounding for Mode 8 operation within the 50 to 58-inches withdrawn control rod position 1 imits. 
FIGURE IV-1

SCRAM REACTIVITY INSERTION COMPARISONS

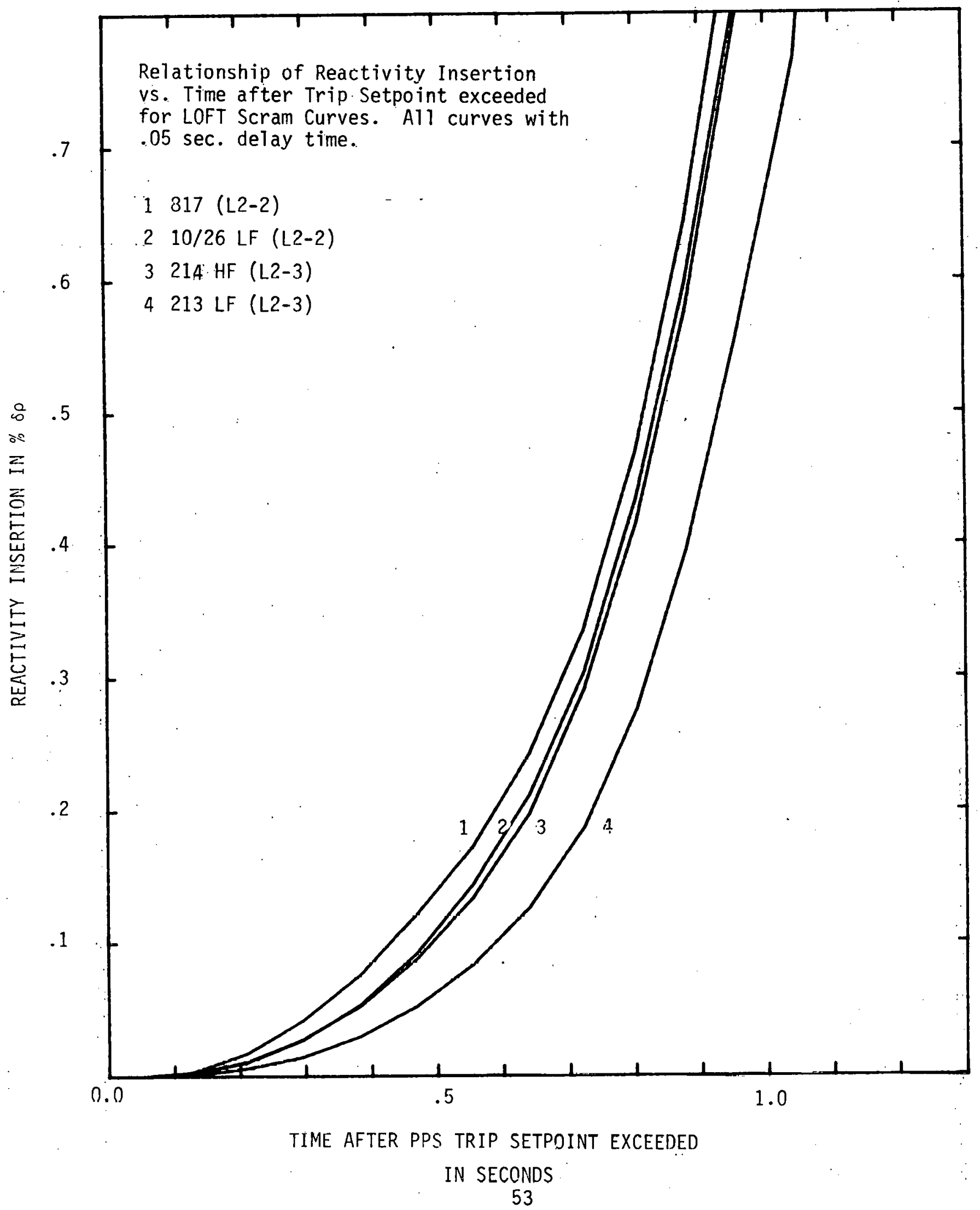


TABLE IV-6

SCENARIO FOR DIFFERENTIAL ROD WORTH CALCULATIONS

\section{Scenario}

zero-power 7.5 hours after shutdown from 42.7 MW burn to equilibrium xenon with CRA bank 50 inches above fuel bottom, PCS flow rate of $1.0 \mathrm{MIbm} / \mathrm{hr}$ and inlet temperature of $555^{\circ} \mathrm{F}$.
Justification and Comments

This case represents the extreme situation for entry into Modes 6 and 7 after operations in Mode 8. The calculated differential rod worths are maximized for these situations because analysis has shown that maximum differential rods worths occur in the top portion of the core (1) at the time of peak xenon following reactor scram and (2) for recovery at zero-power (isothermal core conditions).* Thus, the transition from Mode 7 to Mode 8 without reactor scram (normal Mode 8 entry) will yield differential rod worths high in the core which are lower than calculated for these scenarios. Low flow operation in Mode 8 will reduce rod worth high in the core as compared to high flow operation because of slightly reduced relative power in top portion of the core.

* A complete discussion of these effects is provided by E. C. Anderson letter to W. A. Spencer, "Transient Xenon Effects in the LOFT Reactor," ECA-8-78, September 19, 1978, in Append ix B-3 of Reference [9]. 
TABLE IV -7

RESULTS OF DIFFERENTIAL ROD WORTH CALCULATIONS FOR CRWA

CRA Bank Position

(Inches Withdrawn)

34.5

37.0

39.0

41.0

43.0

45.0

47.0

49.0

51.0

53.7

56.0

58.0

60.0

62.0

64.5

\begin{tabular}{|c|c|}
\hline \multicolumn{2}{|c|}{$\mathrm{d} \rho / \mathrm{dh}(\% \Delta \rho /$ inch $)$} \\
\hline Case $A$ & Case B \\
\hline .1195 & .1375 \\
\hline .1099 & 1209 \\
\hline 1059 & .1165 \\
\hline .1025 & .1128 \\
\hline 1015 & \\
\hline .1025 & .1128 \\
\hline .1050 & .1155 \\
\hline .1076 & .1184 \\
\hline .0984 & .1082 \\
\hline 1039 & .1143 \\
\hline . 1120 & .1232 \\
\hline .1148 & .1263 \\
\hline .1108 & 1219. \\
\hline .0958 & .1054 \\
\hline .0652 & .0717 \\
\hline
\end{tabular}

Note: See Table IV-6 for description of case.

Case A: Data from Appendix A-10

Case B: Case A increased by 10\% conservatism. 
The scenario analyzed considered recovery in Modes 6 and 7 from a. scram while in Mode 8 . The maximum reactivity insertion rate considered from a CRWA in Modes 6 and 7 was $0.207 \% \Delta \rho /$ inch $^{[18]}$. Because the calculated differential rod worths shown in Table IV-7 are below this limiting value, there is no 7 imitation due to reactivity insertion rate considerations on re-entry to Modes 6 or 7 following a scram from Mode 8 .

4.4 Rod Ejection Accident Reactivity Considerations - The control rod position 7 imits of 50 to 58 -inches withdrawn for Mode 8 operation result in conditions that ensure the reactivity insertion resulting from a single control rod ejection accident is bounded by the maximum value assumed for the L2-3 pre-LOCE (Mode 8 ) safety analyses. The maximum reactivity insertion used for the Mode 8 rod ejection safety analyses was $0.363 \% \Delta \rho$ (see Section V.4.1).

For Modes 6 and 7 operations, the maximum reactivity insertion for a single rod ejection accident from an initial rod position of greater than or equal to 50 -inches withdrawn was determined to be $0.351 \% \Delta \rho^{*}$. Based on the results of the differential rod worth calculations presented in Section IV.4:3, the maximum reactivity insertion for a single rod ejection accident in ilode 8 . would be equal or less than the value calculated for Modes 6 and 7 . This is because the differential rod worths high in the core for Mode 8 would be equal to or less than the value calculated for Modes 6 and 7. Therefore, the reactivity insertion for a single rod ejection accident in Mode 8 is bounded by $0.363 \% \Delta \rho$ reactivity.

Appendix A-10 presents the calculations of maximum single rod eject worth. The value calculated for the Mode 8 conditions following the Xenon scenario of Table IV-6 is $.225 \% \Delta p$. This value is bounded by the value used in the analysis. Therefore, the reactivity insertions assumed for the single rod ejection accident analyses for Modes 6 and 7 are still 1 imiting values and there is no limitation due to reactivity insertion considerations on re-entry to Modes 6 and 7 following a scram from Mode 8 .

*R. A. Dimenna 1 tr to E. C. Anderson, "38 MW Operation of the LOFT Reactor", RAD-8-7.8, (September 25, 1978) 
4.5 Xenon Effects - Under certain circumstances, xenon can significantly affect core power distribution which in turn can affect core thermal. margin and differential control rod worth. In order to quantify the effects of xenon on core thermal margin (an evaluation of the effects of xenon on differential control rod worths was given in Section IV.4.3) for Mode 8 operation and for Modes 6 and 7 operations following operation in Mode 8, analyses have been performed for equilibrium and transient xenon conditions. The set of calculations performed were the result of a judicious selection of operational scenarios based upon the experience derived from performing xenon studies for the power range safety analyses.

The dominant influence in the approach to the 1 imting core thermal margin is a peak xenon distribution low in the core forcing a high peak power condition in the middle to upper core regions. The initial condition is best produced by operation at highest allowable power levels at lowest allowable rod position. The final condition is best satisfied by a restart after reactor scram, in which the xenon distribution is allowed to peak, using in general the highest allowable rod position with an appropriate power level (with zero-power producing the highest relative power peak in both magnitude and axial position).

For current considerations, there are two operational regimes; High Flow (Modes 6 and 7), and Low Flow (Mode 8). Using these two regimes, there are three allowable operational changes:

A. Low Flow operation, scram, restart with High Flow operation.

B. High Flow operation, maneuver to Low Flow operation.

C. Low Flow operation, maneuver to High Flow operation.

of the above operational changes, the scram case where peak xenon is allowed to build in is more limiting, and the maneuvering cases ( $B$ and $(C$ above) may be excluded from consideration. 
The initial conditions and event sequence that produces the most limiting power distribution is identical to those that produced the most conservative control rod differential worth for CRWA analysis. See Table IV-6 for the conditions and sequence of events.

The axial power distributions produced by each of the neutron flux calculations involved in generating the differential rod worths, were examined to choose the most limiting distributions. The calculation with an axial rod height of 61 inches above fuel bottom was found to be most limiting. Figure IV-2 presents the axial distribution of relative power density* just prior to reactor scram and at time of zero power start up.

Using the results of the core power distribution analysis discussed above, an analysis of core thermal margins was performed using COBRA IIIC with the 1/8-th core model to determine the effects of the xenon perturbed axial power distribution on core thermal performance. The results of the core thermal analysis showed for steady-state operation at off-nominal Mode 7 conditions but with power restricted to $46 \mathrm{MW}$ or less the MDNBR is greater than obtained with the beginning of life and xenon perturbed axial profile used for the Mode 6 and 7 safety analyses. The calculation assumed a radial peaking of 1.6. Results of this analysis showed that an operational restriction on power (46 MW nominal) due to xenon perturbation is required for re-entry into Modes 6 and 7, following reactor operations in Mode 8 . See Section VI.3 for discussion of this analysis.

*A one-dimensional calculation produces an average pin profile. Radial peaking factors are assumed unchanged in the thermal calculations. 


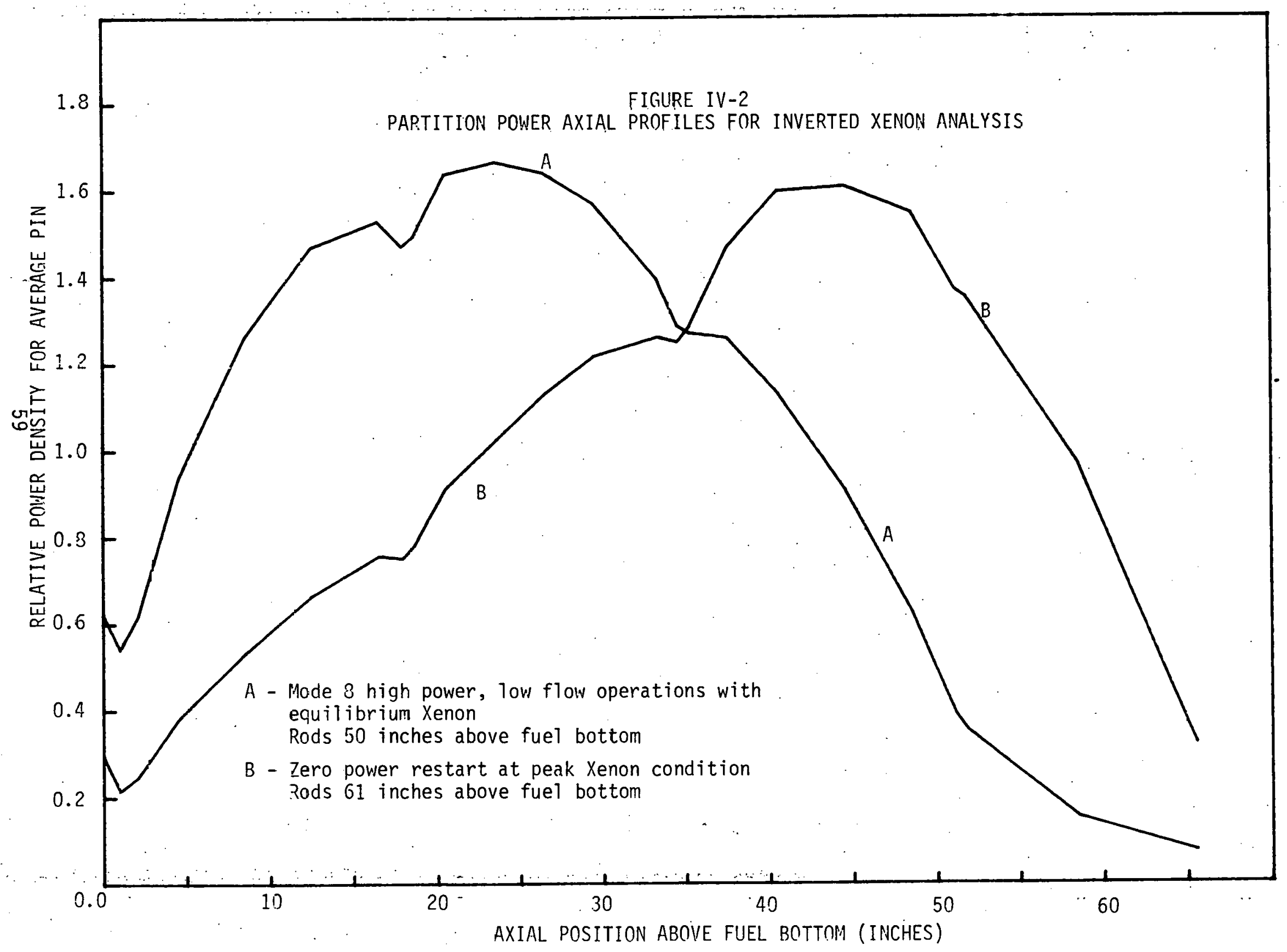

$\frac{r}{00}$
$=$
$\vec{J}$
$\vec{v}$ 


\section{L2-2 MODE 8 ACCIDENT STUDIES}

1. : Introduction - The accidents studied for L2-3 Mode 8 (LOCE preblowdown) operation and discussed below include those accidents discussed in Section 15 of the LOFT FSAR ${ }^{[3]}$ which affect the fuel thermal performance, with the exception of LOCA's and accidents during the LOCE blowdown (which is Mode 9). These exceptions are covered by the scoping analyses discussed in Reference 1 or by the analysis in the FSAR [3]. The potential for non-LOCA accidents is no different during steady-state LOCE pre-blowdown (pre-LOCE) operation than for the normal power. and flow operation studied and reported upon in the FSAR ${ }^{[3]}$ and LTR 111-104 [18]. A unique operation, however, is the potential for accidents during the low flow maneuver, in which loop flow is lowered to pre-LOCE conditions from normal high flow values. During the low flow maneuver, the low flow trippoint will have been lowered to the pre-LOCE (Mode 8) trip level, and flow will be lowered (probably in two steps) while the core primary coolant temperature is adjusted upward (in three steps). Other than the low flow maneuver, the primary difference and consideration for accident analyses between studies for the FSAR and those for pre-LOCE operation is the influence on the consequences of the accidents of operation at low flow (loop flow about one-third of normal full flow).

With the low. flow trip reduced to a Mode 8 trip level prior to the maneuver, it is possible to experience a loss of flow accident with the low flow trip level reduced significantly farther from the initial flow than was analyzed for the FSAR. Loss of flow accidents from normal full flow with a Mode 8 low flow trip were analyzed for the L2-2 Mode 8 safety analysis and the results compared to those for the same accidents initiated from Mode 8 low flow conditions. The comparison showed that the MDNBR was significantly less for the low flow accidents initiated from Mode 8 low flow conditions [37]. Therefore, these accidents were not analyzed again for 1?-3 operation.

Experience with the L2-2 low flow and pre-LOCE maneuvers showed that the following conditions occur during these maneuvers:

A. As flow is reduced from normal full flow values, the reactor power decreases to less than the nominal test power. 
B. The maximum measured peaking $(P / A)$ occurs shortly after flow has been reduced, while power is below nominal.

C. Shortly after flow has been reduced, when peaking is a maximum and power is below nominal, the hot leg temperature is raised to its final test conditions.

D. Shortly before the blowdown is initiated, power is adjusted up to the test nominal based on a final measured P/A (flow was not adjusted for L2-2, but it may be for L2-3).

E. When the blowdown loop isolation valves are opened just prior to blowdown, pressure decreases due to leakage into the blowdown loop. Therefore, pressure is first raised.i. above nominal.

The L2-2 maneuver experience shows that the initial conditions for an accident during Mode 8 operation are likely to be with:

A. Reactor power below nominal, therefore a larger than nominal margin to trip exists.

B. Full test-specified hot leg temperature.

C. Low Mode 8 loop flow.

D. Peaking slightly above nominal (for L2-2 maximum peaking was on 1 y $.0 .4 \%$ above nominal).

E. Prior to blowdown initiation, the pressure may range from high-off nominal to low off-nominal.

The above likely initial conditions are also the worst initial conditions for initiation of limiting Mode 8 transients (power increase accidents). Therefore, the L2-3 transient analyses were analyzed for initial conditions within the 
LTR $111-127$

range indicated in Table $V-1$, with the actual initial conditions for specific transients chosen such that the time to reactor scram is a maximum.

The worst-case trippoints assumed for the transient (or accident) analyses are discussed in Section III.2. The power trippoints are discussed further for the control rod withdrawal accidents. Assumed conditions or trips specific to certain accidents are discussed in the sections for those accidents. See the preceding Section III. for more discussion of analysis assumptions and models. The results of the L2-3 Mode 8 transient analyses are discussed in the following sections and in Appendix B-4.

2.

Boron Dilution Accident and Operational Transients - The reactivity insertion rate due to a boron dilution accident is considered to be $0 . \dot{6} 7 \mathrm{x}$ $10^{-4} \Delta \rho / s^{[3]}$. This insertion rate is bounded by the reactivity assumption for the CRWA analysis in Section V.3.2.

The operational transients considered for the L2-3 Mode 8 conditions are boron dilution ( $6 \mathrm{gpm}$ ) and normal rod motion ( 2 inches per minute). The normal $6 \mathrm{gpm}$ dilution rate (FSAR dilution accident used $27.5 \mathrm{gpm}$ ) for boron dilution gives a maximum insertion rate less than $0.1 \times 10^{-4} \Delta \rho / \mathrm{s}$. A 2-inch per minute control rod withdrawal (assuming maximum worth of $0.126 \% \Delta \rho / i n$. ) gives a maximum reactivity insertion rate of $0.4 \times 10^{-4} \Delta \rho / \mathrm{s}$.

The reactivity insertion rates associated with the above operational transients are bornded by the analysis performed for the CRWA analysis and the resulting MDNBR's satisfy Damage Criteria $A$ as required for operational transients. Therefore, no constraints on normal operation are imposed for Mode 8.

\section{Incidents of Moderate Frequency}

3.1 Startup Accident - A startup accident, that is a continuous withdrawal of the CRA's from initial criticality, was not analysed for L2-3 pre-LOCE operation. Initial criticality and startup with low loop flow is not a part of pre--LOCE operation. That is, startup would only occur under Mode 6 
TABLE $V-1$

\section{INITIAL CONDITIONS FOR L2-3 TRANSIENT ANALYSIS}

Initial Conditions

$\begin{array}{lc}\text { Minimum } & \text { Maximum } \\ 2.30 & 2.60 \\ 30 & 37.2 \\ 1.15 & \\ 2081 & 613^{(a)} \\ & 2257\end{array}$

(a) Transient analyses were done for high off-nominal hot leg temperatures. from $606^{\circ} \mathrm{F}$ to $627^{\circ} \mathrm{F}$. The final limiting analyses were done for $613^{\circ} \mathrm{F}$. 
operating conditions, not Mode 8. Also, it appeared that the damage criteria could not be met for a power transient with CRA's low in the core as they could be during a startup.

With the restriction that criticality and startup must occur in Mode 6 (with full flow), then the startup accident is enveloped by the analysis in the FSAR ${ }^{[3]}$.

3.2 Control Rod Withdrawal Accident (CRWA) - The CRWA analysis simulates a continuous withdrawal of all CRA's from a control rod position (CRP) of 50 inches or above. The hybrid computer calculations for this accident assume a constant ramp rate of reactivity addition, independent of CRP, to scope the possible real behavior of a CRWA.

$\therefore$ FSAR analyses for the CRWA ${ }^{[3]}$ were done for high reactivity ramp rates $\left(10 \times 10^{-4} \Delta \rho / \mathrm{s}\right)$ with low moderator and Doppler feedback coefficients $\left(2 \times 10^{-3} \Delta \mathrm{\rho} / 1 \mathrm{bm} / \mathrm{ft}^{3}\right.$ and $\left.-0.3 \times 10^{-5} \Delta \mathrm{\rho} /{ }^{\circ} \mathrm{F}\right)$, and low reactivity ramp rates $\left(1 \times 10^{-4} \Delta \rho / s\right)$ with high moderator and Doppler feedback coefficients $(9.1 \times$ $10^{-3} \Delta \mathrm{\rho} / \mathrm{lbm} / \mathrm{ft}^{3}$. and $-1.5 \times 10^{-5} \Delta \rho /{ }^{\circ} \mathrm{F}$ ). Analyses were done for CRWA's from high off-nominal power, from intermediate power (15 MW), and from a low power (4.8 MW). A high ramp rate with low feedback coefficients results in a maximum peak power, as the reactivity addition is high, and the feedback effects which tend to lower the transient power are minimized. However, a low ramp rate with high feedback coefficients results in a slow power rise which adds a maximum amount of energy into the PCS before a high power or high hot leg temperature trip finally terminates the power rise. A CRWA from low power can be worse due to the large separation between initial conditions and the trippoints, which allows for more reactivity and energy addition prior to trip. The FSAR analysis showed, for a $53 \mathrm{MW}$ off-nominal power, a $55 \mathrm{MW}$ worst-case high power trip, and a $609^{\circ} \mathrm{F}$ high hot leg temperature trip (with a $12 \mathrm{~s}$ time constant), that the worst CRWA (lowest MDNBR) was for a $1 \times 10^{-4} \Delta \rho / \mathrm{s}$ ramp rate, high moderator and Doppler coefficients, and initiated from low power $[21]$.

The CRWA analyses for the $L 2-2$ test ${ }^{[37]}$ determined that Damage Criteria A was satisfied (the L2-2 CRWA MDNBR is $\geq 1.20$ ) for the analysis assumptions and conditions tabulated in Table $V-2$. The $L 2-2$ analysis determined: 
TABLE $\quad \mathrm{V}-2$

LIMITING CONDITIONS FOR L2-2 CRWA ANALYSES [37]

\begin{tabular}{|c|c|c|c|}
\hline & $\begin{array}{c}\text { Off-nominal } \\
\text { Minimum }\end{array}$ & $\begin{array}{l}\text { Off-nominal } \\
\text { Maximum }\end{array}$ & $\begin{array}{l}\text { Worst-case } \\
\text { Irip }\end{array}$ \\
\hline Measured $P / A$ & & 2.78 & \\
\hline Reactor Power (MW) & & 24.1 & 30 \\
\hline For $602^{\circ} \mathrm{F} \mathrm{T}_{\text {hot }}$ & 15 & & \\
\hline For $568^{\circ} \mathrm{F} \mathrm{T}_{\text {hot }}$ & 10 & & \\
\hline For $554^{\circ} \mathrm{F} \mathrm{T}_{\text {hot }}$ & 4.8 & & \\
\hline PCS Loop Flow $(M T \mathrm{bm} / \mathrm{h})$ & 1.1 & & \\
\hline Hot leg Temperature $\left({ }^{\circ} \mathrm{F}\right)$ & & 602 & 609 \\
\hline Hot Leg Trip Time Constant (s) & & 40 & \\
\hline PCS Pressure (psia). & & 2350 & \\
\hline Moderator Coefficicnt $\left(\Delta \rho / 1 \mathrm{bm} / \mathrm{ft}^{3}\right)$ & $2 \times 10^{-3}$ & $9.1 \times 10^{-3}$ & \\
\hline Doppler Coefficient $\left(\Delta \rho /{ }^{\circ} \mathrm{F}\right)$ & $-0.3 \times 10^{-5}$ & $-1.5 \times 10^{-5}$ & \\
\hline
\end{tabular}


A. MDNBR was always less for maximum P/A.

B. Limiting MDNBR's were obtained for CRWA's from low initial power, for a low reactivity ramp rate $\left(1.0 \times 10^{-4} \Delta \rho / s\right)$, with minimum moderator and Doppler feedback.

C. For CRWA's with maximum moderator and Doppler feedback, the lowest MDNBR is obtained for a $4.0 \times 10^{-4} \Delta \rho / s$ reactivity ramp rate.

These L2 -2 analysis results indicated that L2-3 CRWA's with 50\% higher fue powers could probably not be shown to satisfy the Damage Criteria unless changes were made in the assumed conditions which would tend to increase the safety margin. Therefore, a parametric study was done to determine what enveloping conditions are required in order for the consequences of a CRWA to satisfy Damage Criteria B (a peak cladding surface temperature, or PCST, of $1650^{\circ} \mathrm{F}$ ). The parametric study (which included steady-state analyses, see Section IV.1) determined that the following limits on operational conditions were required:

A. Maximum measured peaking limited to $\leq 2.60$ (see Section III.2).

B. Minimum initial power $\geq 30 \mathrm{MW}$ for $P / A=2.60$, or $4.5 \mathrm{MW}$ less than nominal power.

C. High worst-case pressure trippoint $\leq 2340$ psia.

D. Hot leg temperature (high off-nominal) $\leq 613^{\circ} \mathrm{F}$.

E. Hot leg temperature worst-case trippoint $\leq 617^{\circ} \mathrm{F}\left(8^{\circ} \mathrm{F}\right.$ above nominal).

F. Hot leg temperature trip time constant $\leq 18 \mathrm{~s}$.

G. Moderator and Doppler reactivity feedback coefficients within: 


\begin{tabular}{cc} 
Moderator & Doppler \\
$\left(\Delta \mathrm{pl} / 1 \mathrm{bm} / \mathrm{ft}^{3}\right)$ & $\underline{\left(\Delta \mathrm{\rho} /{ }^{\circ} \mathrm{F}\right)}$ \\
\hline
\end{tabular}

$\begin{array}{lll}\text { Maximum } & 6.5 \times 10^{-3} & -1.08 \times 10^{-5} \\ \text { Minimum } & 2.6 \times 10^{-3} & -0.44 \times 10^{-5}\end{array}$

H. Worst-case power trip 3.8 MW above nominal for $P / A=2.60$ (38.5 MW trip power).

All of the above restrictions on operating conditions or analys is assumptions were required for the consequences of the CRWA's to satisfy the Damage Criteria. Table $V-3$ tabulates the results of the final CRWA analyses within the above bounds.

The. limiting CRWA analyses were done assuming that the initial power and initial pressure were such that the power and pressure were at their respective worst-case trip levels when the reactor is tripped by the slower hot leg temperature trip. These initial powers and pressures are listed in Table V-3. As seen in the Table, the initial power is then generally below nominal (except for the slow $0.1 \times 10^{-4} \Delta \rho / s$ ramp rate), and initial pressures are between nominal and high off-nominal values.

Results of the CRWA parametric study are tabulated in Tables V-4-A, $B$; and $C . *$ The CRWA parametric study resulted in the following conclusions:

A. The worst CRWA (with lowest MDNBR) was for a $0.7 \times 10^{-4} \Delta \rho / \mathrm{s}$ reactivity ramp rate with low moderator and Doppler feedback coefficients. However, the difference in MDNBR was small for ramp rates from $0.4 \times 10^{-4} \Delta \rho / \mathrm{s}$ to $1.0 \times 10^{-4} \Delta \rho / \mathrm{s}$. (See Table V-4-A.)

It is important to note the COBRA spacer grid error is present in these calculations. Therefore while the MDNBR's appear in most cases not to meet Damage Criteria $A$, they in fact du. The data is valid for drawing. conclusions about general trends. 
TABLE $/-3$

FINAL LIMITING CRWA ANALYSIS RESULTS FOR L2-3 P/A $=2.60$

\begin{tabular}{|c|c|c|c|c|c|c|}
\hline \multirow[b]{3}{*}{ Case I.D. } & Ramp & Initial & \multicolumn{4}{|l|}{ Initial } \\
\hline & Rate & Power & Pressure & & Time & $\mathrm{T}_{\text {Hot }}$ \\
\hline & $10^{-4} \Delta \rho / \mathrm{s}$ & MW & ssia & MDNBR & $\mathrm{s}$ & ${ }^{\circ} \mathrm{F}$ \\
\hline CRW 91 D & 0.1 & 36.5 & 2231 & 1.162 & 82 & 618.2 \\
\hline CRW $621 \mathrm{E}$ & 0.5 & 33.7 & 2220 & 1.153 & 34.4 & 620.7 \\
\hline CRW 85 B & 0.7 & 32.5 & 2209 & 1.150 & 30.2 & 621.8 \\
\hline CRW $90 A^{*}$ & 2.0 & 31.7 & 2209 & 1.154 & 26.2 & 622.3 \\
\hline CRW 106** & 0.7 & 32.5 & 2194 & 1.150 & 31.2 & 622.2 \\
\hline
\end{tabular}

* This case was the limiting case with high moderator and Doppler coefficients.

All of the other final cases were with low moderator and Doppler coefficients.

** This case differed from the rest in that a time constant of $18 \mathrm{~s}$ was assumed for the hot leg temperature trip. All other final analysis assumed a $15 \mathrm{~s} T_{\text {Hot }}$ trip time constant. 
TABLE V-4-A

L2-3 CRWA PARAMETRIC STUDY RESULTS ${ }^{(a)}$ EFFECT OF RAMP RATE $(P / A=2.60)$

\begin{tabular}{|c|c|c|c|c|c|c|c|}
\hline $\begin{array}{l}\text { Case } \\
\text { I.D. } \\
\text { CRW. }\end{array}$ & $\begin{array}{c}\text { Ramp } \\
\text { Rate } \\
10^{-4} \Delta \mathrm{J} / \mathrm{s}(\mathrm{d}) \\
\end{array}$ & $\begin{array}{c}\text { Initial } \\
\text { Power } \\
\text { MW } \\
\end{array}$ & $\begin{array}{c}\text { Initiai } \\
T_{\text {Hot }} \\
{ }^{\circ} \mathrm{F} \\
\end{array}$ & MDNBR & $\begin{array}{l}\text { Trip } \\
\text { Power } \\
\text { MW } \\
\end{array}$ & $\begin{array}{l}\text { Pressure } \\
\text { (o MDNBR } \\
\text { psia } \\
\end{array}$ & $F_{E}^{(c)}$ \\
\hline $91 \mathrm{C}$ & 0.1 & 36.2 & 613 & 1.137 & 38.2 & 2340 & 1.026 \\
\hline $621 \mathrm{~B}$ & 0.5 & 33.4 & 613 & 1.125 & 38.2 & 2340 & 1.026 \\
\hline $85 A$ & 0.7 & 32.2 & 613 & 1.120 & 38.2 & 2340 & 1.026 \\
\hline $62 B$ & 0.3 & 35.2 & 613 & 1.087 & 38.7 & 2373 & 1.032 \\
\hline $62 C$ & 0.4 & 34.5. & 613 & 1.080 & 38.7 & 2375 & 1.032 \\
\hline 621 & 0.5 & $3 \approx .9$ & 613 & 1.080 & 38.7 & 2379 & 1.032 \\
\hline 85 & 0.7 & $3 c .5$ & 613 & 1.086 & 38.5 & 2393 & 1.026 \\
\hline 87 & 1.0 & 30.9 & 613 & 1.092 & 38.5 & 2403 & 1.026 \\
\hline $72 \mathrm{~A}$ & 1.5 & 33.3 & 613 & 1.086 & 38.7 & 2384 & 1.032 \\
\hline$"$ & $a$ & $"$ & $"$ & $1.098^{(e)}$ & 38.5 & " & 1.026 \\
\hline 90 & 2.0 & $3^{-} .7$ & 613 & 1.098 & 38.5 & 2396 & 1.026 \\
\hline 55 & 4.0 & 32.0 & 617 & 1.136 & 39.0 & 2333 & 1.032 \\
\hline 56 & 6.0 & 32.0 & 621 & 1.158 & .39 .0 & 2290 & 1.032 \\
\hline 57 & 8.0 & 32.0 & 621 & 1.237 & 39.0 & 2261 & 1.032 \\
\hline
\end{tabular}


TABLE V-4-B

\section{L2-3 CRWA PARAMETRIC STUDY RESULTS $(a)$}

E:FECT OF MODERATOR AND DOPPLER COEFFICIENTS (P/A $=2.60)$

\begin{tabular}{|c|c|c|c|c|c|c|}
\hline $\begin{array}{l}\text { Mod } \\
\text { and } \\
\text { DOP }\end{array}$ & $\begin{array}{c}\text { Initial } \\
\text { Power } \\
\text { MW }\end{array}$ & $\begin{array}{l}\text { Initial } \\
{ }^{\mathrm{T}} \text { Hot } \\
{ }^{\circ} \mathrm{F} \\
\end{array}$ & MDNBR & $\begin{array}{l}\text { Trip (b) } \\
\text { Power } \\
\text { MW } \\
\end{array}$ & $\begin{array}{l}\text { Pressure } \\
\text { a MDNBR } \\
\text { psia }\end{array}$ & $\mathrm{F}_{E}{ }^{(c)}$ \\
\hline Low & 33.4 & 609 & $\begin{array}{l}1.109 \\
1.107(\mathrm{e})\end{array}$ & $\begin{array}{l}38.2 \\
38.5\end{array}$ & $\begin{array}{l}2379 \\
2372\end{array}$ & $\begin{array}{l}1.032 \\
1.026\end{array}$ \\
\hline High & 35.6 & 609 & 1.119 & 38.5 & 2372 & 1.026 \\
\hline Low & 32.5 & 613 & 1.086 & 38.5 & 2393 & 1.026 \\
\hline High & 35.2 & 613 & 1.109 & 38.5 & 2369 & 1.026 \\
\hline Low & 30.9 & 613 & 1.092 & 38.5 & 2403 & 1.026 \\
\hline High & 34.5 & 613 & 1.084 & 38.7 & 2375 & 1.032 \\
\hline$"$ & ," & $"$ & $1.096^{(e)}$ & 38.5 & $"$ & 1.026 \\
\hline Low & $30.0^{(f)}$ & 613 & 1.138 & 38.5 & 2386 & 1.026 \\
\hline High & 33.3 & 613 & 1.086 & 38.7 & 2384 & 1.032 \\
\hline " & " & " & $1.098(\mathrm{e})$ & 38.5 & $"$ & 1.026 \\
\hline Low & $30.0^{(f)}$ & 6.13 & 1.184 & 38.5 & 2355 & 1.026 \\
\hline High & 31.7 & 613 & 1.098 & 38.5 & 2396 & 1.026 \\
\hline
\end{tabular}


TABLE V-4-C

L2-3 CRWA PARAMETRIC STUDY RESULTS $(a)$

EFFECT OF P/A AND POWER TRIP

\begin{tabular}{|c|c|c|c|c|c|c|c|c|}
\hline $\begin{array}{l}\text { Case } \\
\text { I.D. } \\
\text { CRW } \\
\end{array}$ & $P / A$ & 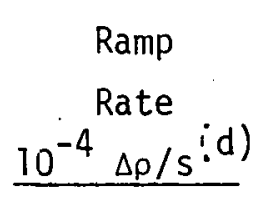 & $\begin{array}{c}\text { Initial } \\
\text { Power } \\
\text { MW } \\
\end{array}$ & $\begin{array}{c}\text { Initial } \\
\mathrm{T}_{\text {Hot }} \\
{ }^{\circ} \mathrm{F} \\
\end{array}$ & MDNBR & $\begin{array}{l}\text { Trip (b) } \\
\text { Power } \\
\text { Mw } \\
\end{array}$ & $\begin{array}{l}\text { Pressure } \\
\text { a MDNBR } \\
\text { psia }\end{array}$ & $\mathrm{F}_{\mathrm{E}}{ }^{(\mathrm{c})}$ \\
\hline 95 & 2.50 & 0.1 & 38.4 & 609 & 1.196 & $40.3^{(i)}$ & 2369 & 1.026 \\
\hline $91 \mathrm{~B}$ & 2.60 & 0.1 & 36.2 & 609 & 1.140 & $38.2^{(g)}$ & 2370 & 1.026 \\
\hline 104 & 2.55 & 0.1 & 37.3 & 613 & 1.143 & $39.2^{(h)}$ & 2340 & 1.026 \\
\hline $91 \mathrm{C}$ & 2.60 & 0.1 & 36.2 & 613 & 1.131 & $38.2^{(g)}$ & 2340 & 1.026 \\
\hline $67 \mathrm{~A}$ & 2.50 & 0.5 & 35.6 & 613 & 1.110 & $40.3^{(i)}$ & 2379 & 1.032 \\
\hline 627 & 2.60 & 0.5 & 33.9 & 613 & 1.080 & $38.7^{(i)}$ & 2379 & 1.032 \\
\hline 103 & 2.55 & 0.5 & 34.2 & 613 & 1.120 & $39.2^{(h)}$ & 2340 & 1.026 \\
\hline $103 A$ & 2.55 & 0.5 & 33.9 & 613 & 1.133 & $38.9^{(g)}$ & 2340 & 1.026 \\
\hline $621 B$ & 2.60 & 0.5 & 33.4 & 613 & 1.125 & $38.2^{(g)}$ & 2340 & 1.026 \\
\hline
\end{tabular}




\section{TABLE $V-4$ Notes}

(a) These caiculations were done with COBRA IIIC using the one-eighth LOFT core model, with the conservative error in the spacer grid loss coefficient equation (see discussion in Section III.3).

(b) The CRWA's with $<4 \times 10^{-4} \Delta \mathrm{p} / \mathrm{s}$ ramp rate tripped on hot leg temperature with power just at the worst-case trip level.

(c) Engineering hot spot factor in COBRA.

(d) Low moderator and Doppler coefficients assumed for ramp rates $\leq 1.0 \times 10^{-4} \Delta \rho / \mathrm{s}$.

High moderator and Doppler coefficients assumed for ramp rates $\geq 1.5 \times 10^{-4} \Delta \rho / \mathrm{s}$.

(e) An estimate.

(f) Minimum starting power assumed was $30 \mathrm{MW}$. This case trips on high power.

(g) A worst-case trip power $3.5 \mathrm{MW}$ above nominal.

(h) A worst-case trip power $3.8 \mathrm{HW}$ above nominal.

(i) A worst-case trip power $4.2 \mathrm{MW}$ above nominal. 
B. The MDNBR is less for lower assumed values for the moderator and Doppler feedback coefficients for reactivity ramp rates $\leq 1.0 \times 10^{-4} \Delta \rho / \mathrm{s}$. The MDNBR is less for high assumed values for the moderator and Doppler feedback coefficients for reactivity ramp rates $\geq 1.5 \times 10^{-4} \Delta \rho / \mathrm{s}$. (See Table V-4-B).

C. MDNBR is less for the maximum peaking cases (with $P / A=2.60$ ), even when the margin to the power trip is greater for the lower peaking cases. Therefore, safety analyses can be based on the $P / A=2.60$ cases. (See Table $V-4-C$ ).

As a result of the CRWA analyses for $P / A=2.60$, as tabulated in Table $\mathrm{V}-3$, and the comparative calculation results tabulated in Table $\mathrm{V}-4-\mathrm{C}$ for different assumed $P / A$, it is concluded that the L2-3 Mode 8 CRWA's can satisfy Damage Criteria $A$ (MDNBR $\geq 1.14$ ) for all measured peaking $\leq 2.60$ with the worst-case high power trip $3.8 \mathrm{MW}$ above nominal power for $P / A>2.50$, and $4.2 \mathrm{MW}$ above nominal power for $P / A \leq 2.50$. This conclusion is, of course, based on the previously stated list of operational conditions and analys is assumptions.

Most of the final CRWA analyses assumed a time constant of $15 \mathrm{~s}$ for the hot leg temperature trip. Measurements for this time constant, with the recommended improvements in the thermal wells, indicated that the time constant may be between 16 and $17 \mathrm{~s}$. Therefore the limiting CRWA (a $0.7 \times 10^{-4} \Delta \rho / \mathrm{s}$ ramp rate) was reanalyzed with an $18 \mathrm{~s} T_{\text {Hot }}$ trip time constant. This analysis (case CRWA 106 in Table V-3) showed that the resulting MDNBR was not significantly different (MONRR $=1.15$ ). This is to be expected since the only significant difference in this transient and the case with a $15 \mathrm{~s}$ time constant (CRW 85B) is a $0.4^{\circ} \mathrm{F}$ increase in the hot. leg temperature at the time of MDNBR. Therefore, the consequences of a CRWA are satisfactory with an $18 \mathrm{~s} T_{\text {Hot }}$ trip time constant.

An analysis was done to see if, for the final analysis conditions, the operating pressure band could be increased to include a high pressure worstcase trip level of 2400 psia. The calculation for a $0.7 \times 10^{-4} \Delta \mathrm{s} / \mathrm{s}$ ramp rate (the worst ramp rate), $P / A=2.60$, a power trip of $38.5 \mathrm{MW}$ (3.8 MW above nominal power), and 2400 psia peak pressure resulted in a MDNBR of 1.120. Therefore, a 2340 psia high pressure worst-case trippoint is required. 
The maximum ramp rate for a CRWA for L2-2 operation was calculated as $0.141 \% \Delta \mathrm{p} /$ inch $^{[8]}$. For L2-3 Mode 8 operation, the maximum differential CRA worth (4 CRA bank withdrawal) is $0.126 \% \Delta \rho /$ inch (see Section IV.4.3). For a maximum withdrawal speed of 29 inches/minute and a $0.141 \% \Delta \rho /$ inch differential worth, the maximum reactivity ramp rate for a CRWA would be:

$$
1.41 \times 10^{-3} \Delta \rho / \text { inch } \frac{1}{60} \frac{\min }{\mathrm{s}} 29 \frac{\mathrm{in} .}{\min }=6.8 \times 10^{-4} \Delta \rho / \mathrm{s}
$$

Therefore, the $8 \times 10^{-4} \Delta \rho / s$ CRWA analyzed for L2-3 operation envelopes the maximum CRWA ramp rate. Conversely, the $8 \times 10^{-4} \Delta \rho / s$ CRWA envelopes 4-CRA bank withdrawal differential worths up to $0.166 \% \Delta \rho /$ inch.

Since these CRWA's (for a ramp rate $\geq 0.1 \times 10^{-4} \Delta \rho / \mathrm{s}$ ) are Incidents of Moderate Frequency, then for Mode 8 operation, it is only required to meet Damage Criteria B (PCST $\leq 1650^{\circ} \mathrm{F}$ ) rather than Damage Criteria A (MDNBR $\geq 1.14)$. This means it would be acceptable to predict a possibility of exceeding CHF in the core as long as the peak clad temperature limit is not exceeded. However, in a analysis for a slow CRWA with a MDNBR of 1.137, PCST was predicted to be $1747^{\circ} \mathrm{F}$. This high temperature results since the hot spot remains in $f i 1 \mathrm{~m}$ boiling for more than 2 seconds after being forced into film boiling when MDNBR $=1.14$, even though the reactor was scrammed $0.3 \mathrm{~s}$ after MDNBR $=1.14$.

The high initial fuel temperature due to the conservative FRAP model assumptions (see Section $I I I .3$ ) results in a rapid increase in clad temperature when the surface is forced into film boiling. A PCST of $1650^{\circ} \mathrm{F}$ is reached in about 1 second. Therefore, there is no significant difference between the consequence limits of Damage Criteria A and Damage Criteria B for slow power rise accidents. This conclusion was also shown for a FRAP T4 calculation for a loss of steam load accident (which is also a slow power increase transient). The loss of steam load case for which the FRAP calculation was done had the following characteristics and results:

$\begin{array}{ll}\text { Time when MDNBR }<1.14 & 13.51 \mathrm{~s} \\ \text { MDNBR } & 1.131 \\ \text { Time of MDNBR } & 13.8 \mathrm{~s} \\ \text { PCST } & 1804^{\circ} \mathrm{F} \\ \text { Time of PCST } & 15.3 \mathrm{~s}\end{array}$


See Section III.3 for a discussion of the LOFT FRAPT fuel pin model.

3.3 Control Rod Drop Accident - A low-worth control rod assembiy (CRA), when dropped, can reduce power to a low value. The drop in power cooled with a continued high steam flow can result in a cooldown and a subsequent power recovery. The analysis for this accident seeks to determine the extent and the consequences of the power recovery.

The FSAR analysis for this accident (Section 15.2.3 ${ }^{[3]}$ ) assumed a worth of $-2.3 \% \Delta \rho$ for the dropped CRA. For the L2-2 pre-LOCE analysis [37], two worths were used for the hybrid calculation: (1) $-2.2 \% \Delta \rho$, and (2) $-3.17 \% \Delta \rho$. The L2-2 analysis demonstrated that the drop of the low worth CRA results in a greater power recovery and less pressure decrease.

The hybrid computer analysis for a dropped CRA for L2-3 Mode 8 operation assumed a worth of $-2.7 \% \Delta \rho$. High moderator and Doppler feedback was assumed to maximize the power recovery. The hybrid computer results for this accident are:

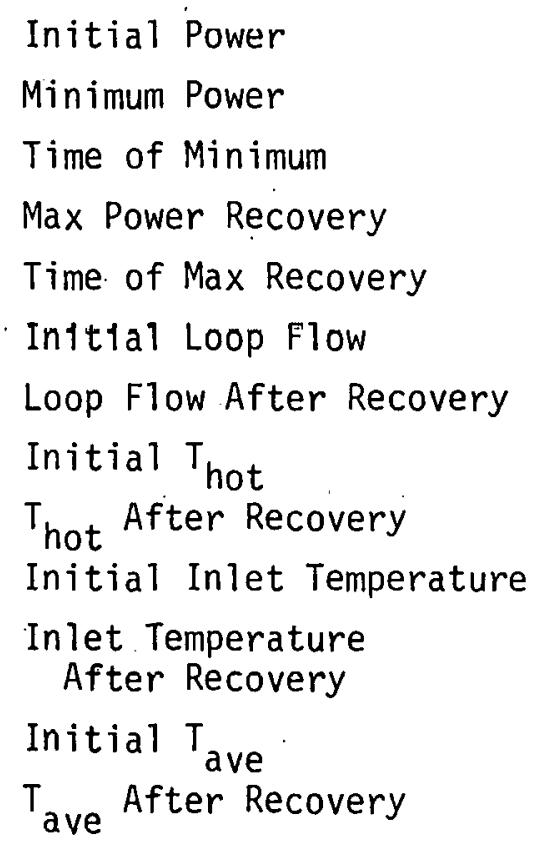

$37.3 \mathrm{MW}$

$10.1 \mathrm{MW}$

$2.05 \mathrm{~s}$

$18.3 \mathrm{MW}$ ( $49 \%$ of initial)

$25.6 \mathrm{~s}$

$1.15 \mathrm{MT} \mathrm{bm/h}$

$1.24 \mathrm{Mlbm} / \mathrm{h}$ (108\% of initial)

$617^{\circ} \mathrm{F}$

$571^{\circ} \mathrm{F}\left(46^{\circ} \mathrm{F}\right.$ less than initial)

$539^{\circ} \mathrm{F}$

$532^{\circ} \mathrm{F}\left(7^{\circ} \mathrm{F}\right.$ less than initial)

$578^{\circ} \mathrm{F}$

$551.5^{\circ} \mathrm{F}\left(26.5^{\circ} \mathrm{F}\right.$ less than initial $)$ 
The transient was terminated by a 2000 psia worst-case low pressure trip at 25.5 seconds.

The dropped control rod causes a radial flux tilt in the core which results in an increased core peak-to-average power ratio and increased integrated rod power for the hot rod. Based on the results of the power distribution calculations [38], the core power peaking and integrated rod power has been estimated to increase by approximately 10\%. Physics calculations [38] indicate that the axial power shape is essentially unchanged by the dropped rod.

The effect of the increased radial power factor is to reduce the core MDNBR after the dropped rod. However, as shown above, the core power level and other thermal-hydraulic conditions after power recovery are less severe than before initiation of the accident. The improved power level and other thermalhydraulic conditions tend to increase the MDNBR. After the rod drop, power decreases to $10 \mathrm{MW}$ and an increase in the MDNBR will occur. As the transient progresses, the MDNBR will decrease to a value corresponding to the reactor conditions at maximum recovery before the reactor trip. This value of the MDNBR after recovery can be estimated based only on the change in power level and the change in radial power distribution by:

$$
\triangle \text { MDNBR }=\left[(1-0.10) \frac{\text { Initial Pwr }}{\text { Max Recovery Pwr }}-1\right]
$$

This estimate assumes that the change in MDNBR is linear with power. Analysis experience with COBRA has shown that the MDNBR will change by more than the power change since a change in power also influences the channel flow and quality. Use of this equation will neglect the beneficial effects of lower core coolant temperature and increased loop flow. Using the above equation for the L2-3 control rod drop, MDNBR will increase by more than:

$$
\triangle M D N B R=\frac{0.90}{0.49}-1=84 \%
$$

In conclusion, the MDNBR for the control rod drop accident will be well above the Damage Criteria A consequence limit of MDNBR $\geq 1.14$. Reactor scram will be provided via a low-pressure trip for a worst-case trippoint of 2000 psia. 
3.4 Control Rod Assembly Misalignment - L2-3 LOCE pre-blowdown

(Mode 8) operation will be controlled within a maximum band for control rod position of 50 to 58 inches withdrawn. All steady-state and transient thermal analyses have been done to include operation down to a control rod position of 50 inches above fuel bottom, at which the highest peaking occurs for operation within this CRP band. Thus, operation with control rod misalignment within the operation band is enveloped.

An undetected control rod misalignment with the misaligned control rod assembly (CRA) below 48 inches indicated withdrawn (CRP $=50$ inches) could result in peak powers significantly greater than analyzed for L2-3 Mode 8 operation. Therefore, control rod position and CRA movement must be controlled to limit a potential misalignment below 48 inches withdrawn to a very low probability event. The requirements for control rod position surveillance are detailed in the LOFT Technical Specifications with observance of these controls, the conclusions for misalignment remain unchanged from those in the $\operatorname{FSAR}^{[3]}$.

3.5 Primary Coolant Addition and Control System Malfunction - A malfunction or operator error effecting a potential addition of unborated (or low boron) water to the PCS can result in a slow reactivity addition to the core. The maximum reactivity addition rate for this accident, as is described in Section 15.2 .5 of the FSAR ${ }^{[3]}$, is enveloped by the analyses for CRWA's, discussed in the preceding Section V.3.2 of this report.

3.6 Primary Coolant Flow Loss with Flywheel Assisted Coastdown - A loss of both PCS pumps, with coastdown, was analyzed for L2-3 pre-LOCE initial (off-nomina1) operating conditions. Analysis for this type of accident in Section 15.2 .6 of the FSAR ${ }^{[3]}$ showed that the loss of both pumps envelopes the consequences for loss of only one pump (with coastdown). Therefore, only the loss of both pumps was analyzed for L2-3 Mode 8 operation.

Analysis for loss of power to both PCS pumps due to a loss of. commercial (off-site) power in Section 15.2.9 of the FSAR ${ }^{[3]}$, showed that the loss of both pumps without a loss of commercial power was the more limiting case. This is because a loss of commercial power aiso drops the CRA's, thus 
providing an instantaneous scram. Therefore, loss of commercial power was not specifically analyzed for L2-3 pre-LOCE operation.

A loss of both PCS pumps with coastdown, was analyzed for $P / A=2.60$, a high off-nominal hot leg temperature of $617^{\circ} \mathrm{F}$, and a low flow worst-case trippoint of $1.01 \mathrm{Mlbm} / \mathrm{h}$. The MDNBR was 1.209 , well above the Damage Criteria A consequence limit of 1.14 .

The L2-2 analyses for loss of flow accidents showed that the low flow trippoint was not required to be a function of measured peaking, even though nominal and off-nominal flow vary with measured peaking [37]. A comparative steady-state analysis (Appendix B-1) was done for L2-3 for loop flow at the worst-case low flow trip level of $1.01 \mathrm{Mlbm} / \mathrm{h}$, with two different assumptions for peaking: The results were (for $T_{\text {hot }}=621^{\circ} \mathrm{F}$ and 2350 psia pressure):

$\begin{array}{ccc}\text { P/A } & \text { Off-Nominal Power (MW) } & \text { MDNBR } \\ & 36.4 & 1.161 \\ 2.37 & 40.6 & 1.157\end{array}$

These results verify the L2-2 analysis conclusion for L2-3 conditions: The MDNBR for Mode 8 conditions is relatively insensitive to small changes in initial loop flow, and therefore the low flow trippoint can be single-valued for all values of allowable measured peaking:

3.7... Loss of Steam Load - A loss of steam load in the LOFT reactor will result in an increase in temperature and pressure as heat transfer to the secondary system is lost. This accident was analyzed in Section 15.2.7 of the FSAR $^{[3]}$ as a closure of the Steam Flow Control Valve (SFCV) at a rate of $5 \%$ (of full open) per second (a $20 \mathrm{~s}$ stroke time). Analyses for power range testing safety analysis ${ }^{[18]}$ for SFCV stroke times between 1 and $40 \mathrm{~s}$. determined that the safety margins are not significantly decreased from the FSAR case for SFCV closure for stroke times between (and including) 10 and $40 \mathrm{~s}^{[19]}$. The analyses also showed that the minimum DNBR is obtained for SFCV closure at the fastest rate (shortest stroke time). 
A study of potential stroke time for the SFCV determined that the stroke time was not likely to be faster than $18 \mathrm{~s}$ (measured stroke time has been between 19 and $20 \mathrm{~s}$ ). A $17 \mathrm{~s}$ stroke time was assumed for the final L2-3 Mode 8 loss of steam load accident analysis.

The L2-3 analysis adjusted the initial power and pressure such that when the reactor was tripped by high pressure, the power was at the high worst-case trip value. The transient was initiated from a low off-nominal initial pressure of $2081 \mathrm{psia}$, in order to maximize the time to scram.

The FSAR analysis ${ }^{[3]}$ (Section 15.2.7) determined that maximum PCS pressure was calculated assuming that the pressurizer spray and power-operated relief valves did not operate. But, the minimum DNBR was calculated assuming operation of these pressure limiting plant features. The FSAR analysis envelops L2-3 pre-LOCE operation for maximum PCS pressure, since the high pressure is primarily a function of the imbalance between the reactor power and the heat rejection to the secondary system. Therefore, for the L2-3 pre-LOCE analys is, those conditions which tend to reduce DNBR during the transient were assumed, that is pressurizer spray and power-operated relief valve operation, off-nominal initial conditions, and a low (absolute) value for the moderator feedback coefficient. Measured P/A was assumed to be 2.60 , the off-nominal hot leg temperature was $613^{\circ} \mathrm{F}$, and the worst-case power trip level was $38.2 \mathrm{MW}$. Since this is a limiting transient, the worst-case L2-3 scram curve was used. Most of the analysis assumptions are 1 isted in Appendix B-4 for this and other L2-3 transients.

For the L2-3 Mode 8 loss of steam load accident with 2081 psia initial pressure, PCS pressure rises to the 2340 psia high pressure trippoint (initiating reactor trip) in $12.75 \mathrm{~s}$, and the control rods drop at $13.6 \mathrm{~s}$, pressure continues to rise slowly, and the inlet temperature is just starting to rapidly increase when scram occurs. The MDNBR was 1.156 at $14.15 \mathrm{~s}$. Therefore, the consequences of the loss of steam load accident are seen to be comparable to those for the limiting CRWA's, for which MDNBR $=1.15$ for a 38.5 MW high power trip level. The consequences of this accident are seen to meet the consequence limit for Damage Criteria A (MDNBR $\geq 1.14$ ). 
Since this transient involves a simultaneous slow power rise and pressure increase, as did the CRWA's, then little gain in operating bounds or trippoints is expected by taking the consequences to the Damage Criteria B limit since there is no significant difference between the Damage Criteria. $A$ and $B$ limits using present conservative assumptions for the FRAPT analyses.

\subsection{Steam Generator Feedwater Accidents - These accidents include} loss of feedwater, and excessive heat removal due to excessive feedwater. These accidents were shown in the FSAR analyses [3] in Sections 15.2.8 and 15.2.10, to result in very little change in the safety margins, and are thus enveloped by other steam generator accidents (loss of steam load, steam load increase). Therefore, feedwater accidents were not specifically analyzed for L2-3 pre-LOCE operation.

3.9 Steam Load Increase - A steam load increase, due to an inadvertent opening of the SFCV, results in reactor PCS cooldown and a subsequent power rise due to the negative feedback coefficients. FSAR analysis for this accident, in Section 15.2.11 of the FSAR ${ }^{[3]}$, was done for both a high and a low initial power. The high initial power case was shown to be limiting, and therefore, the analysis of this accident for L2-3 pre-LOCE operation was done for high off-nominal power. Analyses for LOFT Power Range Testing for different SFCV stroke times showed that safety margin was not significantly decreased from the FSAR analysis for stroke times between 1 and $40 \mathrm{~s}$, and that the longer stroke time $(40 \mathrm{~s})$ was most limiting [19]. This conclusion was confirmed by the L2-2 Mode 8 safety analyses for the steam load increase accident $[37]$.

The steam load increase accident was analyzed for L2-3 Mode 8 operation for a SFCV stroke time of $40 \mathrm{~s}$ (an opening rate of $2.5 \%$ per second). Analysis was performed for $P / A=2.60$ off-nominal conditions for a high initial pressure of 2257 psia since pressure decreases during this accident. The maximum value was assumed for the moderator feedback coefficient so as to increase the positive reactivity feedback due to the cooldown. A minimum value was assumed for the Doppler feedback, as in FSAR analyses. The assumed off-nominal hot leg temperature was $617^{\circ} \mathrm{F}$, and the power worst-case trippoint was $38.7 \mathrm{MW}$. The MDNBR. for this accident is 1.24 , well above the consequence limit for Damage Criteria $A$. The accident was tripped by high power. 
3.10 Failure of Automatic Pressure Control System - Analysis for the FSAR for this accident (Section 15.2.12 of the LOFT FSAR ${ }^{[3]}$ ) determined that safety margins (MDNBR) increased throughout the transient. Still, this accident was analyzed for L2-2 pre-LOCE operations ${ }^{[37]}$, since it is the limiting anticipated low pressure transient.

The accident simulated, using the Hybrid computer, inadvertent opening of the power-operated relief valves, which results in the most severe low pressure transients for this accident type. During the transient, reactor power, PCS pressure, and PCS temperature all slowiy but steadily decrease. Reactor flow also decreases slightly. The L2-2 analysis assumed no trip occurred. Even without the trip, MDNBR increased throughout the transient; just as it did for the FSAR analysis. The L2-2 analysis was terminated at $115 \mathrm{~s}$ when pressure equals 1674 psia. No specific analysis was done for L2-3 operation for this accident since both the FSAR and L2-2 analyses showed no decrease in MDNBR prior to scram of the reactor by the low pressure trip.

3.11 Inadvertent Opening of Reflood Assist Bypass Valves - Inadvertent opening of both Reflood Assist Bypass Valves (RABV's) was reanalyzed for LOFT Power Range Testing in LTR $111-104^{[39]}$. The analyses for power range operation determined that the Damage Criteria $A$ consequence level (MDNBR $\geq 1.13$ using the LOFT-1 correlation) could be satisfied with a worst-case trippoint of $15 \%$ of the full valve opening area, and a time constant of $0.10 \mathrm{~s}$. This analysis was for an opening rate of $10 \%$ per second. An analysis for a $10 \%$ opening area trip and. a $5 \% / \mathrm{s}$ opening rate predicted a MDNBR $=1.25$.

The upening of both RABV's was analyzed for L2-3 Mode 8 operation for both a $5 \% / \mathrm{s}$ and a $10 \% / \mathrm{s}$ opening rate with a $10 \%$ open area worst-case trip-.. point. A 0.10 second scram delay was assumed after reaching the trippoint. The accident was analyzed for high measured peaking conditions $(P / A=2.60)$ with a $617^{\circ} \mathrm{F}$ off-nominal $T_{\text {Hot }}$.

The results of the analysis for inadvertent opening of the RABV.'s are: 
5\%/s opening

$\begin{array}{lll}\text { Reactor trip time (s) } & 2.15 & 1.15 \\ \text { MDNBR } & 1.205 & 1.195 \\ \text { MDNBR time (s) } & 1.3 & 1.2 \\ \begin{array}{l}\text { Fraction of initial core flow } \\ \quad \text { O MDNBR }\end{array} & 0.906 & 0.834 \\ \begin{array}{l}\text { Fraction of initial power } \\ \quad \text { o MDNBR }\end{array} & 0.951 & 0.904 \\ \begin{array}{l}\text { Power to Flow Ratio } \\ \quad \text { o MDNBR }\end{array} & 1.050 & 1.084 \\ \begin{array}{l}\text { Fraction of initial core flow } \\ \quad \text { o trip }\end{array} & 0.851 & \\ \begin{array}{l}\text { Fraction of initial power } \\ \quad \text { o trip }\end{array} & 0.873 & \\ \text { Power to Flow Ratio } & & \\ \quad \text { a trip }\end{array}$

As seen above, for the slower opening time the MDNBR is a minimum prior to reactor trip since the moderator feedback brings the power down. With the faster $10 \% / \mathrm{s}$ opening time, feedback is not as influencial, and MDNBR occurs shortly after the initiation of the reactor trip. For either case, however, MDNBR is above the Damage Criteria A consequence limit. Low feedback coefficients were assumed to minimize the effect of feedback on power.

4

Infrequent. Faults

4.1 Rapid Primary Coolant Flow Coastdown - This accident analys is simulates a loss of power to one of the PCS pumps without a flywhecl assisted coastdown. Although a loss of field trip could occur and provide a quick reactor trip, the accident was analyzed with a low flow trip with a worst-case trippoint of $0.98 \mathrm{Ml} \mathrm{bm} / \mathrm{hr}$. This accident was analyzed for $P / A=2.60$ offnominal conditions with an off-nominal $T_{\text {hot }}$ of $617^{\circ} \mathrm{F}$.

The reactor is tripped at $2.05 \mathrm{~s}$ by the low flow trip, but MDNBR occurs at $1.4 \mathrm{~s}$, prior to the trip. This is due to the effect moderator feedback has on lowering reactor power in response to a flow decrease. A minimum 
value for the moderator feedback coefficient was assumed. This accident was analyzed for two different scram reactivity assumptions. One analysis was done using the "10/26 LF" scram curve as used for the L2-2 Mode 8 safety analyses, and as used for most L2-3 Mode 8 transients as well (except for the final steam load increase accident). Another analysis was done using the more conservative L2-3 worst-case scram curve discussed in Section IV.4.2. The comparison is made to determine if the difference in the resulting MDNBR due to the scram assumption is significant. As discussed for the power range testing safety analysis [40], the rapid flow coastdown accidents are considered to be the most sensitive to the scram reactivity assumption (demonstrated by the power range testing safety analyses for the rapid flow coastdown accidents).

The results of the analysis for the rapid coastdown of one. PCS pump are:

MDNBR $\frac{10 / 26 L F " \text { scram }}{1.188} \frac{\text { L2-3 worst-case scram }}{1.183}$

The two-pump rapid coastdown, discussed below, was also analyzed with both scram reactivity assumptions with even less effect on MDNBR due to the scram assumption. Thus, none of the L2-3 transient analysis results will be changed significantily (no change in MDNBR in the second decimal place) by the use of either the "10/26 LF" or the L2-3 worst-case scram curves.

As seen above, the consequences of the one-pump rapid coastdown for L2-3 Mode 8 operation satisfies the consequence limit. for Damage Criteria A.

5. Limiting Faults

5.1 Rod Ejection Accident - An ejection of a CRA out of the LOFT core, although an extremely low probability event, can result in a large and rapid reactivity addition to the core. As such, the rod ejection accident is the design basis reactivity excursion for LOFT.

The results of the L2-3 Mode 8 analysis for a maximum control rod ejection accident are discussed in Appendix B-4. The maximum rod ejection accident analysis was done using the LOFT RELAP4 rod ejection kinetics mode 1 to 
LTR 111-127

calculate power and PCS response, using COBRA IIIC to calculate hot channel conditions and the LOFT-3 DNBR's, and using FRAPT4 to calculate maximum cladding temperature. Assumptions used for the L2-3 maximum rod ejection accident are:

$\begin{array}{ll}\text { Ejected rod worth } & 0.363 \% \Delta p \\ \text { Measured } \mathrm{P} / \mathrm{A} & 2.66 \\ \text { Worst-case power trippoint } & 46.5 \mathrm{MW} \\ \text { Off-nominal } \mathrm{T}_{\text {hot }} & 621^{\circ} \mathrm{F}\end{array}$

The ejected rod worth was input as a step insertion of reactivity. The ejected worth used is significantly greater than the maximum calculated worth of $0.225 \% \Delta \rho$ for an ejected rod for L2-3 operation (see Section IV.4.4). The high power trippoint is $9 \mathrm{MW}$ above the expected worst-case trip level for high measured $P / A$, and is high enough to envelope the trip power for any measured $P / A$ down to $P / A=2.13$. "The off-nominal $T_{\text {Hot }}$ is significantly greater than the value of $613^{\circ} \mathrm{F}$ set by the limiting slow power rise transients. A discussion in Appendix B-4 further describes the conservatisms in the L2-3 rod ejection analysis.

The results of the maximum L2-3 rod ejection accident analysis are:

$\begin{array}{ll}\text { Peak power } & 70 \mathrm{MW}(192 \% \text { initial) } \\ \text { MDNBR } & 1.03 \\ \text { Time of MDNBR } & 0.9 \mathrm{~s} \\ \text { Maximum average hot spot } & 153 \mathrm{cal} / \mathrm{gm} \\ \quad \text { fuel enthalpy } & \\ \text { Peak centerline fuel temperature } & 4670^{\circ} \mathrm{F} \\ \text { Maximum cladding temperature } & 1943^{\circ} \mathrm{F} \\ \text { PCST } & 1910^{\circ} \mathrm{F} \\ \text { Time of peak temperatures } & 2.3 \mathrm{~s} \\ \text { Vessel pressure increase } & 15 \mathrm{psi}\end{array}$

The maximum enthalpy is significantly less than the Damage Criteria C limit of $280 \mathrm{cal} / \mathrm{gm}$, and is approximately equal to the maximum enthalpy for a rod ejection from 50 inches withdrawn during full power operation (154 cal/gm). The maximum clad temperature is below the Damage Criteria C limit. The peak centerline fuel 
temperature remains below the melting temperature for the fuel. Therefore, the consequences of the rod ejection accident not only meet Damage Criteria D (as required by the Technical Specifications), but also satisfy Damage Criteria $C$.

A rod ejection analysis was also done for a measured $P / A=2.37$, for comparison to the high peaking case. Off-nominal power $=40.6 \mathrm{MW}$ and offnominal loop flow $=1.28 \mathrm{Mlbm} / \mathrm{h}$ for $P / A=2.37$. The peak power was relatively the same as for the $P / A=2.66$ case $(192 \%$ of initial), but the peak centerline temperature and clad temperatures were less. The maximum overage fuel enthalpy at the hot spot was greater $(158 \mathrm{cal} / \mathrm{gm})$, but not significantly. Therefore, the worst rod ejection accident is for the maximum assumed $P / A$.

The rod ejection analysis used the "10/26 LF" scram reactivity curve. However, as discussed in Appendix B-4, the combination of reactivity assumptions for this rod eject analysis $(0.363 \% \Delta \rho$ step insertion and a "10/26 LF" scram curve) is conservative compared to the final L2-3 reactivity assumptions (0.225\% $\Delta \rho$ ramp insertion and a L2-3 worst-case scram curve).

\section{$5.2 \quad$ Steam Line or Feedwater Line Rupture}

5.2.1 $\quad$ Steam Line Rupture at Ful1 Pre-LOCE Power - Analysis and discussion in the FSAR for steam line and feedwater line ruptures were based on steam line breaks, which are more severe than feedwater line breaks, and showed that a maximum power rise is calculated for a $100 \%$ steam line break from full power while a maximum cooldown (with a potential for re-criticality) is calculated for a $50 \%$ steam line break at low power ${ }^{[3]}$.

A $100 \%$ steam line break at off-nominal power (the maximum power rise case) was analyzed for L2-2 pre-LOCE operation [37]. The accident was analyzed using the Hybrid LOFT steam line break mode ${ }^{[28]}$ assuming a worstcombination of L2-2 pre-LOCE initial off-nominal conditions. Although the power increased quickly to trip level, the concurrent rapid decrease in reactor inlet temperature and a slower decrease in pressure resulted in minimum DNBR at the start of the transient, with MDNBR increasing thereafter. Part of the influence of the transient PCS conditions on MDNBR is due to a characteristic of the LOFT 
DNB correlations (both LOFT-1 and LOFT-3) in which a larger DNBR is calculated for a lower pressure, within the normal pressure operational range (2000 to $2400 \mathrm{psia})$. But the major influences increasing MDNBR during the transient are the rapid decrease in coolant temperature, and the short duration of the power burst (approximately $4 \mathrm{~s}$ ). Therefore, the consequence of a large steam line break near full power for pre-LOCE operation is the same as for the FSAR analysis (Section 15.4.5 in the LOFT FSAR ${ }^{[3]}$ ), that is no decrease in MDNBR during the transient.

This transient was not analyzed specifically for L2-3 Mode 8 operation since the consequences would be no different than those discussed above.

5.2.2 Maximum Cooldown Accident - A maximum cooldown is calculated for a $50 \%$ steam line break at low operating power as shown for the FSAR steam line break analyses [28][3]. This accident was analyzed for L2-2 Mode 8 conditions [37]. The analysis ${ }^{[37]}$. Considered the case in which the reactor was tripped concurrentiy with initiation of the steam line break, and was therefore conservative, since an early reactor trip increases the cooldown. The L2-2 analysis actually applies to any. low. flow operation with off-nominal loop flow $\geq 1.045 \mathrm{Mlbm} / \mathrm{h}$, since the analysis. is for low power operation $(2.5 \mathrm{MW})$, and is an analysis for PCS cooldown only, without any dependence on power distribution. The L2-2 analysis and its conclusions therefore also apply to L2-3 Mode 8 operation.

The cooldown calculated for pre-LOCE (low flow) operation is larger than was calculated for normal (high flow) operation. The cooldown calculated for the FSAR was from an average temperature of $544^{\circ} \mathrm{F}$ to $335^{\circ} \mathrm{F}$ for a $209^{\circ} \mathrm{F}$ cooldown ${ }^{[3]}$, approximately the same as for the above. However, even without the feedwater trip the cooldown is still less than the $225^{\circ} \mathrm{F}$ maximum cooldown used as a basis for LOFT shutdown reactivity control 1 imits. Therefore, with LOFT adherence to the shutdown reactivity limits based on a $225^{\circ} \mathrm{F}$ cooldown, the cooldown due to the 50\% steam iine break for L2-2 or L2-3 pre-LOCE operation will not result in re-criticality. 
5.3 Rapid Loss-of-Flow from Both Primary Coolant Pumps - This accident, a loss of both PCS pumps simultaneously, without a flywheel assisted coastdown, is the design basis loss of flow accident for the LOFT reactor. This twopump rapid coastdown was analyzed for $P / A=2.60$ off-nominal conditions, with an off-nominal $T_{\text {hot }}$ of $617^{\circ} \mathrm{F}$. It was analyzed for both a reactor trip due to the low flow trip, and due to the faster loss of field current trip.

The result with the loss of field current trip was a MDNBR of 1.20 at $0.8 \mathrm{~s}$. With a low flow trip at $0.98 \mathrm{M} 7 \mathrm{bm} / \mathrm{n}$ loop flow, the MDNBR was 1.175 at $1.4 \mathrm{~s}$. The MDNBR meets the consequence limit for Damage Criteria $A$ (MDNBR $\geq 1.14$ ). Therefore, Damage Criteria $B$ and $C$ are also satisfied, which satisfies the consequence limits required for this accident. Assumptions and results for this accident are listed in Appendix B-4.

6. Accident Analysis Conclusions - The following Table V-5 summarizes the results and consequences of the accident analyses for L2-3 LOCE pre-blowdown (Mode 8) operation. The consequences for all of the accidents analyzed for L2:3 LOCE pre-blowdown operation meet the consequence limits for Damage Criteria $A$ (MDNBR $\geq 1.14$ ), with the exception of the rod ejection accident. The consequences of the rod ejection accident meets the consequence limits for Damage Criteria $\mathrm{C}$ (maximum clad temperature $<2200^{\circ} \mathrm{F}$, maximum fuel enthalpy $<280 \mathrm{cal} / \mathrm{g},<17 \%$ cladding oxidation). Since the rod ejection accident is a limiting fault, then satisfaction of the consequence limits for Damage Criteria $C$ is acceptable (see Section III.1). The limiting transients were the control rod withdrawal accident $\left(0.7 \times 10^{-4} \Delta \rho / \mathrm{s}\right.$ reactivity ramp rate was the worst $)$, the loss of steam load accident, and the control rod ejection accident.

Reactivity or power increase transients are the most limiting type of accidents for pre-LOCE conditions because it is these accidents which increase the power to near full power levels while the flow is below that which would be obtained for a loss of one PCS pump from normal full flow (high flow) conditions. Therefore, for normal full power, full flow operation, the loss of flow accidents are limiting, but for pre-LOCE, low flow operation, reactivity transients (power excursions) are limting. Analys is was not done for a. start-up accident for pre-LOCE conditions because no start up in Mode 8 is allowed due to the low power restriction vs. core $P / A$. 
TABLE $V-5$

\section{L2-3 MODE 8 ACCIDENT ANALYSIS SUMMARY}

Event Category

Operational

Transient

Incident of

Moderate

Frequency
Infrequent

Fault

Limiting

Fault
Accident

Boron Dilution and

Rod Motion

$\mathrm{R} \leq 0.4 \times 10^{-4} \Delta \rho / \mathrm{s}$

CRWA (or Boron Dilution)

$\mathrm{R} \leq 8 \times 10^{-4} \Delta \rho / \mathrm{s}$

Control rod drop

Control rod misalignment

Loss of pumps with flywheel coastdown

Loss of steam load $17 \mathrm{~s}$

stroke time on SFCV

Steam generator feedwater accidents

Steam load increase $40 \mathrm{~s}$

stroke time on SFCV

Pressure control failure

RABV opening $10 \% / \mathrm{s}$

opening rate

Rapid one pump loss of

flow

Control rod ejection

(0.363\% $\Delta \rho$ step)
${\underline{\operatorname{Tot}\left({ }^{\circ} \mathrm{F}\right)}}^{(\mathrm{a})} \quad \underline{\text { MDNBR }}^{(\mathrm{b})} \quad \underline{\text { Notes }}$

$613 \quad 1.16$

613

1.15

613

$>1.25$

(c)

(d)

617

1.21

(g)

613

1.16

(e)

617

1.24

$>1.25$

(c)

617

1.20

617

1.18

(g)

621

1.03

$\max$ clad

temp $=1943$

Hot spot fue 1

enthalpy $=153 \mathrm{cal} / \mathrm{g}$

Steamline break

(f)

Two pump loss rapid

coastdown low flow

trip

Same as above with field trip
617

1.175

(g) 
TABLE V-5 Notes:

(a) High off-nominal hot leg temperature. This temperature is $4^{\circ} \mathrm{F}$ above nomina 1 .

(b) Calculated using the LOFT-3 correlation.

(c) MDNBR increases throughout this transient. See discussion for control rod drop accidents in Appendix B-4.

(d) Consequences and protective controls for this accident are no different than for L2-2 Mode 8 operation.

(e). The consequences of loss of feedwater or increased feedwater accidents are enveloped by the steam load accidents.

(f) The analysis and consequences for the steamline break maximum cooldown is no different from that analyzed for L2-2 Mode 8 operation, as discussed in Reference [37]. As discussed in Reference [37], the MDNBR increases throughout a steam line break transient, even if initiated from high off-nominal power.

(g) A loss of flow accident during the low flow maneuver is not as severe as during low flow operation. This was shown in the L2-2 Mode 8 safety analysis $[37]$. 
As was shown for the L2-2 core safety analyses, the consequences of the accidents are always the worst for the highest assumed measured peak-tocore average power ratio (peaking or $P / A$ ). The maximum assumed $P / A$ for the $L 2-3$ analyses was $P / A=2.60$. Also, as for the $L 2-2$ analyses, it was shown for L2-3 that the low flow trip can be single valued, that is it is not a function of measured $P / A$. The worst case low flow trip for $L 2-3$ analyses is $1.01 \mathrm{MIbm} / \mathrm{h}$ loop flow. The high power trip, however, could not be single valued. The required high power WCT is:

$$
\begin{aligned}
& P / A>2.55 \quad W C T=\text { nomina } 7+3.5 \mathrm{MW} \\
& 2.55>P / A \leq 2.50 \quad W C T=\text { nominal }+3.8 \mathrm{MW} \\
& P / A \leq 2.50 \quad W C T=\text { nominal }+4.2 \mathrm{MW}
\end{aligned}
$$

Nominal power $=90.23 /(P / A)$ MW, as specified in the L2 EOS.

Satisfactory mitigation of the slow power rise transients (CRWA's and loss of steam load) required that the potential initial operating conditions be restricted. The required operating condition bounds included a need to lower the nominal operating pressure in order to gain DNBR margin. The case for lowering the L2-3 operating pressure is discussed in Section III.2 and Appendix A-4. The required operating bounds are:

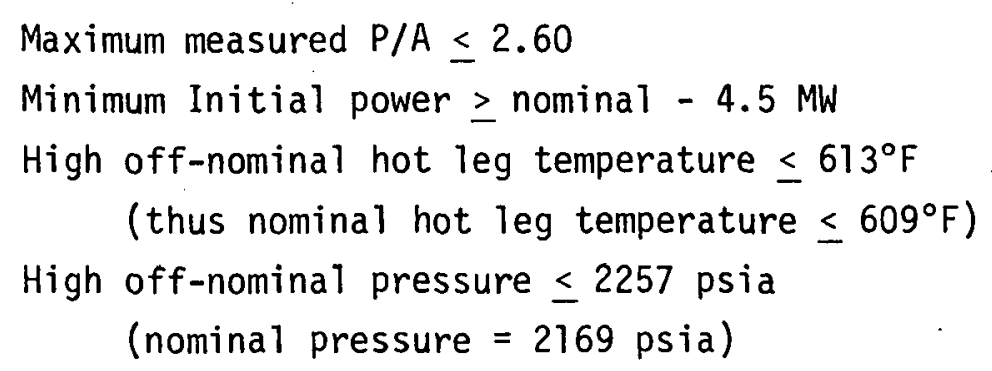

Other bounds may or may not have been required, but were a part of the assumed analysis conditions. These were:

High off-nominal power $\leq$ nominal $+2.5 \mathrm{MW}$

Low off-nominal loop flow $\geq[3.327 /(\mathrm{P} / \mathrm{A})]-0.125 \mathrm{Mlbm} / \mathrm{h}$

Low initial pressure $\geq 2081$ psia

Differential control rod worth $\leq 0.165 \% \Delta \rho /$ inch

Steam flow control vaive stroke time $\geq 17 \mathrm{~s}, \leq 40 \mathrm{~s}$

RABV opening rate $\leq 10 \%$ open $/ \mathrm{s}$ 
The limiting values of worst-case trippoints assumed for the L2-3 Mode 8 accident analyses are:

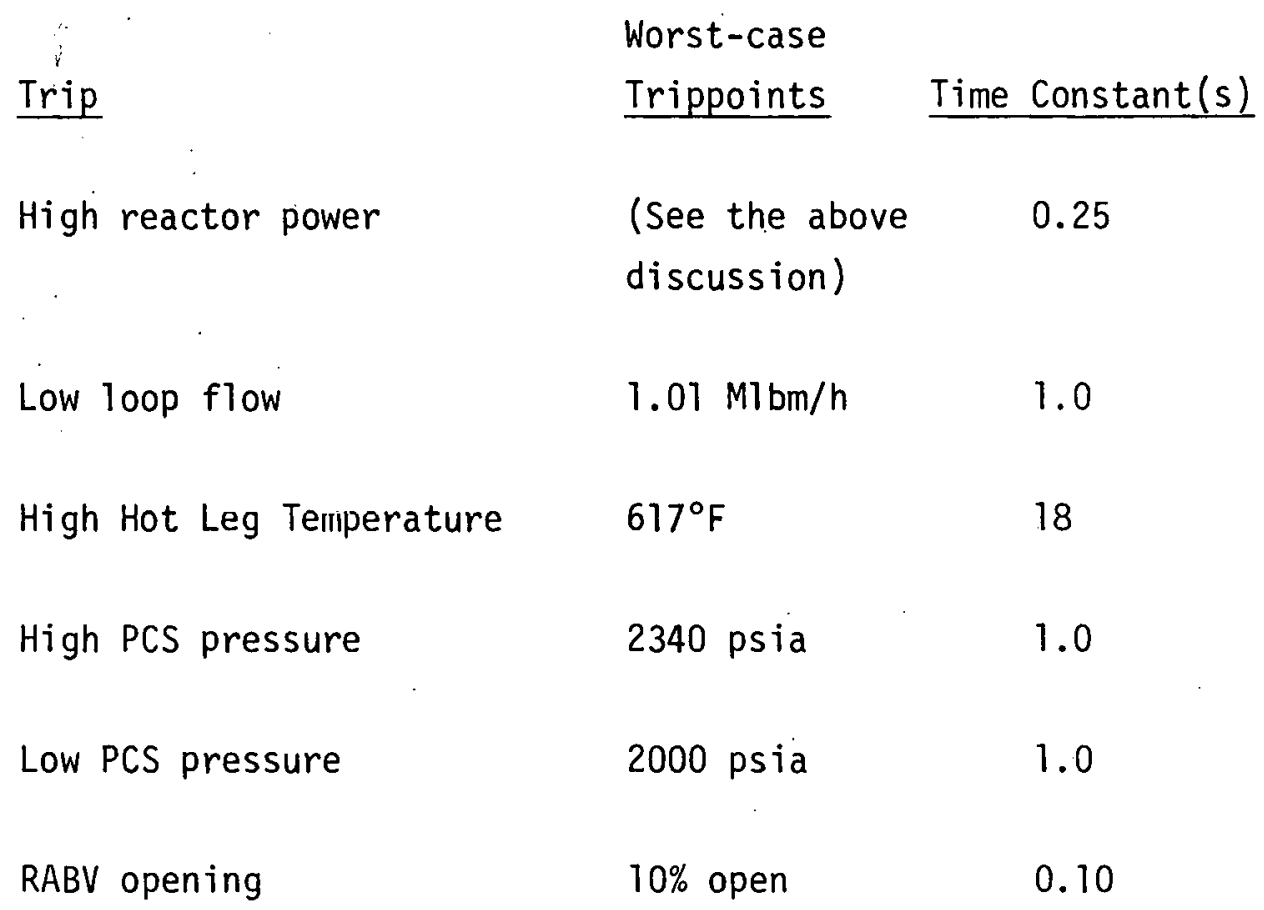

The hot leg temperature trip time constant needed to be significantly decreased from the $40 \mathrm{~s}$ assumed for the L2-2 Mode 8 safety analysis for satisfactory mitigation of the CRWA's. The high pressure WCT had to be lowered to 2340 psia (2440 psia was assumed for previous safety analyses) for satisfactory mitigation of the L2-3 CRWA's and the loss of steam load accident. Other trippoint assumptions, shown above, may not be bounding, but are as assumed for the L2-3 safety analyses.

Most of the L2-3 accidents were analyzed using the "10/26 LF" scram reactivity insertion curve used for the L2-2 Mode 8 analyses. A more conservative scram curve, the L2-3 worst-case scram curve (213 LF), was developed after most analyses were complete. However, comparative calculations for the most scram-sensitive transients (rapid loss of flow accidents) showed that use of the L2-3 worst case scram curve did not significantly change the resulting MDNBR. This is discussed further in Section V.4.1.

Analyses for CRWA's and loss of steam load accidents for L2-3 conditions showed that the use of Damage Criteria $A$ or $B$ made no significant 
difference for these accidents since a peak cladding surface temperature is reached very shortly following forcing the FRAP hot fuel pin surface into film boiling when MDNBR $<1.14$ (when the probability for DNB first exceeds $5 \%$ ). This is largely due to many conservatisms in the LOFT fuel pin model assumptions used with the FRAPT4 code.

In conclusion, the accident analyses show that the LOFT reactor can be operated safely at L2-3 Mode 8 conditions within the final analysis envelope assumed, and with trippoints within the final assumed worst-case trippoints, since the analysis results demonstrate that the accident consequences satisfy the consequence limits of the applicable damage criteria (see Section III.1). 


\section{MODES 5, 6, AND 7 ANALYSES FOR L2-3 OPERATION}

1. Operation With Reduced Nominal Pressure - As discussed in Sections 3.2 and 4.1 , satisfactory mitigation of limiting transients and establishment of satisfactory Mode 8 safety limits required that the initial safety margins be improved by lowering the LOFT nominal pressure. As shown in Appendix A-4, a pressure decrease will result in an increase in the DNB heat flux, an effect that is seen in the use of the LOFT-3 correlation for DNB heat flux. For Mode 8, the nominal pressure was reduced from 2262 psia to 2169 psia, high offnominal reduced from 2350 to $2257 \mathrm{psia}$, the high pressure worst-case trippoint (WCT) reduced from 2490 to $2340 \mathrm{psia}$, and the low pressure WCT was reduced from 2076 to $2000 \mathrm{psia}$. The safety analyses for L2-3 Mode 8 operation demonstrates the operational acceptability of operation with these pressure bounds and trips.

Additional analyses and reviews of the LOFT FSAR and subsequent safety analysis summaries were done to demonstrate that LOFT operation with the same reduced nominal pressure and reduced WCT's was also acceptable for operation in Modes 5, 6, and 7. The only transients terminated by a low pressure trip for the Mode 7 (at power, full flow) safety analyses are:
(a) Control rod drop.
(b) Failure of the automatic pressure control system (a 2076 psia WCT was assumed).
(c) Steam line break at low power (maximum cooldown accident).
(d) LOCA.

Hybrid computer simulation was done for a control rod drop accident during full power (Mode 7) operation with a 2000 psia low-pressure WCT. The original analysis for this case in the FSAR ${ }^{[3]}$ assumed an initial pressure near nominal (2259 psia) and a dropped CRA worth $2.39 \% \Delta \rho$. These conditions were also assumed for this analysis. Two analyses were done. One with the FSAR 
maximum values for moderator and Doppler feedback coefficients $\left(9.1 \times 10^{-3}\right.$ $\Delta \mathrm{p} / 1 \mathrm{bm} / \mathrm{ft}^{3}$ and $-1.5 \times 10^{-5} \Delta \mathrm{\rho} /{ }^{\circ} \mathrm{F}$, respectively), and another with values increased $7 \%$ to $10 \%$ above those in LTR $111-52^{[43]}$ for a hot reactor. The results for the control rod drop from full power (53 MW off-nominal power) are:

(a) The reactor is tripped by a 2000 psia low pressure WCT.

(b) At the time of maximum power recovery:

FSAR Max.

LTR 111-52

Feedback

Max Feedback

Power Recovery

$\%$ of Initial

74

50

(see Figures $A .3$ and A.4)

Core Average Temp

Decrease $\left({ }^{\circ} \mathrm{F}\right)$

29

29

ronre Flow Inereace

6

Increase in MDNBR

with $10 \%$ Flux Tilt (\%)

22

78

Since the assumption from near nominal pressure (2259 psia) is above the high off-nominal pressure for the assumed decrease in nominal pressure for L2-3 operation (2257 psia high off-nominal), then the above results apply to operation with reduced nominal pressure as well. Therefore, the Mode 7 control rod drop accidents analyzed demonstrate that a 2000 psia low-pressure WCT is suitable for llode 7 operation with the nominal pressure reduced to $2169 \mathrm{psia}$. The control rod drop accident analyses for both Modes 7 and 8 are discussed in Appendix B-4.

A failure of the automatic pressure control system results in a slow and continuous decrease in PCS pressure. The decreasing pressure causes a 
reduction in power due to the pressure coefficient of reactivity (a moderator density decrease occurs). Analysis for the FSAR determined that MDNBR increases throughout the transient (FSAR ${ }^{[3]}$, Section 15.2.12). Therefore, the level of the low pressure WCT is not important as long as it is sufficient to trip the reactor within a reasonable time. A 2000 psia WCT will therefore terminate operation during this transient just as satisfactorily as the 2076 psia WCT assumed for the FSAR analysis. For operation with 2169 psia nominal pressure, a 2000 psia WCT is 17 psi closer to nominal than a 2076 psia WCT during operation with a 2262 psia nominal pressure.

A steam line break accident from low power is a cooldown transient in which the safety concern is not power level or DNBR, but the potential for recriticality after scram. The pressure decrease and scram for this transient are significantly faster than the cooldown. Therefore, a small difference in the low pressure trippoint is insignificant. A 2031 psia trip was assumed for the FSAR analysis [28]. Protection for a cooldown transient is provided by assuring sufficient shutdown reactivity in the core. The LOFT requirements for shutdown reactivity for cooldown accident protection are discussed in LTR $111-97^{[34]}$ for Modes 2-7 and LTR $111-116^{[41]}$ for Mode 8 . The requirements are based on a maximum cooldown transient due to a $50 \%$ steam line break at zero power, hot reactor conditions, with a high steam generator level, and a reactor average power trippoint of $1 \mathrm{MW}$. Operation with lower nominal pressure, to $2169 \mathrm{psia}$, or with a 2000 psia low pressure trip will therefore not change the consequences of this maximum cooldown transient.

The ECCS trippoint for a LOCA is 1850 psia. As long as the low pressure WCT is above this, then. the level of the low pressure WCT is not a consideration during a LOCA uniess the time to reactor trip is important. However, upon the initiation of 1 imiting LOCA's, pressure very rapidly drops to saturation ( $1700 \mathrm{psia}$ ). Therefore, a slight difference in the low pressure. reactor trip or the initial operating pressure will not significantly effect the consequences of a LOCA.

The above discussions lead to the conclusion for LOFT operation in any mode that the consequences of transients which are terminated by a low. 
pressure trip are not significantly changed by operation with a 2000 psia low pressure WCT or with nominal pressure reduced to $2169 \mathrm{psia}$.

Another consideration is the pressure assumptions used for safety analyses for transients other than those few terminated by a low pressure trip. The COBRA analyses for the FSAR assumed an initial pressure of 2205 to near nominal pressure (2262 psia). The analyses for the low flow safety limit used a high pressure 2240 psia, because the LOFT- 1 correlation was slightly more conservative at high pressure for calculations with below nominal flow ${ }^{[45]}$. However, a study for the effect of pressure on DNB heat flux at LOFT full-flow levels concluded [44]: "At loop flows below $4 \times 10^{6} 1 \mathrm{bm} / \mathrm{hr}$, the actual DNB data do not show any trend with pressure. This pressure effect study concluded that below loop flows of $4 \times 10^{6} \mathrm{lbm} / \mathrm{hr}$, pressure in the range of 1820 to 2240 psia has no significant effect on the calculated DNB heat flux (the predicted differences are well within the scatter of the data). Therefore, the pressure assumed for these analyses is not a significant consideration." The reduction in DNBR calculated using the LOFT- 1 correlation for a change in pressure from nominal (2262 psia) to 1820 psia at a loop flow of $3.22 \times 10^{6} 1 \mathrm{bm} / \mathrm{hr}$ was onl $\mathrm{y} 1.3 \%$. Therefore, the Mode 7 safety margins are not significantly affected by reducing nominal pressure to $2169 \mathrm{psia}$. Even for PCS flow greater than $4 \times 10^{6} \mathrm{lbm} / \mathrm{hr}$, the estimated decrease in DNBR for the 442 psia decrease in pressure to 1820 psia is not more than $7 \%$.

Operation for zero power physics testing (Mode 5) was analyzed for PCS pressures as low as 1820 psia[15]. As long as the position of the control rod bank is 35 inches or more withdrawn when at 1820 psia then no reduction in safety margin is predicted from that existing for operation at 2262 psia and a minimum critical control rod position (24 inches withdrawn). However, this analysis was based on a possible $7 \%$ reduction in DNBR for a reduction in pressure from 2262 to $1820 \mathrm{psia}$, and an initial DNBR > 40. Therefore, even if control rod position was not changed, the change in safety margin would not be significant since the difference in the probability for DNB between a DNBR of 40 and 37 ( $7 \%$ less) is not significant. Also the possible $7 \%$ decrease in DNBR is based on high flow data (loop flow $>4 \times 10^{6} \mathrm{lbm} / \mathrm{h}$ ). 
Transient analyses for zero power operation are referred back to the FSAR analyses noting that the consequences are much less severe for zero power operation [15]. Therefore, since operation with lowered nominal pressure and/or a 2000 psia low pressure WCT is satisfactory for Mode 7, it is also satisfactory for Mode 5. The conclusions for Mode 6 (start up) are no different than for Mode 5 and Mode 7.

The conclusions regarding a possible low pressure safety limit for Modes 5, 6 and 7 are not changed by operation at 2169 psia nominal pressure with a 2000 psia low pressure WCT. The conclusion is still as stated in LTR 111-104 [44], and LTR 111-116, Section 1[9]. That is, "Core safety margins are not significantly changed by lowering pressure to as low as 1820 psia. Although no steady state power range safety limit has been determined for low pressure (where MDNBR would $=1.13$ [LOFT-1]), it is definitely below 1820 psia." "The only implied limits on the pressure in these steady-state analyses are the limits of the data for the LOFT-3 DNB correlation (2000 to 2400 psia)."

In conclusion, operation of the LOFT reactor with nominal pressure reduced to 2169 psia and/or with a 2000 psia worst-case trippoint does not significantly change the safety margins for operation in any operating mode. Loss of steam load accident, as discussed in Section 15.2.7 of the FSAR [3], is mitigated by a high pressure trip with a worst-case trippoint of 2440 psia. The accident was analyzed from an initial pressure of 2247 psia ${ }^{[21]}$, or 15 psi less than the nominal 2262 psia. An increase in the spread between nominal and trip could result in a lower MDNBR for the transient. Therefore, for a 93 psi decrease in nominal pressure (from 2262 to $2169 \mathrm{psia}$ ), the worst-case trippoint will need to also be decreased by at least 93 psia, unless additional analys is is done to show that no significant change results for the consequences of the loss of steam load accident. In the absence of a re-analysis for this accident, a reduction in the high pressure worst-case trippoint to 2340 psiala 100 psi decrease) as for L2-3 Mode 8 operation is needed for Modes 5, 6, and 7 . (Mode 7 or FSAR conditions are limiting for Modes 5 and 6 also for a loss of steam load accident.) 
2. L2-3 Mode 7 Operation With Revised Scram Curve - The L2-3 Mode 7 scram curve (the "2l4 HF"curve) described in Section 4.4 .2 is more conservative than the "817" scram curve used for previous Mode 7 core safety analyses:

Therefore, the effect of this more-conservative scram curve on Mode 7 transients needed to be considered. As discussed in LTR 111-104 [40], the Mode 7 trainsients most sensitive to a change in the scram assumption are the one-pump loss and two-pump loss rapid coastdown accidents. For L2-3 power levels (nominally. $75 \%$ of full rated power), the consequences of a rapid coastdown transient from an initial low flow level will envelop the consequences for the same accident from initial high flow levels. This was shown by comparative analyses for the rapid flow coastdown for the L2-2 test safety analysis [37]. This is especially true since use of the L2-3 low flow scram curve (the "213 LF" curve) results in the insertion of less scram reactivity with time than the "214 HF" curve (see Figure IV-1).

The consequences of the rapid loss of flow accidents for L2-3 power and initial low flow are (from section 5.):

$$
\begin{array}{cc}
\begin{array}{c}
\text { One-pump loss } \\
\text { rapid loss-of-flow }
\end{array} & \text { Two-pump loss } \\
\end{array}
$$

$\begin{array}{lll}\text { MDNBR } & 1.183 & 1.174\end{array}$

Therefore, Damage Criteria $A$ is also satisfied for Mode 7 operation (full flow) with L2-3 power levels and the L2-3 scram curve (the "214 HF" curve).

Analyses were also done for the rapid loss-of-flow (or rapid coastdown) accidents with the "214 HF" scram curve and full Mode 7 power (53 MW off-nominal power). The analysis assumptions were the same as for the power range safety analyses in Reference [40], except for the scram curve: The results of these analyses are discussed with comparisons to the power range testing aralysis results in Appendix B-5.

The $53 \mathrm{MW}$ analysis for the one-pump loss rapid coastdown calculated a peak cladding surface temperature (PCST) of $1669^{\circ} \mathrm{F}$, whereas the PCST 
with the "817" scram (Case FLOW .40) was $1638^{\circ} \mathrm{F}$ [40]. Thus, the consequence 7 imit of $1650^{\circ} \mathrm{F}$ for Damage Critiera $B$ for this accident would be exceeded for $53 \mathrm{MW}$ operation. The MDNBR with the "214 HF" scram is 1.092 , whereas MiDNBR $=1.11$ for FLOW .4D. It appears that the Damage Criteria would be satisfied at a maximum off-nominal power of $50 \mathrm{MW}(6 \%$ less power, whereas the difference in MDNBR's and PCST's is only $2 \%$ ).

The consequences and results of the $53 \mathrm{MW}$ analysis for the twopump loss rapid coastdown with the "214 HF" scram were less severe in every case than for the calculation using the "817" scram (problem designation FLOW .6K). The MDNBR's were approximately the same, but the "214 HF" scram case (problem designation FLOW .6Q) went into DNB later in time (when MDNBR < 1.14), had a higher mass flow rate at the hot spot, and had less of the hot fuel pin in the film boiling regime. Therefore, no FRAPT4 calculation was run for FLO:N .6Q, since it is apparent that the calculated maximum clad temperatures will be less than for FLOW.6K.

In conclusion, the Damage Criteria can be satisfied for Mode 7 operation with the more conservative L2-3 high flow scram assumption (the "214 HF") scram curve, as long as Mode 7 power is restricted to $50 \mathrm{MW}$ or less (high off-nomina1). This off-nominal power limit corresponds to a $47.5 \mathrm{MW}$ nominal power.

3. L2-3 Xenon Effects on Mode 7 Operation - The worst Xenon perturbed axial power distribution for LOFT L2-3 operation is discussed in Section 4.4.5. The worst distribution (a worst axial distribution is one with a maximum peak high up in the core) is obtained just at start up (zero power) with the CRA's 61 inches above fuel bottom after building in Xenon during Mode 8 operation with the CRA's 50 inches above fuel bottom. This worst power distribution profile is plotted in Figure IV-2. As seen in Figure IV-2, the profile is nearly axially inverted from an equilibrium Xenon profile.

Steady state COBRA IIIC calculations were done for LOFT operation at power assuming the axial power distribution to be as plotted in Figure IV-2, Case $B$, and assuming a radial peaking in the hot pin of 1.60 . Calculations were 
done for Mode 7 conditions, and for two power levels: (1) $50 \mathrm{MW}$, as for previous Mode 7 Xenon effects analyses, and (2) $39 \mathrm{MW}$, and L2-3 power level for total peaking $=2.3$. The results of the calculations are:

$$
\underline{39 \mathrm{MW}} \quad \underline{50 \mathrm{MW}}
$$

$\begin{array}{lll}\text { MDNBR } & 1.84 & 1.38\end{array}$

Previous Mode 7 Xenon effects analyses showed that with steady-state and transient analyses, the Xenon perturbed distribution resulted in significantly higher MDNBR's than the BOL axial power distribution with 50 inches CRA position that was used as a basis for FSAR and other power range safety analyses [46]. The MDNBR for the base case distribution is 1.40 (case $\times 50-1$ in Reference [46]). The MDNBR for the previous-worst Xenon perturbed Mode 7 distribution is 1.55 (Case X50-2 in Reference [46]). These previous Xenon effects analyses assumed a radial hot pin peaking of 1.586 .

The COBRA IIIC calculations for the L2-3 worst Xenon perturbed axial power distribution are discussed in Appendix B-3. The analys is showed that a nearly linear relationship exists between power and MDNBR for these steady-state calculations with everything else held constant. Therefore, it is shown that at a L2-3 worst-case trip power level of $43 \mathrm{MW}$, the MDNBR would be 1.69 , and similarly, that a MDNBR of 1.55 would be obtained for a power of 46 MW with the L2-3 Xenon perturbed power distribution. Therefore, for a power of $46 \mathrm{MW}$, the safety margins would be approximately the same as for the previous Mode 7 Xenon perturbed case analyzed in Reference [46]. However, the MnNRR's were still significantly greater than for the FSAR and power range safety analyses (9 to $10 \%$ greater $[46]$ ). Therefore, operation with the $12-3$ Xenon perturbed power distribution at a power $9 \%$ greater than $46 \mathrm{MW}$, or $50 \mathrm{MW}$, should result in safety margins no less than those for the FSAR and other power range core safety analyses, especially since the peaking for the Xenon restart will decrease as power is increased above zero power. However, without additional analysis, the L2-3 Mode 7 nominal recovery power following Mode 8 operations should not exceed $46 \mathrm{MW}$; i.e., that power at which the safety margin is approximately the same as for the previous Mode 7 Xenon effects studies done for a 50 MW nominal power [46]. 
4. Miscellaneous L2-3 Mode 7 Analyses - COBRA IIIC steady-state calculations were done for the LOFT core and full power (Mode 7) conditions to determine the effect of fuel burnup or lifetime on the MDNBR. An earlier study for the FSAR (using FRAPS) had shown that the fuel centerline temperatures at beginning of life (BOL) are limiting over the core lifetime ${ }^{[35]}$. The MDNBR vs fuel lifetime study is discussed in Appendix B-5. Power distributions calculated by PDQ 07 for two different control rod positions (CRP at 36 and 54 inches) as a function of core 1 ifetime (expressed as effective full power hours or EFPH) were used for the analysis. The calculations for 36 inches CRP were done for a power of $33 \mathrm{MW}$, whereas the 54 inches CRP calculations assumed full off-nominal power, or $53 \mathrm{MW}$. All conditions, other than the power distribution, were held constant with burnup. The result of the analysis showed that as for the fuel centerline temperature, MDNBR is most limiting at BOL and increases as fuel burnup or lifetime increases. 


\section{REFERENCES}

1. C. H. Cooper, 는-3 Blowdown Scoping Experiment Safety Analys is (ESA) (November 27, 1978).

2. J. L. Plum, L2-3 Test Experiment Safety Analysis (ESA).

3. LOFT Integral Test System Final Safety Analysis Report, Revision I (August 1977), Section 15.

4. Ibid, Section 4.2.3.1.11.

5. Ibid, Section 4.2.3.1.

6. Ibid, Section $4 \cdot 1 \cdot 2 \cdot 3 \cdot 3$.

7. Ibid; Section 4.2.3.2.

8. S. A. Atkinson and T. M. Howe, L2-2 Pre-LOCE Maneuver Core Safety Analysis, LTR 111-116, Rev. A (RE-A-78-257) (March 22, 1979), Section IV.4.4.

9. S. A. Atkinson and T. M. Howe, L2-2 Pre-LOCE Maneuver Core Safety Analysis, LTR 111-116, Rev. A (RE-A-78-257) (March 22, 1979).

10. Ibid, Section II.

11. Ibid, Section IV.4.3, Table IV-9.

12. Ibid, Apperidix A-4.

13. Ibid, Section 3 .

14. Ibid, Appendix B-4.

15. R. A. Dimenna, Zero-Power Physics Testing Safety Analysis, LTR 111-88, Rev. D (June: 16, 1978). 
16. Ibid, Appendix A.

17. Ibid, Appendix B.

18. S. A. Atkinson, R. A. Dimenna, and T. M. Howe, Power Range Testing Core Safety Analysis, LTR 111-104, Rev. A (December 4, 1978).

19. Ibid, Section III.5.5.

20. J.A. Dearien, et al, FRAP-TY, A Computer Code for the Transient Analysis of Oxide Fuel Rods, TFBP-TR-237 (November 1977).

21. S. W. Hills, Steady-State and Transient Analys is of Depurture from Nucleate. Boiling and Fuel Pellet Centerline Temperature for LOFT Core I, LTR 111-38 (Juity 14, 1977).

22. S. A. Eide and R. C. Gottula, LOFT Steady-State Critical Heat Flux Tests (470 to $\left.680 \mathrm{~kg} / \mathrm{som}^{2}\right)$, LTR $111-128(\mathrm{RE}-\mathrm{A}-79-042)$.

23. Guide to the Content of Technical Specifications for Nuclear Reactors, U.S. Atomic Energy Commission (November 1968).

24. P. A. Harris, et a1, LOFT Experiment Operation Specification, Volume 2, Power Ascension Test Series L2, Revision 2 (July 1978).

25. Standard Technical Specifications for Westinghouse Pressurized Water Reactors, U.S. Nuclear Regulatory Commission (May 15, 1976), PB 3/4 2-4.

26. F. K. Hyer, J. J. Feeley, and M. J. Konya, Hybrid Computer Simulation of the LOFT Plant, LTR 10-28 (August 29, 1977).

27. J. J. Feeley, A Digital Simulation of the. LOFT Reactor Coolant Loop System (SICLOPS), LTR 1142-16 (August 24, 1978).

28. F. K. Hyer, Computer Simulation of LOFT Plant Secondary Blowdown Due to Main Steam Line Break, LTR 16-8 (August 30, 1977). 
29. B. S. Anderson and R. A. Dimenna, LOFT Core-I Rod Ejection Accident Analysis, LTR 111-65, Rev. I (Ju1y 6, 1977).

30. E. F. Aber, LOFT Core-I: Low Flow Power Distributions As A Function of Control Rod Position, Core Power Level, and Inlet Enthalpy, LTR 111-86 (RE-P-77-076) (August 29, 1977).

31. E. F. Aber, LOFT-I: High Flow Power Distributions As A Function of Control Rod Position and Core Power Level, LTR 111-81 (RE-P-77-053) (July 1977).

32. S. A. Eide, LOFT Fuel Rod Temperatures, Steady-State, High Flow Rate, LTR 1111-17 (June 1975).

33. Technical Report on Densification of Light Water Reactor Fuels, USAEC Regulatory Staff (November 14, 1972).

34. D. G. Satterwhite, Shutdown Reactivity Analysis for Modes 2 Through 7 , LTR 111-97 (August 21,1978 ).

35. S. A. Eide, Fuel Melting Limitations On Power for Various Control Rod Withdrawals - 0 to 2000 EFPH, LTR 1111-21, Rev. 1 (June 1977).

36. S. A. Eide, Instability Study for LOFT for L2-1, L2-2, and L2-3 Pre-Test Steady-State Operating Conditions, LTR 111-103 (November 15, 1978).

37. S. A. Atkinson and T. M. Howe, L2-2 Pre-LOCE Maneuver Core Safety Analysis, LTR 111-116, Rev. A (RE-A-78-257) (March 22, 1979), Section V.

38. E. F. Aber, Power Distributions from XYZ Synthesis Calculations to Support LOFT Low-Power Reactor Physics Measurements, LTR 111-76 (Apri1 9, 1976).

39. S. A. Atkinson, R. A. Dimenna, and T. M. Howe, Power Range Testing Core Safety Analysis, LTR 111-104, Rev. A (December 4, 1978), Section III.5.4.

40. Ibid, Section III.5.3. 
41. S. A. Atkinson and T. M. Howe, L2-2 Pre-LOCE Maneuver Core Safety Analysis, LTR 111-116, Rev. A (RE-A-78-257) (March 22, 1979), Section IV.4.

42. D. R. Cooper, LOFT Calculated Integral and Differential Control Rod Worths for the As-Built Ag-Alloy Rod Clusters, LTR 111-82 (November 1976). 
APPENDIX A

ANA.LYSIS ASSUMPTIONS AND MODELS 


\section{PAGES ii to $\mathrm{V}$ WERE INTENTIONALLY LEFT BLANK}




\section{APPENDICES}

APPENDIX.A. ANALYSIS ASSUMPTIONS AND MODELS

A-1. The LOFT-3 DNB Correlation

A-2. Pin Power Distribution Spread and Uncertainty for $12 \mathrm{~kW} / \mathrm{ft}$ Test

A-3. L2-3 Mode 8 Trippoints, Operating Conditions, and Predicted L2-3 Power Distribution

A-4. Nominàl Pressure Decrease for L2-3 Mode 8

A-5. L2-3 Moderator and Doppler Reactivity Feedback Coefficient Spread

A-6. Power Distribution Assumptions for L2-2 Thermal Safety Analysis

A-7. Statistical Evaluation of the LOFT Heat Flux Engineering Hot Spot Factor

A-8. L2-3 COBRA Models Input

A-9. COBRA IIIC - COBRA IV-I Comparison and Spacer Grid Loss Calculation Error

A-10. Results of Requested Rod Worth Calculations for LOFT (L2-3)

APPENDIX B. ANALYSIS RESULTS

B-1. L2-3 Mode 8 Steady-State Analysis Results

B-2. $\quad$ MDNBR vs MLHGR Plot for L2-3 Conditions

B-3. COBRA Analysis for L2-3 Mode 7 Operation with Maximum Xenon Buildin

B-4. L2-3 Mode 8 Transient Analysis Results 
APPENDIX $A-1$

THE LOFT-3 DNB CORRELATION 


\section{INTEROFFICE CORRESPONDENCE}

date August 30,1978

10 T. M. Howe

irom S. A. Eide t $\ddot{4} \dot{\varepsilon i l}$.

subject LOFT-3 CHF CORRELATION - AN EXTENSION OF THE LOFT- 1

CORRELATION TO LOW MASS FLUXES - SAE-4-78

The new steady-state LOFT CHF correlation, LOFT-3, developed to include the recent low flow $\left(0.4 \times 10^{6}, 0.5 \times 10^{6} 1 \mathrm{bm} / \mathrm{hr} . \mathrm{ft}^{2}\right)$ data obtained at Columbia University, is presented below:

$$
\begin{aligned}
{ }^{9} \mathrm{CHF}=1.31569 \times 10^{6}-3.79605 \times 10^{2} \mathrm{P}+8.32015 \times 10^{-2} \mathrm{G} \\
+1.08312 \times 10^{2} \mathrm{PX}-1.01982 \mathrm{GX}
\end{aligned}
$$

where

$$
\begin{aligned}
{ }^{{ }^{C} C H F} & \left.=\text { predicted CHF (Btu/hr. } \mathrm{ft}^{2}\right) \\
P & =\text { system pressure }(\mathrm{psia}) \\
G & =\text { local mass flux }\left(1 \mathrm{bm} / \mathrm{hr} . \mathrm{ft}^{2}\right) \\
X & =\text { local equilibrium quality. }
\end{aligned}
$$

The applicable range of LOFT-3 is:

Pressure 2000 to 2400 psia

Mass flux $0.4 \times 10^{6}$ to $2.5 \times 10^{6} 1 \mathrm{bm} / \mathrm{hr}_{\mathrm{ft}}{ }^{2}$

Equilibrium quality -0.3 to 0.2 .

In SI units, the LOFT- 3 correlation is:

$$
\begin{aligned}
{ }^{9} \mathrm{CHF}=4.14837 \times 10^{6} & -1.73589 \times 10^{2} \mathrm{P}+1.93605 \times 10^{2} \mathrm{G} \\
& +4.95298 \times 10^{1} \mathrm{PX}-2.37306 \times 10^{3} \mathrm{GX}
\end{aligned}
$$

where

$$
{ }^{q_{C H F}}-w / m^{2}
$$


August 30, 1978

$$
\begin{aligned}
& P-k P a \\
& G-\mathrm{kg} / \mathrm{s} \cdot \mathrm{m}^{2} .
\end{aligned}
$$

The applicabie range is:

$$
\begin{aligned}
& \text { Pressure } 1.38 \times 10^{4} \text { to } 1.65 \times 10^{4} \mathrm{kPa} \\
& \text { Mass flux } 540 \text { to } 3400 \mathrm{~kg} / \mathrm{s} \cdot \mathrm{m}^{2} \\
& \text { Equilibrium quality }-0.3 \text { to } 0.2
\end{aligned}
$$

The LOFT-3 correlation has the following statistics:

$$
\begin{aligned}
& \bar{x}=1.000 \\
& s=0.0686 \\
& n=526 \text { (455 previous }+71 \text { new low flow data). }
\end{aligned}
$$

A MDNBR of 1.14 with the LOFT-3 correlation provides a $95 \%$ probability at a $95 \%$ confidence level that ONB will not occur on a rod at that DNBR.

A separate $\mathrm{CHE}$ correlatign for the data with mass fluxes between $0.40 \times 10^{6}$ and $1.30 \times 10^{6} \mathrm{lbm} / \mathrm{hr} . \mathrm{ft}^{2}$ was developed, but the transition between this correlation and LOFT- 1 at $1.30 \times 10^{6} \mathrm{lbm} / \mathrm{hr} . \mathrm{ft}^{2}$ was not smooth. The two correlation predictions differed by as much as $15 \%$, depending on the quality and pressure. Therefore, a single CHF correlation, LOFT-3, was developed to cover the complete range of mass fluxes.

u1

cc: E. C. Anderson

S. A. Atkinson

R. A. Dimenna

D. F. Elger

N. F. Fausz

J. E. Fisher

R. C. Gottula

J. L. Liebenthal

R. P. Wadkins pp

Central File 


\title{
INTEROFFICE CORRESPONDENCE
}

\author{
date September 18, 1978 \\ to. T. M. Howe \\ Irom S. A. Eide la $\xi_{i}$ \\ subject COMPARISON OF LOFT- 1 CHF CORRELATION WITH THE NEW LOFT-3 \\ CORRELATION - SAE-6-78 \\ Ref: (1) S. A. Eide and R. C. Gottula, Evaluation and Results of \\ LOFT Steady State Departure from Nucleate Boiling Tests, \\ TREE-NUREG-1043 (Apri17 1977). \\ (2) Letter from S. A. Eide to T. M. Howe, August 30, 1978, \\ SAE-4-78.
}

The LOFT-1 CHF correlation (Ref. 1) has been compared with the new low flow, 540 and $680 \mathrm{~kg} / \mathrm{s} \cdot \mathrm{m}^{2}\left(0.4\right.$ and $\left.0.5 \times 10^{6} 1 \mathrm{bm} / \mathrm{hr} \cdot \mathrm{ft}^{2}\right)$, CHF data obtained at Columbia University. The LOFT-1 is conservative (i.e., predicts lower CHF's than the experimental CHF's) for the new data.

The LOFT- $i$ has also been compared with the new LOFT-3 (Ref. 2) which was developed from the LOFT-1 data base and the new low flow data base. The results are presented in the attached five tables. For each ratio, the numerator is the maximum heat flux allowable (for a given pressure, mass flux and equllibrium quality) using LOFT-3 without experiencing CHF on a rod at 95\% probability and confidence. The denominator is the same quantity except that LOFT-1 is used. Wherever the ratio is less than one, the use of the LOFT-3 correlation would be more limiting on core power than the use of the LOFT-1, and for ratios greater than one the LOFT -3 would be less limiting.

Either CHF correlation can be used in the extended mass flux range of 540 to $1020 \mathrm{~kg} / \mathrm{s} \cdot \mathrm{m}^{2}\left(0.40\right.$ to $\left.0.75 \times 10^{6} 1 \mathrm{bm} / \mathrm{hr} . \mathrm{ft}^{2}\right)$. However, the new LOFT-3 was developed from a data base including the new low mass flux data, and its use is recommended. Except for equilibrium qualities less than - 0.20, the LOFT-3 is less limiting than the LOFT-1 in this low mass flux range.

u1

Attachments :

As stated

$c c$ :
E. C. Anderson
S. A. Atkinson
R. A. Dimenna
D. F. Elger
N. F. Fausz

FORM EG8G-954 (Hev. 2-77)
R. C. Gottula Ry

L. P. Leach

J. L. Liebenthal $\alpha$

C. W. Solbrig

R. P. Wadkins nm

Central File 
COMPARISON OF LOFT-3 I LOFT- 2 CORRELATIONS - $195 / 95$ LOHER LIMITI ${ }^{*}$

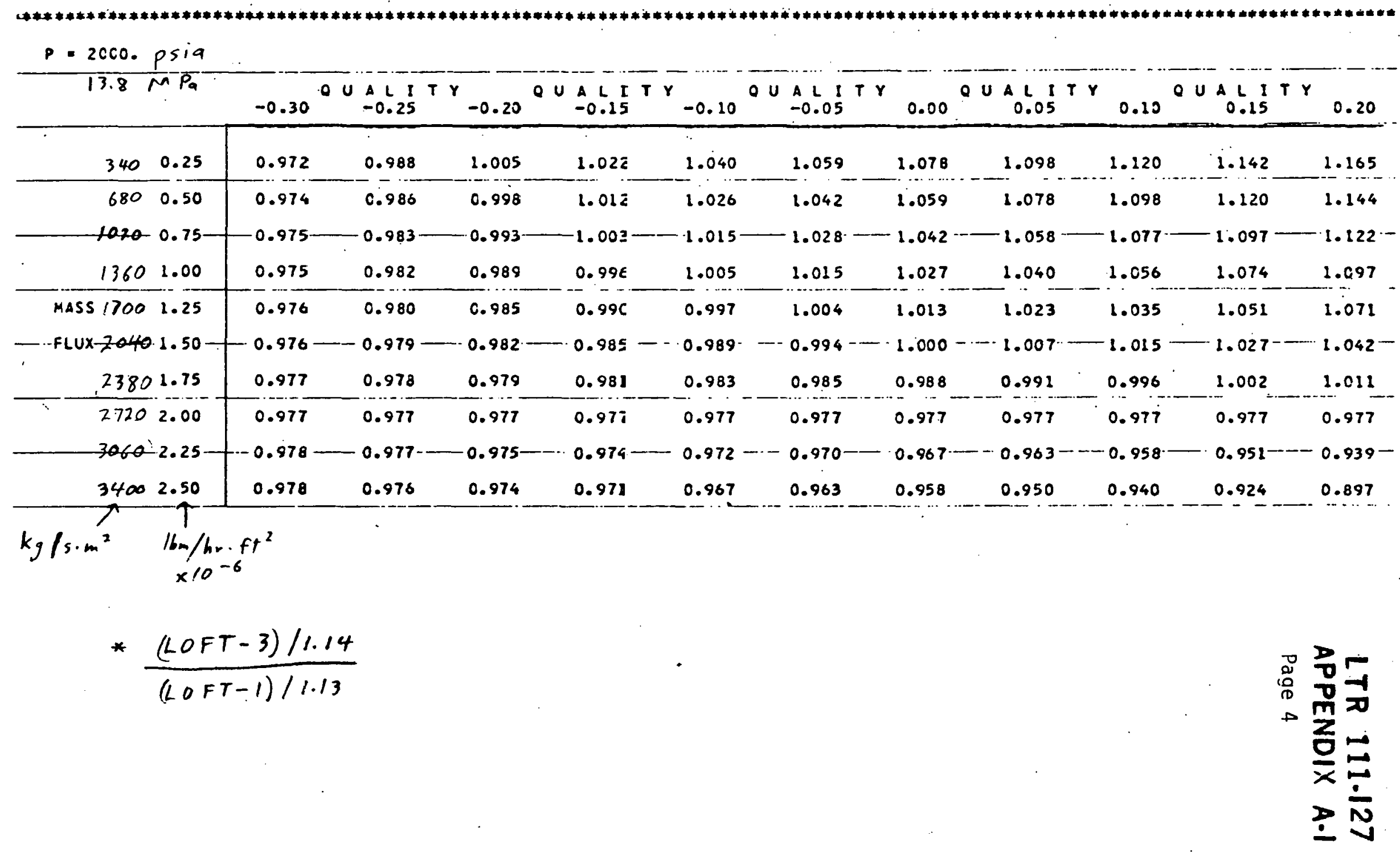


COMPARISON OF LOFT-3 $\%$ LOFT-1 CORRELATIONS - $195 / 95$ LOHER LIMITI *

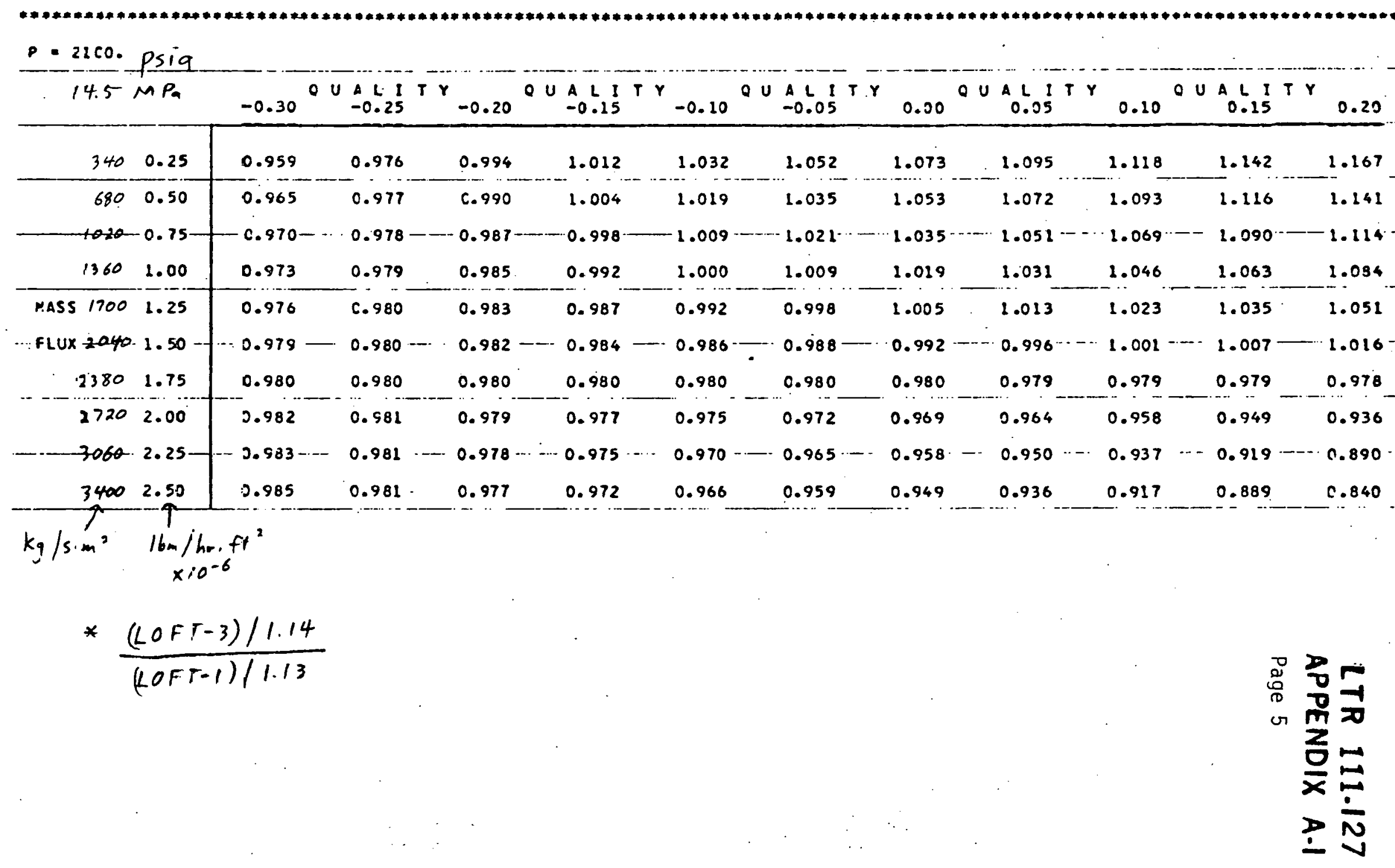


"COMPARISCN OF LOFT-3 , LOF--2 CORRELATIONS - $195 / 95$ LOYER LIMITI *

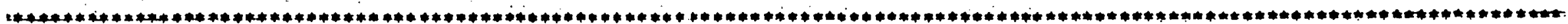

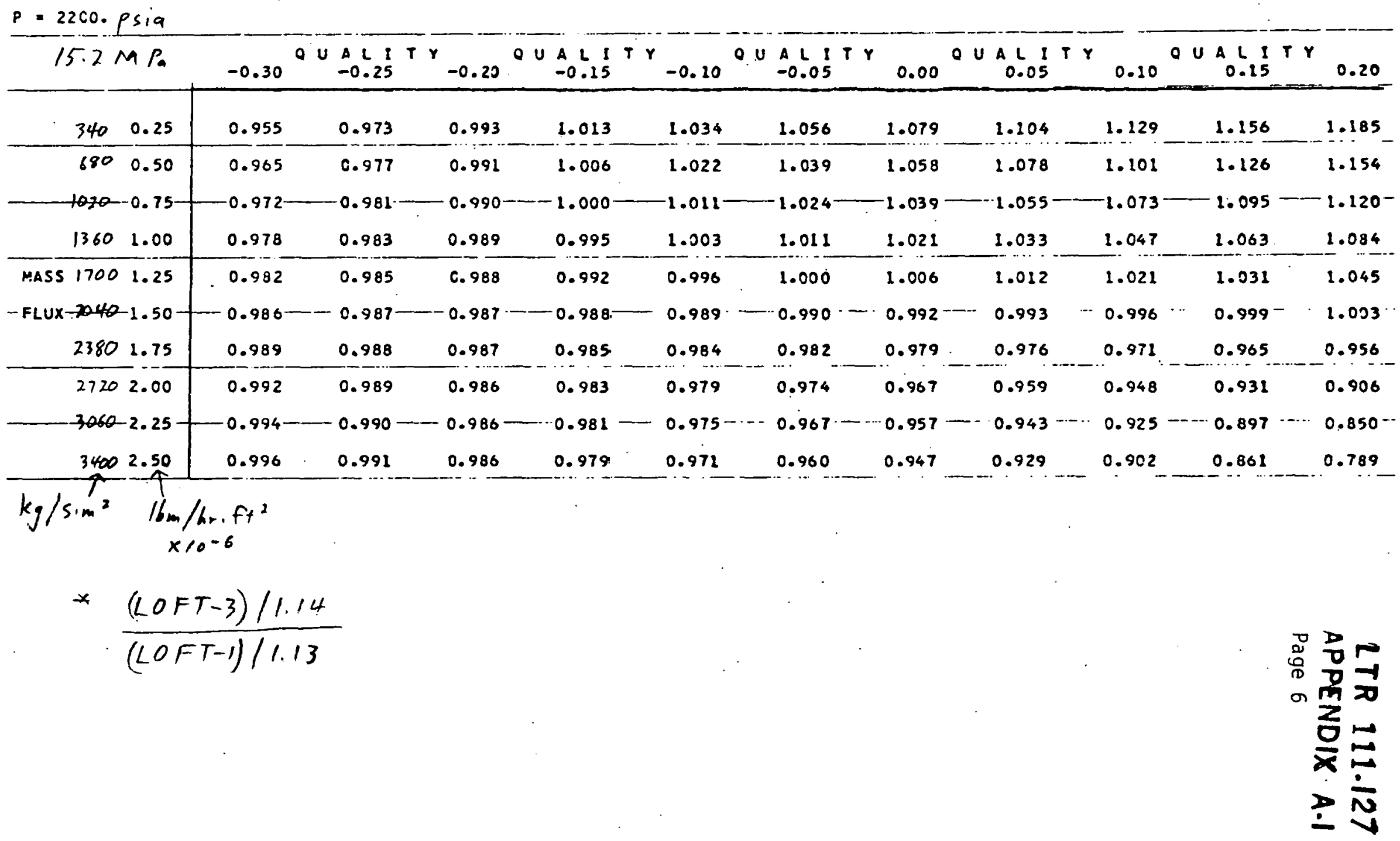


COMFARISEN OF LOFT-3, LOFT-I CUKKELATIUNS - I9SIOS LOMER LIMITI *

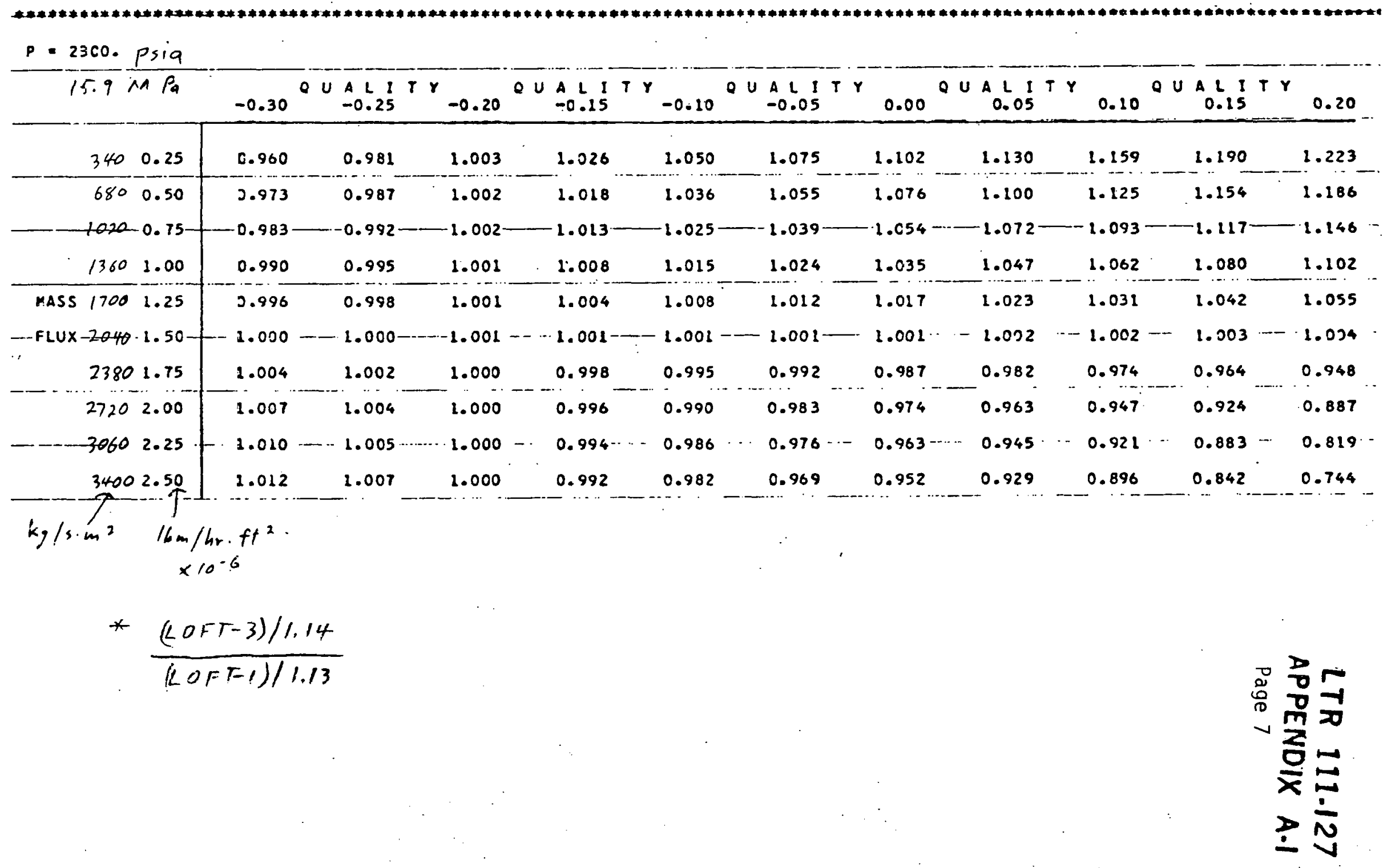


COMPARISON OF LOFT-3, LCFT-1 CORRELATIONS - $195 / 95$ LOWER LIMITI *

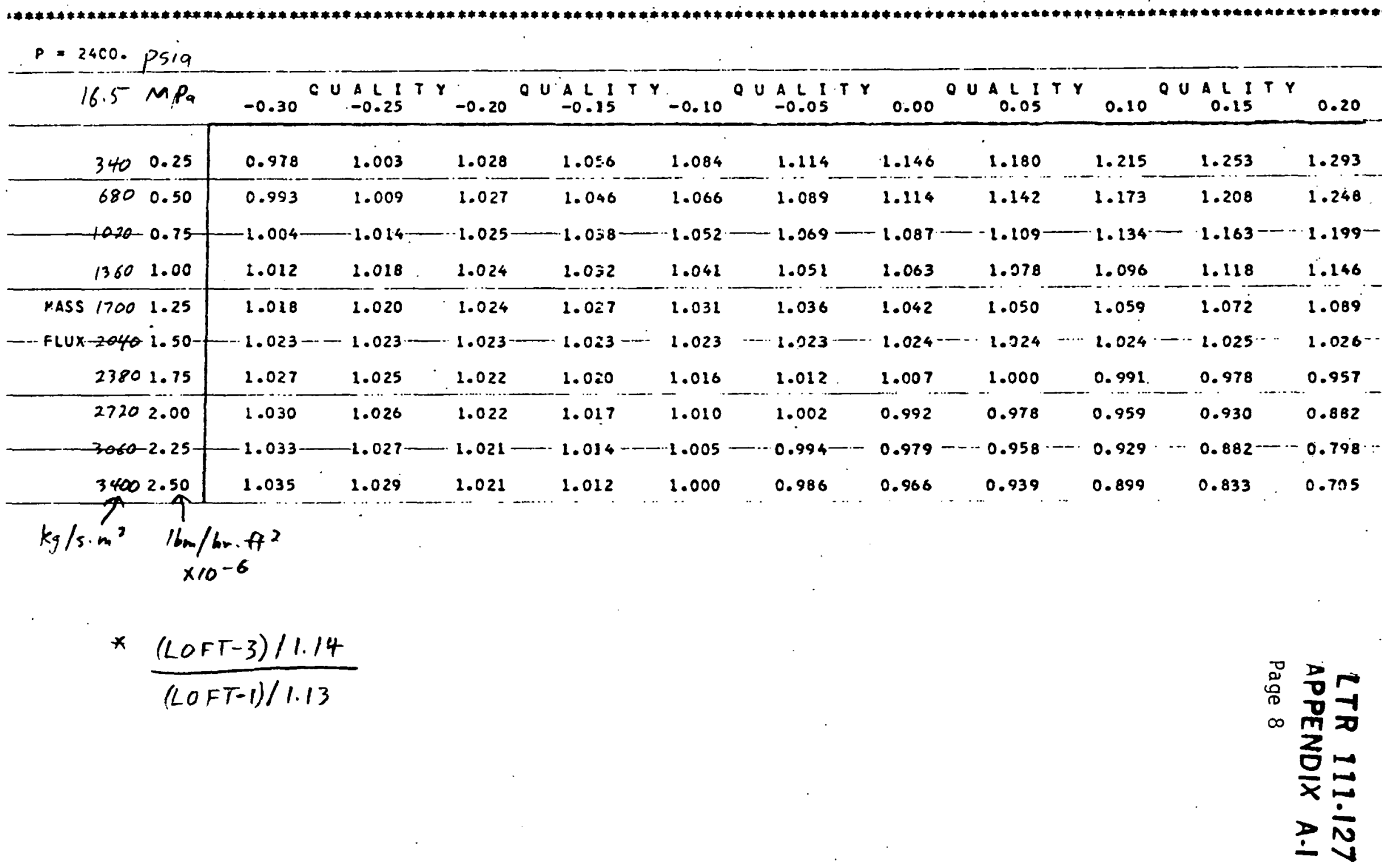




\title{
INTEROFFICE CORRESPONDENCE
}

\author{
date January 15, 1979 \\ to D. G. Satterwhite \\ rom S. A. Atkinson \&uldetiunsom \\ subjec1 PIN POWER DISTRIBUTION SPREAD AND UNCERTAINTY FOR 12 KW/FT TEST \\ Atki-1-79
}

Attached are two studies: (1) To determine the potential spread in TIP measured hot pin power for the next LOCE and, (2) To obtain an estimate for the 2 standard deviation $(2 \sigma)$ uncertainty on hot pin or hot channel power as determined by TIP measurements.

The first study was based on comparisons of pre-test 3-D PDQ7 predictions to the power distributions inferred by TIP measurements for power range testing and the L2-2 test. The study looked at the total peaking, i.e., the ratio of peak power to core average power $(P / A)$, and the radial peaking, the ratio of average hot pin power to core average power. The conclusions and results of the study are:

1. For good corresponsence between the conditions for the PDQ7 prediction and actual test conditions during the TIP measurements, close agreement is obtained: Within $0.1 \%$ for total $P / A$, within $1 \%$ for radial $P / A$. Therefore, TIP-inferred hot pin power should be within $1 \%$ of a good pre-test PDQ7 prediction.

2. Axial power distribution shapes show close agreement, particularly in the high power (mid-core) regions.

3. Discrepancies between pre-test predictions and TIP-measured distribution seems to be larcely due to differences in core conditions between the PDQ7 reference case and actual test conditions. However, even for wide differences in reactor power, flow, or depletion, the difference between prediction and TIP measurement is about $3 \%$, and nearly always within $4 \%$. The radial $P / A$ will agree within $2 \%$.

4. Based on the above, the expected total peaking for the next test (a $12 \mathrm{~kW} / \mathrm{ft}$ maximum linear heat generation rate LOCE) is $P / A=2.43$. This is for a control rod.position (CRP) of 54 inches withdrawn, and a core depletion of 200 to $300 \mathrm{EFPH}$. The power distribution should closely correspond to PDQ7 case L1056 in LTR 111-86. 
5. The potential spread in total P/A for a limit on CRP of 50 to 58 inches withdrawn is:

$$
\begin{array}{ll}
\text { CRP }=50 \text { inches } & \text { CRP }=58 \text { inches } \\
P / A<2.66 & P / A>2.23
\end{array}
$$

These values include an uncertainty of 3 to $4 \%$ for the TIPmeasured P/A without closely corresponding PDQ7 predictions. The measured hot pin radial $P / A$ should be $\leq 1.56$.

6. If the minimum CRP was 52 inches withdrawn, then maximum total $P / A<2.60$.

The nominal, off-nominal, and limiting worst case values for reactor power and loop flow corresponding to a spread in total peaking of 2.30 to 2.66 are in the attached Table 1.

The study for hot pin power $2 \sigma$ uncertainty determined that the $7 \%$ uncertainty used for the L2-2 core safety analyses is a good estimate for the 20 uncertainty. The standard deviation from this study for the uncertainty of total P/A as inferred for TIP measurements is 3.4 to $3.8 \%$.

The hot pin is shifted in the LOFT COBRA models to a location that is adjacent to the hot channel. This hot pin location shift in the COBRA model: represents an increase in that pin's peak powier of $2.3 \%$. Therefore, the additional uncertainty allowance required in COBRA for a $2 \sigma$ hot pin power uncertainty is $4.7 \%$, or a hot spot factor of 1.047 . The use for the L2-2 safety analyses of a 1.07 hot channel factor for power distribution uncertainty plus the hot pin location shifi was equivalent to allowing for a $9.3 \%$ total uncertainty.

A low flow, 50 inch CRP power distribution with a maximum radial $P / A$ is proposed for COBRA analyses for the $12 \mathrm{kw} / \mathrm{ft}$ test. The radial $P / A$ then is increased to 1.61 to obtain a total peaking of 2.66 in the hot pin. For the proposed profile (case 1012 in LTR 111-86), the hot pin location shift plus the additional increase in radial $P / A$ represents an additional hot channel power increase of $3.1 \%$. Therefore, the hot channel factor for a total hot channel power distribution uncertainty of $7 \%(2 \sigma)$ needs to be 1.039 .

If the hot pin is not shifted in the COBRA model, then the increase in hot pin radial P/A represents an increase of $2.6 \%$ in all channel powers in the model since the radial distribution is normalized to 1.0 at the hot pin. This $2.6 \%$ w11l satisfactorily allow for the potential difference between measured and predicted radial power distribution. Then, the full $7 \%$ power distribution uncertainty needs - to be applied to the pins 
adjacent to the hot channel. This approach would be applicable for any power distribution and does not appiy extra conservatism and therefore is considered preferable.

In summary, these studies conclude for the COBRA analyses for the next LOCE that:

1. Maximum peaking is 2.66 for a CRP of 50 inches withdrawn. The corresponding off-nominal and limiting worst-case values for reactor power and loop flow are as listed. in the attached Table 1.

2. Radial P/A is not likely to exceed 1.56. However, the use of a power distribution with a maximum radial $P / A$ as used for the L2-2 core safety analys is, should be retained for the COBRA analysis. Use of a maximum radial P/A allows use of the COBRA analysis as a scoping analysis for future $12 \mathrm{kw} / \mathrm{ft}$ tests with more depletion and flatter axial profiles.

3. The 20 local power distribution uncertainty is $7 \%$, to be applied as a hot spot/hot channel factor to the pins adjacent to the hot channel.

u1

Attachments:

As stated

cc: w/attachments

B. S. Anderson

S. A. Atkinson (2)

D. F. Elger

N. F. Fausz

J. E. Fisher

TAB File 3.7

w/o attachments

E. C. Anderson

J. L. Liebentha1

R. P. Wadkins

Central File 
TABLE I

REACTOR POWERS AND LOOP FLOWS FOR 12 KW/FT LOCE

$\begin{array}{lcccc}\text { Control rod position (inches) } & 50 & 52 & 54 & 58 \\ \text { Case description } & \text { max peak } & \text { max peak } & \text { nominal } & \text { min expected } \\ \text { Total peaking } & 2.66 & 2.60 & 2.43 & 2.30 \\ \text { Nominal power (MW) } & 33.9 & 34.7 & 37.2 & 39.2 \\ \text { Nominal loop flow (Ml bm/h) } & 1.314 & 1.345 & 1.44 & 1.52 \\ \text { Off-nominal power (MW) } & 36.4 & 37.2 & 39.7 & 41.7 \\ \text { Off-nominal loop flow (Ml bm/h) } & 1.12 & 1.15 & 1.245 & 1.32 \\ \text { Minimum worst-case power (MW) } & 37.4 & 38.2 & 40.7 & 42.7 \\ \text { Maximum worst-case flow }(\mathrm{Ml} \mathrm{bm} / \mathrm{h}) & 1.01 & 1.04 & 1.12 & 1.19\end{array}$




\section{S. A. Atkinson}

A study of TIP-measured LOFT core power distributions for power range testing, and how the measured distributions compared to PDQ pre-test predictions was reported by Reference (a). Reference (a) reported that the difference in the measured peak to core average power ratio (or peaking, $P / A$ ) from that predicted by available PDQ cases was $+0.6 \%$ to $-5.1 \%$. The radial power distribution (average pin power to core average ratio) was within $\pm 2 \%$ for hot pins, and within $4.4 \%$ for outer core positions. The maximum differences in power were at the core extremes, top or bottom and edges. The hot pin axial: profiles were in good agreement in the high power (central) region. The TIP axial distributions were generally less than the PDQ prediction upstream of the hot spot, and greater than PDQ prediction downstream of the hot spot. Therefore, the actual enthalpy increase to the point of minimum DNBR should be less than calculated based on the PDQ predicted distribution. The calculations for MDNBR (Minimum Departure from Nucleate Boiling Ratio) are therefore conservative.

Additional study has been done both for the power range TIP measurements and for TIP-measured hot pin power distribution for the L2-2 test. This additional study oniy looked at the hot pin (PDQ pin 10) powers. The results of the additional study, based in part on Reference (a), are discussed as follows:

Table 1 shows a comparison of PDQ7 predictions for full power, full flow BOL (Beginning of Life) operation to power range TIP measurements at $11.5 \mathrm{MW}$. Although the $11.5 \mathrm{Ml}$ data is not $\mathrm{BOL}$, as no specific $\mathrm{BOL}$ data was taken, it is close to BOL for the power range tests. Higher power data was not taken until after considerable core depletion (approaching $200 \mathrm{EFPH}$ ). These relative powers are for a control rod position (CRP) of 54 inches withdrawn.

Tabie 2 shows a comparison of PDQ7 predictions for full power full flow operation for BOL and 200 EFPH to the TIP measurements at $48.7 \mathrm{MW}$. The eștimated depletion at $48.7 \mathrm{MW}$ during power range testing was near $200 \mathrm{EFPH}$. 
Study for Measured Hot Pin Peaking. Spread for Next LOCE S. A. Atkinson

Page 2

Table 3 shows a comparison of PDQ7 predictions for full flow operation with a CRP of 36 inches withdrawn. The PDQ predictions are for $B O L$, whereas the TIP measurement was taken with partial depletion (less than $200 \mathrm{EFPH}$ ). The TIP measured relative powers are compared to two PDQ predictions; (1) for low inlet enthalpy, and (2) for high inlet enthalpy. The test inlet enthalpy w:s somewhere in between (about $529 \mathrm{Btu} / 1 \mathrm{bm}$ for $535^{\circ} \mathrm{F}$ inlet temperature).

Table 4 shows a comparison of PDQ7 predictions for low flow operation, with $200 \mathrm{EFPH}$ and other depletions, to L2-2 TIP measured hot pin relative powers. The comparison is for a CRP of 54 inches withdrawn. The approximate depletion for the L2-2 TIP measurement was also $200 \mathrm{EFPH}$.

The comparisons between PDQ pre-test predictions and TIP-measured power distributions shown in Tables 1 through 4 show the following results:

1. For close correspondence of reactor conditions, the total P/A is predicted well within $1 \%$, as close as $0.1 \%$. This is especially evident when comparing the TIP data for 48.7 MW and the LTR 111-60B PDQ prediction for $55 \mathrm{MW}$ and $200 \mathrm{EFPH}$ in Table 2, and when comparing the L2-2 TIP data and the LI057 PDQ prediction in Table 4 . The radial $P / A$ is predicted within $1 \%$.

2. Even when there is a wide difference in reactor conditions, (such as the amount of depletion, the operating power, inlet enthalpy, flow rate, but not including control rod position) the difference between TIP values and PDQ prediction is about $3 \%$ or less for total P/A and about $2 \%$ or less for radial $P / A$. The largest difference was $4.9 \%$ when comparing TIP measurements for $200 \mathrm{EFPH}$ and high inlet enthalpy to PDQ run LI037 for BOL and low inlet enthalpy.

3. The comparisons show that if a closely corresponding PDQ7 prediction is available, the potential difference between pre-test predictions and TIP-determined relative powers in the hot pin will be within $1 \%$.

4. The comparisons show that as long as a PDQ7 prediction is avallable for the desired control rod position, the measured hot pin total P/A can be expected to be within $3 \%$ of the prediction, and the hot pin radial $P / A$ can be expected to be within $2 \%$ of the prediction. However, the 
Page 3

comparisons show that inlet enthalpy (which strongly influences the boron concentration requirement) is a sensitive parameter. Therefore, care should be taken to try to use a PDQ prediction for a comparable inlet enthalpy.

Figure 1 shows the TIP-determined hot pin axial relative power profile for the L2-2 tests as compared to the PDQ prediction from run L1057 in LTR $111-86^{[\mathrm{d}]}$. As seen in Figure 1, the agreement is very good.

Since it has now been determined that the PDQ7 predictions are reliable predictions of the core power distribution as determined by the use of the TIP system even if the reactor conditions do not closely correspond, then PDQ predictions can be used to determine what the measured peaking may be for future test conditions. A PDQ7 predicted hot pin total peaking is plotted as a function of core depletion in Figure 2. Two lines are plotted in Figure 2, one for CRP $=54$ inches, and one for CRP $=50.6$ inches. As seen in Figure 2, the effect of depletion on total P/A appears to be linear after $200 \mathrm{EFPH}$. The lack of sufficient predictions for $\mathrm{BOL}$ at the same reactor conditions as for the depleted predictions prevented a resolution of how total $P / A$ varies up to 200 EFPH depletion. However, the BOL points (for 54 inch CRP) are still within $3 \%$ of each other.

Figure 3 shows PDQ predictions for hot pin total P/A as a function of CRP for low flow operation. Based on the points in Figure 3, the potential measured $P / A$ for the next LOCE test can be predicted. The predicted relative powers (or peaking) are:

$\begin{array}{ccc}\begin{array}{c}\text { CRP } \\ \text { (inches) }\end{array} & \begin{array}{c}\text { Total } \\ \text { P/A }\end{array} & \begin{array}{c}\text { Total P/A } \\ \pm 3 \%\end{array} \\ 50 & 2.57 & 2.65 \\ 52 & 2.50 & 2.58 \\ 54 & 2.43 & \\ 58 & 2.3 & 2.23\end{array}$


Study for Measured Hot Pin Peaking Spread for Next LOCE S. A. Atkinson

Page 3

Therefore, total P/A can be considered to be less than 2.66, for 50 inch CRP, or 2.60 (allowing for $4 \%$ uncertainty) for 52 inch CRP. The hot pin radial $\mathrm{P} / \mathrm{A}$ is greatest for the higher CRP, equal to 1.501 to 1.534 at 54 inch CRP. Radial $P / A$ is less at the lower CRP's, about 1.48 for run L1038 in LTR 111-86 [d] (for 50 inch CRP and $12 \mathrm{~kW} / \mathrm{ft}$, low flow conditions). Therefore, radial P/A is expected to be less than 1.56 .

For the predicted range in total $P / A$, the corresponding nominal reactor power and flow for a $12 \mathrm{Kw} / \mathrm{ft}$ test are ${ }^{[\mathrm{e}]}$ :

$$
\begin{aligned}
& P_{N}=7.579 \frac{12}{P T A} M W \\
& \dot{m}_{N}=\frac{P_{N}}{88.07} 3.413 \times 10^{6}=\left(3.875 \times 10^{4}\right) P_{N} 1 \mathrm{bm} / \mathrm{h}
\end{aligned}
$$

The off-nominal values are:

$$
\begin{aligned}
& P_{O N}=P_{N}+2.5 M W \\
& \dot{m}_{O N}=0.95 \dot{m}_{N}-0.125 \times 10^{6} .1 \mathrm{bm} / \mathrm{h}
\end{aligned}
$$

The limiting worst-case trip (KCT) values, that is those values as close as practical to desired nominal operating points, are:

$$
\begin{aligned}
& P_{W C T}=P_{N}+3.5 \mathrm{MW} \\
& \dot{m}_{W C T}=0.91 \dot{\mathrm{m}}_{N}-0.01 \dot{\mathrm{m}}_{N}-0.175 \times 10^{6} 1 \mathrm{bm} / \mathrm{h}
\end{aligned}
$$

These equations for off-nominal and limiting W'CT values are based on the PPS trippoint and accuracy information discussed in Appendices A- 1 and A-2 of Reference [f].

The following Table 5 shows the values of reactor power and loop flow that correspond to. the predicted range in measured peaking (for CRP between 50 and 58 
Study for Measured Hot Pin Peaking Spread for Next LOCE S. A. Atkinson

Page 4

\section{LTR 111.127 \\ APPENDIX A-2}

inches withdrawn). The 58 inch CRP values are based on the predicted P/A of 2.30 instead of a P/A 3\% less. This is done since safety analys is for higher $P / A$ was shown to be most 1 imiting for the $L 2-2$ core safety analyses ${ }^{[\mathrm{g}]}$ and in steady-state parametric studies for a $12 \mathrm{kw} / \mathrm{ft}$ test, and since no PDQ power distributions are available for P/A less than 2.30.

\section{REFERENCES}

[a] B. S. Anderson to S. A. Atkinson, "Comparison of TIP. Power Measurements to PDQ Predictions", EG\&G Idaho Interoffice correspondence BSA-4-78, November $30,1978$.

[b] E. F. Aber, "LOFT-I: High Flow Power Distributions as a Function of Control Rod Position and Core Power Level", LTR 117-81 (RE-P-77-053) JuTy 1977.

[c] B. L. Rushton, "LOFT-I: Results from Three-Dimensional PDQ-7 Calculations with Thermal Feedback \& Depletion to $2000 \mathrm{EFPH",} \mathrm{LTR} \mathrm{111-60,} \mathrm{Rev.} \mathrm{B}$ (RE-N-76-038) November 12, 1976.

[d] E. F. Aber, "LOFT Core-I: Low Flow Power Distributions as a Function of Control Rod Fosition, Core Power Level, and Inlet Enthalpy", LTR 1]7-86 (RE-P-77-076) August 29, 1977.

[e] P. A. Harris, et al, "LOFT Experiment Operating S pecification, Volume 2, Power Ascension Test Series L2", July 1978, pp. 18-23.

[f] S. A. Atkinson, R. A. Dimenna, and T. M. Howe, "Power Range Testing Core Safety Analysis", LTR 111-104, Rev. A, December 4, 1978.

[g] S. A. Atkinson, "L2-2 Pre-LOCE Maneuver Core Safety Analysis," LTR 111-116 (RE-A-78-257) November 17, 1978, Section II. 


\section{TABLE 1}

HOT PIN RELATIVE POWERS FOR FULL FLOW CRP $=54$ INCHES WITHDRANN AND BOL

Source

Depletion

Power (MW)

Loop Flow $(\mathrm{Mlbm} / \mathrm{h}) \quad 3.78$

Inlet Enthalpy

(Btu/lbm) 529

Radial P/A

Axial $P / A$

Total P/A
1.573

1.575

2.477
PDQ
LTR $111-81^{[b]}$ Different

Case L1037

$\mathrm{BOL}$

60.3

3.25

500.1

1.572

$+.06$

$-3.1$

1.625

2.555

$-3.1$

557.2

\subsection{2}

1.548

$+1.6$

$-2.3$

1.672

$-0.7$ 


\section{TABLE 2}

HOT PIN RELATIVE POWERS FOR FULL FLOW

$$
\text { CRP }=54 \text { INCHES WITHDRAWN } 200 \mathrm{EFPH}
$$

Source

Depletion

Power (MW)

Loop Flow $(M 7 \mathrm{bm} / \mathrm{h})$

Inlet Enthalpy (Btu/lbm)

Radial $P / A$

Axial P/A

Total P/A

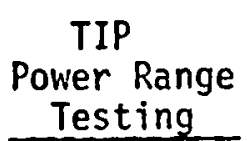

2200 EFPH

48.7

3.78

$\sim 529$

1.548

1.570

2.430

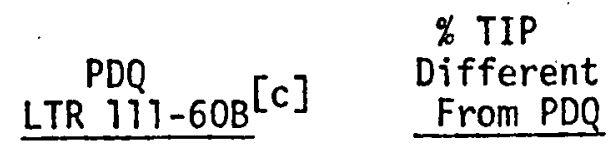

$200 \mathrm{EFPH}$

55

3.42

539.8

1.532

$+1.0$

1.588

$-1.1$

$-0.1$

2.433

Source

\begin{tabular}{|c|c|c|c|}
\hline $\begin{array}{l}\text { PDQ } \\
\text { TR } 111-81^{[\mathrm{b}]} \\
\text { ase }[1037\end{array}$ & $\begin{array}{c}\% \text { TIP } \\
\text { Different } \\
\text { From PDQ }\end{array}$ & $\begin{array}{c}\text { PDQ } \\
\text { LTR } 111-60 \mathrm{~B} \\
\end{array}$ & $\begin{array}{l}\text { \% TIP } \\
\text { Different } \\
\text { From PDQ }\end{array}$ \\
\hline
\end{tabular}

Depletion

Power (MW)

Loop Fiow (MLBM/h)

Inlet Enthalpy (Btu/lbm)

Radial P/A

Axial P/A

Total P/A
BOL

60.3

3.25

500.1

1.572

1.625

2.555
BOL

55

3.42

557.2

1.548

0

1.612

$-2.6$

$-3.4$

2.495

$-2.6$ 


\section{TABLE 3}

HOT PIN RELATIVE PONERS FOR FULL FLOW

$$
\text { CRP }=36 \text { INCHES WITHDRAWN }
$$

Source

Depletion
Power (MVi)
Loop Flow (MTbm/h)
Inlet Enthalpy (Btu/
Radial P/A
Axial P/A
Axial Peak Location
(inches)

Total P/A.

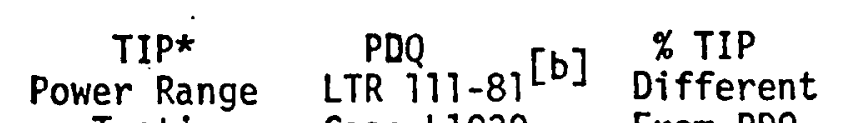

Testing Case L1030

Partial

15

BOL

31

3.25

485.7

1.629

2.055

22.5

22.5

3.236

3.347

$-3.3$

$-1: 1$

$-2.2$

3.221

$+1.9$

1.581

$-1.4$

2.037

\% TIP

Different From PDQ

\section{BOL}

49.5

3.42

557.2

17.4

*Actual CRP was 37 inches withdrawn. 
TABLE 4

HOT PIN RELATIVE POWERS FOR LOW FLOW

CRP $=54$ INCHES WITHDRAWN $200 \mathrm{EFPH}$

Source

Power (MW)

Loop Flow $(\mathrm{MTbm} / \mathrm{h})$

Inlet Enthalpy (Btu/1bm)

Radial P/A

Axial P/A

Total P/A

$\omega$

Source

Depletion

Power (MW)

Loop Flow $(M 1 \mathrm{bm} / \mathrm{h})$

Inlet Enthaipy (Btu/lbm)

Radial P/A

Axial P/A

Total P/A

\begin{tabular}{|c|c|c|c|c|c|c|}
\hline $\begin{array}{l}\text { TIP } \\
\text { L2 } 2\end{array}$ & $\begin{array}{l}\text { PDQ } \\
\text { LTR } 117-86^{[\mathrm{d}]} \\
\text { Case } L 1057 \\
\end{array}$ & $\begin{array}{l}\% \text { TIP } \\
\text { Different } \\
\text { From PDQ }\end{array}$ & $\begin{array}{l}\text { PDQ } \\
\text { LTR } 111]-86^{[d]} \\
\text { Case L } 1058\end{array}$ & $\begin{array}{l}\% \text { TIP } \\
\text { Different } \\
\text { From PDQ }\end{array}$ & $\begin{array}{l}\text { PDQ } \\
\text { LTR } 111-86^{[d]} \\
\text { Case L1056 }\end{array}$ & $\begin{array}{l}\% \text { TIP } \\
\text { Qifferent } \\
\text { From PDQ }\end{array}$ \\
\hline 24.9 & 23.1 & & 13.8 & & 35.0 & \\
\hline 1.48 & 1.36 & & 1.38 & & 1.33 & \\
\hline$\sim 553$ & 552.2 & & 553.7 & & 550.3 & \\
\hline 1.542 & 1.533 & +0.6 & 1.534 & +0.5 & 1.501 & +2.7 \\
\hline 1.576 & 1.584 & -0.5 & 1.591 & -0.9 & 1.616 & -2.5 \\
\hline 2.430 & 2.429 & +0.04 & 2.441 & -0.5 & 2.426 & +0.2 \\
\hline
\end{tabular}

\% IIP LTR 111-60B [C] $\begin{aligned} & \text { Different } \\ & \text { From PDO }\end{aligned}$

$\%$ TIP

PDQ $[c]$ Different From PDQ LTR 111-60B ${ }^{[C]}$ From PDQ Case L1075 From PDQ

2.04

539.8

\section{$200 \mathrm{EFPH}$}

55

1.509

1.624

2.450
BOL

55

3.42

557.2

1.548

1.612

2.495
$650 \mathrm{EFPH}$

24.6

1.44

553

$\begin{array}{ll}-0.4 & 1.523\end{array}$

$+1.2$

$-2.2$

1.561

$+1.0$

$-2.6$

2.378

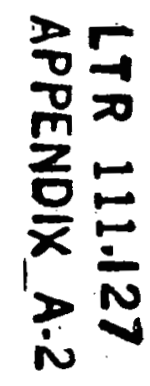


TABLE 5

NOMINAL, OFF-NOMINAL, AND LIMITING WCT VALUES

FOR POWER AND FLOW FOR $12 \mathrm{KW} / \mathrm{FT}$ TEST

\begin{tabular}{lllll}
\hline CRP (inches) & 50 & 52 & 54 & 58 \\
Measured Total P/A & 2.66 & 2.60 & 2.43 & 2.30 \\
Nominal Power (MW) & 33.9 & .34 .7 & 37.2 & 39.2 \\
Nominal Flow (MI bm/h) & 1.314 & .1 .345 & 1.44 & 1.520 \\
Off-Nominal Power (MW) & 36.4 & 37.2 & 39.7 & 41.7 \\
Off Nominal Flow (Mlbm/h) & 1.12 & 1.15 & 1.245 & 1.32 \\
Min.Power WCT (MW) & 37.4 & 38.2 & 40.7 & 42.7 \\
Max Flow WCT (MIbm/h) & 1.01 & 1.04 & 1.12 & 1.19 \\
\hline
\end{tabular}




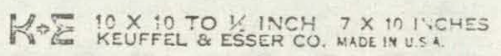

8

461322

06

FIGURE I

HOT PIN AXIAL POWER PROFILE COMPARISON

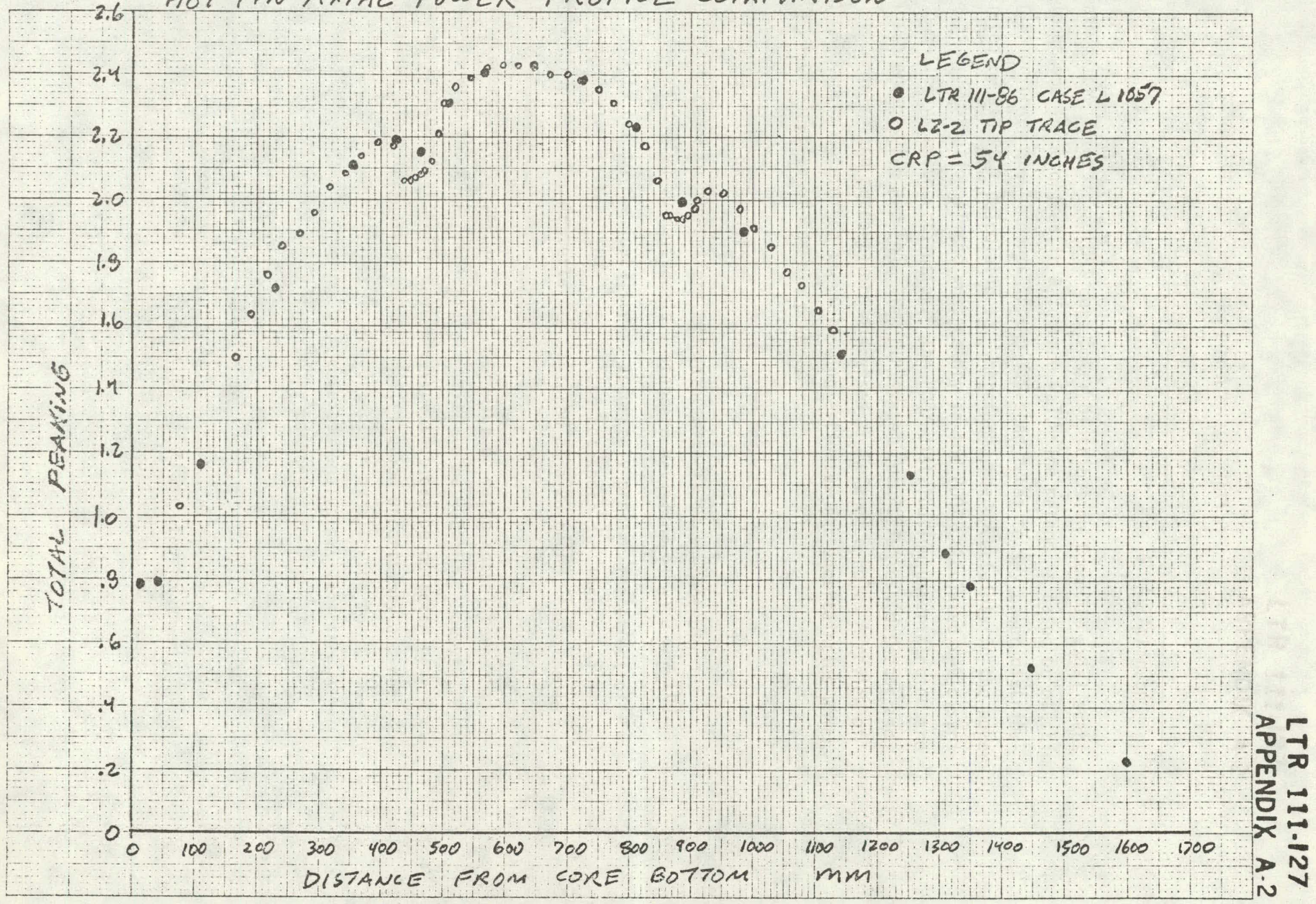


LI N $11101<$,

APPENDIX A.2

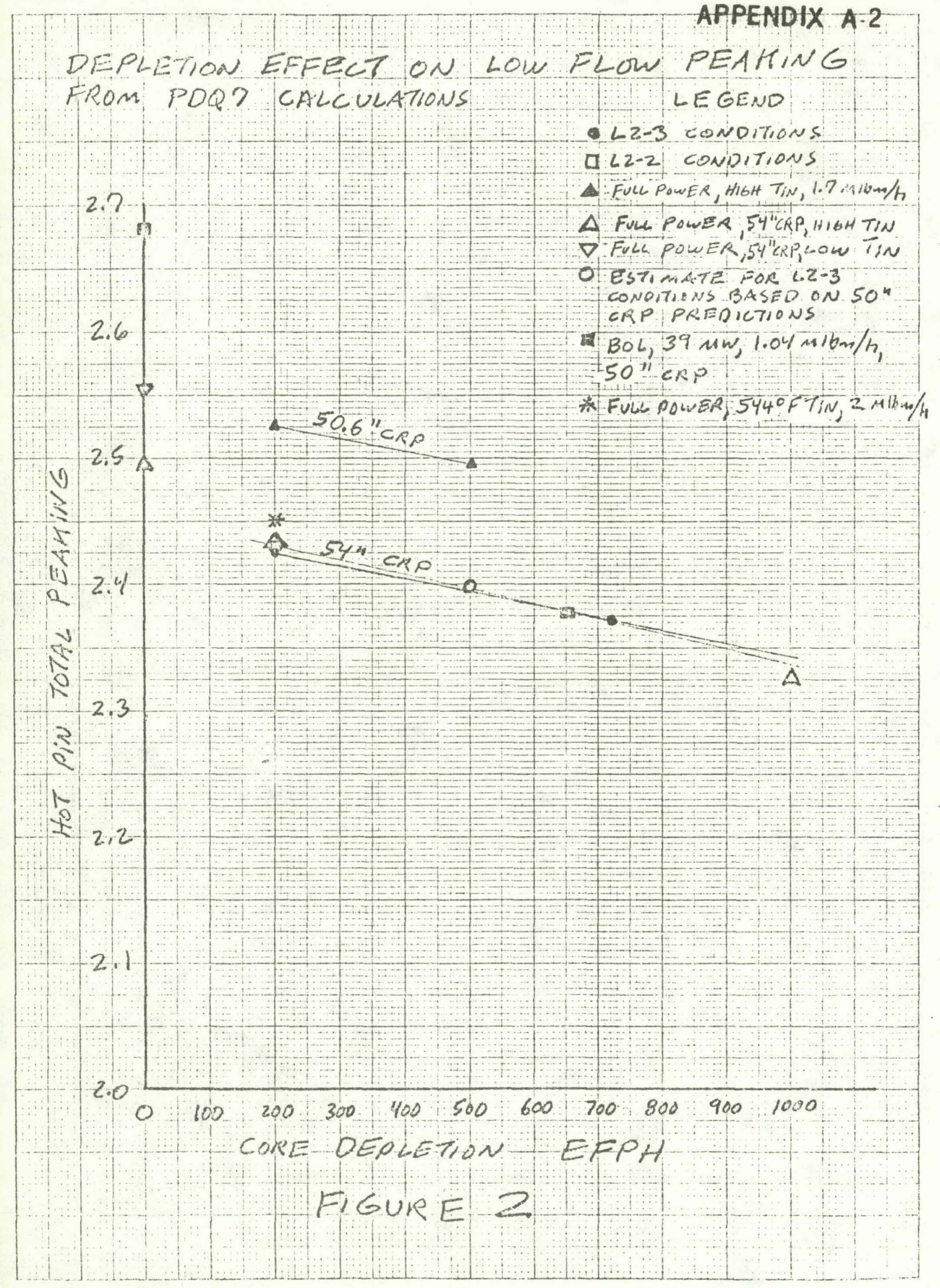

16 
PDQ PREDICTED HOT PIN PEAHING WITH AND WITHOUT DEPLETION FOR LOFT L-Z SERIES OPERATION
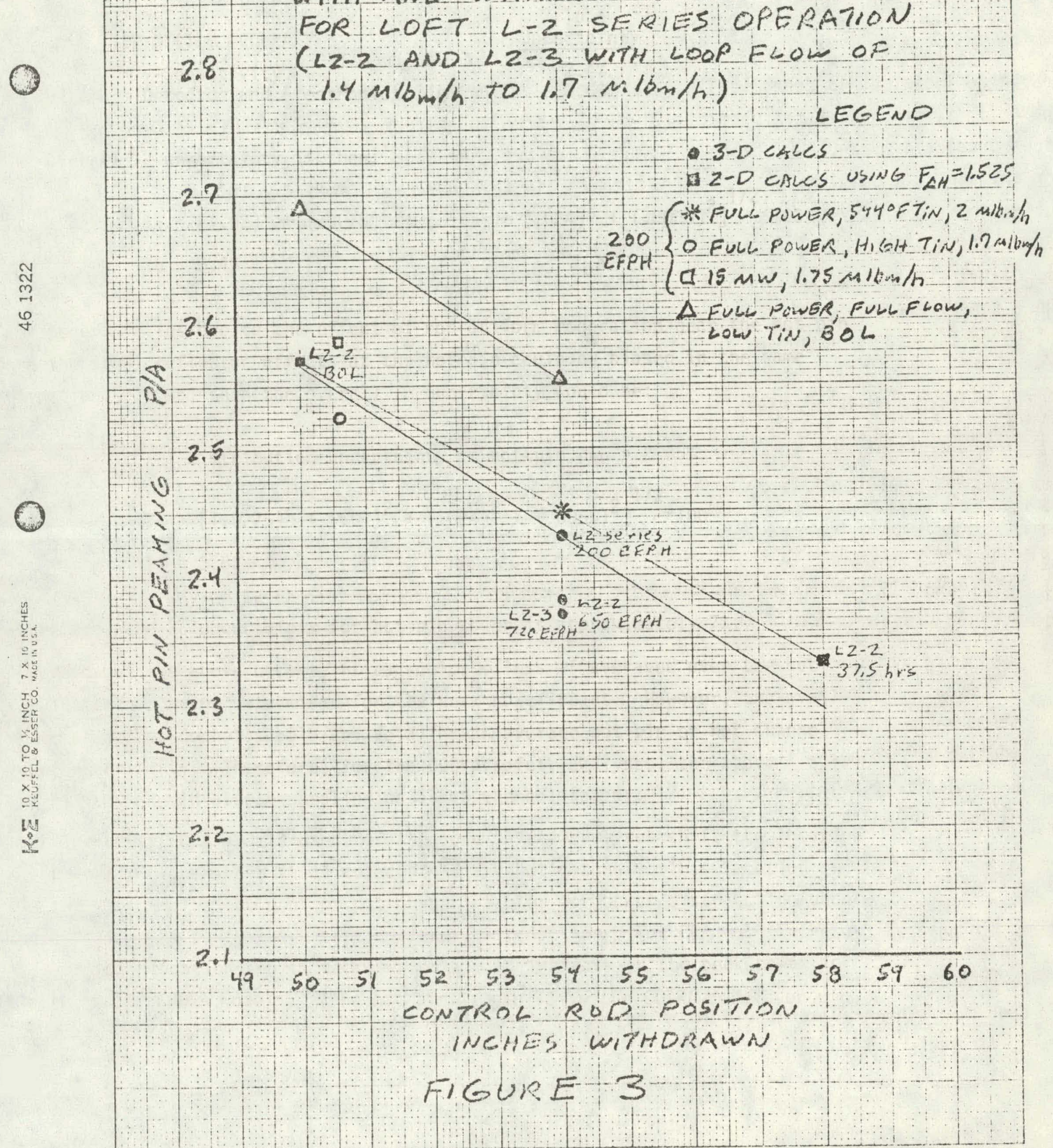
The method for inferring a LOFT core power distribution from TIP axial scans in 3 core locations is described in Reference [a]. The method is based on matching the axial fission power measurements in the TIP scan tubes to $x-y$ power distributions predicted by 3-D PDQ7 calculations. Therefore, the uncertainty in the power for any pin is a combination of the uncertainty in the PDQ7 calculated $x-y$ distribution and the TIP system uncertainties. The PDQ7 distribution uncertainties are discussed in References [a] and [b]. The TIP system uncertainties (detector and associated electronics and support) are discussed in Reference [c]. A review of these three references determined the following estimates for uncertainties which relate to the determination of hot pin power.

\section{PDQ7 $X-Y$ DISTRIBUTION UNCERTAINTIES}

1. The uncertainty due to non-uniform moderator effects in the hot pin next to a water-filled guide tube is 1 standard deviation $(1 \sigma)= \pm 2 \%[b]$.

2. The uncertainty due to the inability to accurately predict the effect of the steel reflector is less than $1.5 \%$ at the hot spot ${ }^{[b]}$. Therefore, if this estimate for maximum uncertainty is taken as a $2 \sigma$ bound, then the $1 \sigma$ uncertainty is $0.75 \%$.

3. Remaining uncertainty in the ability to predict or match actual power distribution with the PDQ7 prediction is taken to be $<2 \%[b]$. However, these remaining uncertainties are of the type that can be detected by the TIP traces since they are a general distribution uncertainty and not a local effect. This uncertainty is accounted for by allowing for a maximum spread in measured peaking in the safety analysis. This spread is based on a 3 to $4 \%$ uncertainty derived by comparing PDQ7 predictions to TIP measured distributions.

\section{IIP FACTOR UNCERTAINTY}

The fission densities measured in a TIP tube are translated to power densities in an adjacent pin location, but in the $3 / 4$ of the LOFT core 
Study for LOFT Hot Pin Power Uncertainty Given Tip

Power Distribution Measurements

S. A: Atkinson

Page 2

without the air-filled TIP tubes by use of TIP factor multipliers. These TIP factors are based on PDQ7 calculations. An uncertainty in the TIP factors represents a possible bias in theTIP-determined core power distribution. This uncertainty is estimated to be within $\pm 2 \%$ for the hot pin peak power $[a]$. Since this is an estimate for maximum uncertainty, it is taken to be a $2 \sigma$ bound. Then, the $1 \sigma$ uncertainty for hot pin peaking is $\pm 1 \%$.

\section{TIP SYSTEM ACCURACY}

1. The major source of possible inaccuracy in the TIP measurements is the uncertainty of the sensitivity of the detector to gamma radiation $(\gamma \text {-sensitivity })^{[c]}$. This $\gamma$-sensitivity uncertainty is within $2.9 \%$ of the reading plus $1.3 \%$ of range $[c]$. The relationship of range to normal peak plane readings is not described. If $1.3 \%$ of range is taken to be approximately the same as $1.9 \%$ of reading in the peak power plane, then the effect of the $\gamma$-sensitivity uncertainty is $4.8 \%$ of reading. Taking this maximum estimate to be a 20 bound, then the $1 \sigma$ uncertainty for TIP detector $\gamma$-sensitivity is $\pm 2.4 \%$.

2. The remaining accuracy of the detector and supporting electronics is within $\pm 1.3 \%$ of reading $[c]$. Taking this maximum estimate to be a $2 \sigma$ bound, then the lo uncertainty is $0.65 \%$.

3. Reference [c] also discusses a positional accuracy. However, the practice of axially translating all TIP traces to the same grid spacer. locations tends to minimize the effect of positional accuracy [a]. Therefore, the uncertainty due to positional accuracy. is neglected.

In sumiary, the LOFT hot pin power uncertainties for a TIP-measured power distribution are:

CALCULATIONAL ACCURACY

10 Local Non-Uniform Moderator Effect $2 \%$ Reflector Effect on X-Y Distribution $0.75 \%$ TIP Factor Uncertainty 
Study for LOFT Hot Pin Power Uncertainty Given Tip

Power Distribution Measurements

S. A. Atkinson

Page 3

TIP SYSTEM ACCURACY

$\gamma$-Sensitivity

Detector and Electronics
10

Uncertainty

$2.4 \%$

$0.65 \%$

The overall $1 \sigma$ uncertainty is then:

$$
\begin{aligned}
& 1 \sigma=\left[(.02)^{2}+(.0075)^{2}+(.01)^{2}+(.024)^{2}+(.0065)^{2}\right]^{1 / 2} * 100 \\
& 1 \sigma=3.4 \%
\end{aligned}
$$

The uncertainties due to the effect of non-uniform moderation near the hot pin and the steel: reflector effects at the hot pin could be biased in the same direction. If so, then the overall lo uncertainty would be:

$X-Y$ distribution uncertainty at hot pin, $l_{0}=2.75 \%$

$$
\begin{aligned}
& 10=\left[(.0275)^{2}+(.01)^{2}+(.024)^{2}+(.0065)^{2}\right]^{1 / 2} \star 100 \\
& 10=3.8 \%
\end{aligned}
$$

Therefore, the. $2 \sigma$ uncertainty for hot pin power is approximately $7 \%$.

Some of the above uncertainties would be less if averaged over the hot pin instead of being determined for the peak power point. However, the available references do not supply any data for an average hot pin or hot channel power uncertainty. Therefore, for the COBRA safety analyses, the above uncertainty should also be applied as a hot channel factor.

The LOFT COBRA models used for the core safety analyses shift the location of the hot pin such that it is adjacent to the hot channel.: This location shift has the effect of a hot spot or hot channel factor for power distribution uncertainty. For the power range testing power distributions, for CRP $=50$ inches, this hot pin locations shift represented a $2.3 \%$ increase in the peak power for pin 20 in the COBRA models. (The hot pin is pin 13 in the COBRA models or pin 10 
Study for LOFT Hot Pin Power Uncertainty Given TIP

Power Distribution Measurements

S. A. Atkinson

Page 4

in the PDQ7 model). The case L1012 PDQ7 distribution from LTR 111-86 ${ }^{[d]}$ is being proposed for use as the base power distribution for a total $P / A=2.66$. The predicted radial $P / A=1.570$ in case $L 1012$ for the hot $p$ in is adjusted to a radial $P / A=1.61$ to obtain total $P / A=2.66$ (the case $L 1012$ predicted total $P / A=2.585)$. Shift of the hot pin location from pin 13 to pin 20 in the L1012 distribution represents an increase in pin 20 peak power of $2.3 \%$. Therefore, for a total 20 power distribution uncertainty of $7 \%$, the additional potential increase in pin power is $4.7 \%$. Thus, the power distribution uncertainty hot spot factor should be 1.047 for a 20 hot pin power distribution uncertainty of $7 \%$.

An alternate way to handle a $7 \%$ power distribution uncertainty in the COBRA analyses would be by eliminating the hot pin shift, and apply the full $7 \%$ uncertainty to the pins adjacent to the hot channel (COBRA channel 15). This approach would be applicable for any power distribution, whereas with the hot pin shift, the additional adjustment could vary with power distribution. Therefore, elimination of the hot pin shift in the COBRA model and use of a 7\% power distribution uncertainty factor for the pins surrounding the hot channel is the more straightforward and preferable approach.

\section{REFERENCES}

[a] G. E. Putnam and B. L. Rushton, "Three-Dimensional Pin Powers from LOFT Core-I TIP Data", LTR 111-87 (RE-Z-77-001) September 1977.

[b] Harvey W. Graves, Jr., "A Review of Uncertainties Associated with the Evaluation of Peak Linear Power Density and DNB Flux During LOFT Steady State Operation," A report for the Nuclear Regulatory Commission, December 30, 1977.

[c]. P. A. Quinn, "LOFT Traversing IN-Core Probe (TIP) Uncertainty Analysis," LTR 141-39, Supplement 7, November 1975.

[d] E. F. Aber, "LOFT Core-I: Low Flow Power Distributions as a Function of Control Rod Position, Core Power Level, and Inlet Enthalpy", LTR 111-86 (RE-P-77-076) August 29, 1977. 
APPENDIX $A-3$

L2-3 MODE 8 TRIPPOINTS, OPERATING CONDITIONS, AND PREDICTED L2-3 POWER DISTRIBUTION 


\title{
INTEROFFICE CORRESPONDENCE
}

\author{
dote $\quad$ March 26, 1979 \\ to E. C. Anderson ecd \\ trom \\ D. G. Satterwhite 218 \\ sublect LOCE L2-3 MODE 8 PPS TRIP SETPOINTS AND OFF-NOMINAL OPERATING \\ CONDITIONS - DGS-1-79
}

Ref: (a) R. A. Dimenna/G. L. Hunt 1 tr to S. A. Atkinson, RAD-2-78, GLH-4-78, "PPS Trip Setpoints and Time Constants for L2-2 Safety Analysis," May 16, 1978

(b) E. C. Anderson itr to J. R. White, ECA-14-77, "Off-Nominal Plant Conditions for L2-3 Pre-LOCE Operation," December 14, 1977

(c) E. F. Aber, "LOFT Core-1: Low Flow Power Distributions as a Function of Control Rod Position, Core Power Level, and Inlet Enthalpy," LTR 111-86, August 29, 1977

(d) B. L. Rushton, "LOFT Core-1: Physics Methods Verification," LTR 111-19, March 15, 1971

(e) Harvey W. Graves, Jr., "A Review of Uncertainties Associated with the Evaluation of Peak Linear Power Density and DNB Flux During LOFT Steady State Operation," A report for the Nuclear Regulatory Commission, December 30, 1977

(f) P. A. Quinn, "LOFT Traversing In-Core Probe (TIP) Uncertainty Analysis," LTR 141-39, Supplement 7, November 1975

(g) N. F. Fausz 1tr to E. C. Anderson, NFF-1-79, "Statistical Evaluation of the LOFT Heat Flux Engineering Hot Spot Factor," February 27, 1979

The purpose of this letter is to detail the LOCE L2-3 Mode 8 PPS trip setpoints and off-nominal operating conditions. Included in the discussion are deviations from the EOS, Volume 2, Revision 2, test conditions required by Mnde 8 safety analysis. 
Page 2

\section{Plant and LOCE EOS Modification}

The worst case postulated transient in the anticipated category is a slow reactivity insertion in the range of $0.7 \times 10^{-4} \mathrm{\partial p} / \mathrm{sec}$. that would result in the worst case power trip and worst case hot leg temperature trip to be initiated coincidentaliy. This reactivity insertion rate could result from a slow control rod withdrawal accident or a boron dilution accident. In order to minimize the consequences of these transients and to assure adequate thermal margin to DNB, the following requirements have been incorporated in the Mode 8 safety analysis.

(1) Reduction of nominal primary system pressure from 2250 psia to 2169 psia

(2) Reduction of nominal PCS hot leg temperature from $617^{\circ} \mathrm{F}$ to $609^{\circ} \mathrm{F}$

(3) Require PCS hot leg RTO response time constant $<15 \mathrm{sec}$.

Nominal Power and Flow

The nominal power and flow for given LOCE condition are determined as functions of the core peak to average power ratio, Fq. The current LOCE L2-3 conditions affecting this determination are:

$$
\begin{aligned}
\text { Vessel coolant temperature differential }(\Delta \mathrm{T}) & =64.5^{\circ} \mathrm{F} \\
\text { Peak linear heat rate (PLHR) } & =12 \mathrm{~kW} / \mathrm{ft} \\
\text { Vessel outlet coolant temperature }\left(T_{H}\right) & =609^{\circ} \mathrm{F} \\
\text { Primary system pressure }(P) & =2169 \text { psia }
\end{aligned}
$$

Using the above condition, the required core enthalpy increase, $\Delta H$, is $86.31 \mathrm{BTU} / \mathrm{lbm}$. Then using the expression developed in Reference (a), nominal power becomes:

$$
P(M W)=7.519 \frac{(12 \mathrm{~kW} / \mathrm{ft})}{\mathrm{Fq}}=\frac{90.23}{\mathrm{Fq}}
$$

and nominal loop flow in

$$
\begin{aligned}
\dot{m}(1 \mathrm{bm} / \mathrm{hr}) & =\frac{P(M W)}{\Delta \mathrm{H}(\mathrm{BTU} / \mathrm{fbm})} \times 3.413 \times 10^{6} \frac{\mathrm{BTU} / \mathrm{hr}}{\mathrm{MW}} \\
& =\frac{3.568}{\mathrm{Fq}} \times 10^{6} \mathrm{ibm} / \mathrm{hr}
\end{aligned}
$$


E. C. Anderson

March 26, 1979

DGS-1-79

Page 3

The values obtained from these expressions are graphically presented in Figure 1 (attached) for the range of $\mathrm{Fq}$ used in the safety analysis.

\section{PPS Trip Setpoints}

The PPS trip stepoints and instrument error stackup for worst case trip values developed for the LOCE L2-3 are derived in the same manner with the same assumption for instrument and drift accuracies as detailed in Reference $(z)$. Deviations in values and implementation are as follows: (See Figure 2-7, attached)

\section{Temperature Channel}

No changes from Reference (a). Nominal $T_{H}$ is set at $609^{\circ} \mathrm{F}$ by safety analysis considerations.

\section{Pressure Channel}

The reduction in pressure results from safety analysis requirements. The LOFT-3 DNB correlation indicates that at low mass fluxes, CHF increases significantly with decreasing pressure (other accepted correlations corroborate this result). The worst case low pressure trip was maintained at 2000 psia because that coincides with the low pressure limit of the data used in developing the LOFT-3 DNB correlation. Nominal pressure is set at 2169 psia (93 psid from LOCE L2-2).

\section{Flow Channel}

The low flow trip setpoint is determined using the worst case $\mathrm{Fq}=2.6$. Variation of the trip with variation of $\mathrm{Fq}$ is not required. The high and low flow alarms remain set to $\pm 5 \%$ of nominal flow and thus are functions of $\mathrm{Fq}$.

Peak Power Charmel - N/A

Average Power Channel

Stringent controls are required for Pre-LOCE power levels. The nominal trip setpoint and control band $(+1,-2 \mathrm{MW})$ must vary as functions of $\mathrm{Fq}$. The lower control band was necessitated by the need to minimize the power differential between an initial power and resulting trip power during a reactivity insertion transient. Operationally, the lower control band will be administratively controlled while the nominal trip setpoint and high power alarm will be functionally controlled. The implementation of the functional control is accomplished by setting the instrumentation 
such that $75 \%$ indicated power corresponds to the required actual power based on $\mathrm{Fq}$. The upper control band alarm is then set at $77 \%$ with the nominal trip at $78 \%$. This scheme assures the required constant power differential between nominal power and nominal trip power and can be easily adjusted with variation in $\mathrm{Fq}$.

\section{Off-Nominal Operating Conditions}

\section{Power Distribution and $\mathrm{Fq}$}

Reference (b) transmitted a recommended axial/radial power distribution for use in ESA enveloping analyses. The recommended distribution is PDQ07 case L1012 from Reference (c) with an associated Fq of 2.585 . For comparison purposes, the current best estimate distribution ( $\mathrm{Fq}=$ 2.447), calculated using the LOFT core follow physics model, for LOCE L2-3 is presented in Tables 1 and 2 (attached). A comparison of the hot pin power profiles of the two distributions is presented in Figure 8 (attached).

The best estimate distribution was calculated using the same maneuvering history as L2-2 with the active rod material positioned at $54 \mathrm{in}$. above fuel bottom. In order to present an estimate of actual expected $\mathrm{Fq}$ for the LOCE, the $F q(B E)$ must be reduced by $2 \%$. This is the effect of active rod material being positioned at 56 in. (indicated 54 in. withdrawn). Therefore, the expected $\mathrm{Fq}$ for the LOCE (assuming same maneuvering history as LOCE $\mathrm{L2}-2$ ) is $\mathrm{Fq}=2.40$.

In general, the higher in the core the axial peak occurs, the more conservative the calculation when concerned with margin to DNB. However, LOCE calculations are predominately sensitive to PLHR and not initial local channel properties.* Therefore, the original power distribution is still applicable for all types of safety analysis.

The range of $\mathrm{Fq}$ used in the Mode 8 safety analys is is $2.3 \leq \mathrm{Fq} \leq 2.6$. While as stated the recommend distribution is applicable, it is modified to conform to the enveloping worst case situation; i.e., scaling the peak to the $\mathrm{Fq}=2.6$ and flattening the peak as required by analys is techniques. The nominal power and flow would then follow based on $\mathrm{Fq}$.

\section{Uncertainty in PLHR}

Given a desired PLHR, various uncertainty factors must be applied to determine the actual value attainable. There are uncertainties in measurement of $\mathrm{Fq}$, uncertainties in indicated vs. actual core average power, as well as

* As long as DNB is not present. 
E. C. Anderson

March 26, 19.79

DGS-1-79

Page 5

control band considerations, and uncertainties in local power due to effect of fuel rod fabrication tolerances and fuel densification effects. All uncertainties are expressed as two standard deviation $(2 \sigma)$ values.

The uncertainties in $\mathrm{Fq}$ measurement stem from two basic sources. The first source is the actual XY physics calculations that supply the basis vectors used in the TIP program. In general, for an XY calculation, the uncertainty of the local pin power is $3 \%$ to $4 \%$ of value for unrodded environments. Reference (d) states a value of $3 \%$ for LOFT physics methods. Reference $(e)$ expresses concern over the effect of the radial steel reflectors on overall power, thus affecting the relative pin power. While this latter effect has not been demonstrated by higher order transport physics calculation, an additional $1 \%$ uncertainty is included. Therefore a total physics uncertainty of $4 \%$ of value is assumed.

The second source of uncertainty in Fq results from TIP system properties. The TIP system uncertainties are developed in Reference ( $f$ ). The results are:

$\begin{array}{ll}\text { Gamma Sensitivity } & 2.9 \% \text { reading plus } 1.3 \% \text { range } \\ \text { Detector } / \text { Electronics } & 1.3 \% \text { reading }\end{array}$

The $1.3 \%$ range uncertainty stems from propogated uncertainty in an offset related to the gamma sensitivity. The author of Reference 6 chose to sum rather than statistically combine these errors. This is overly conservative. The detectur/electronics uncertainty will be statistically combined with the gamma sensitivity terms. For power range applications, the peak reading is assumed to be one-half the range. Therefore, $1.3 \%$ of range is equivalent to $2.6 \%$ of reading thus yielding a total of $5.5 \%$ of reading uncertainty for gamma sensitivity. Note that if the reading is very low, the error would become quite large. Upon statistical combination the total TIP system uncertainty is estimated to be $5.7 \%$.

Statistical combination of physics and TIP system uncertainties then yield an $\mathrm{Fq}$ measurement uncertainty of $7 \%$.

The FSAR adequately addresses the densification factor (1.011), therefore its discussion will not be presented here. The engineering hot channel factor of 1.032 (FSAR value) has been replaced by a statistical value of 1.026. Reference $(\mathrm{g})$ presents the derivation of the statistical hot channe1 factor.

For completeness, in addition to the channel properties affecting PLHR, all of the channel parameters used to obtain off-nominal condition for Mode 8 safety analys is is presented below: 
E. C. Anderson

March 26, 1979

DGS-1-79

Page 6

\begin{tabular}{|c|c|c|}
\hline Channel & Control Band & Accuracy \\
\hline Power & $+1,-2 \mathrm{MW}$ & $1.5 \mathrm{MW}$ \\
\hline Flow & $+5 \%$ Nom. & $0.125 \mathrm{Mibm} / \mathrm{hr}$ \\
\hline Temperature & $\pm 2^{\circ} \mathrm{F}$ & $2^{\circ} \mathrm{F}$ \\
\hline Prassure & \pm 50 psid & 38 psid \\
\hline
\end{tabular}

The off-nominal PLHR should then be determined using the following factors:

Fq Measurement Uncertainty $\quad=1.07$

Fq Engineering Hot Channel Factor $=1.026 \times 1.011=1.037$

Operational CV and Inst. Accuracy $=\frac{40.1 \mathrm{MW}}{37.6 \mathrm{MW}}=1.066$

(Assumes $\mathrm{Fq}=2.4$ )

Then the PLHR would become:

PLHR $=12 \mathrm{~kW} / \mathrm{ft} \times 1.07 \times 1.037 \times 1.066=14.2 \mathrm{~kW} / \mathrm{ft}$

If any questions should arise with regards to the contents of this letter please contact me.

im

Attachments:

1-8 Figures 1. through 8

9-10 Tables 1 and 2 .

CC: S. A. Atkinson
M. A. Bray
W. R. Carpenter
C. H. Cooper
G. A. Dinneen
H. Henze
G. L. Hunt
N. C. Kaufman
L. P. Leach
O. R. Meyer
S. A. Naff
M. D. Peters

J. L. Plum

T. F. Pointer

B. L. Rushton

T. K. Samuels

W. A. Spencer

J. C. Stachew

K. C. Sumpter

J. R. White

Central File

D. G. Satterwhite File

S. A. Naff

M. D. Peters 


\section{ITR 111.127 \\ APPENDIX A.3 Page 1 of 10}

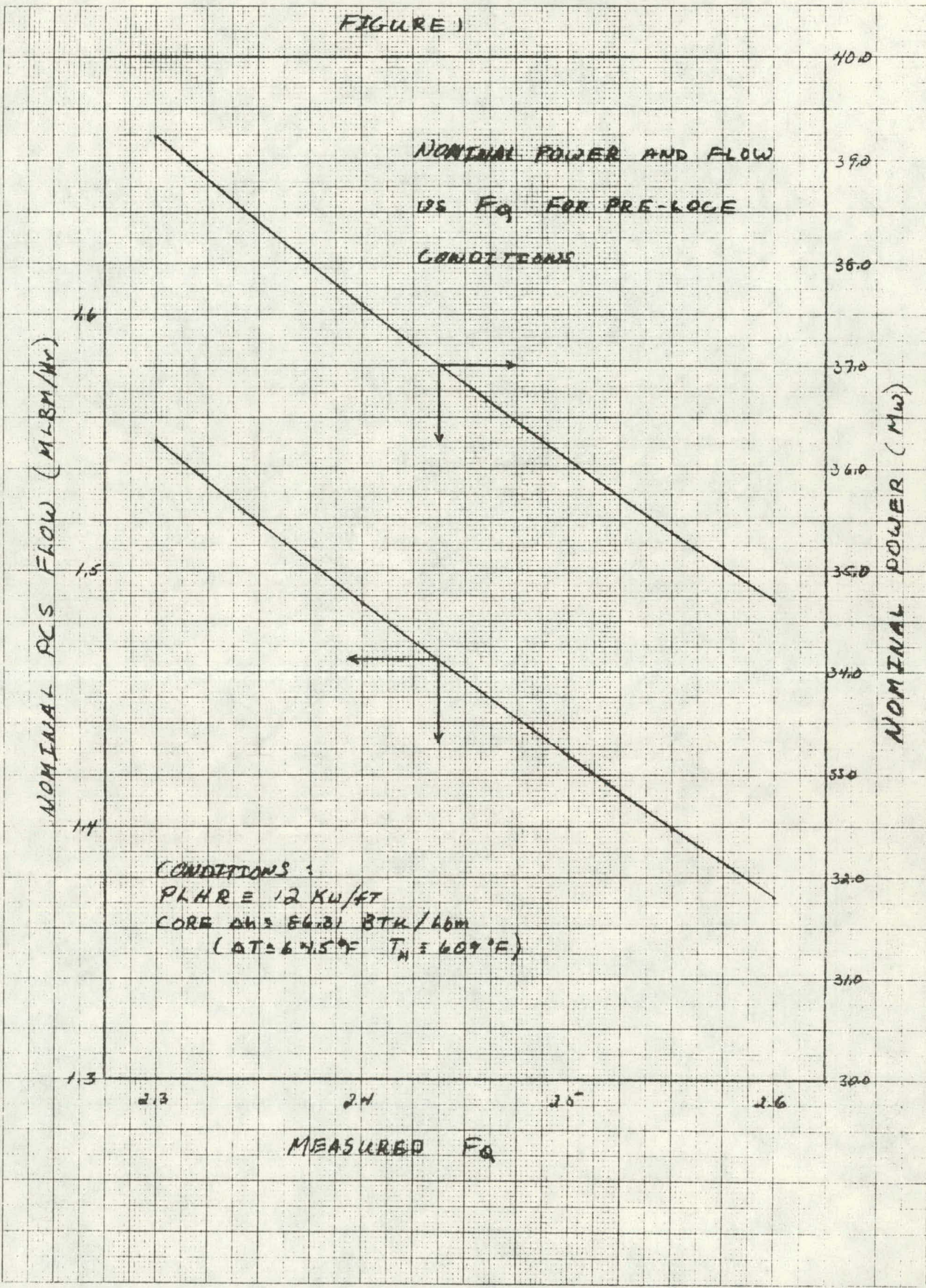




\section{LTR 111.127 Attachment 2 APPENDIX A.3 Page 2 of 10}

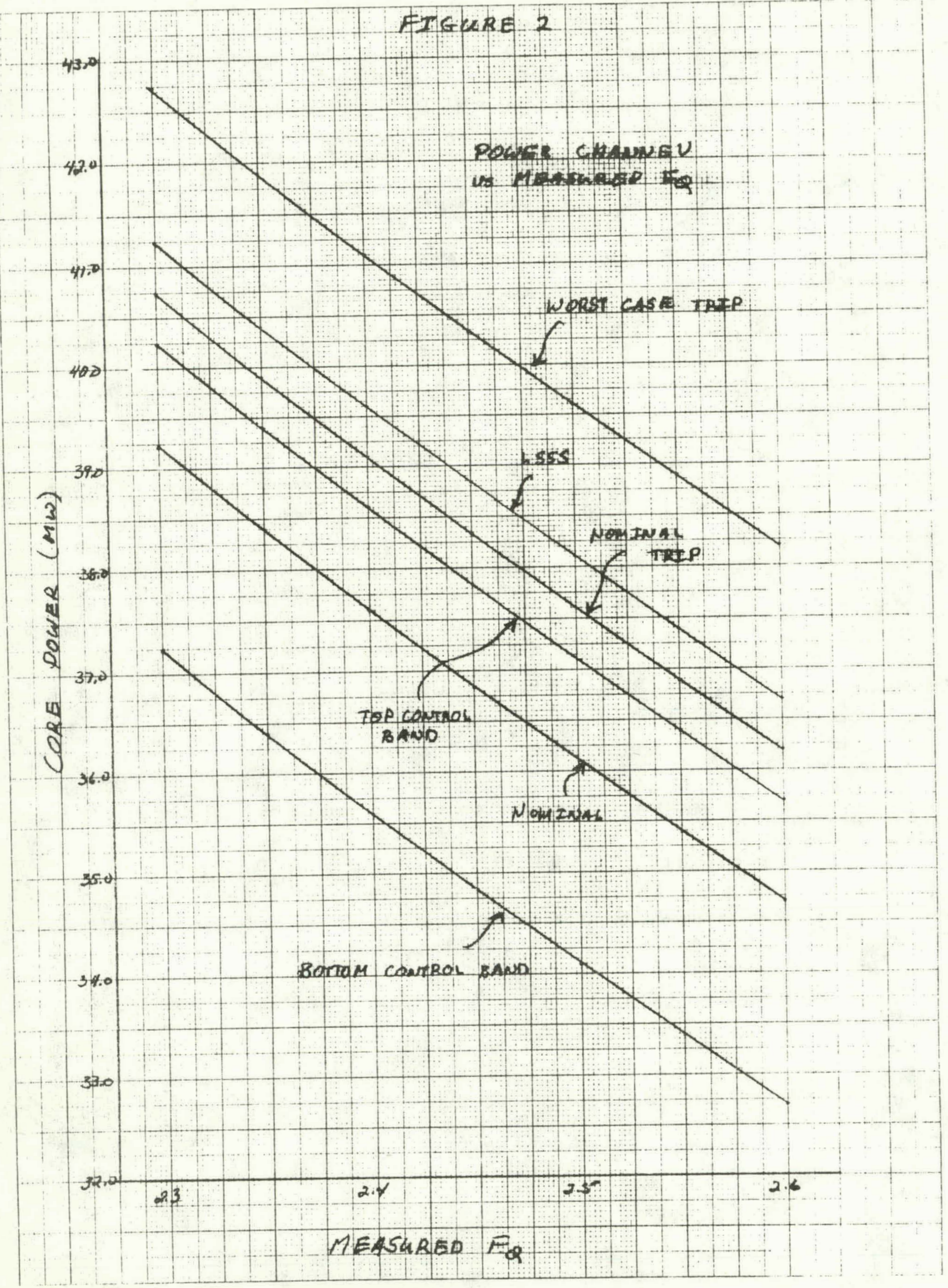


LTR ITI.127 Attacnment 3
APPENDI A-3 Page 3 of 10

frourt 3

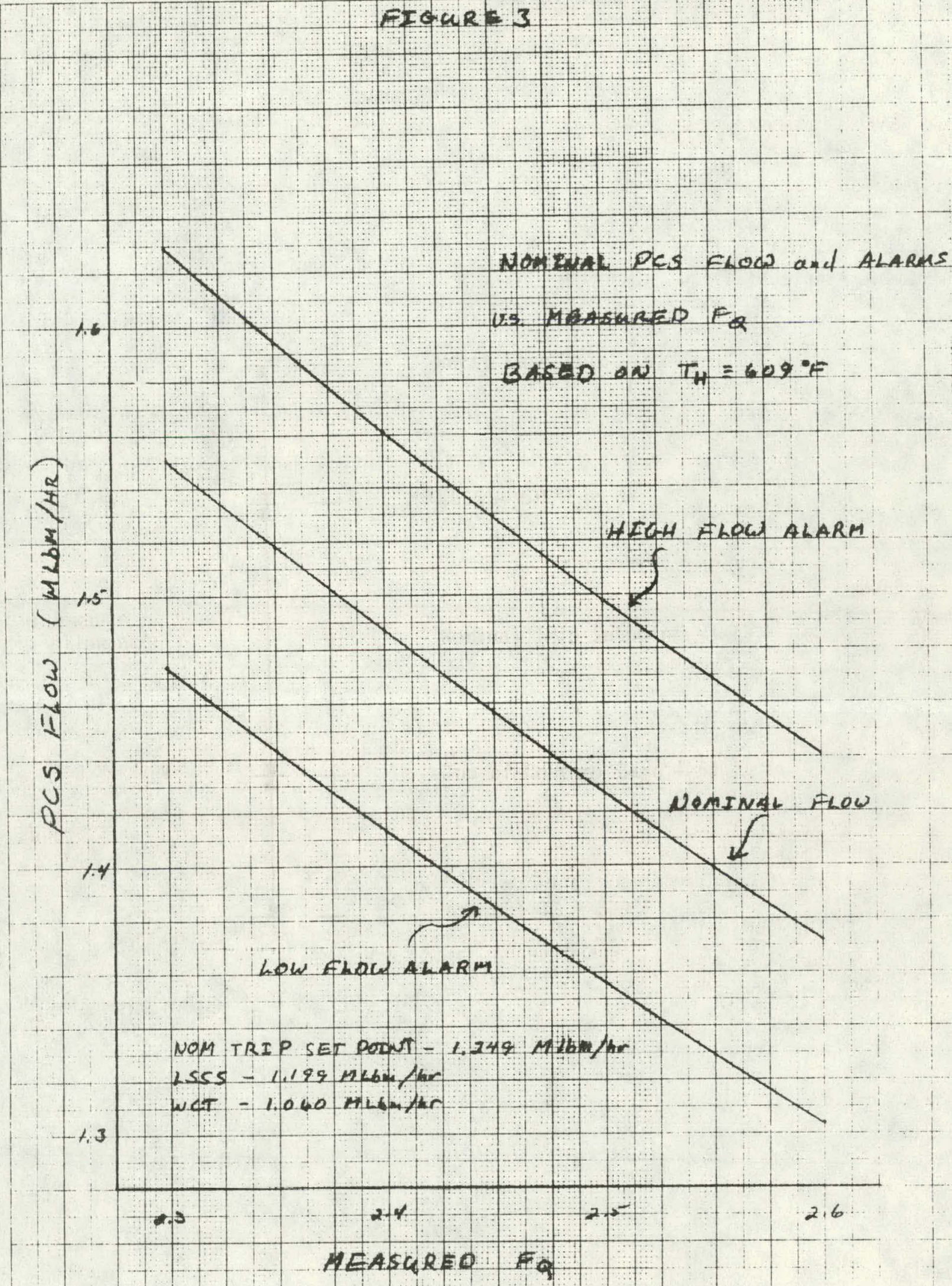




\title{
LTR 111.127 \\ APPENDIX A.3

FIGURE 4

AVERAGE POWER CHANNEL

Calorimetric Error $1 \mathrm{MW}$

+ Instrument Accuracy

$0.5 \mathrm{MW}$

Setpoint + Drift

Allowance $=0.5 \mathrm{MW}$

Control Band

$+1 \mathrm{MW}$

$-2 \mathrm{MW}$

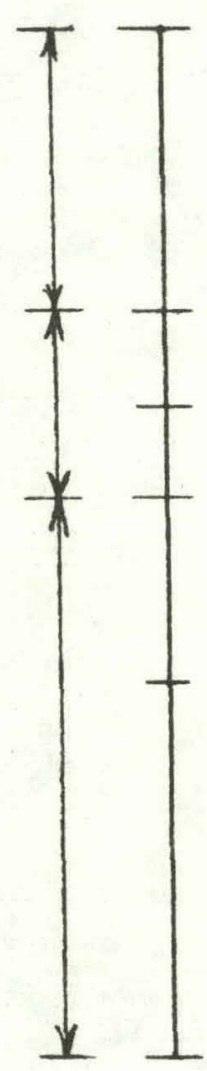

Worst Case Trip $-90.23 / \mathrm{P} / \mathrm{A}+3.5 \mathrm{MW}$

LSSS $-90.23 / P A+2 M W$

Nominal Trip Setpoint-90.23/P/A + 1.5 MW

Top of Control Band-90.23/P/A + 1 MW High Power Alarm

Nominal Power - 90.23/P/A MW

Bottom of Control Band-90.23/P/A -2 MW

\begin{abstract}
Off-Nominal High Average Power - 90.23/P/A + $2.5 \mathrm{MW}$
Off-Nominal Low Average Power - 90.23/P/A - 3.5 MW
\end{abstract}




\section{LTR 111.127 APPENDIX A.3 Attachment 5 APPENDIX A.3 Page 5 of 10}

FIGURE 5

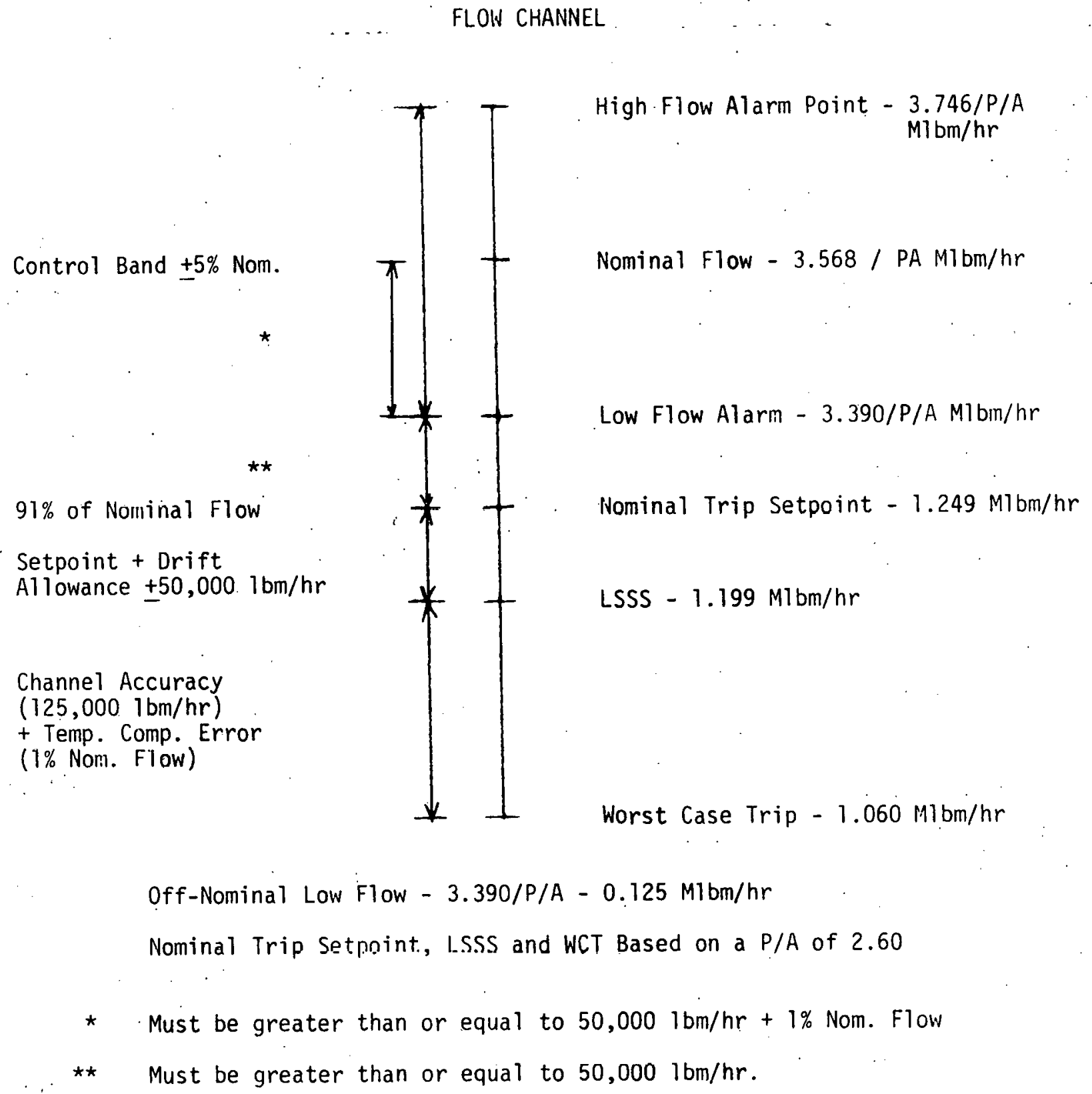




\section{LTR 111.127 Attachment 6 APPENDIX A.3 Page 6 of 10}

FIGURE 6

$T_{H}$ CHANNEL

Trip Measurement

Accuracy $2^{\circ} \mathrm{F}$

Setpoint Allowance plus Drift Allowance $+2^{\circ} \mathrm{F}$

Control Band $2^{\circ} \mathrm{F}$

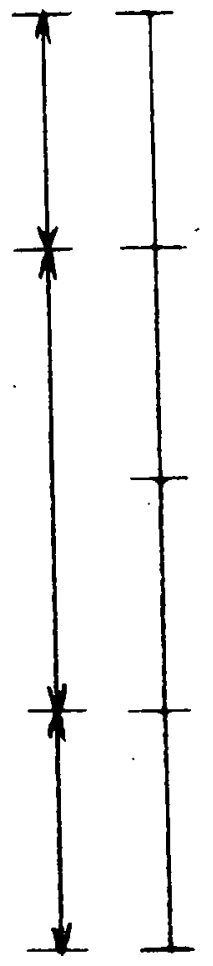

Worst Case Trip $-617^{\circ} \mathrm{F}$

$$
\text { LSSS }-615^{\circ} \mathrm{F}
$$

Nominal Trip Setpoint $-613^{\circ} \mathrm{F}$

Top of Control Band - $611^{\circ} \mathrm{F}$

Nominal $T_{H}-609^{\circ} \mathrm{F}$

Off-Nominal High $T_{H}=613^{\circ} \mathrm{F}$ 
FIGURE 7

\section{APPENDIX A.3 Attacnment ,

PRESSURE CHANNEL

Trip Accuracy -

28 psid

Setpoint + Drift

Allowance +30 psid

Control Band

+50 psid

Setpoint + Drift

Allowance +30 psid

Trip Accuracy -

28 psid
Worst Case High Pressure Trip - 2340 psia

High Pressure LSSS - 2312 psia

Nominal High Pressure Trip Setpoint - 2282 psia

Top of Control Band - 2219 psia

Nominal Pressure - 2169 psia

Bottom of Control Band - 2119 psia

Nominal Low Pressure Trip Setpoint - 2058 psia

Low Pressure LSSS - 2028 psia

Worst Case Low Pressure Trip - 2000 psia

Off-Nominal High Pressure - 2257 nsia

Off-Nominal Low Pressure - 2081 psia

For Conservatism: High Pressure Channel Use $P_{\text {atm }}=13$ psia.

Low Pressure Channel Use $P_{\text {atm }}=12$ psia 


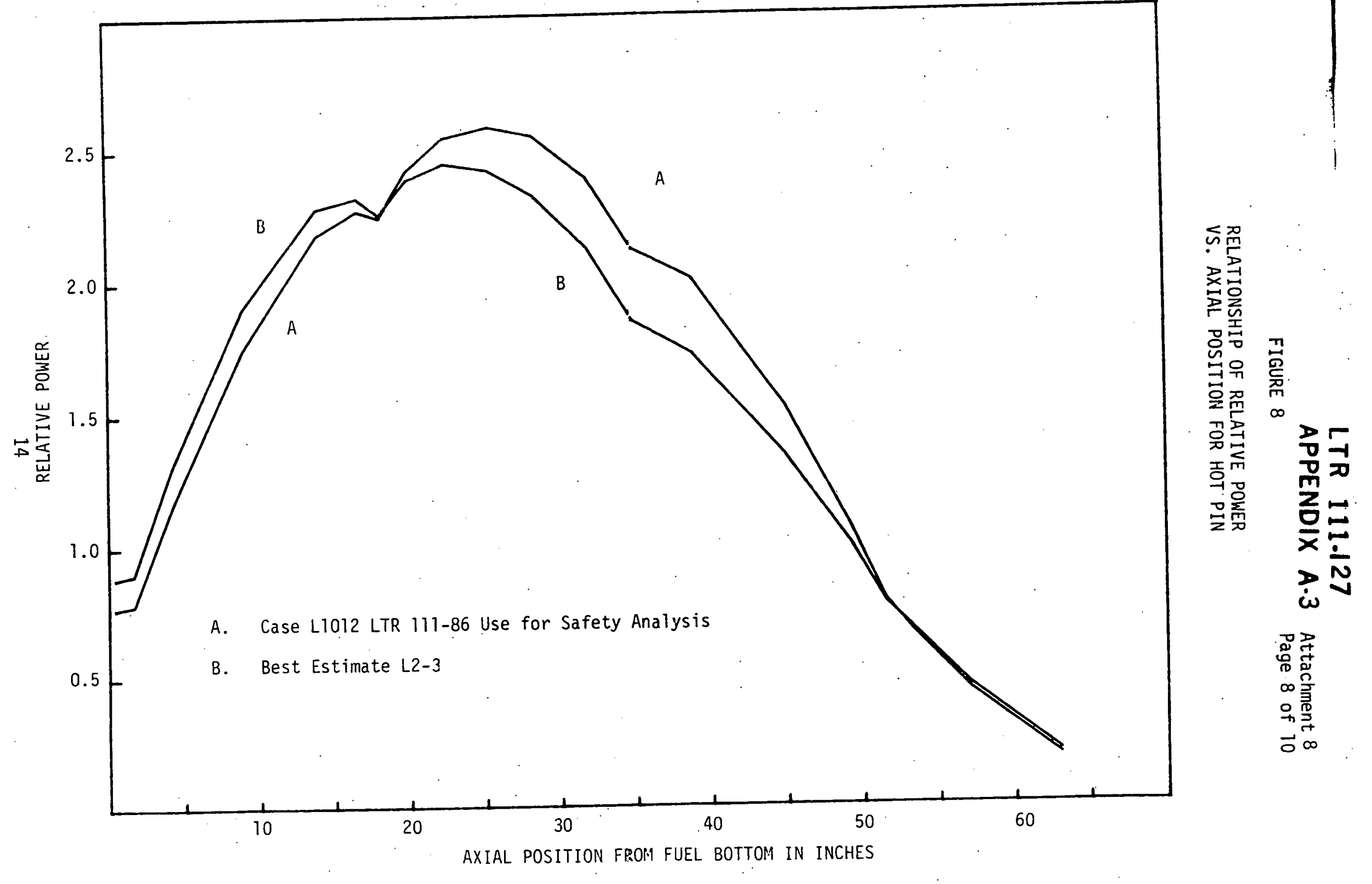




\section{LTR 111.127 \\ Attachment 9 \\ APPENDIX A.3 \\ Page 9 of 10}

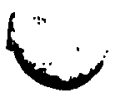

TABLE 1

$11.191, L 2-3$ PRE-DOCE CONDITICNS, 19 HR'S DEPLETICN AT LCLCFLCW,

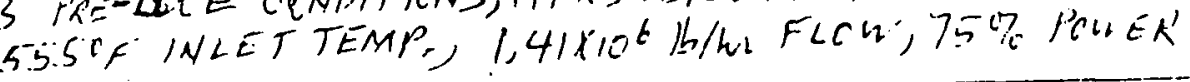

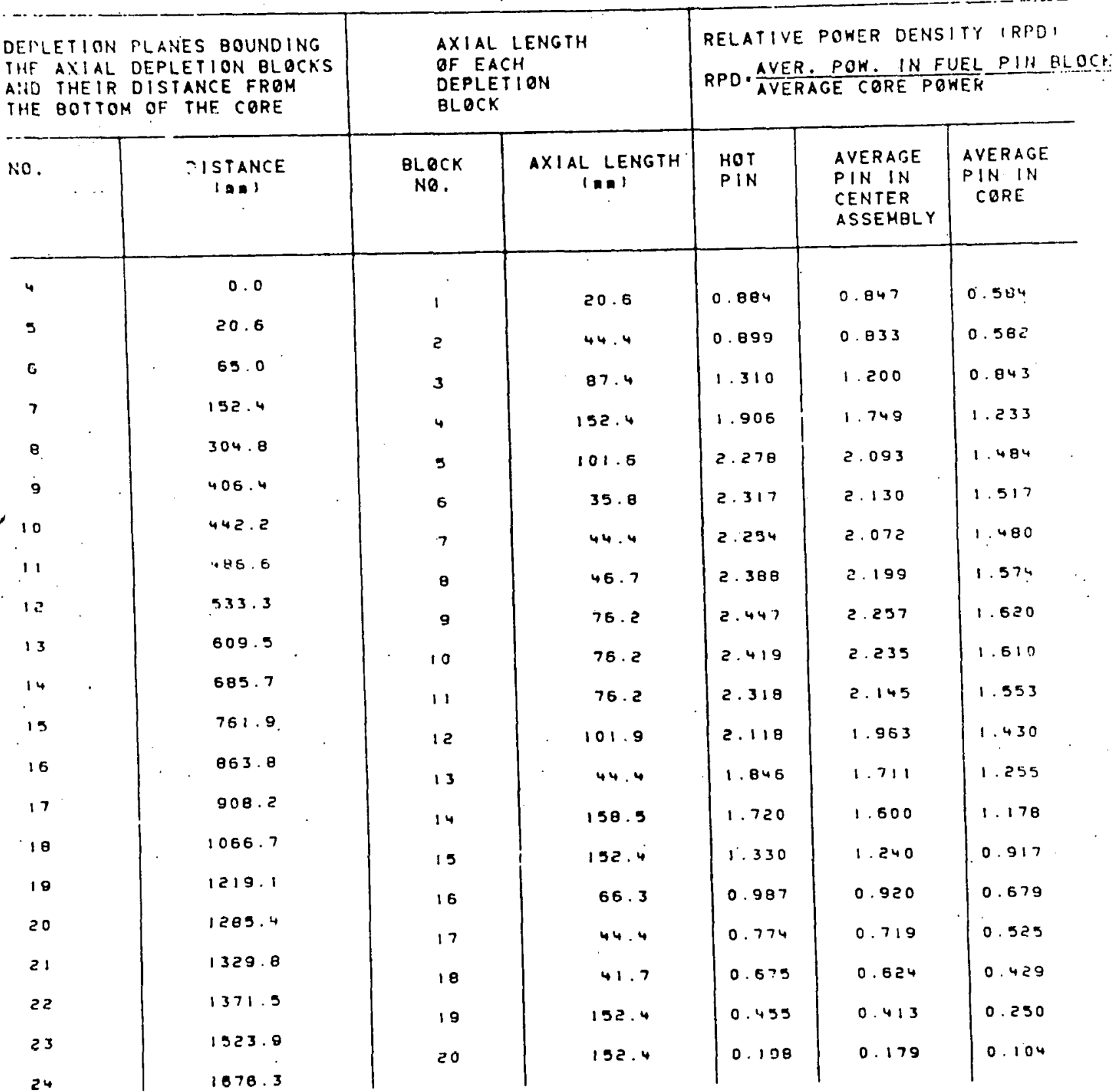




\section{LTR 111.127 \\ APPENDIX A.3}

Attachment 10

Page 10 of 10

\section{Table 2}

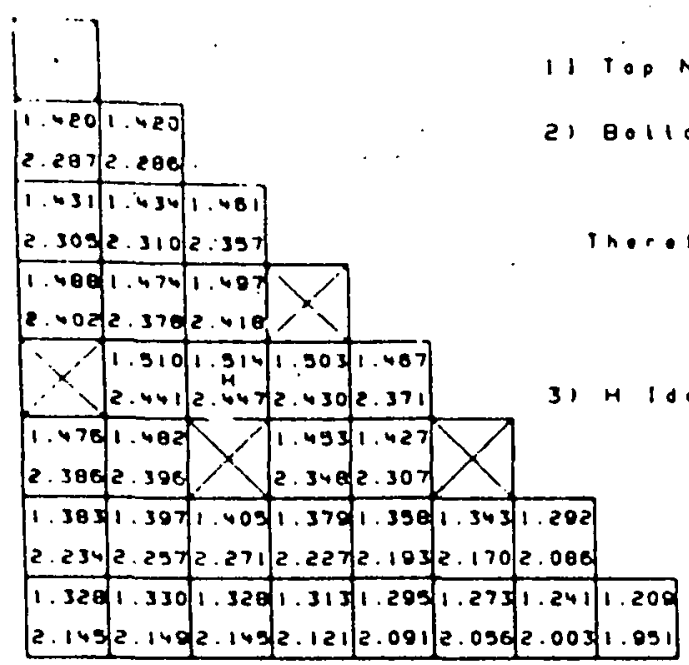

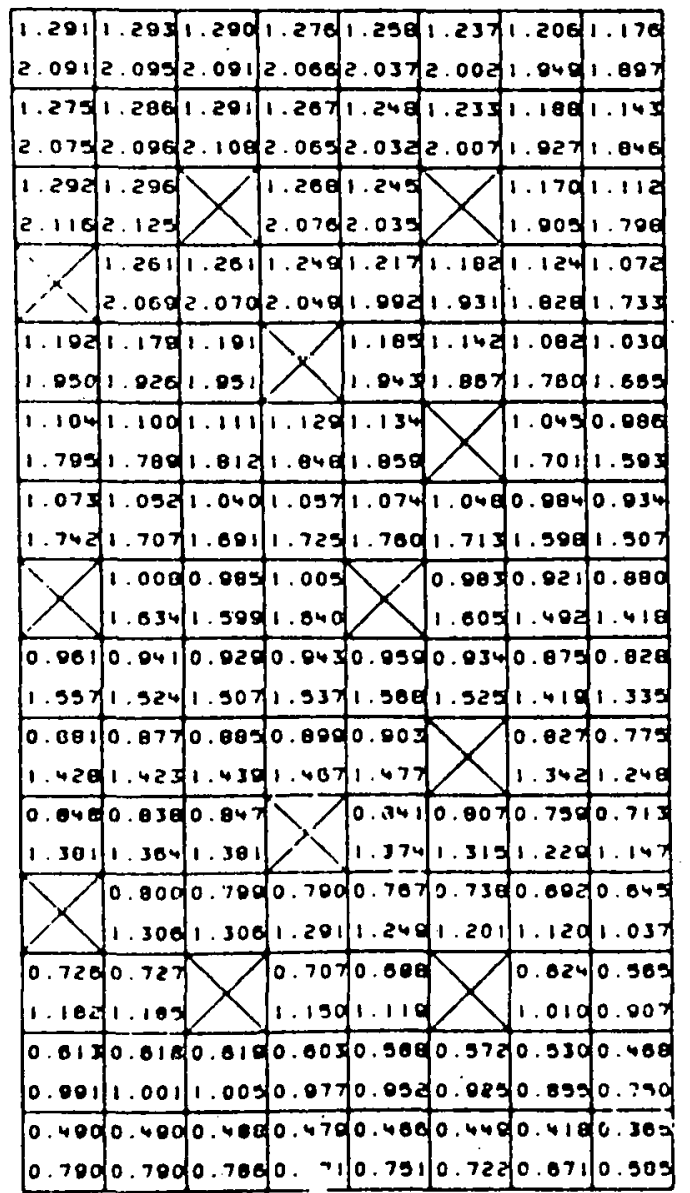

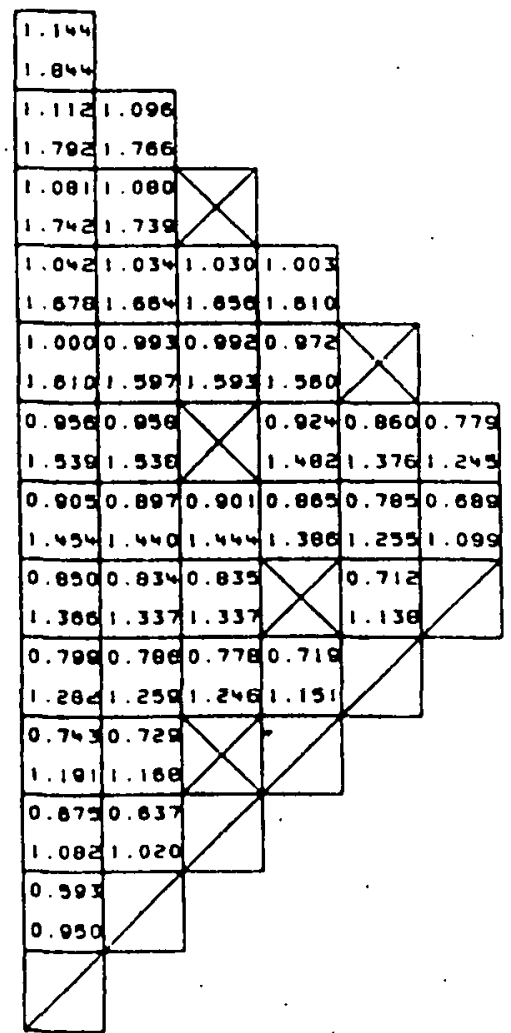

WQ. LIOUL2-3 TRE-LOCE CONDITICNS, HHRS HEPLETIEN AT LCW FLOW,

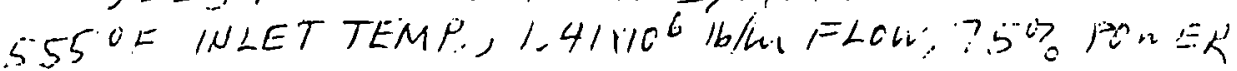


APPENDIX A-4

NOMINAL PRESSURE DECREASE

FOR L2-3 MODE 8 
APPENDIX $A-2$

PIN POWER DISTRIBUTION SPREAD AND UNCERTAINTY FOR $12 \mathrm{KW} / \mathrm{FT}$ TEST 


\section{INTEROFFICE CORRESPONDENCE}
date February 2, 1979
10
E. C. Anderson
from
S. A. Atkinson

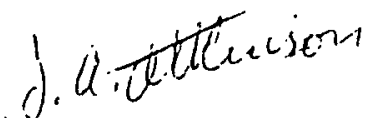
subject
NOMINAL PRESSURE DECREASE FOR L2-3 MODE 8 - Atki-3-79
Refs: (a) Richard C. Gottula and Steven A. Eide, "Evaluation and Results of LOFT Steady State Departure from Nucleate Eoiling Tests", TREE-NUREG-1043, Apri] 1977
(b) Richard C. Gottula, "LOFT Steady State Critical heat Flux Tests (6.9 to $13.8 \mathrm{MPa}$ )", TREE-NUREG-1156 (NUREG/CR-0237), June 1978
(c) Steven A. Eide and Richard C. Gottula, "LOFT Steady State Critical Heat Flux Tests (470 to $680 \mathrm{~kg} / \mathrm{s} \cdot \mathrm{m}^{2}$ )," TBP.

COBRA analyses for steady-state limits and control rod withdrawal accidents (CRWA) for operation of the LOFT reactor in Mode 8 prior to the L2-3 LCCE have indicated the necessity of changing some of the reactor operating conditions for $\mathrm{L} 2-3$ in order to show compliance with the Damage Criteria. The change that appears to gain the most in safety margin with a minimal effect on previous analyses or the results of a $L O C E$ is a reduction in operating pressure of the primary coolant system (PCS). A reduction in the nominal operating pressure (in the pressurizer) from 2262 psia to 2169 psia (about a 100 psi decrease) increases the MDNBR for the CRWA's by about $4 \%$, when using the LOFT-3 CHF correlation. This increase in safety margin due to a reduction in pressure is required for the L2-3 Mode 8 steady-state analysis to show compliance with Damage Criteria A (MDNBR $\geq 1.14$ using LOFT-3) for operation at the worst-case power trip level. As you know, we are finding it very difficult to show compliance with Damage Criteria $B$ for the slow CRliA!s. The gain in safety margin from a decrease in operating pressure (and maybe more) is required for the CRWA analyses. Therefore, I strongly recommend that nominal operating pressure in the LOFT PCS be reduced 93 to 100 psi for L2-3 operation.

The attached plots show the influence of pressure on the critical heat flux. (CHF), or DNB, for data taken from the simulated LOFT fuel bundles. This data is reported in References $a, b$, and $c$. The high flow data from Reference a (loop flows from about $1.7 \mathrm{Micm} / \mathrm{h}$ to $4 \mathrm{Nl} \mathrm{bm} / \mathrm{h}$ ) and the low flow data from Reference c (loop flows from about $0.8 \mathrm{MIbm} / \mathrm{h}$ to $1.3 \mathrm{Mlbm} / \mathrm{h}$ ) were combined to derive the LOFT-3 correlation. Figures 1 through 3 show the 1 ow flow data (ANC-6 bundle data). The CHF data is plotted as a function of the enthalpy at the point of DNB. These plots definitely show an increase in CHF as pressure is decreased. Figures 4 and 5 show CHF data for the same fluw ranges (flow being expressed as mass velocity in the hot channel) including low 
February 2, 1979

\section{LTR III-127 \\ APPENDIX A.4}

E. C. Anderson

Atki-3-79

Page 2

pressure CHF data from Reference $b$. The clata indicates that the effect of reduced pressure on increased CHF probably extends down to 1000 psia. Figure 6 shows CHF data from Reference a for the low end of the hich flow data, and low pressure data for the same flows from Reference $b$. For this data, any pressure effect between 2000 and 2300 psia is lost in the data scater. However, there is a visible increase in CHF as pressure is decreased from the 2000 to 2300 psia group to 1500 or $1000 \mathrm{psia}$. Both the LOFT-1 correlation (based only on high flow data) and the l.OFT-3 correlation indicate ar jncrease in CHF as pressure is decreased at these flows $\left(0.69\right.$ to $\left.0.84 \mathrm{MIbm} / \mathrm{h}-\mathrm{ft}^{2}\right)$.

Figures 7 and 8 show how the low flow data compares to the LOFT-3 prediction. As seen in Figure 7, at the ANC-6 flows, LOFT-3 underpredicts most of the data. For the higher flow rates for the ANC-2 data $\left(0.69\right.$ to $\left.0.84 \mathrm{MIbm} / \mathrm{h}-\mathrm{ft}^{2}\right)$, LOFT 3 overpredicts most of the data. However, the mass velgcity range of concern for the L2-3 safety analyses is near to $0.5 \mathrm{MImm} / \mathrm{h}-\mathrm{ft}^{2}$ at an enthalpy near $680 \mathrm{Btu} / \mathrm{lbm}$. For these conditions, LOFT-3 is expected to underpredict the data. The LOFT-3 prediction is compared to the CHF data in Figure 1 for $0.5 \mathrm{Milbm} / \mathrm{h}-\mathrm{ft}^{2}$. It appears that LOFT-3 overpredicts the effect of pressure change on CHF. However, for a change in high off-nominal pressure from 2350 psia to 2250 psia, due to lowering nominal PCS pressure by 100 psia, LOFT-3 will still be underpredicting the data.

In conclusion, a 93 to 100 psia reduction in nominal operating pressure is recommended for LOFT operation for L2-3, and for operation for other LOCE's with a nominal MLHGR of $12 \mathrm{kw} / \mathrm{ft}$ or greater. This reduction in pressure $1: i 11$ increase the safety margin for operation in Mode 8 prior to the blowdown as calculated using the LOFT-3 correlation for CHF. The LOFT bundle data for CHF at low flows (ANC-6 data) supports the calculated increase in safety margin (increase in DNBR) for a decrease in pressure.

The corresponding trippoints and justification for those trippoints for operation with reduced nominal pressure will be presented in following correspondence after a review of accidents for L2-3 Mode 8 and other operational modes. At this time, it appears that the high pressure worst-case trip (WCT) should be no greater than 2400 psia. The low pressure WCT should be 2024 psia (for a 100 psia nominal pressure decrease) to 2031 psia (for a 93 psia nominat pressure decrease).

ul

Attachments: As stated

cc: B. S. Anderson
S. A. Atkinson
D. F. Elger
N. F. Fausz
J. E. Fisher

R. C. Gottula

J. L. Liebenthaig/t

W. A. Spencer

R. P. Wadkins paper

Central File

TAB File 3.13 


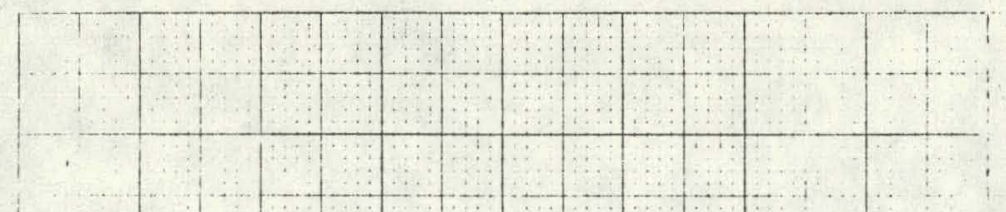

\section{APPENDIX A.4}

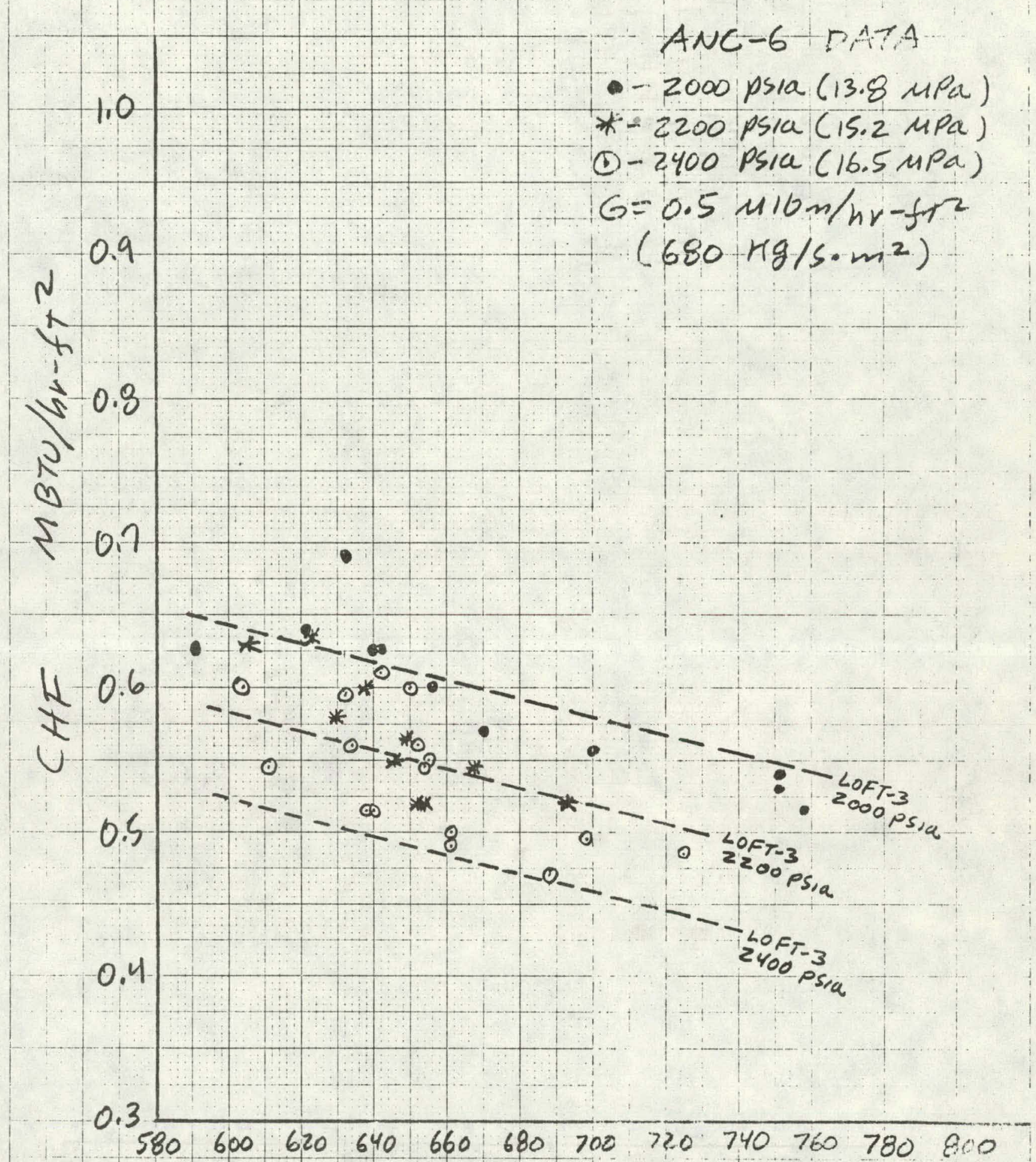

$r$

0.3

$$
\text { LOCAL ENTHALPY BTU/1bm }
$$

FIGURE I 


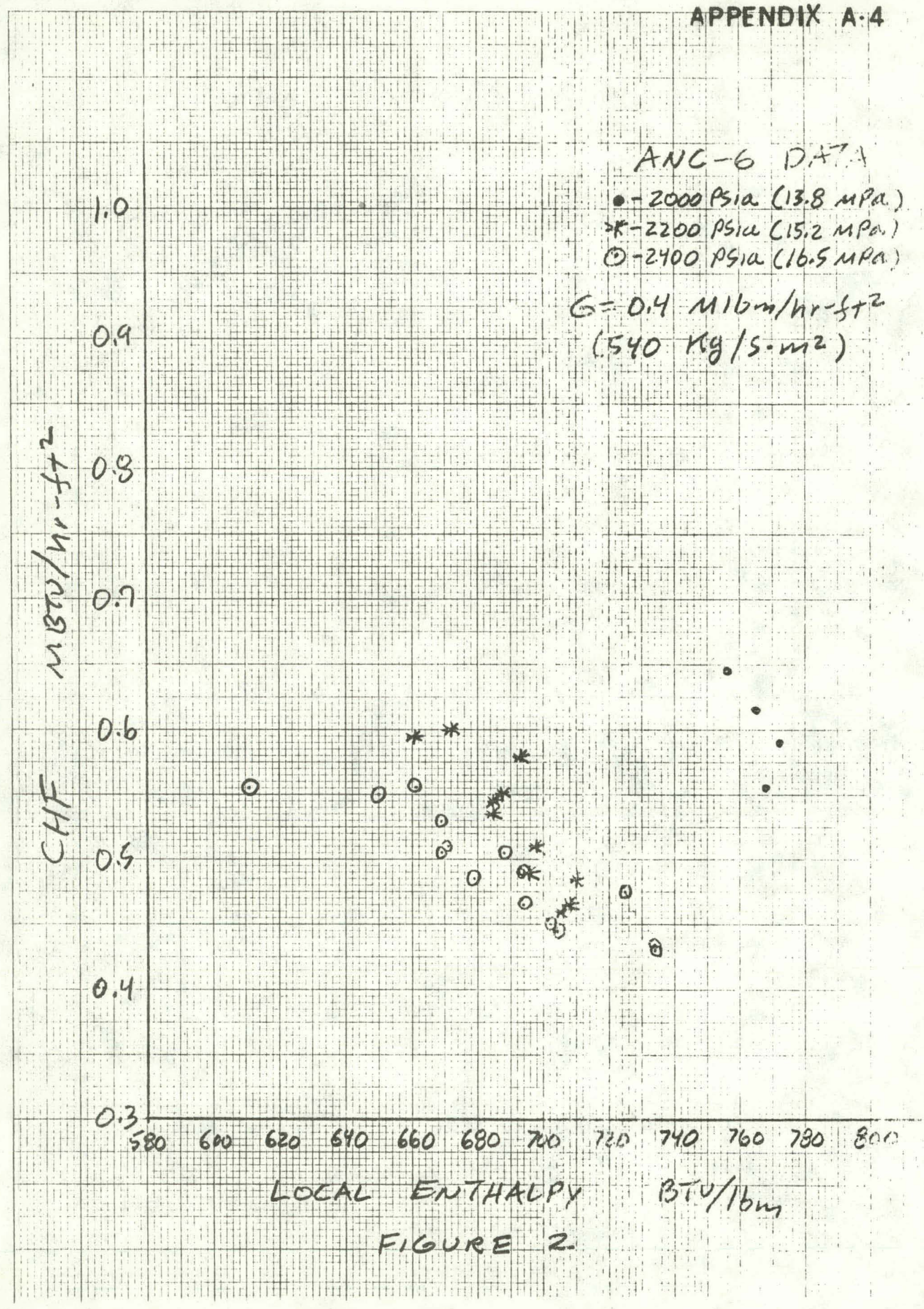




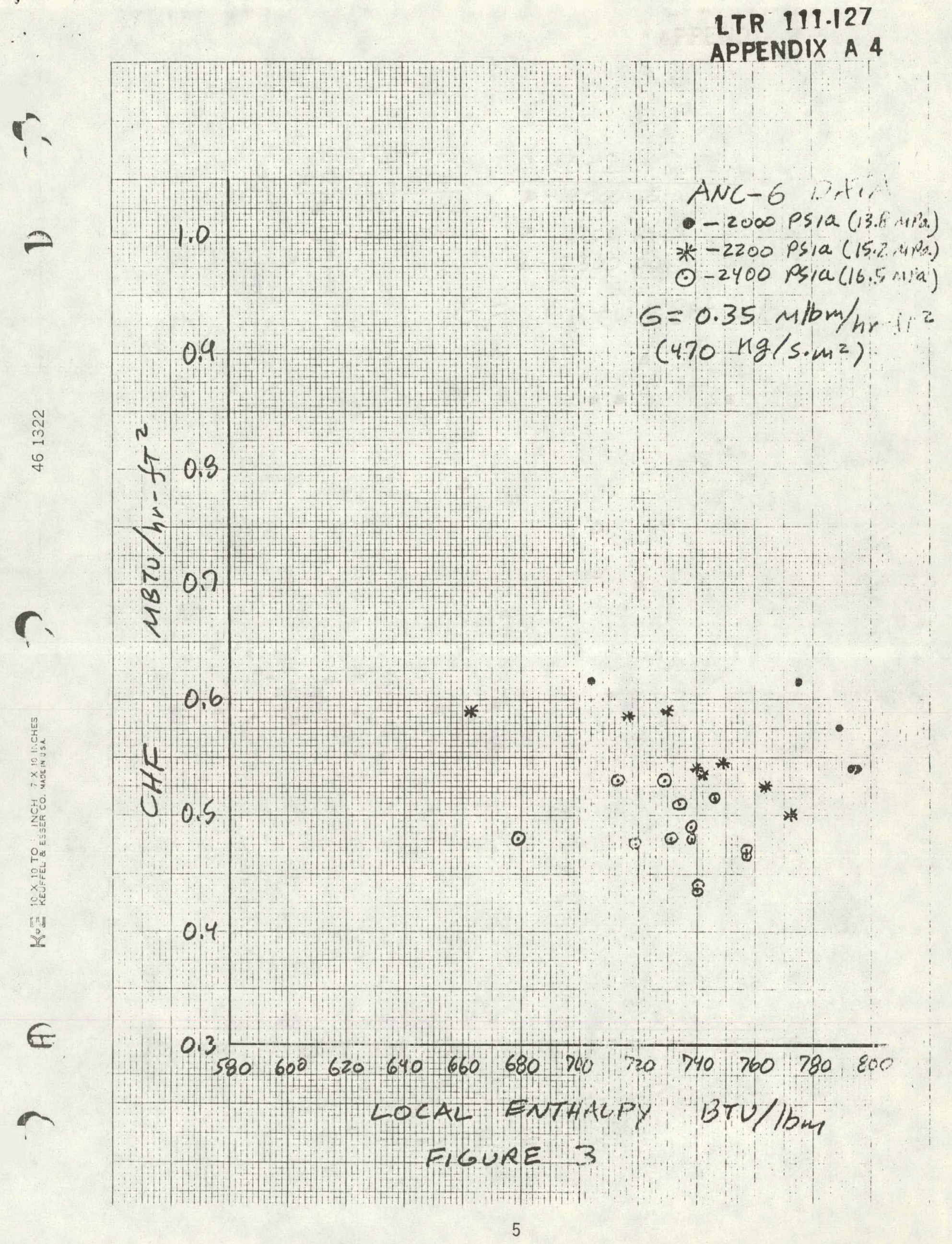




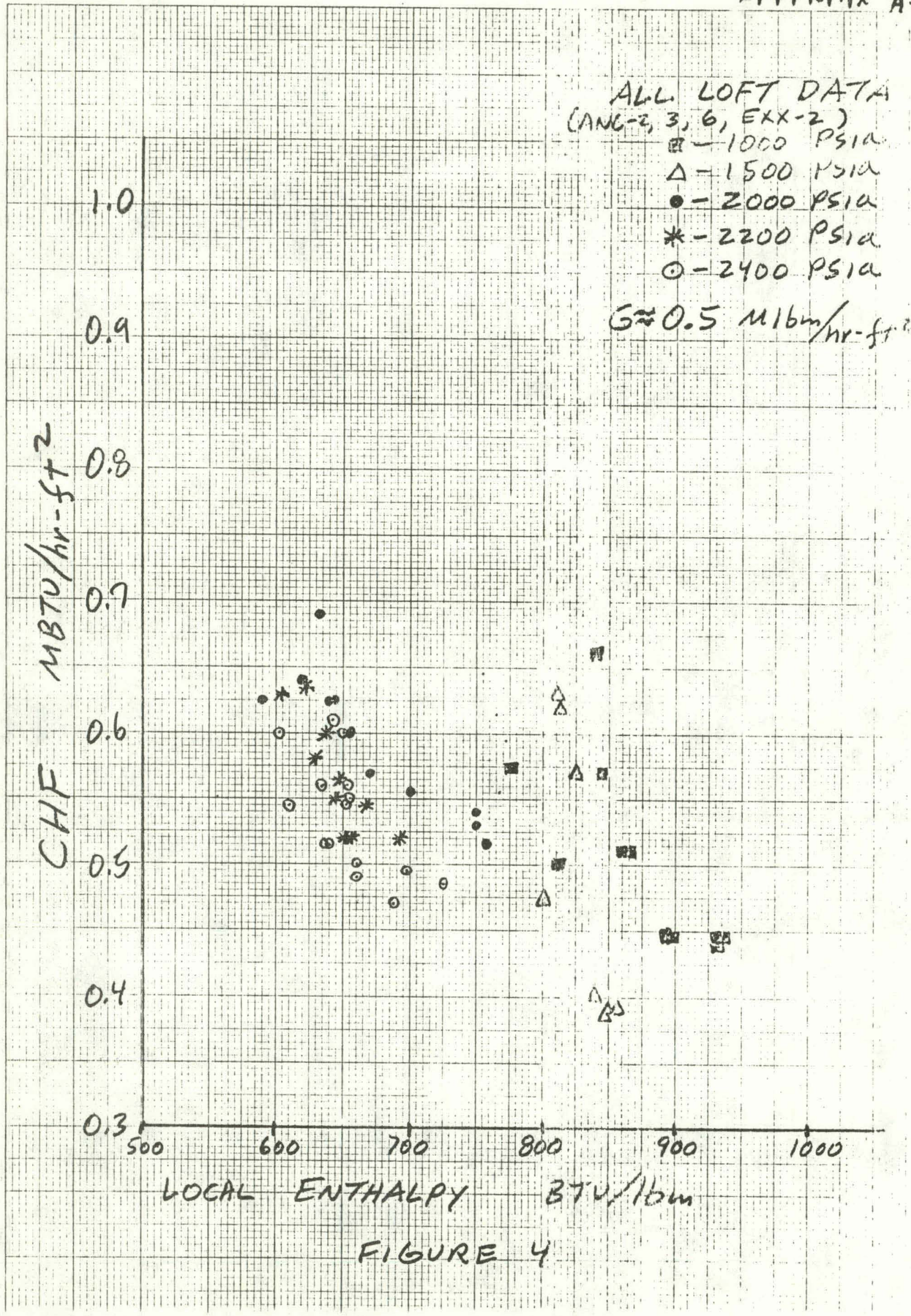


LTR 111.127

APPENDIK A.4

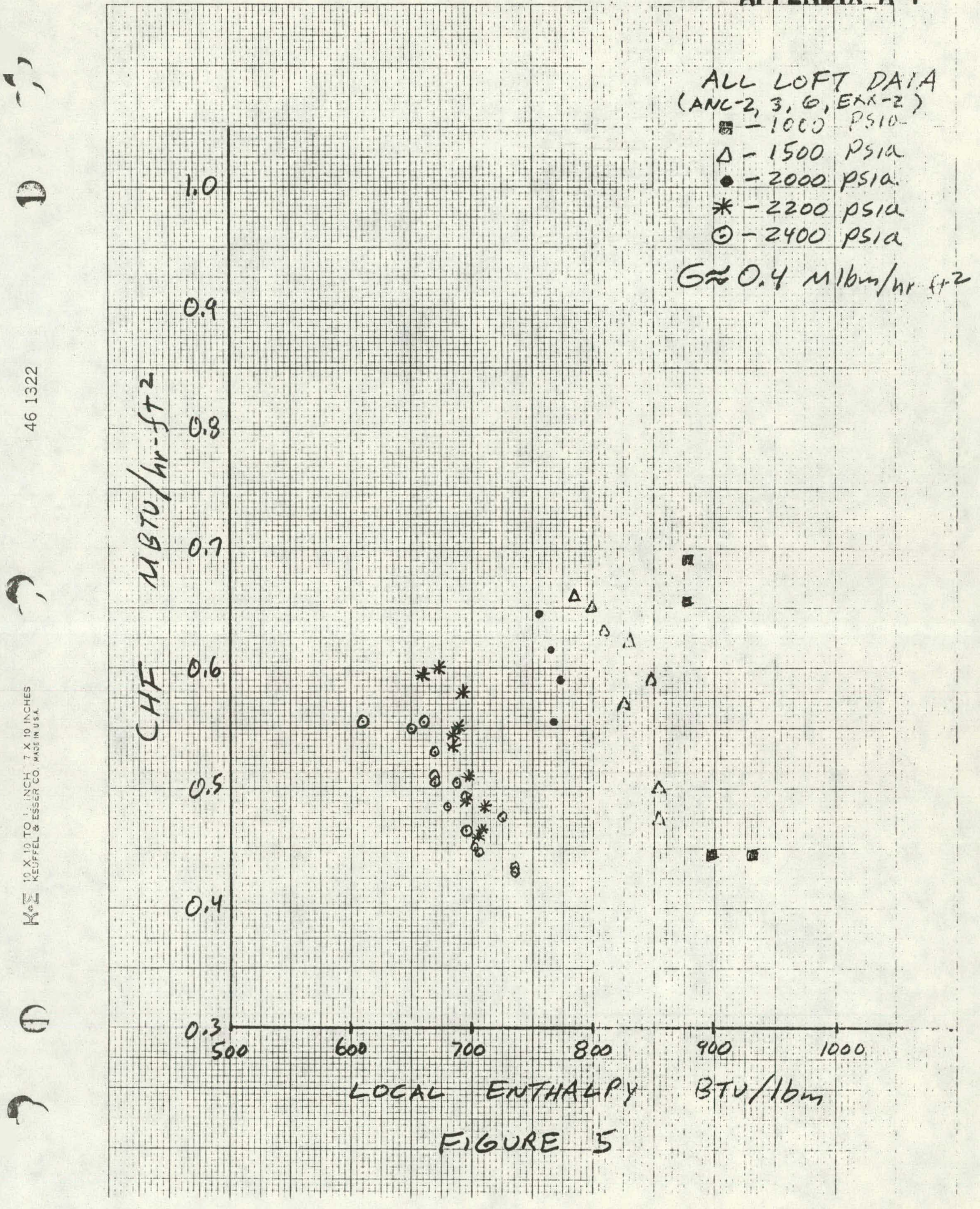

7 
LP" $11301<1$
APPENDIR A.4

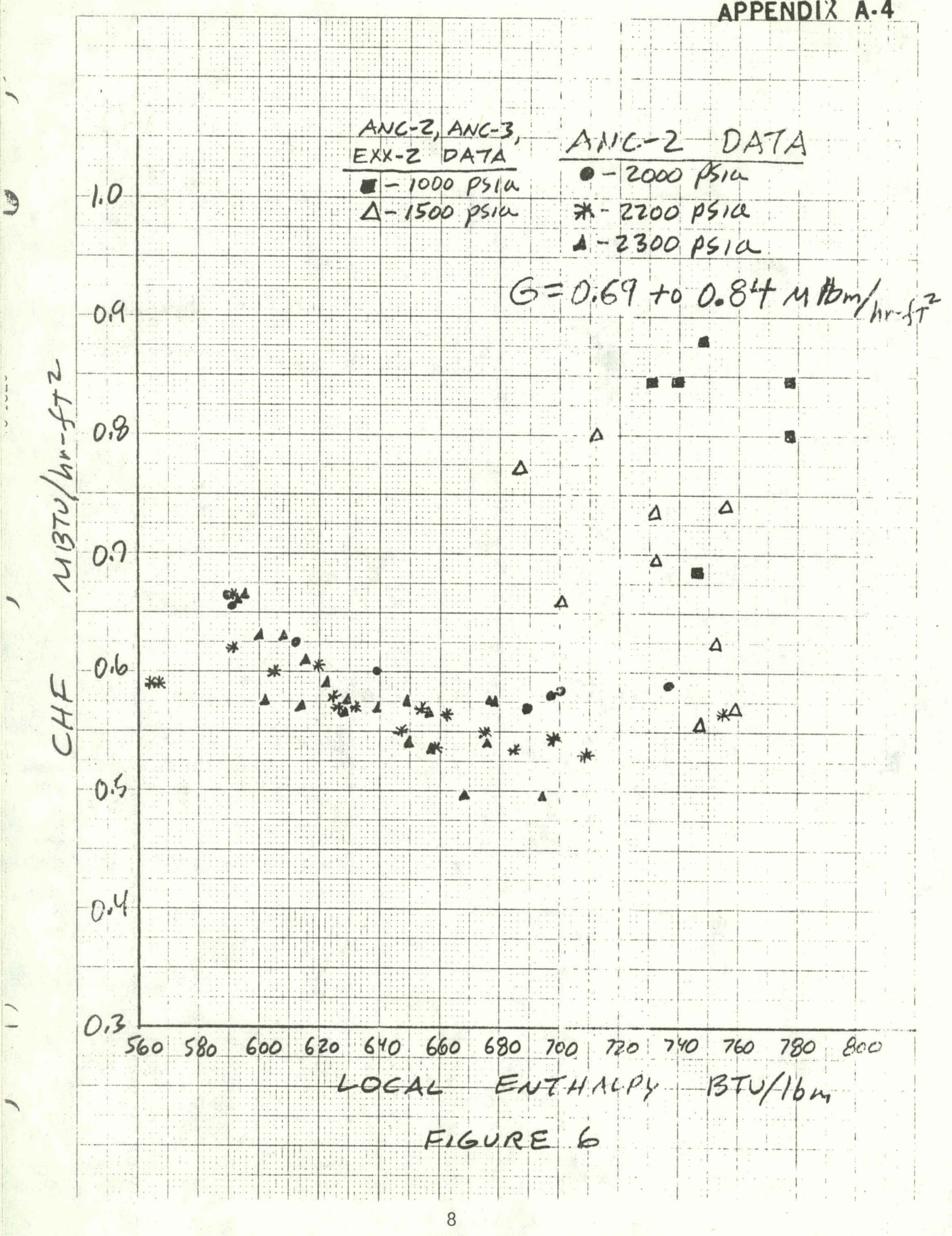




\section{LTR III-IZI APPENDIX A.4}

1

3

ANC-6 DATA

- 2000 psia

* - 2200 psia

0 - 2400 psia

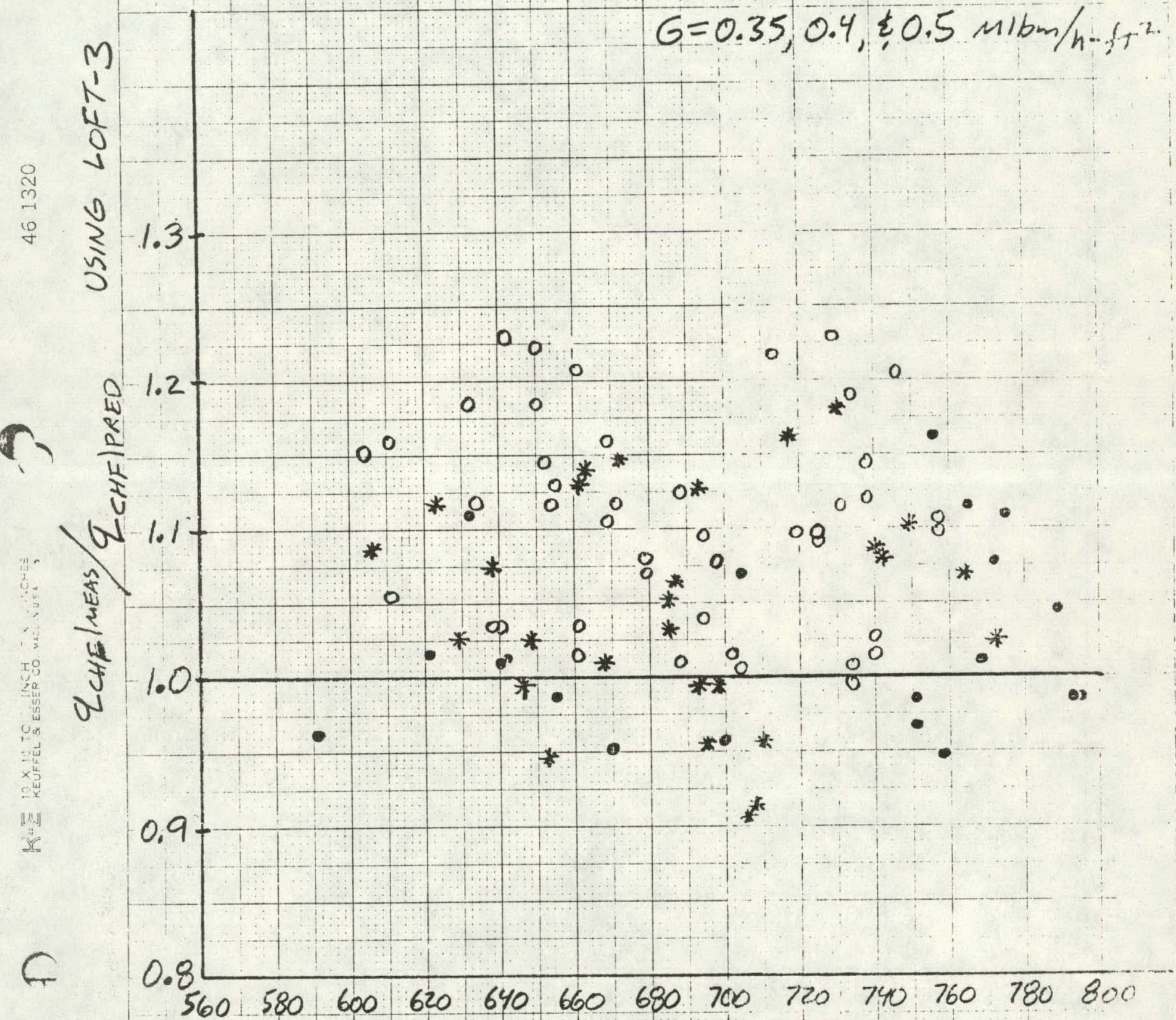

$\begin{array}{llllllllllllll}560 & 580 & 600 & 620 & 640 & 660 & 680 & 700 & 720 & 740 & 760 & 780 & 800\end{array}$ LOCAL ENTHALPY BTULIbM

FIGURE ? 


\section{LTR 111.127 \\ APRENDIX A.4}

$$
\begin{aligned}
& \text { ANC-2 DATA } \\
& \text { - } 2000 \text { PSI a } \\
& \text { * }-2200 \text { PSII- } \\
& \text { - } 2300 \text { PSIa } \\
& G=0,69+0.0 .83 \mathrm{M} / \mathrm{bm} / \mathrm{h}-f t^{2}
\end{aligned}
$$

$M$
J

3. 1.3

s



क्षे

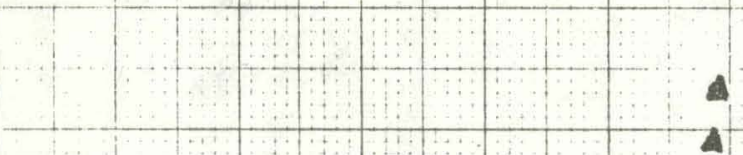

1.0

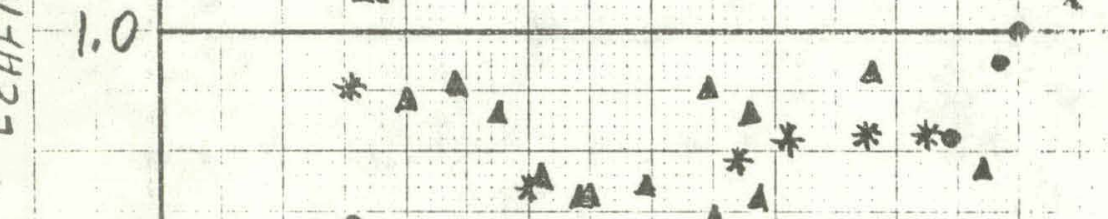

0.9

0.9

$* 4 * * * *$

$\begin{array}{llllllllllllll}560 & 580 & 600 & 620 & 640 & 660 & 680 & 700 & 720 & 740 & 760 & 780 & 800\end{array}$

LOCAL ENTHALPY BTU/1bM

FIGURE 8 


\section{L2-3 MODERATOR AND DOPPLER REACTIVITY FEEDBACK COEFFICIENT SPREAD}

The safety analyses for the LOFT FSAR, zero power physics, and power range testing assumed the following values for the moderator and Doppler reactivity feedback coefficients ${ }^{[a]}$ :

$\begin{array}{lcc} & \text { High Value } & \text { Low Value } \\ \text { Moderator Coefficient } & 9.1 \times 10^{-3} \Delta \rho / 1 \mathrm{bm} / \mathrm{ft}^{3} & 2.0 \times 10^{-3} \Delta \rho 1 \mathrm{bm} / \mathrm{ft}^{3} \\ \text { Doppler Coefficient } & -1.52 \times 10^{-5} \Delta \rho /{ }^{\circ} \mathrm{F} & -0.30 \times 10^{-5} \Delta \rho /{ }^{\circ} \mathrm{F}\end{array}$

Either the high or low value of coefficient, whichever was most limiting for the accident being analyzed, was assumed. However, based on moderator temperature and power coefficient measurements taken during zero power and power range physics testing, it appears that it is possible to reduce the conservative spread in these coefficients used in the safety analyses.

From power range physics testing, the following coefficients were measured:

$\%$ Ful1 power

Average core temperature $\left({ }^{\circ} \mathrm{F}\right)$

PCS boron concentration

Moderator temperature coefficient $\left(\$ /^{\circ} \mathrm{F}\right)$

Power coefficient ( $\phi / \%$ power $)$
30

533

1096

2.56

2.29
50 .

537

970

3.01

2.28
75

541

861

2.59

1.99

For 2250 psia pressure and for the range of average temperatures for the measurements, the change in moderator density per change in moderator temperature is (for water) $0.0631 \mathrm{bm} / \mathrm{ft}^{3} /{ }^{\circ} \mathrm{F}$. The measured moderator temperature coefficients can be converted to the moderator density coefficient used for LOFT safety analysis using the above conversion factor. For LOFT, $\beta=0.00725$. Therefore, the power range measured moderator density coefficients are: 
Average core temperature $\left({ }^{\circ} \mathrm{F}\right)$

PCS boron concentration 1096

970

361

Moderator density coefficient $\left(\Delta \rho / 1 \mathrm{bm} / \mathrm{ft}^{3}\right)$

$2.94 \times 10^{-3} \quad 3.46 \times 10^{-3} \quad 2.98 \times 10^{-3}$

The moderator coefficients measured during the zero power physics tests are discussed in Reference (b). The measured range of moderator density coefficients for power range testing was $2.9 \times 10^{-3}$ to $3.5 \times 10^{-3} \Delta \rho / 1 \mathrm{bm} / \mathrm{ft}^{3}$. For the zero power physics tests, for the same range of moderator temperature $\left(530\right.$ to $\left.540^{\circ} \mathrm{F}\right)$ the moderator density coefficient varies from 0.37 to $0.42 \$ / 7 \mathrm{bm} / \mathrm{ft}^{3}$ or $2.7 \times 10^{-3}$ to $3.1 \times 10^{-3} \Delta \rho / 1 \mathrm{bm} / \mathrm{ft}^{3}$ for a boron concentration of approximately $1500 \mathrm{ppm}$.

Predicted reactivity coefficients were calculated and reported in LTR 111-52(c). For a moderator temperature of $540^{\circ} \mathrm{F}$ and a boron concentration of $1100 \mathrm{ppm}$ (above that existing during power range testing), the predicted moderator coefficient is $3.8 \times 10^{-3} \Delta \rho / 7 \mathrm{bm} / \mathrm{ft}^{3}$ (from Figure A-5-1). The coefficient becomes larger for lower boron concentration. Therefore, it is seen that the increased coefficients are 9 to $27 \%$ smaller than the predicted coefficients in LTR 111-52. Therefore, the use of the values from LTR 111-52 should be sufficient as a high value for the moderator coefficient. Especially since the LTR 111-52 values are for the rods all the way out (withdrawn), and thus should be low values.

The range of boron concentration in the coolant or moderator for L2-3 operation. is predicted to be 600 to $1000 \mathrm{ppm}$. The moderator temperature will be high for L2-3 Mode 8 operation. Figure 8 of LTR 111-52 shows that both these conditions (low boron concentration, high temperature) result in higher values for the moderator coefficient. For $600 \mathrm{ppm}$ boron concentration and $584^{\circ} \mathrm{F}$ moderator temperature (average reactor coolant temperature or $T_{a v e}$ ), Figure 8 of LTR 111-52 predicts a moderator temperature coefficient of $-41.5 \times 10^{-5} \Delta \rho /{ }^{\circ} \mathrm{F}$, or a density coefficient of $6.5 \times 10^{-3} \Delta \rho / 1 \mathrm{bm} / \mathrm{ft}^{3}$. This value can be taken as the maximum value for moderator coefficient for L2-3 Mode 8 operation, even if boron concentration should be as low as $500 \mathrm{ppm}$. For $500 \mathrm{ppm}$, the density coefficient would be $6.76 \times 10^{-3} \Delta \mathrm{p} / 1 \mathrm{bm} / \mathrm{ft}^{3}$, only $4 \%$ greater, and power range measurements showed that the actual coefficients are 9 to $27 \%$ less than calculated. 
For low moderator temperature for power operation, $500^{\circ} \mathrm{F}$, a moderator density coefficient from the zero power physics tests was $0.277 \$ / 1 \mathrm{bm} / \mathrm{ft}^{3}$ or $2.0 \times 10^{-3} \Delta \mathrm{p}$ $11 \mathrm{bm} / \mathrm{ft}^{3}$, equal to the low FSAR value. But, this value is lower than reasonable for L2-3 operation. The minimum moderator coefficient measured during power range testing was $2.94 \times 10^{-3} \Delta \rho / 1 \mathrm{bm} / \mathrm{ft}^{3}$. Since this value was for a boron concentration higher than likely for L2-3 operation, and for a temperature lower than likely for $\mathrm{L} 2-3$ operation $\left(533^{\circ} \mathrm{F} \mathrm{T}_{\text {ave }}\right)$, then it should be reasonable to use this value as a minimum for $12-3$ operation. If the minimum power range value is reduced by an extra $10 \%$, it becomes $2.6 \times 10^{-3} \Delta \mathrm{p} / 1 \mathrm{bm} / \mathrm{ft}^{3}$. This was the value chosen as a minimum for the L2-3 safety analyses.

A Doppler coefficient can be derived from the measured power coefficients. The full power MLHGR is approximately $19 \mathrm{Kw} / \mathrm{ft}$. A $1 \%$ power change therefore represents an increase in MLHGR of approximately $0.2 \mathrm{Kw} / \mathrm{ft}$. From previous calculations for LOFT fuel pin temperatures using FRAPS ${ }^{[d]}$, for a change in MLHGR from $16 \mathrm{Kw} / \mathrm{ft}$ to $16.2 \mathrm{Kw} / \mathrm{ft}$ (a $0.2 \mathrm{kw} / \mathrm{ft}$ change), the change in fuel temperature is approximately $30^{\circ} \mathrm{F}$. Using an equivalence of $30^{\circ} \mathrm{F}=1 \%$ power change, then the power range measured Doppler coefficients are (for $\beta=0.00725$ ):

\% Full power $\quad 30 \quad 50 \quad 75$ Doppler coefficient $\left(\Delta \rho /{ }^{\circ} \mathrm{F}\right)-0.55 \times 10^{-5}-0.55 \times 10-0.63 \times 10^{-5}$

From LTR 111-52 for hot reactor conditions and $1313 \mathrm{ppm}$ boron, the predicted Doppler coefficient is $-0.98 \times 10^{-5} \Delta \rho /{ }^{\circ} \mathrm{F}$. The measured coefficients are seen to be significantly smaller than those from LTR 111-52. Therefore, the LTR 111-52 values should be sufficient as a maximum value for Doppler coefficient. Adding an extra $10 \%$ to the LTR $111-52$ (hot reactor) value gives the maximum value used for $L 2-3$ safety analyses, or $-1.08 \times 10^{-5} \Delta \rho /{ }^{\circ} \mathrm{F}$. A minimum value for the Doppler coefficient was derived by reducing the minimum power range testing vaiue by $20 \%$ to obtain $0.44 \times 10^{-5} \Delta \rho /{ }^{\circ} \mathrm{F}$. 


\section{LTR 111.127 \\ APPENDIX A. 5}

In conclusion, for the L2-3 safety analyses, the following spread (maximum and minimum) values were used for moderator density and Doppler reactivity feedback coefficients:

Maximum Minimum
Moderator density coefficient
$\left(\Delta \rho / 1 \mathrm{bm} / \mathrm{ft}^{3}\right)$
$6.5 \times 10^{-3}$
$2.6 \times 10^{-3}$
Doppler coefficient $\left(\Delta \rho /{ }^{\circ} \mathrm{F}\right)$
$-1.08 \times 10^{-5}$
$-0.44 \times 10^{-5}$ 


\section{REFERENCES}

[a] LOFT Integral Test System Final Safety Analys is Report, Revision 1, (August 1977), Section 15.2.2.3

[b] B. L. Rushton and T. M. Howe, Comparison of LOFT Zero Power Physics Testing Measurement Results with Predicted Values, LTR 1T1-107 (June 26, 1978).

[c] A. J. Scott, Temperature Coefficients and Boron Worth for LOFT I at Beginning of Life, LTR 111-52, (August 31, 1973)

[d] S. A. Eide, Fuel Melting Limitations on Power for Various Control Rod Withdrawals - 0 to 2000 EFPH, LTR 1171-21, Rev. I (June 1977). 


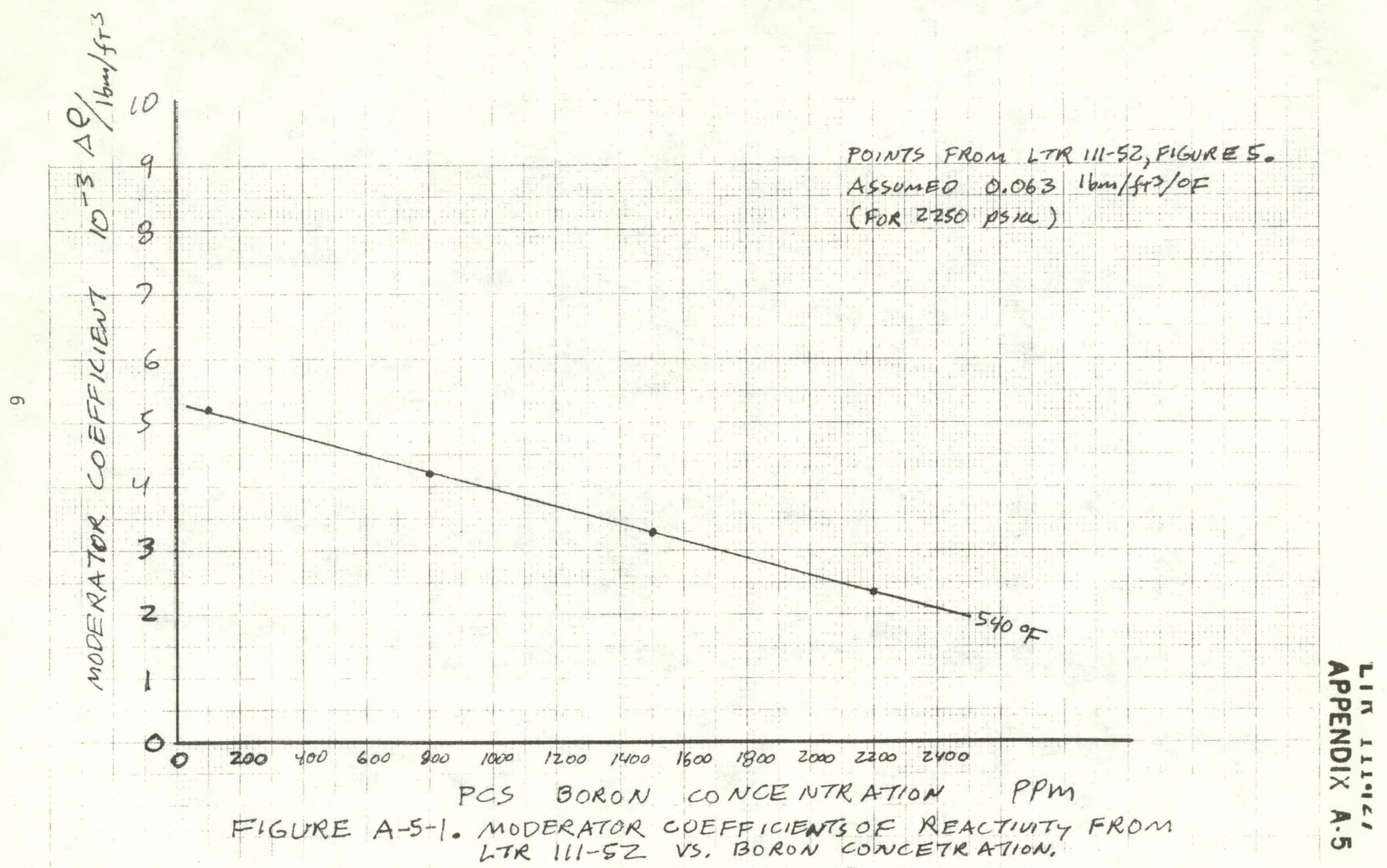


APPENDIX A-5

L2-3 MODERATOR AND DOPPLER REACTIVITY

FEEDBACK COEFFICIENT SPREAD 
APPENDIX $A-6$

POIIER DISTRIBUTION ASSUMPTIONS FOR

L2-2 THERMAL SAFETY ANALYSIS 
S. A. Atkinson

C. H. Cooper

S. A. Eide
N. F. Fausz

R. C. Gottula

S. W. Hills

\title{
INTEROFFICE CORRESPONDENCE
}

\author{
date May 8, 1978 \\ 10 T. M. Howe and R. A. Dimenna \\ Irom D. F. Elger S.Qlutteinson for $D_{1}, E$ : \\ subject POWER DISTRIBUTIONS FOR L2-1 and L2-2 THERMAL SAFETY ANALYSIS - \\ DFE-1-78
}

references a) S. A. Eide and R. C. Gottula, Evaluation and Results of LOFT Steady State Departure from Nucleate Boiling Tests, TREE-NUREG1043, (Aprit 1977).

b) L. S. Tong, Boiling Crisis and Critical Heat Flux, Oak Ridge, Tennessee: USAEC Technical Information Center, 1972.

The intention of this letter is to discuss the core thermal power distributions used for DNB analysis. The letter is separated into three parts: (a) Power profile influence on calculated DNBR, (b) Incorporating power profiles into COBRA and $(c)$ Uncertainties applied to the power profile. These three parts are included as an attachment.

For ESA work, DNBR is defined at an axial location of a fuel rod as:

$$
\text { DNBR }=\frac{q^{\prime \prime} \text { DNB }}{q^{\prime \prime}{ }_{\text {LOC }} \cdot F_{f}}
$$

q"DNB, the DNB heat flux, is defined as the heat flux which will produce DNB at that location. It is a function of local fluid conditions surrounding the fuel rod and is calculated using the LOFT-1 correlation (Ref. a). Specifically, DNB heat flux is a function of local mass flux, local equilibrium quality and system pressure.

q"LOC is the local heat flux at the axial location of the fuel rod.

$F_{f}$ "is the Tong nonuniform flux factor. (Ref. 'b). The LOFT DNB correlation is based on data obtained from uniformly heated fuel rod models. The nonuniform flux factor is to account for the nonuniform power profiles encountered under reactor conditions. Typical values range from 1.01 to 1.06 .

jh

Attachment: As stated 
Attachment to

DFE- $1-78$

May 8, 1978

Page 1 of 5

\section{LTR III.127 \\ APPENDIX A. 6}

Part I - Power Profile Influence on Calculated DNBR

In the DNBR calculation, the power profile will influence local mass flux, the Tong nonuniform flux factor, equilibrium quality and local heat flux. Power profile influence on local mass flux and the Tong nonuniform flux factor will not be considered in this letter.

In order to provide flexibility to meet desired $L 2-1$ and $L 2-2$ test conditions, thermal analysis is done as a function of the power profile peak-to-average ratio, $\mathrm{F}_{\mathrm{Q}}$.

For nominal L2-2 conditions the predicted value of peak-to-average is $2.43(1)$. The intention of this letter is to establish criteria for characteristics of a conservative power profile as a function of $F_{Q}$. Clearly the most limiting power profile at a given $F_{0}$ is the profile which produces the highest value of equilibrium quality and local heat flux at the point of MDNBR. Equilibrium quality increases as more heat is deposited in the coolant up to the point of MDNBR.

There are two criteria which influence the value of equilibrium quality at a given $F_{0}$ at the point of MDNBR. The first criteria is the location of the power peak. ONBR typically occurs a short distance following the power peak. As the location of the power peak moves down the core (towards the core exit) the value of equilibrium quality at the point of MDNBR increases. Thus, MDNBR decreases and so the power profile which peaks farthest down stream in the core is the most conservative. An analys is of predicted power profiles which could occur in L2-1, L2-2 or under high flow conditions shows that the farthest down stream in the core a power profile peaks is 25.5 inches ( 7.5 inches below core midplane). Note: These profiles are found in References 1,2 and 3 . So, all power profiles used for ESA had the peak power located at 7.5 inches below core midplane. Additionally, as an added conservatism, the peak heat flux is assumed to be flat between 25.5 and 27 inches.

The other criteria which influences equilibrium quality also influences the local heat flux at the point of MDNBR. This criteria is the shape of the axial power profile. As a power profile becomes flatter, at a given $F_{Q}$, the values of equilibrium quality and local heat flux increase. Thus, at a given $F_{Q}$, flatness is the criteria for a conservative power profile.

Choice of a flat axial power profile, for a given value of $F_{Q}$, is based on using a high value of the hot channel enthalpy rise factor, $F_{\Delta H}$. $F_{\Delta H}$ is defined as the integral of the hot fuel rod power divided by the integral of the average fuel rod power. Assuming separability of radial and axial power shapes, $F_{\Delta H}$ has the same value as the power peaking in the radial direction. Raising the value of $\mathrm{F}_{\Delta H}$ is done by simply scaling a predicted power profile.

A high value of $F_{\Delta H}$ insures a flat axial power profile because of the following: The value of $F_{\Delta H}$ is equivalent to the value of radial peaking. Thus, the total peaking, $F_{Q}$ is equal to the product of $F_{\Delta H}$ and the axial peaking, $F_{Q}=F_{\Delta H} \cdot F_{Q} A_{x}$. Therefore, at a fixed value of $F_{Q}$ a high value of $F_{\Delta H}$ means a low value of $F_{Q} A x$. And as the axial peaking, $F_{Q} A_{x}$, decreases the axial power profile will flatten out. 


\section{LTR 111.127 Attachment to \\ APPENDIX A.6 May 8 , 1978 \\ Page 2 of 5}

Another viewpoint is that $F_{\Delta H}$, as previously defined, is approximately equal to enthalpy rise in the hot subchannel divided by core average enthalpy rise. Thus, as $F_{\Delta H}$ increases, more heat is dumped into the hot subchannel. At a fixed $F_{0}$, this additional heat could only be explained by higher relative power densities along the axial power profile. This is equivalent to flattening out the axial power profile. The nominal power profile has a value of $F_{\Delta H}=1.53$. An analys js of many predicted power profiles showed that $F_{\Delta H}$ never exceeded a value of $1.6(4)$. Thus all power profiles used in analysis had value of $F_{\Delta H} \geq 1.6$.

For ESA the range of peaking analyzed is $2.3 \leq F_{0} \leq 2.78$. Four profiles were used to cover this range. The profiles were chosen on the basis of location of the power peak ( $7.5^{\prime \prime}$ below core midplane) and the value of $F_{0}$ for that profile (not on the basis of the conditions for which they were generated). All profiles were then scaled such that $F_{\Delta H}=1.6$ with the exception of the profile for $F_{Q}=2.78$. This profile has a $F_{\Delta H}=1.64$. The actual power profiles which were used are:

\begin{tabular}{|c|c|c|c|}
\hline Case & $\mathrm{F}_{\mathrm{Q}}$ & $\mathrm{F}_{Q}{ }^{\mathrm{AX}}$ & $F_{\Delta H}$ \\
\hline 2000 EFPH High Flow (3) & 2.3 & 1.44 & 1.6 \\
\hline 1000 EFPH High Flow (3) & 2.43 & 1.52 & 1.6 \\
\hline $\operatorname{Li012}(1)$ & $2: 63$ & 1.64 & 1.6 \\
\hline L $1020(2)$ & 2.78 & 1.70 & 1.64 \\
\hline
\end{tabular}

In summary, the choice of a conservative power profile at a given $F_{Q}$ is met by using two criteria. The criteria are: 1) the location of the power peak is 7.5 inches below core midplane and 2) a value of $F_{\Delta H} \geq 1.6$.

\section{Part II - Incorporating Power Profiles Into COBRA}

DNB analysis is done using the computer code COBRA to predict reactor coolant conditions. Then the computer code "DNBR" is used to calculate MDNBR. (This is now called as a subroutine to COBRA). The description of the model used in COBRA is discussed in Reference 5.

In the COBRA model, subchannel number 15 is the subchannel with the most limiting fluid conditions $(6)$. This means that the DNB heat flux, q"DNB, is lower in subchannel 15 than in any other subchannel at typical MDNBR locations. A sketch of this subchannel and a few surrounding subchannels is shown in Figure 1. Subchannel 15 is composed of three fuel rods and one guide tube. Based on physics predictions fuel rod number 13 is the hottest fuel rod. Because this fuel rod does not occur in channel number 15, fuel rod number 20 is artificialiy raised in power to become the hottest fuel rod. Thus, the most limiting subchannel in terms of fluid conditions is combined with the hottest fuel rod.

Power profile input into COBRA is done in an axial relative power vs relative location table, and as a radial relative rod power factor for each fuel rod. 
For ESA all radial factors are 1.0 (flat radial assumption) and the radial and axial contributions to the power shape are combined in the axial heat flux table. An exception is the fuel rods forming subchannel number 15 . The radial factors for these subchannels are greater than 1.0 to allow for uncertainties, as described in Part III of this letter.

All fuel rods in the model have the same axial power shape. The power shape used for a given $F_{Q}$ is the predicted hot pin power profile scaled such that $\mathrm{F}_{\Delta H} \geq 1.6$.

The values of relative power density which go into COBRA are found from physics data in the following manner. The predicted hot pin power profile is plotted as a function of distance. Data points are taken from the center of each calculation block. Then a smooth curve is drawn through these points and from this curve the axial heat flux table for COBRA input is found. The location of the peak is stretched over a distance of at least 1.5 inches.

In the COBRA model, the core thermal power is distributed as follows: $95.09 \%$ of the core thermal power is deposited in the fuel rods, $2.29 \%$ is deposited in the coolant directly and $2.62 \%$ is depgsited in the core support structures, reflectors and other core materials $(7)$.

Part III - Uncertainties Applied to the Power Profile

The uncertainties and conservatisms applied to the power profile are divided into two groups: (1) Factors influencing the local heat flux at the point of MONBR and (2) factors influencing equilibrium quality at the point of MDNBR.

Factors which influence the local heat flux are local factors. That is, they are only applied to the local heat flux at the point of MDNBR. So these factors are used only to calculate the DNBR and they have no effect on the DNB heat flux value. Thus, they are used only to calculate MDNBR.

Since equilibrium quality is a function of enthalpy rise in the hot subchannel, factors effecting equilibrium quality are applied over the full length of the hot subchannel. These factors are only used in COBRA for calculation of the DNB heat flux. Typically, these factors are applied by increasing the heat flux along the full length of the three rods forming the hot subchannel. . Sometimes the factors are applied only to the hottest fuel rod in the hot subchannel.

The conservatisms applied to the local heat flux are:

1. FU: Uncertainty on the value of the peak to average ratio. The LOFT reactor safety limits for L2 pre-LOCE operation are to be set on the basis of a measured $P / A$ ratio. This uncertainty makes an allowance for measurement and calculational errors in the determination of the $P / A$ ratio. It has a value of $7 \%(8)$.

2. $F_{Q} E$ : Engineering hot spot factor. This factor has a value of $3.2 \%$ and is to account for possible heat flux increases due to manufacturing variations. It is determined statistically from data on fuel pellet manufacturing tolerances for fuel enrichment, fuel density and fuel pellet diameter. The value of $3.2 \%$ represents a probability limit of three standard deviations. (9) 


\section{LTR 111.127 Attachment to APPENDIX A 6 DFE- $1-78$ \\ May 8,1978 \\ Page 4 of 5}

3. $F_{0}{ }^{D}$ : Densification hot spot factor. This factor takes into account increase in local heat flux due to densification induced fuel stack shortening. Credit is then taken for thermal expansion $(5)$. The value of this factor is $1.1 \%$.

The conservatisms which are applied to the hot subchannel which effect the value of equilibrium quality are:

1. $F_{\Delta H} U$ : Hot channel enthalpy rise uncertainty factor. The factor is to account for measurement and calculational errors in the determination of the hot channel enthalpy rise. It has a value of $7 \%$ and is applied to the three fuel rods which form the hot subchannel $(8)$.

2. $F_{\triangle} H^{E}$ : Engineering hot channel factor. This factor takes into account manufacturing variations in average pellet density, enrichment and diameter between fuel rods. However, the required data base is not available for the LOFT fuel assemblies. So as recommended in Reference 10, the engineering hot spot factor, a local uncertainty of $3.2 \%$, is applied over the fuel length of the hot fuel rod. The application of a local engineering factor as an integral uncertainty to three fuel rods would be overly conservative.

Westinghouse reports values of the engineering hot spot factor and hot channel factor of $3 \%$ and $1.0 \%$, respectively. (8) By comparison, it would be expected that the engineering hot channel factor for the LOFT reactor would be approximately $1 \%$. The approach used for ESA is roughly equivalent to applying a $1 \%$ factor to all three fuel rods forming the hot subchanne1. Thus, the approach used is reasonable.

3. $\mathrm{F}_{\mathrm{H}} \mathrm{D}$ : Densification enthalpy rise factor. A factor of $1.1 \%$ is applied to the full length of the three fuel rods forming the hot subchannel. This factor is to account for increased energy deposition in the hot subchannel due to increased linear power caused by densification induced fuel stack shortening. (5) Credit is taken for thermal expansion.

Two additional conservatisms used in DNB analysis as discussed earlier are the use of a flat radial power profile and the use of $F_{\Delta H} \geq 1.6$.

\section{References}

1. E. F. Aber, LOFT Core I:Low Flow Power Distributions as a Function of Control Rod Position, Core Power Level, and Inlet Enthalpy, LTR 117-86 (August 1977).

2. E. F. Aber, LOFT Core I: High Flow Power Distributions as a Function of Control Rod Position and Core Power Level, LTR 111-81 (July 1971).

3. B. L. Rushton, LOFT-I: Results from Three Dimensional PDQ-7 Calculations with Thermal Feedback and Depletion to 2000 EFPH. LTP 111-60 (November 1976).

4. T. M. Howe, Personal Communication, October, 1917.

5. S. W. Hills, Steady State and Transient Analys is of Departure from Nucleate Boiling and Fuel Centerline Temperature for LOFT Core I, LTR 1111-38, (JuTy 1977).

6. R. C. Gottula, Personal Communication, October 1977. 


\section{LTR 111.127 \\ APPENDI: A.6. Attachment to \\ May 8, 1978 \\ Page 5 of 5}

7. T. E. Young, Energy Deposition in the LOFT Reactor at 54.71 MW, LTR 111-58 (August 1974).

8. H. W. Graves, Jr., A Review of Uncertainties Associated with the Evaluation of Peak Linear Power Density and DNB Flux During LOFT Steady State Operation, (December 30,1977 ).

9. R. C. Gottula, LOFT Core Hot-Spot and Hot Channel Factors Due to Fuel Pellet Density, Enrichment, and Diameter Fabrication Tolerances, LTR 1117-19 (May T975). 


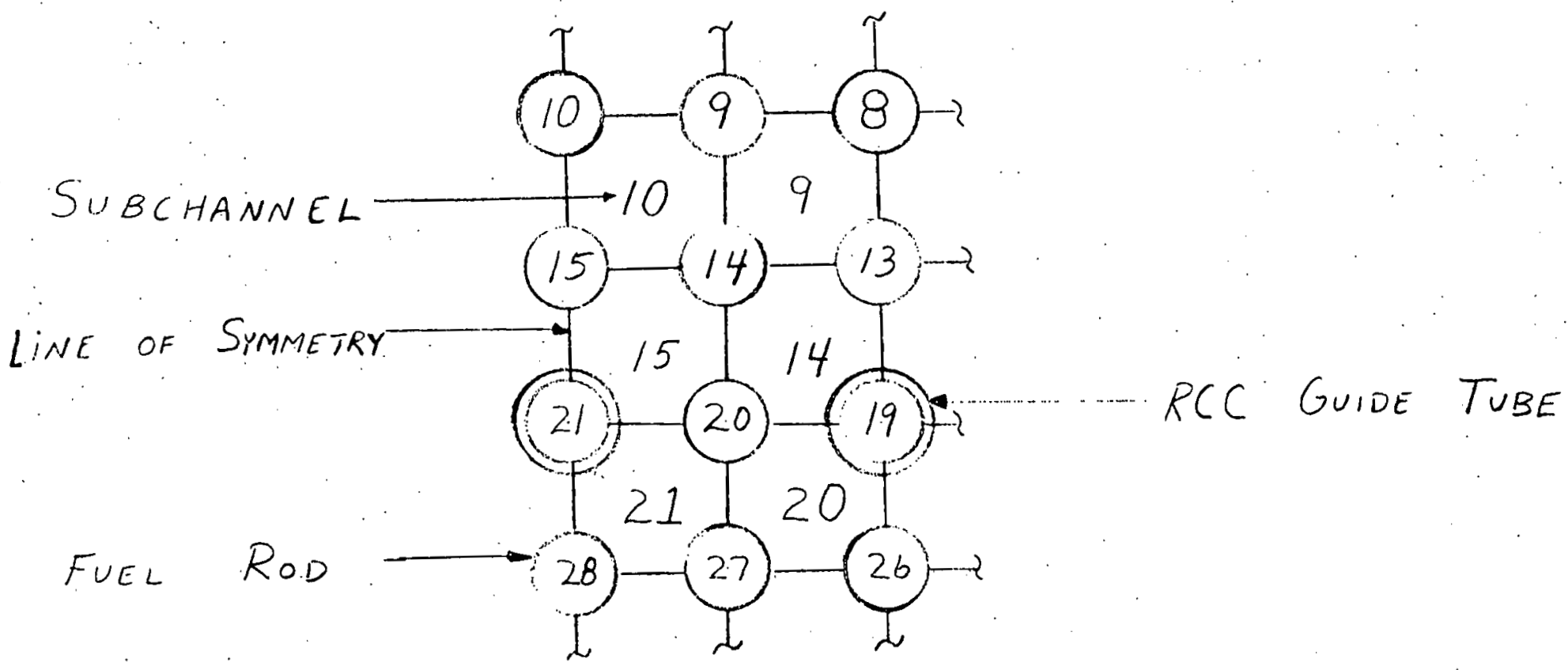

FIGURE 1 SUBCHANNEL $15^{\star}$

* No thenrocouples shown 
APPENDIX A-7

STATISTICAL EVALUATION OF THE LOFT HEAT FLUX ENGINEERING HOT SPOT FACTOR 
cc: B. S. Anderson,

18. A. Atkinsonffild

G. A. Dinneen

D. F. Elger

J. E. Fisher

J. L. Liebenthale
D. G. Satterwhite

R. P. Wadkins Roen

TAB File 3.4

Central File

N. F. Fausz - 2

\section{INTEROFFICE CORRESPONDENCE}

date February 27, 1979

LTR 191.177

to E. C. Anderson

from

N. F. Fausz

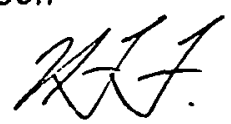

subject

STATISTICAL EVALUATION OF THE LOFT HEAT FLUX ENGINEERING HOT SPOT FACTOR - NFF-1-79

Ref: (a) R. C. Gottula, "LOFT Core Hot Spot and Hot Channel Factors Due to Fuel Pellet Density, Enrichment, and Diameter Fabrication Tolerances", LOFT Technical Report LTR 1111-19, TR-635 (May 21, 1975).

(b) L. S. Tong and S. J. Weisman, Thermal Analys is of Pressurized Water Reactors, Published by American Nuclear Society (1970) pp 239.

(c) S. D. Matthews and J. P. Poloski,."MOCARS: A Monte Carlo Code For Determining Distribution and Simulation Limits and Ranking System Components by Importance", TREE-1138 (Revision 1), August 1978.

The LOFT heat flux engineering hot spot factor $\left(F_{q}{ }^{E}\right)$ has been reevaluated using statistical techniques. The statistical treatment resulted in a value of $F_{q}=1.026$ as opposed to the old value of $F_{q} E=1.032$, Ref. $(a)$.

The old value of $F_{q} E=1.032$ was obtained using the definition of $F_{q} E$ from Ref. (b):

$$
\begin{aligned}
& F_{q} E=\left(W_{\text {Max Local }} / W_{\text {Nom }}\right)\left(e_{\text {Max Local }} / e_{\text {Nom }}\right) \\
& \text { where } \\
& W \equiv \text { Fuel pellet weight per unit lenyth } \\
& e \equiv \text { Fuel pellet enrichment }
\end{aligned}
$$

Subscripts: Max Local = Maximum local value of subscripted quantity Nom = Nominal value of subscripted quantity

The fuel pellet weight per unit length for LOFT was determined from 160 data points, Ref. (b), taken to be normally distributed with a nominal (mean) value of $17.1627 \mathrm{gm} / \mathrm{in}$. and a standard deviation of $0.10742 \mathrm{gm} / \mathrm{in}$. The value for W Max Local was then taken at three standard deviations above nominal. 
Page 2

For the fuel pellet enrichment, only 23 data points were available, and the data does not follow a normal distribution (Figure 1 shows a histogram of the enrichment data and a normal distribution with the same mean $=3.9784$ and standard deviation $=0.017840)$. For that reason, the value of $e_{\text {Max Local was }}$ taken at the upper bound of the manufacturing tolerance limit. The manufacturing tolerance limits for fuel pellet enrichment are $4.0 \pm 0.05$ wt\%. Thus, $\mathbf{e}_{\text {Max Local }}=4.05$. The LOFT heat flux engineering hot spot factor was then obtained as follows:

$$
F_{q}^{E}=\left(\frac{17.1627+3(0.10742)}{17.1627}\right)\left(\frac{4.05}{4.0}\right)=1.032
$$

In the statistical evaluation of $F_{Q} E$, the mean and standard deviation of fuel pellet weight per unit length were determined at the $99 \%$ confidence level (see Attachment 1). The resulting values are

$$
\begin{aligned}
& \mu_{w} \leq 17.1827 \mathrm{gm} / \mathrm{in} . \\
& \sigma_{w} \leq 0.12341 \mathrm{gm} / \mathrm{in} .
\end{aligned}
$$

at the $99 \%$ confidence leve1.

The MOCARS, Ref. (c), computer code was then used to determine the mean and standard deviation of $F_{q}{ }^{t}$ by use of a Monte Carlo technique. As input to MOCARS, the fuel pellet weight per unit length was input as a normal distribution with $\mu_{W}=17.1827$ and $\sigma_{W}=0.12341$. Due to the fact that the 23 fuel pellet enrichment data points were non-normally distributed, the data points were input into MOCARS as an empirical distribution. The MOCARS computer code was then used to perform a Monte Carlo sampling of the function

$$
F_{q}^{E}=\left(W_{\text {Max Local }} / W_{\text {Nom }}\right)\left(e_{\text {Max Loca }} / e_{\text {Nom }}\right) \text {, where }
$$

the values of $W_{\text {Max Local }}$ and $e_{\text {Max Local }}$ were picked from their respective cumulative distribution functions by MOCARS for each sample of $F_{q} E$. A total of 3,000 samples of $F_{q} E$ were used in MOCARS to. determine the sample mean ( $\left.X_{E} E\right)$ and sample standard deviation $\left(S_{F_{q}} E\right)$ of the function. The results of MOCARS for 3,000 samples gave;

$$
\begin{aligned}
& \bar{X}_{F_{q}}=0.9995 \\
& S_{F_{q} E}=0.00838 .
\end{aligned}
$$


E. C. Anderson

February 27, 1979

NFF $-1-79$

Page 3
LTR 111.127

APPENDIX A.7

Figure 1

ENRICHMENT DATA

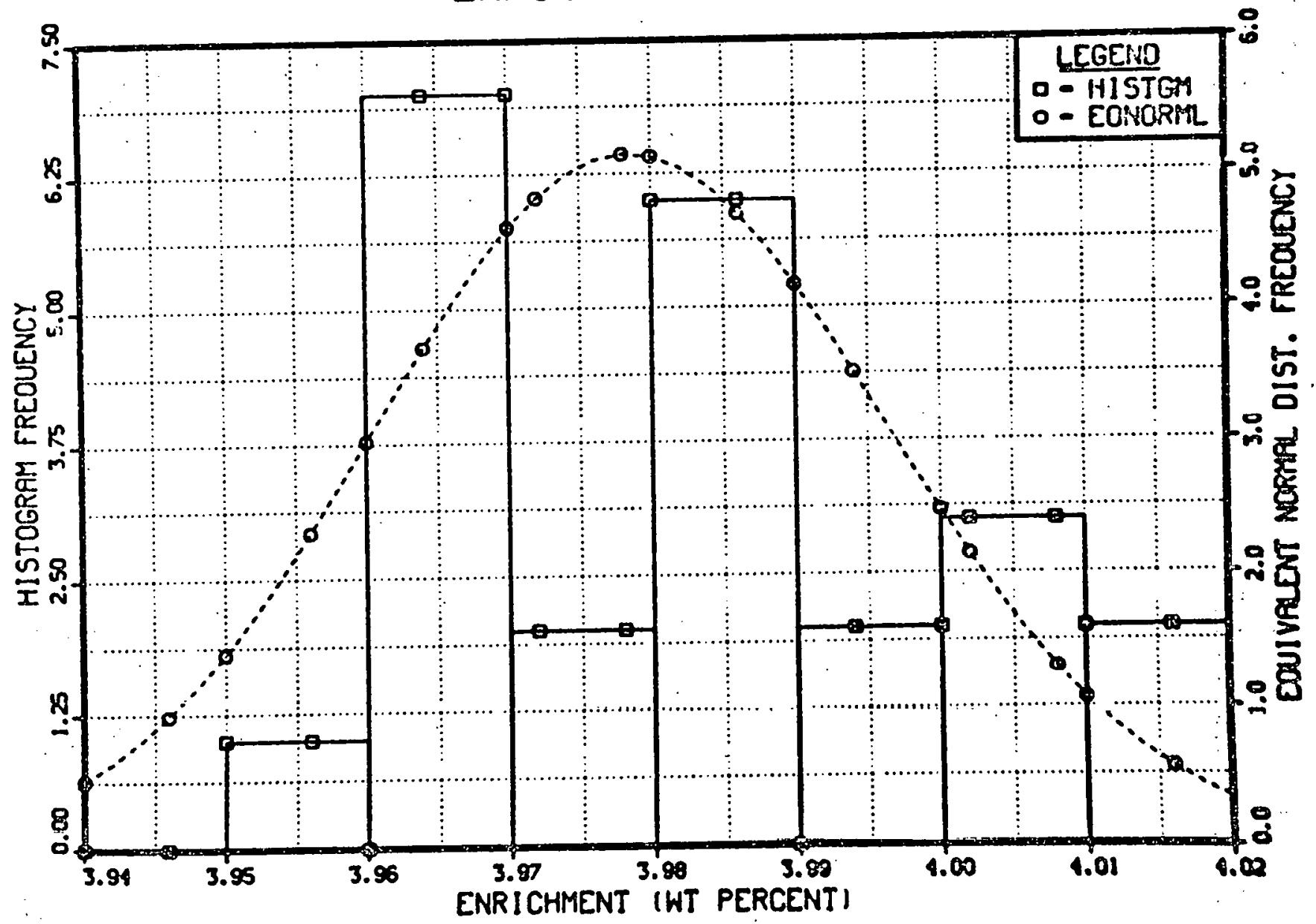


E. C. Anderson

February 27, 1979

NFF $-1-79$

Page 4

MOCARS also determined that $F_{0} E$ follows a normal distribution at the $99 \%$ confidence level using the Kolmogorov-Smirnov goodness-of-fit test. A histogram of the MOCARS results for 3,000 samples of $F_{g} E$ compared with a normal distribution having mean $=0.9995$ and standard deviation $=0.00838$ is shown in Figure 2. Because the MOCARS code output for $F_{q} E$ has a normal distribution, the Student's $t$ Distribution and Chi-Square Distribution, as shown in Attachment 1, can be used to obtain:

$$
\begin{aligned}
& { }_{F_{q} E} \leq 0.9999 \cong 1.000 \\
& \sigma_{F_{q} E} \leq 0.00864
\end{aligned}
$$

at the $99 \%$ confidence level.

The value of $F_{q} E$ is then taken to be:

$$
F_{q}^{E}=1.000+3 \sigma_{F_{q}}{ }^{E}=1.026
$$

Taking the value of $F_{Q} E$ at three standard deviations above its mean is equivalent to saying that there is a $99.9 \%$ probability that the actual value of $F_{g} E$ is less than or equal to 1.026 when $F_{q} E$ follows a normal distribution with the mean and standard deviation having the values shown above.

If the engineering hot spot factor were to be taken at two standard deviations above its mean, then

$$
F_{q}^{E}=1.000+2 \sigma_{F_{q}} E=1.017
$$

For a two standard deviation level, there is still a $97.7 \%$ probability that the actual value of $F_{q} E$ is less than or equal to 1.017 .

$j b$

Attachment:

As stated 
E. C. Anderson

February 27, 1979.

NFF-1-79

Page 5
LTR 111.127

APPENDIX A.7

Figure 2

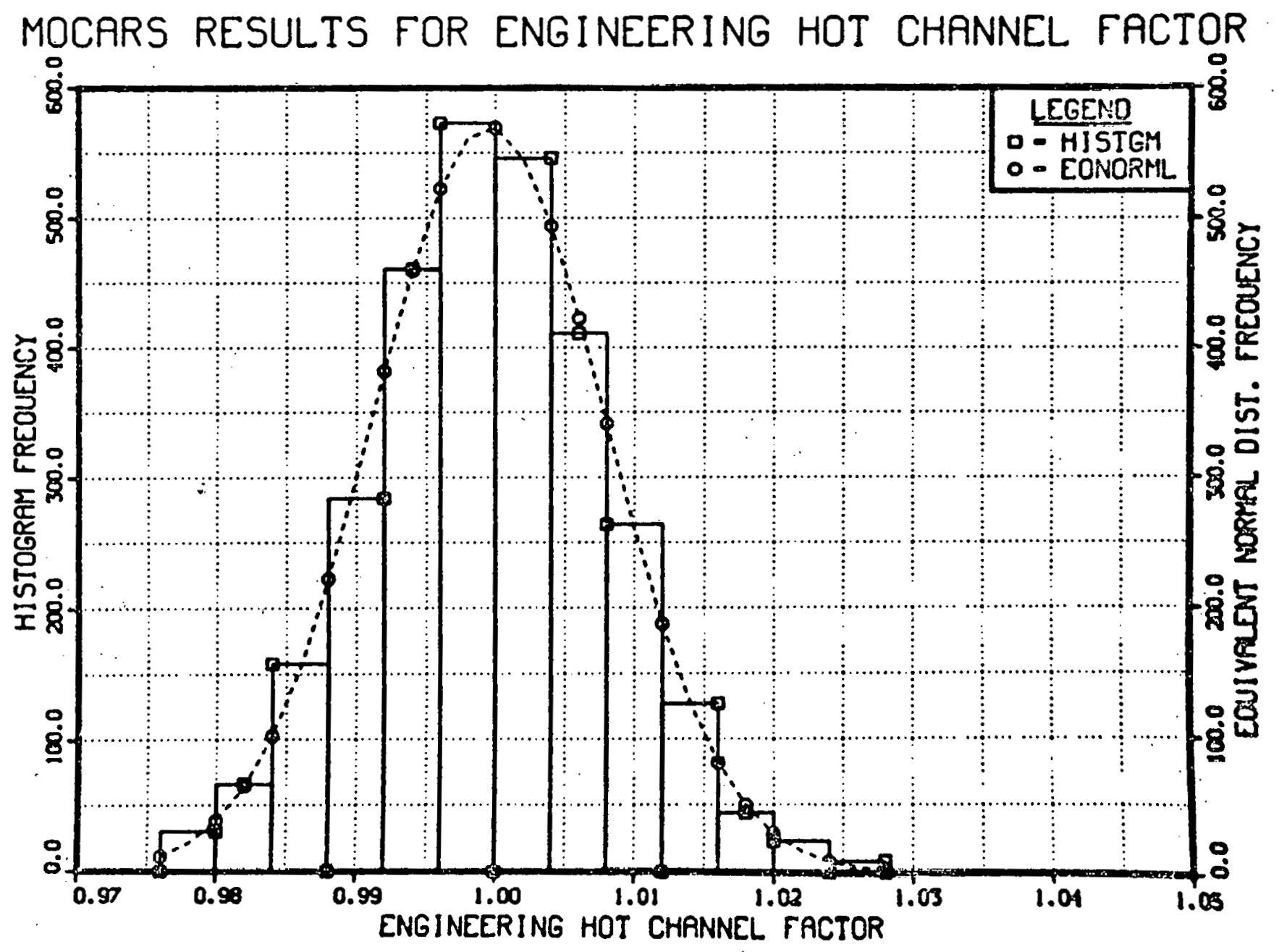


Attachment 1

A. Use of the Student's $t$ Distribution to determine the mean of a normal distribution at a specified confidence level.

$$
p\left\{-t_{\alpha ; \nu} \leq \frac{(\bar{x}-\mu) \sqrt{n}}{s}\right\}=1-\alpha
$$

this can be rewritten as

$$
P\left\{\mu \leq \bar{x}+\frac{t_{\alpha v^{s}}}{\sqrt{n}}\right\}=1-\alpha
$$

where $\quad \bar{X}=$ sample mean

$s$ = sample standard deviation

$n=$ number of samples taken

$v=n-1=$ degrees of freedom

$1-\alpha=$ fractional confidence level

$\alpha=$ tail probability of the $t$ distribution

$t_{\alpha \nu}=$ value of $t$ for tail probability $\alpha$ and $v$ degrees of freedom

e.g.

$$
\begin{aligned}
\bar{X} & =17.1627 \\
s & =0.10742 \\
n & =160 \\
\nu & =159 \\
1-\alpha & =0.99=99 \%
\end{aligned}
$$

then, $\quad t_{0.01,159}=2.350$

thus, $\quad \mu \leq 17.1627+\frac{(2.350)(0.10742)}{\sqrt{160}}=17.1827$

at the $99 \%$ confidence level. 
B. Use of the Chi-Square Distribution to determine the standard deviation of a normal distribution at a specified confidence level.

$$
p\left\{x_{1-\alpha, \nu}^{2} \leq \frac{v s^{2}}{\sigma^{2}}\right\}=1-\alpha
$$

this can be rewritten as

$$
P\left\{\sigma \leq\left[\frac{v s^{2}}{x_{I \mu, \nu}^{2}}\right]^{3 / 2}\right\}=1-\alpha
$$

where $\quad x_{1-\alpha, \nu}^{2}=$ value of Chi-Square for probability $1-\alpha$ and $\nu$ degrees

$$
\begin{aligned}
\nu=n-1 & =\text { degrees of freedom } \\
s & =\text { sample standard deviation } \\
\sigma & =\text { population standard deviation }
\end{aligned}
$$

Examp 1e:

$s=0.10742$

$$
n=160
$$$$
v=159
$$

then

$$
1-\alpha=.99=99 \%
$$

$$
x^{2} .98,159=120.47
$$

$$
\sigma \leq\left(\frac{(159)(.10742)^{2}}{120.47}\right)^{\frac{1}{2}}
$$

$\sigma \leq 0.12341$ at the $99 \%$ confidence level. 
APPENDIX A-8

L2-3 COBRA MODELS INPUT 


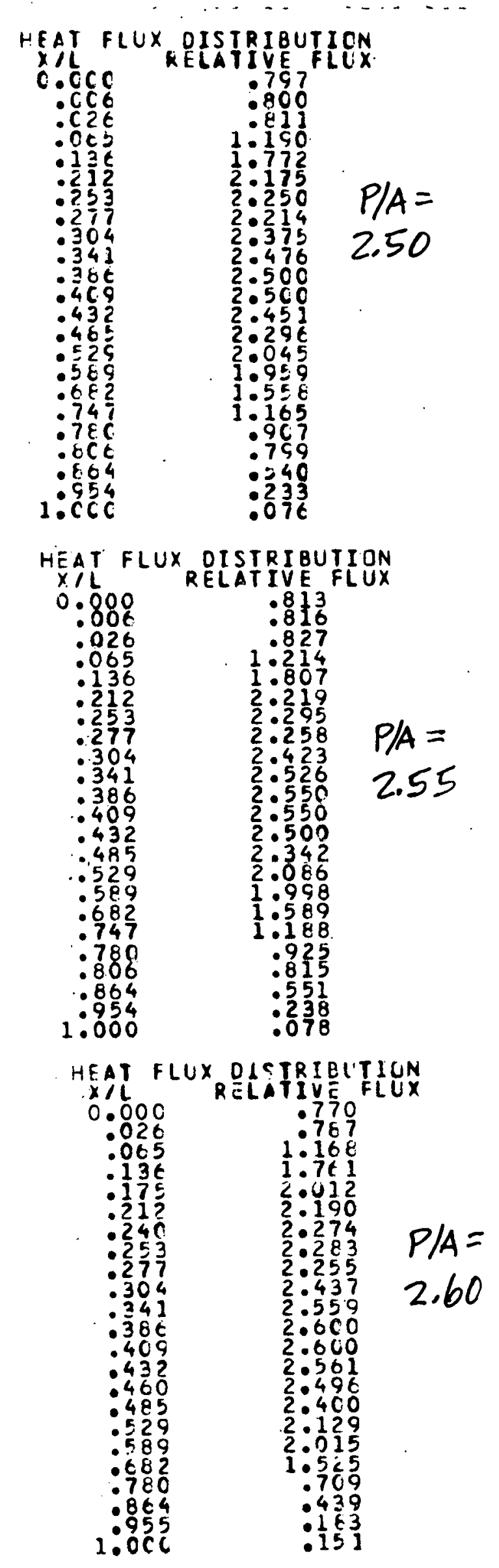

2 


\title{
E\&G Idaho
}

\section{INTEROFFICE CORRESPONDENCE}

\author{
date March 14, 1979 \\ to E. C. Anderson

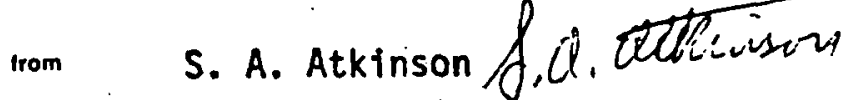 \\ subject COBRA IIIC - COBRA IV I COMPARISON AND SPACER GRID LOSS \\ CALCULATION ERROR - AtKi-8-79
}

In the development of LOFT models for use with the COBRA IV-I computer code, it was determined that the predictions for channel mass flux were significantly different from the predictions obtained using COBRA IIIC for slow transients. COBRA IIIC predicted significantiy more flow diversion out of the hot channel, and thus predicted significantly smaller values for mass flux and DNBR. The CORRA IV results appeared reasonable, since it predicted results close to those obtained using a steady-state assumption. For slow power rise transients, such as boron dilution or slow control rod withdrawal accidents, a pseudosteady-state solution approach should be reasonable and conservative.

Jim Fisher, of Thermal Analysis, investigated possible reasons or causes for this discrepancy, and determined that the equation for calculating the spacer grid (or spacer blade) loss coefficients in the COBRA LOFT models was in error. The equation, as it existed in both the COBRA III and COBRA IV versions, was:

$$
C D=C D+K(\operatorname{Re})^{r}
$$

This equation was added to COBRA to make the spacer loss coefficient (CD) a function of Reynolds number (Re). For the LOFT fuel bundle, CD is initially set to zero, and $r=-0.142$. As a result of the above equation, upon every axial flow solution iteration, $C D$ was increased by an increment equal to $K(\operatorname{Re})^{r}$. Therefore, the spacer loss coefficients were continually increasing through the transient. As a result, the axial flow restriction continualiy increases. Since the Reynolds number exponent is negative, the increase in the coefficient is greater in the channels with iess flow, particularly in the hot channel (channel 15 in the COBRA model). This results in increased flow diversion out of the hot channel as the transient progresses. The correct equation for spacer loss coefficient is:

$$
\operatorname{CDS}=\operatorname{CDI}+K(\operatorname{Re})^{r}
$$

where COI has an initial constant value set by the user (equal to zero for LOFT). 
COBRA IV hâs an improved and significantly more efficient solution algorithm for the flow solution in the implicit solution scheme. As a result, COERA IIIC requires more iterations for a flow solution than does COBRA IV. As a result of this difference between the codes, the spacer loss coefficient built up much more in the COBRA III solution, resulting in significantly less hot channel mass flux for a slow transient. Since the spacer loss coefficient is initialiy a small value, fast transients, with few total flow solution iterations, would be little effected by the loss coefficient equation error.

The attached Figure 1 compares the COBRA IIIC and COBRA IV results for the LOFT 3 MDNBR vs. time for a $0.5 \times 10^{-4} \Delta \rho / s$ slow reactivity increase accidents with the spacer loss coefficient equation error. As seen in Figure 1, the solutions diverge significantly. Figure 2 plots the hot channel mass fluxes at the axial location at which MONBR occurred ( 33 inches up the channel) for the COBRA III and COBRA IV solutions. COBRA IIIC continuously decreases the hot channel mass flux in response to the increasing spacer grid loss coefficients, while the COBRA IV mass flux remains nearly constant at $0.59 \mathrm{Mibm} / \mathrm{h}-\mathrm{ft}^{2}$. Figure 3 shows the calculated hot channel mass fluxes at the axial location at which MDNBR occurred after the spacer grid loss coefficient equation was corrected. The COBRA IIIC and COBRA IV mass fluxes are now in close agreement with a nearly constant mass flux of $0.60 \mathrm{MIbm} / \mathrm{h}-\mathrm{ft}^{2}$. This behavior is as expected for a slow power increase transient before significant voiding occurs in the channels. Figure 4 is a plot of the MDNBR for the COBRA III and COBRA IV solutions after the spacer: grid loss coefficient equation was corrected. The small differences observed in the solutions are primarily due to small differences in the location of MDNBR, and therefore small differences in the heat flux.

Therefore, it is seen that the difference in the COBRA IIIC and COBRA IV solutions was due to the spacer grid loss coefficient equation error. With the loss coefficient equation corrected, both versions of COBRA give similar results. These results are what would be expected for a slow transient, that is little change in flow behavior, and a MDNBR close to but less severe than for a steady-state solution of equal conditions. As seen in Figure 4, MDNBR $=1.151$ at 34.6 s using COBRA IIIC. A pseudo-steady-state solution for the MDNBR for the transient conditions at 34.6 s resulted in MONBR $=1.141$. It is not certain that the COBRA IV solution was fully converaed. al thouah it seems certain that it was close. Therefore, no judgement can be made at this time as to which solution is best. We will complete an investigation into COBRA IV convergence and make a recommendation for use of COERA IV at a later time, especially since COBRA IV is a faster and cheaper version to run.

The spacer grid loss coefficient equation error existed in the COBRA IIIC model used for LOFT FSAR and subsequent analyses. However, the error acts to increase the flow resistance in the hot channel more than in other channels with greater initial flow. Therefore, the existance of the error should resuit in conservative results for all the LOFT core safety analysis, since it should result in lower mass fluxes, higher qualities, and therefore lower MDNBR's for all transients. This conservatism was evident for the slow reactivity 
Page 3

increase accident discussed above. Additional comparative calculations were done for a very slow reactivity addition accident, a fast reactivity increase accident, a loss of steam load accident, and a rapid loss of flow accident (simultaneous loss of pump power without flywheel assisted coastdown). The calculations were done for the severe L2-3 mode 8 off-nominal operating conditions for a measured $P / A=2.60$. The results of the comparative calculations using COBRA IIIC are listed in the attached Table 1.

The rapid loss of flow accident is considered to be the type of accident for which the loss coefficient equation error would have the least effect, or might possibly be non-conservative. However, as seen in the comparative calculation results in Table 1, although the error had little effect for the rapid loss of flow, it still remains a conservative effect. Therefore, we conclude that the analyses performed with the spacer grid loss coefficient equation error in COBRA IIIC were conservative for all types of limiting transients. Therefore, use of COBRA versions for future LOFT safety analyses with a corrected spacer grid loss coefficient equation will not result in any reduction in safety margins.

The results in Table 1 point out another effect of the loss coefficient equation error not discussed before. As the loss coefficients for the spacer grids are compounded during transient solution iterations, the axial flow calculated in the vicinity of the spacer grids is severely depressed in relation to the flow in the rest of the channel. This flow depression (due to cross-flow divergence near the grids) results in the point of MDNBR being near the grid at 35 inches up the channel, instead of being closer to the peak power location.

i1

Attachments :

As stated

cc: B. S. Anderson

S. A. Atkinson

G. A. Dinneen

D. F. Elger

N. F. Fausz

J. E. Fisher

J. L. Liebenthal

R. P. Wadkins erow

TAB File 3.A

Central Files 


\section{LTR 111.127 \\ APPENDI: A.9}

TABLE 1

RESULTS OF COAPARATIVE COBRA IIIC CALCULATIONS FOR

EFFECT OF SPACER GRID LOSS COEFFICIENT EQUATION ERROR

With Loss Coefficient With Corrected Loss

Equation Error

Coefficient Equation

Very Slow Reactivity Increase

$0.1 \times 10^{-4} \Delta \rho / s$

Case No.

MDNBR

Time of MDNBR (s)

MDNBR Axial Location (in.)

Mass Flux (Mibm/hr-ft $\left.{ }^{2}\right)$

Quality

CRW 91C

1.131

82.0

33

0.512

$-0.077$
CRW 910

1.174

82.0

31.5

0.600

$-0.111$

Rapid Reactivity Increase

$2.0 \times 10^{-4} \cdot \Delta p / s$

Case No.

MDNBR

Time of MDNBR (s)

MDNBR Axial Location (in)

Mass Flux (Mlbm/h-ft $)$

Quality

Loss of Steam Load

MDNBR

Time of MDNBR (s).

MDNBR Axial Location (in.)

Mass Fiux (M1mb/h-ft ${ }^{2}$ )

Quality

Two Pump Loss Without Flywheel

Assisted Coastdown

MDNBR

Time of MDNBR (s)

MDNBR Axial Location (in.)

Mass Flux (Mibm/h-ft2)

Quality
CRH 90

1.098

26.2

34.5

0.444

$-0.054$

1.120

14.0

34.5

0.481

$-0.104$
CRW 90A

1.154

26.2

31.5

0.591

$-0.082$

1.156

14.0

31.5

0.607

$-0.144$
1.175

74.0

31.5

0.400

0.002
1.179

14.0

31.5

0.412

$-0.008$ 


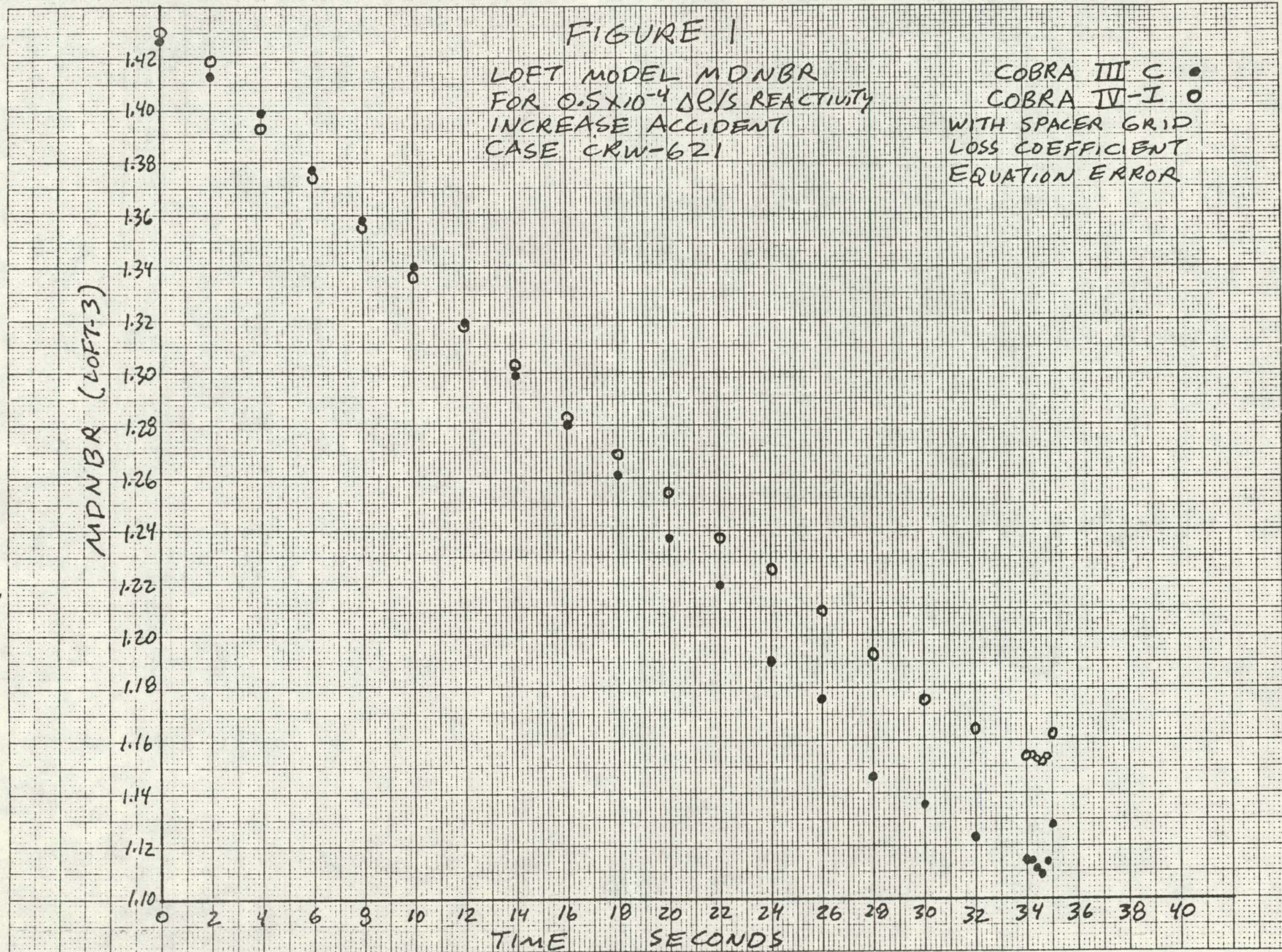




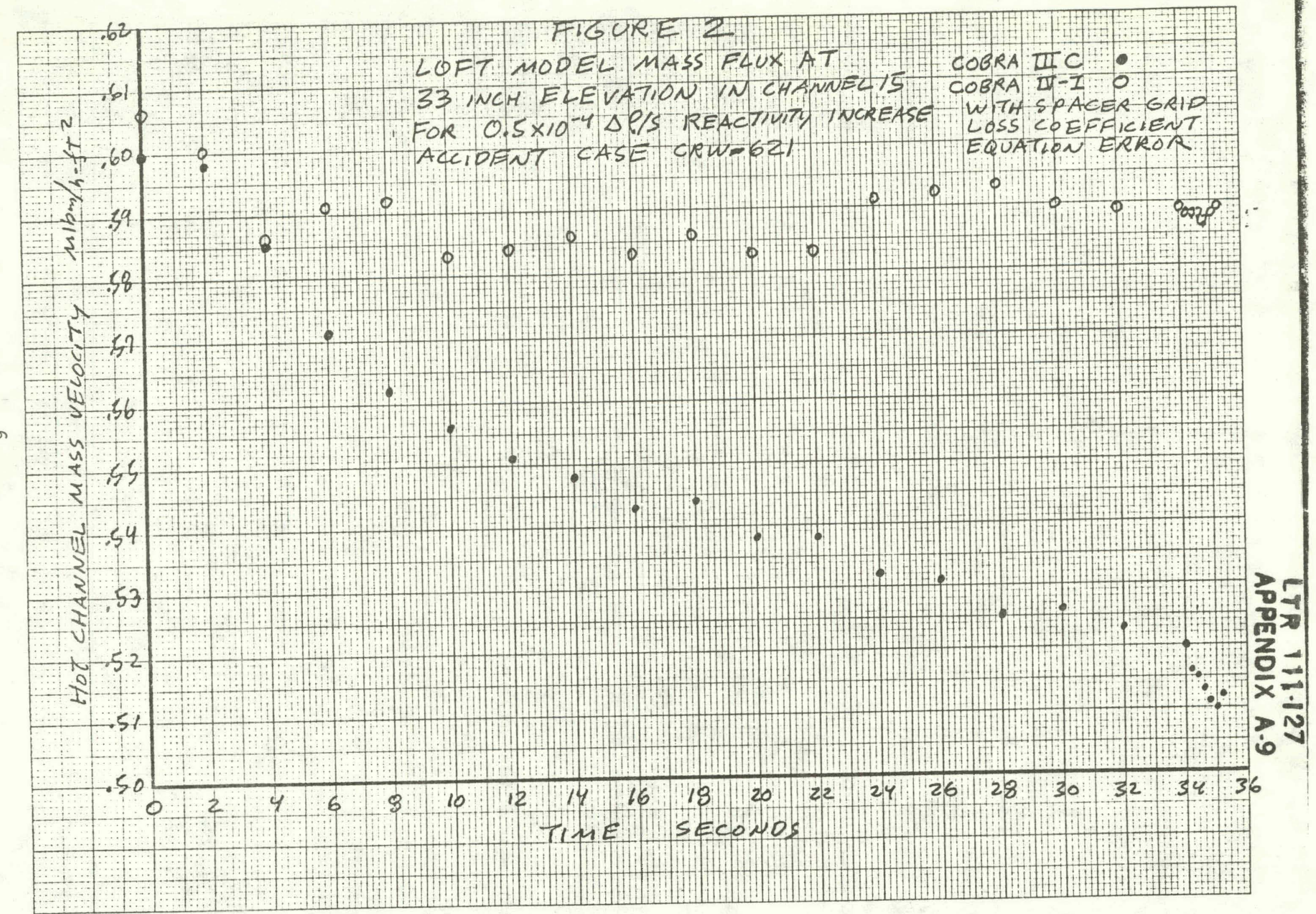




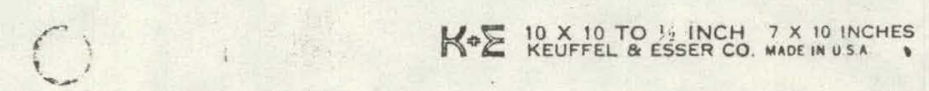

FIGURE 3

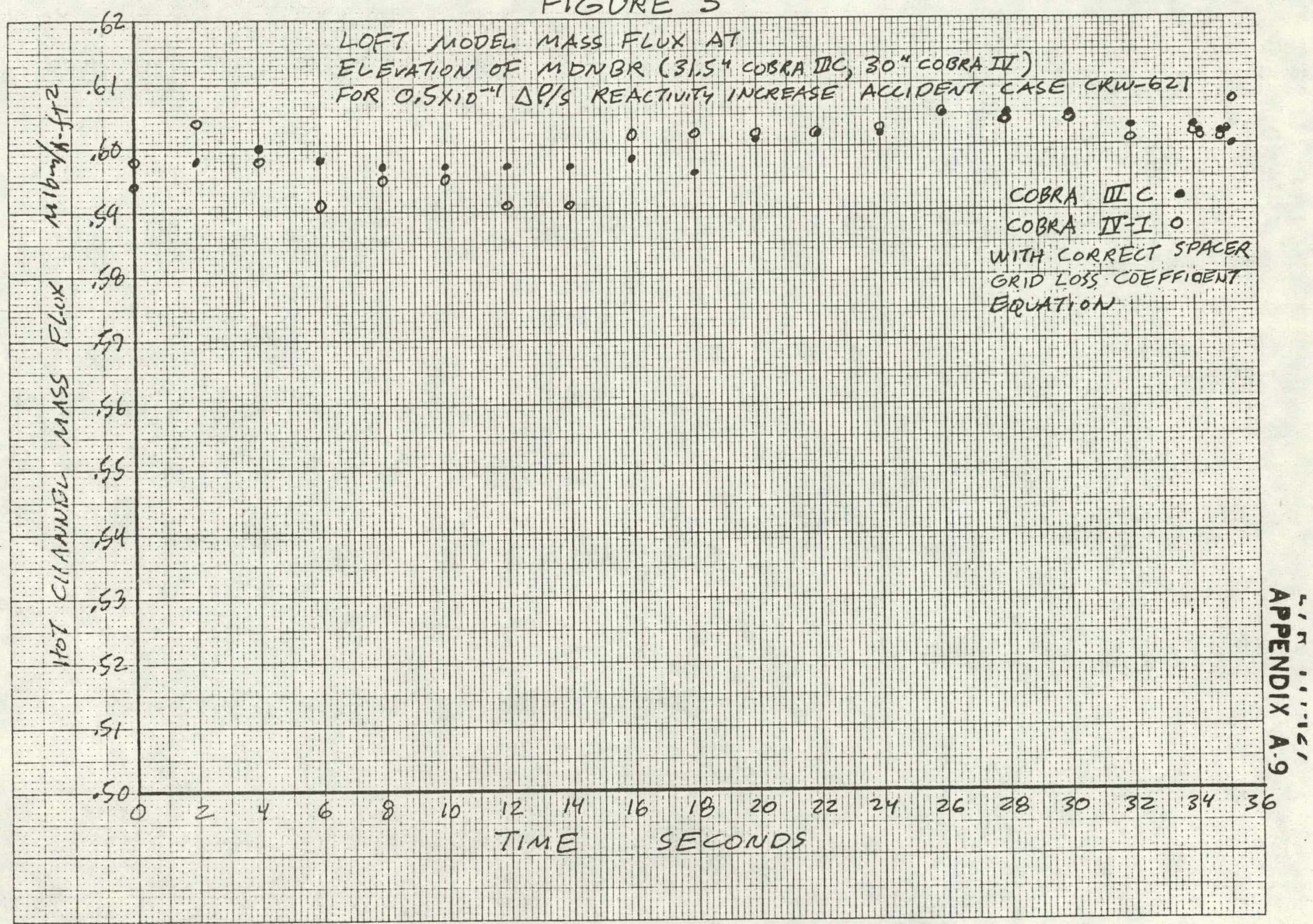




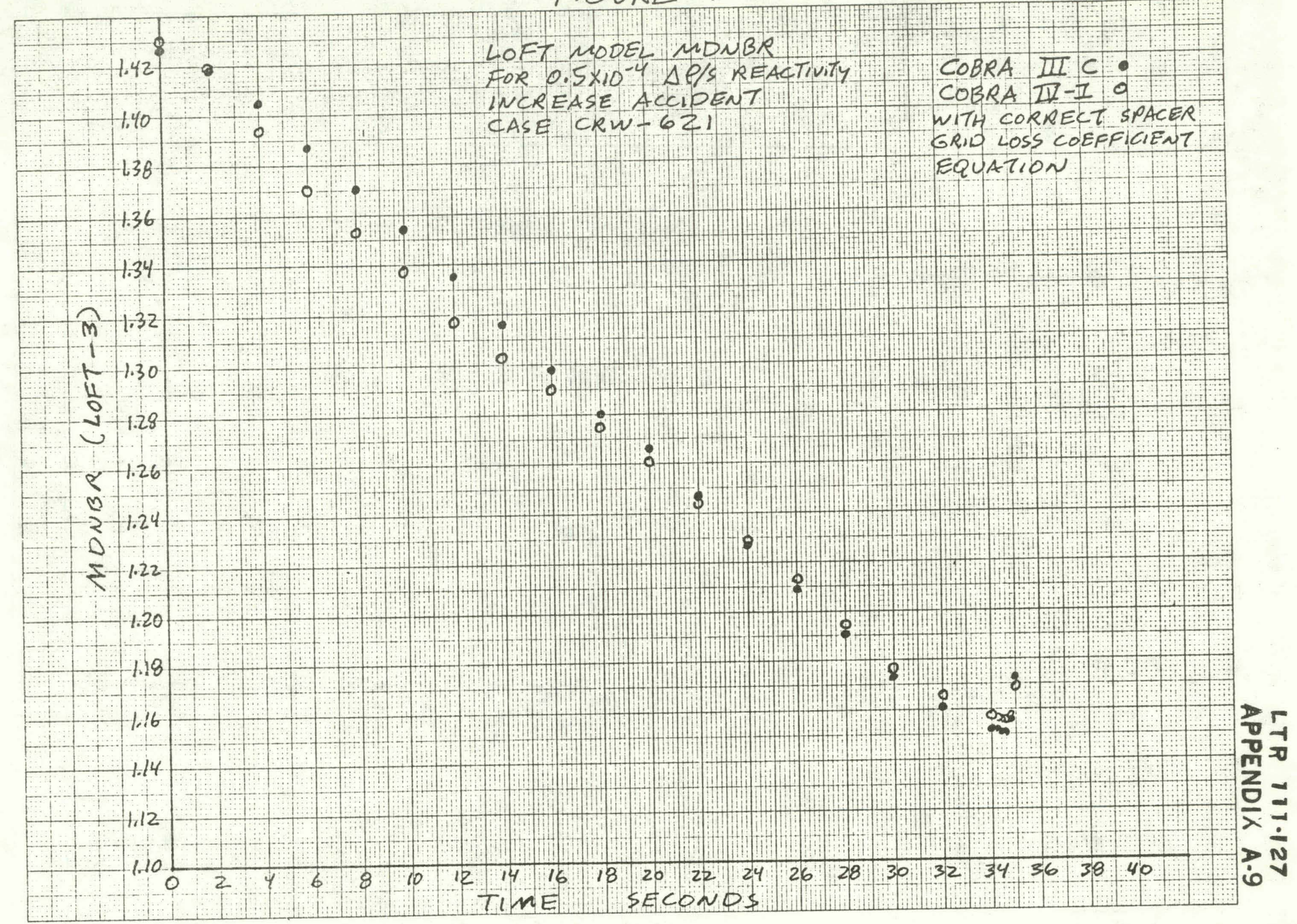




\author{
APPENDIX $A-9$ \\ COBRA IIIC-COBRA IV-T COMPARISON \\ AND SPACER GRID LOSS CALCULATION ERROR
}


APPENDIX $A-10$

RESULTS OF REQUESTED ROD WORTH

CALCULATIONS FOR LOFT L2-3 


\section{INTEROFFICE CORRESPONDENCE}

$\begin{array}{ll}\text { date } & \text { March } 21,1979 \\ \text { to } & \text { W. R. Carpenter } \\ \text { irom } & \text { B. L. Rushton } 32 \\ \text { subject } & \begin{array}{l}\text { RESULTS OF REQUESTED ROD WORTH CALCULATIONS FOR LOFT } \\ (\text { L2-3) }- \text { RUSh-5-79 }\end{array}\end{array}$

Calculations to provide data for input to L2-3 safety analyses have been completed. These calculations provide differential rod worth data for the following control rod moves:

1) Single rod-cluster ejection from the 50 in. bank (three rod clusters remain banked at 50 in. withdrawn),

2) Four rod-cluster withdrawal from the 50 in. bank,

3) Three rod-cluster scrams from 50 and $60 \mathrm{in.}$

For items 1 and 2, core conditions were specified to maximize the reactivity insertion effected by control rod withdrawal. For item 3, core conditions were specified to minimize the worth effected by scram. This was accomplished by performing limited scoping calculations and reliance on past experience.

The one-dimensional POQ-7 model with Version II thermal feedback was used for this study.

\section{Items 1 and 2}

For these analyses, calculations were performed to simulate reactor operation at the $75 \%$ power level for 100 hours with the control rods banked at 50 inches. Input data for two flow conditions are given in Table I. 
W. R. Carpenter

March 21, 1979

Rush-5-79

Page 2

TABLE I

SPECIFIED OPERATING PARAMETERS

\begin{tabular}{|c|c|c|}
\hline & Low Flow & High Flow \\
\hline Core Power $(\%)^{[a]}$ & 75 & 75 \\
\hline Core Flow (1b/hr) & $1.41+6$ & $3.42+6$ \\
\hline Inlet Temperature $\left({ }^{\circ} \mathrm{F}\right)$ & 555 & 535 \\
\hline Control Rod Position (in.) ${ }^{[b]}$ & 50.0 & 50.0 \\
\hline $\begin{array}{l}\text { a] } 100 \% \text { Core Power }=48.5 \mathrm{MW} \\
\text { b] } \\
\text { in. wi thdrawn }\end{array}$ & & \\
\hline
\end{tabular}

At the 100-hour time point, zero-power was assumed and the shutdown transient was computed to the time of maximum ${ }^{135} \mathrm{Xe}$ concentration (approximately 7.5 hours). The buildup of $135 \times$ e is distributed as the power distribution prior to assuming zero power (skewed down the core) and this will maximize the insertion caused by subsequent rod withdrawal. The rod worth analyses were, therefore, performed with the ${ }^{135} \times \mathrm{xe}$ concentration and distribution computed after the 7.5 hour shutdown interval. Tables A-I through A-IV give the computed results for singlerod and four-rod withdrawal. Low-flow operation followed by the shutdown transient effect the maximum reactivity insertions on subsequent rod withdrawal from 50 inches. The data in Tables A-I through A-IV were computed for zero power conditions; i.e., uniform $555^{\circ} \mathrm{F}$ or $535^{\circ} \mathrm{F}$. For additional information, results are given in Table $A-V$ that show the effect of going to power at the 7.5 hour time point. That is, after the 7.5 hour shutdown interval a feedback calculation was performed under the low flow conditions of Table I and single-rod withdrawal calculations were then performed. In this case, the power shifts down the core away from the rod tips effecting a reduction in the computed. reactivity insertions.

$\underline{\text { Item } 3}$

As opposed to rod withdrawal, these analyses provide rod worth data for terminating a positive reactivity transient with 3-rod scram and should, therefore, be minimized for conservatism. The calculations were performed for both power range and pre-loce conditions with the reactor in the $135 \times$ e-free state. Input data for the two conditions are specified in. Table II. 
W. R. Carpenter

March 21, 1979

Rush-5-79

Page 3

TABLE II

SPECIFIED POWER RANGE AND PRE-LOCE CONDITIONS

\begin{tabular}{lcc}
\hline & Power Range & Pre-Loce \\
Core Power (MW) & 53.4 & 41.4 \\
Core Flow (1b/hr) & $3.06+6$ & $0.99+6$ \\
Inlet Temperature ( $\left.{ }^{\circ} \mathrm{F}\right)$ & 560. & 550. \\
Control Rod Positions (in.) & 50 and 60 & 50 and 60 \\
\hline
\end{tabular}

Results are given in Tables $A-V I$ through $A-I X$. These data span a range of conditions and the most conservative case can be chosen for input to subsequent safety analyses.

tgs

Attachments:

Tables A-I-IX

cc: E. C. Anderson

E. F. Aber

D. R. Cooper

G. S. Gill

O. G. Satterw

A. J. Scott

G. K. Wachs \&s $2 u$

R. I. Rushton File

Central Files 
TABLE A-I

SINGLE-ROD WITHDRAWAL FROM 50 INCHES $^{\text {[a] }}$

LOW FLOW CASE $(1.41+61 \mathrm{~b} / \mathrm{hr})^{[\mathrm{b}]}$

(Three Clusters Remain Banked At 50 Inches)

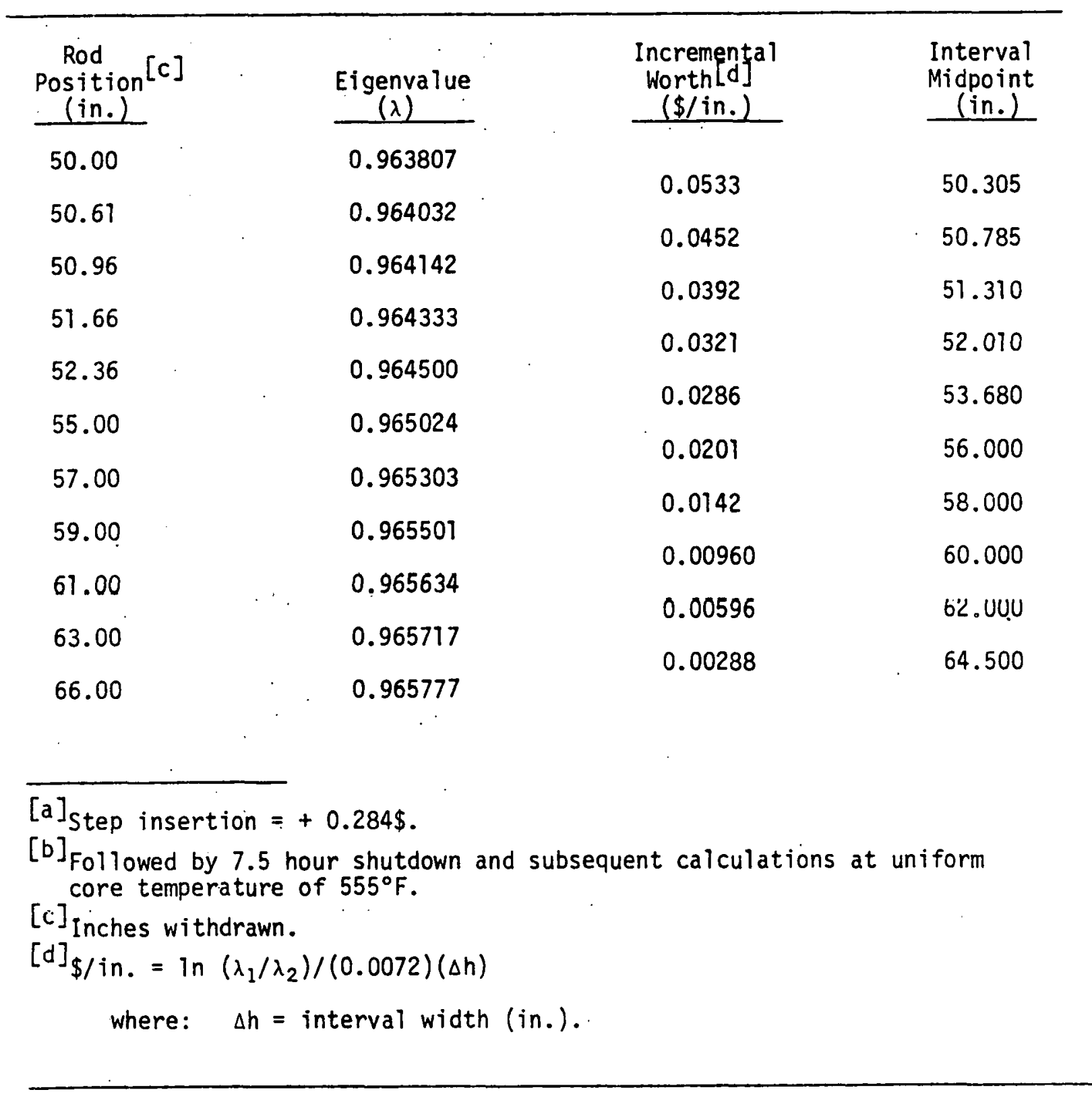


TABLE A-II

SINGLE ROD WITHDRAWAL FROM 50 INCHES ${ }^{[a]}$

HIGH FLOW CASE-2 $(3.42+6 \mathrm{lb} / \mathrm{hr})^{[\mathrm{b}]}$

(Three Clusters Remain Banked At 50 Inches)

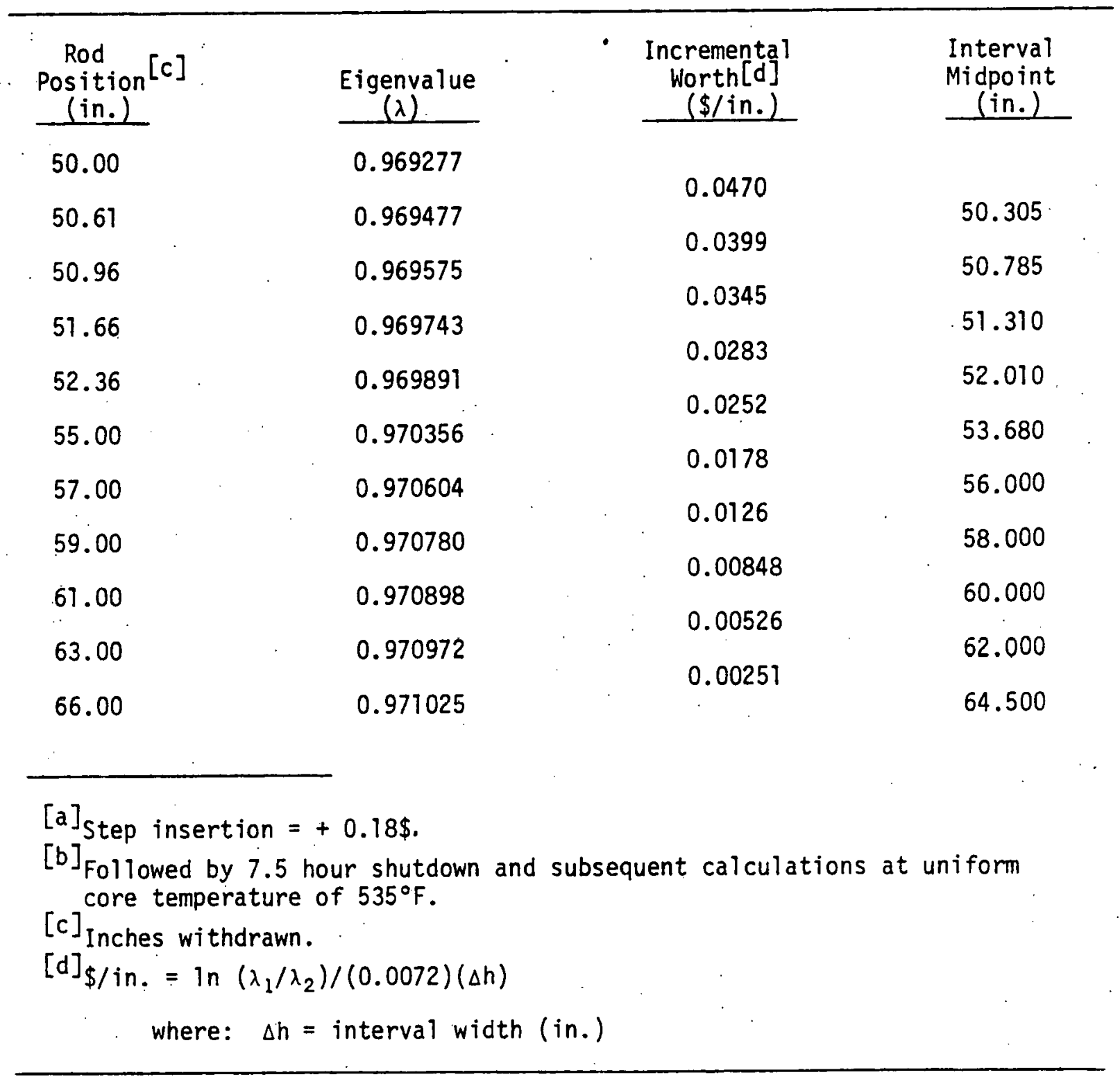


TABLE A-III

4-ROD WITHDRAWAL FROM 50 INCHES

LOW FLOW CASE $(1.41+61 \mathrm{~b} / \mathrm{hr})^{[\mathrm{a}]}$

\begin{tabular}{|c|c|c|c|c|c|}
\hline $\begin{array}{l}\text { Rod } \\
\text { Position [b] } \\
\text { (in.) } \\
\end{array}$ & $\begin{array}{c}\text { Eigenvalue } \\
(\lambda) \\
\end{array}$ & • & $\begin{array}{c}\text { Incremepta] } \\
\text { Worth[c] } \\
(\$ / \text { in. }) \\
\end{array}$ & & $\begin{array}{l}\text { Interval } \\
\text { Midpoint } \\
\text { (in.) }\end{array}$ \\
\hline 50.00 & 0.963807 & & & & \\
\hline 50.61 & 0.964426 & & 0.14630 & 1005 & 50.305 \\
\hline & & & 0.13950 & .1004 & 50.785 \\
\hline 50.96 & 0.964765 & & 0.13250 & .0954 & 51.310 \\
\hline 51.66 & 0.965410 & & 0.12220 &., 688 & 52.010 \\
\hline 52.36 & 0.966047 & & 0.14430 & .1039 & 53.680 \\
\hline 55.00 & 0.968699 & & 0.15560 & .1120 & 56.000 \\
\hline 57.00 & 0.970873 & & 0.15940 & .1148 & 58.000 \\
\hline 59.00 & 0.973104 & & 0.15390 & .1108 & 60.000 \\
\hline 61.00 & 0.975263 & & 0.13310 & .0958 & 62.000 \\
\hline 63.00 & 0.977134 & & 0.09062 & $. c 16 x=$ & 64.500 \\
\hline 66.00 & 0.979049 & & & & \\
\hline
\end{tabular}

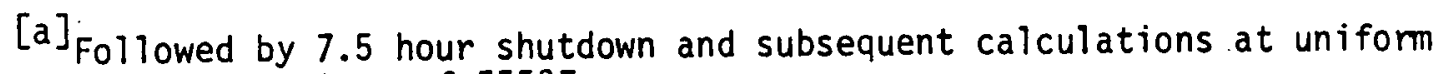

$[b]_{\text {Inches withdrawn. }}^{\text {core temperature }}$

$[c]_{\$ / \text { in. }}=\ln \left(\lambda_{1} / \lambda_{2}\right) /(0.0072)(\Delta h)$

where: $\Delta h=$ interval width (in.). 


\section{TABLE A-IV}

4-ROD WITHDRAWAL FROM 50 INCHES

HIGH FLOW CASE $(3.42+6 \mathrm{lb} / \mathrm{hr})^{[\mathrm{a}]}$

\begin{tabular}{|c|c|c|c|}
\hline $\begin{array}{l}\text { Rod } \\
\text { Position }[b] \\
\text { (in.) }\end{array}$ & $\begin{array}{c}\text { Eigenvalue } \\
(\lambda)\end{array}$ & $\begin{array}{c}\text { Incrementą } \\
\text { Worth[c] } \\
(\$ / \text { in. }) \\
\end{array}$ & $\begin{array}{l}\text { Interval } \\
\text { Midpoint } \\
\text { (in.) } \\
\end{array}$ \\
\hline 50.00 & 0.963923 & 0.1304 & 50.305 \\
\hline 50.61 & 0.964476 & 0.1242 & 50.785 \\
\hline 50.96 & 0.964777 & 0.1184 & 51.310 \\
\hline 51.66 & 0.965353 & 0.1092 & 52.010 \\
\hline 52.36 & 0.965923 & 0.1296 & 53.680 \\
\hline 55.00 & 0.968306 & 0.1417 & 56.000 \\
\hline 57.00 & 0.970284 & 0.1472 & 58.000 \\
\hline 59.00 & 0.972343 & 0.1444 & 60.000 \\
\hline 61.00 & 0.974367 & 0.1267 & 62.000 \\
\hline 63.00 & 0.976146 & 0.0873 & 64.500 \\
\hline 66.00 & 0.977988 & & \\
\hline \multicolumn{4}{|c|}{$\begin{array}{l}{[\mathrm{a}]_{\text {Followed by } 7.5 \text { hour shutdown and subsequent calculations at uniform }}} \\
\text { core temperature of } 535^{\circ} \mathrm{F} \text {. } \\
{[\mathrm{b}]_{\text {Inches withdrawn. }}} \\
{[\mathrm{c}]_{\$ / \text { in. }}=\text { in }\left(\lambda_{1} / \lambda_{2}\right) /(0.0072)(\Delta \mathrm{h})} \\
\quad \text { where: } \Delta h=\text { interval width (in.) }\end{array}$} \\
\hline
\end{tabular}


TABLE A-V

\section{LTR 1 111.127 \\ APPENDIK A.10}

SINGLE ROD WITHDRAWAL FROM 50 INCHES [a]

LOW FLOW CASE $(1.41+61 \mathrm{~b} / \mathrm{hr})^{[\mathrm{b}]}$

75\% POWER BEFORE WITHDRAWAL

(Three Clusters Remain Banked At 50 Inches)

\begin{tabular}{|c|c|c|c|}
\hline $\begin{array}{l}\text { Rod } \\
\text { Position [c] } \\
\text { (in.) }\end{array}$ & $\begin{array}{c}\text { Eigenva lue } \\
\frac{(\lambda)}{}\end{array}$ & $\begin{array}{c}\text { Incremental } \\
\text { Worth }[d] \\
(\$ / \text { in. }) \\
\end{array}$ & $\begin{array}{l}\text { Interval } \\
\text { Midpoint } \\
\text { (in.) } \\
\end{array}$ \\
\hline 50.00 & 0.932625 & 0.031440 & 50.305 \\
\hline 50.61 & 0.932754 & 0.026890 & 50.785 \\
\hline 50.96 & 0.932817 & 0.023310 & 51.310 \\
\hline 57.66 & 0.932926 & 0.019040 & 52.010 \\
\hline 52.36 & 0.933022 & 0.016840 & 53.680 \\
\hline 55.00 & 0.933321 & 0.011880 & 56.000 \\
\hline 57.00 & 0.933481 & 0.008406 & 58.000 \\
\hline 59.00 & 0.933534 & 0.005713 & 60.000 \\
\hline 61.00 & 0.933671 & 0.003555 & 62.000 \\
\hline $\begin{array}{l}63.00 \\
66.00\end{array}$ & $\begin{array}{l}0.933718 \\
0.933755\end{array}$ & 0.001835 & 64.500 \\
\hline \multicolumn{4}{|c|}{$\begin{array}{l}{[a]_{\text {Step insertion }}=+0.1685 \$ \text {. }} \\
{[b]_{\text {Followed by } 7.5 \text { hour shutdown and subse }}} \\
\text { converging feedback at } 75 \% \text { power. } \\
{[c]_{\text {Inches withdrawn. }}} \\
{[d]_{\$ / \text { in. }}=\text { in }\left(\lambda_{1} / \lambda_{2}\right) /(0.0072)(\Delta h)} \\
\text { where: } \Delta h=\text { interval width (in.). }\end{array}$} \\
\hline
\end{tabular}


TABLE A-VI

3-ROD SCRAM FROM 60 INCHES ${ }^{\text {[a] }}$

POWER RANGE[b]

( $135 \times$ e-free)

\begin{tabular}{|c|c|c|c|}
\hline $\begin{array}{l}\text { Rod }[c] \\
\text { Position }[c] \\
\text { (in.) } \\
\end{array}$ & $\begin{array}{c}\text { Eigenva lue } \\
(\lambda) \\
\end{array}$ & $\begin{array}{c}\text { Incrementa] } \\
\text { Worth[d] } \\
(\$ / \text { in. }) \\
\end{array}$ & $\begin{array}{c}\text { Interval } \\
\text { Midpoint } \\
\text { (in.) } \\
\end{array}$ \\
\hline 60.00 & 1.0016110 & 0.02906 & 59.00 \\
\hline 58.00 & 1.0011920 & 0.03698 & 57.00 \\
\hline 56.00 & 1.0006590 & 0.04339 & 55.00 \\
\hline 54.00 & 1.0000340 & 0.04747 & 53.00 \\
\hline 52.01 & 0.9993540 & 0.05446 & 51.01 \\
\hline 50.00 & 0.9985667 & 0.06803 & 49.00 \\
\hline 48.00 & 0.9975890 & 0.07635 & 47.00 \\
\hline 46.00 & 0.9964928 & 0.08403 & 45.00 \\
\hline 44.00 & 0.9952877 & 0.09193 & 43.00 \\
\hline 42.00 & 0.9939710 & 0.10080 & 41.00 \\
\hline 40.00 & 0.9925292 & 0.11095 & 39.00 \\
\hline 38.00 & 0.9909447 & 0.12080 & 37.00. \\
\hline 36.00 & 0.9892223 & 0.12400 & 35.53 \\
\hline 35.06 & 0.9873783 & 0.13580 & 34.54 \\
\hline 0.00 & 0.9067342 & & \\
\hline \multicolumn{4}{|c|}{$\begin{array}{l}{[\mathrm{a}]_{1-\text { rod cluster remains at } 60 \mathrm{in} .}} \\
{[\mathrm{b}]_{\text {Power }}=53.4 \mathrm{MW} \text {, core flow }=3.03+6 \mathrm{lb} / \mathrm{hr} \text {, Inlet }=560^{\circ} \mathrm{F} \text {, Converge }} \\
\text { feedback at } 60 \mathrm{in} \text {. rod bank position and perform scram calculations. } \\
{[\mathrm{c}]_{\text {Inches withdrawn. }}} \\
{[\mathrm{d}]_{\$ / \text { in. }}=\ln \left(\lambda_{1} / \lambda_{2}\right) /(0.0072)(\Delta \mathrm{h})} \\
\quad \text { where: } \Delta h=\text { interval width (in.) }\end{array}$} \\
\hline
\end{tabular}


TABLE A-VII

3-ROD SCRAM FROM 60 INCHES [a]

PRE-LOCE $(L 2-3)^{[\mathrm{b}]}$

(135Xe-free)

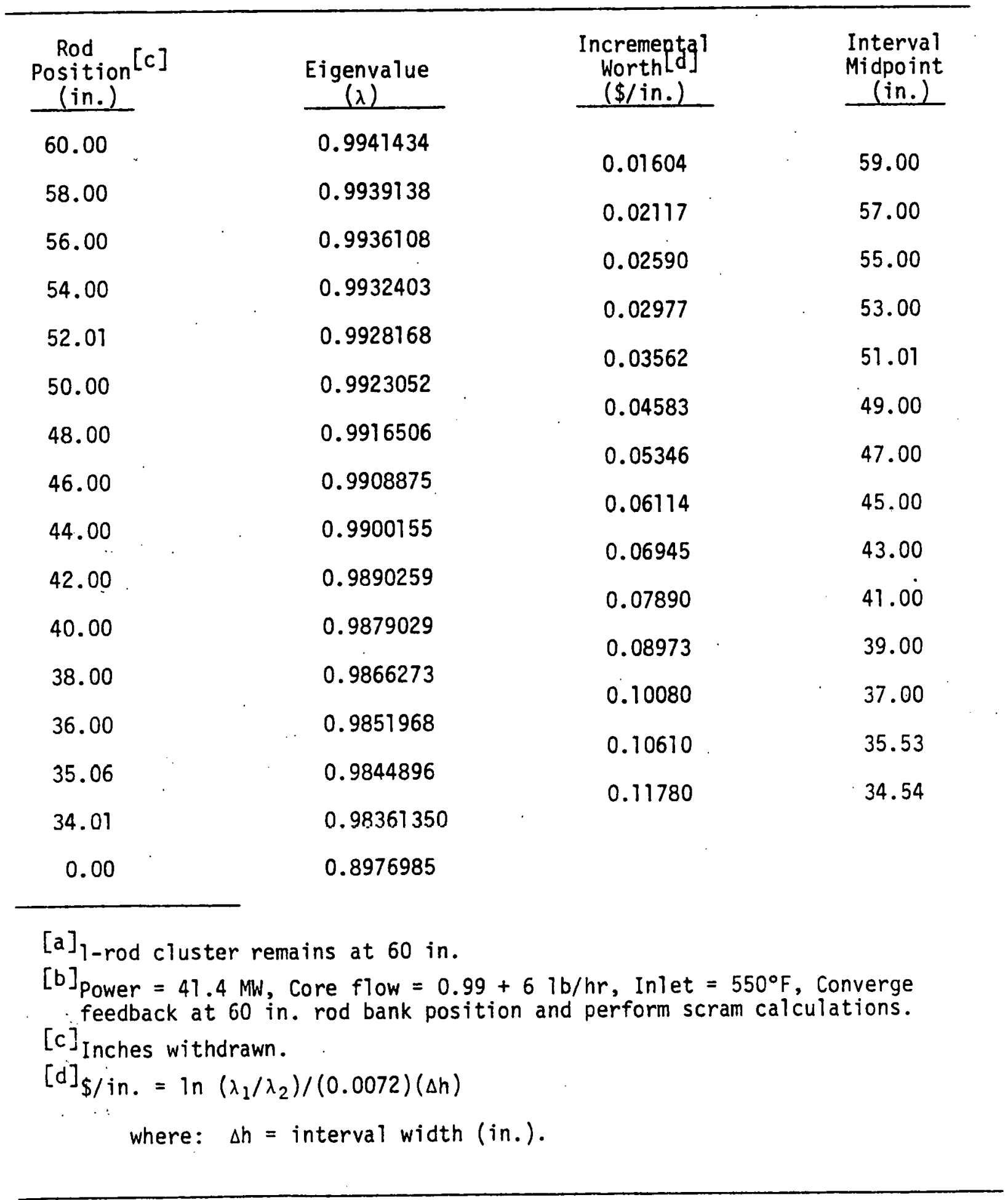


TABLE A-VIII

3-ROD SCRAM FROM 50 INCHES ${ }^{[a]}$

POWER RANGE[b]

(135Xe-free)

\begin{tabular}{|c|c|c|c|}
\hline $\begin{array}{l}\text { Rod } \\
\text { Position [c] } \\
\text { (in.) }\end{array}$ & $\begin{array}{c}\text { Eigenvalue } \\
(\lambda)\end{array}$ & $\begin{array}{c}\text { Incremeptal } \\
\text { Worth }[d] \\
(\$ / \text { in. }) \\
\end{array}$ & $\begin{array}{l}\text { Interval } \\
\text { Midpoint } \\
\text { (in.) }\end{array}$ \\
\hline 50.00 & 0.995935 & 0.05895 & 49.00 \\
\hline 48.00 & 0.995090 & 0.07212 & 47.00 \\
\hline 46.00 & 0.994057 & 0.08246 & 45.00 \\
\hline 44.00 & 0.992877 & 0.09205 & 43.00 \\
\hline 42.00 & 0.991562 & 0.10177 & 41.00 \\
\hline $40.00^{\circ}$ & 0.990110 & 0.11235 & 39.00 \\
\hline 38.00 & 0.988509 & 0.12237 & 37.00 \\
\hline 36.00 & 0.986769 & 0.12558 & $35.53^{\circ}$ \\
\hline 35.00 & 0.985931 & 0.13732 & 34.54 \\
\hline 34.01 & 0.984908 & & \\
\hline 0.00 & 0.902974 & & \\
\hline \multicolumn{4}{|c|}{$\begin{array}{l}{[\mathrm{a}]_{1-\text { rod cluster remains at } 50 \mathrm{in} .}} \\
{[\mathrm{b}]_{\text {Power }}=53.4 \mathrm{MW}, \text { Core flow }=3.03+6 \mathrm{ib} / \mathrm{hr} \text {, Inlet }=560^{\circ} \mathrm{F} \text {, }} \\
\text { Converge feedback at } 50 \mathrm{in} \text {. rod bank position and perform scram } \\
\text { calculations. } \\
{[\mathrm{c}]_{\text {Inches withdrawn. }}} \\
{[\mathrm{d}]_{\$ / \mathrm{in} .}=\ln \left(\lambda_{1} / \lambda_{2}\right) /(0.0072)(\Delta \mathrm{h})} \\
\quad \text { where: } \Delta \mathrm{h}=\text { interval width (in.) }\end{array}$} \\
\hline
\end{tabular}


TABLE A-IX

3-ROD SCRAM FROM 50 INCHES ${ }^{[a]}$

PRE-LOCE $(L 2-3)^{[b]}$

(135Xe-free)

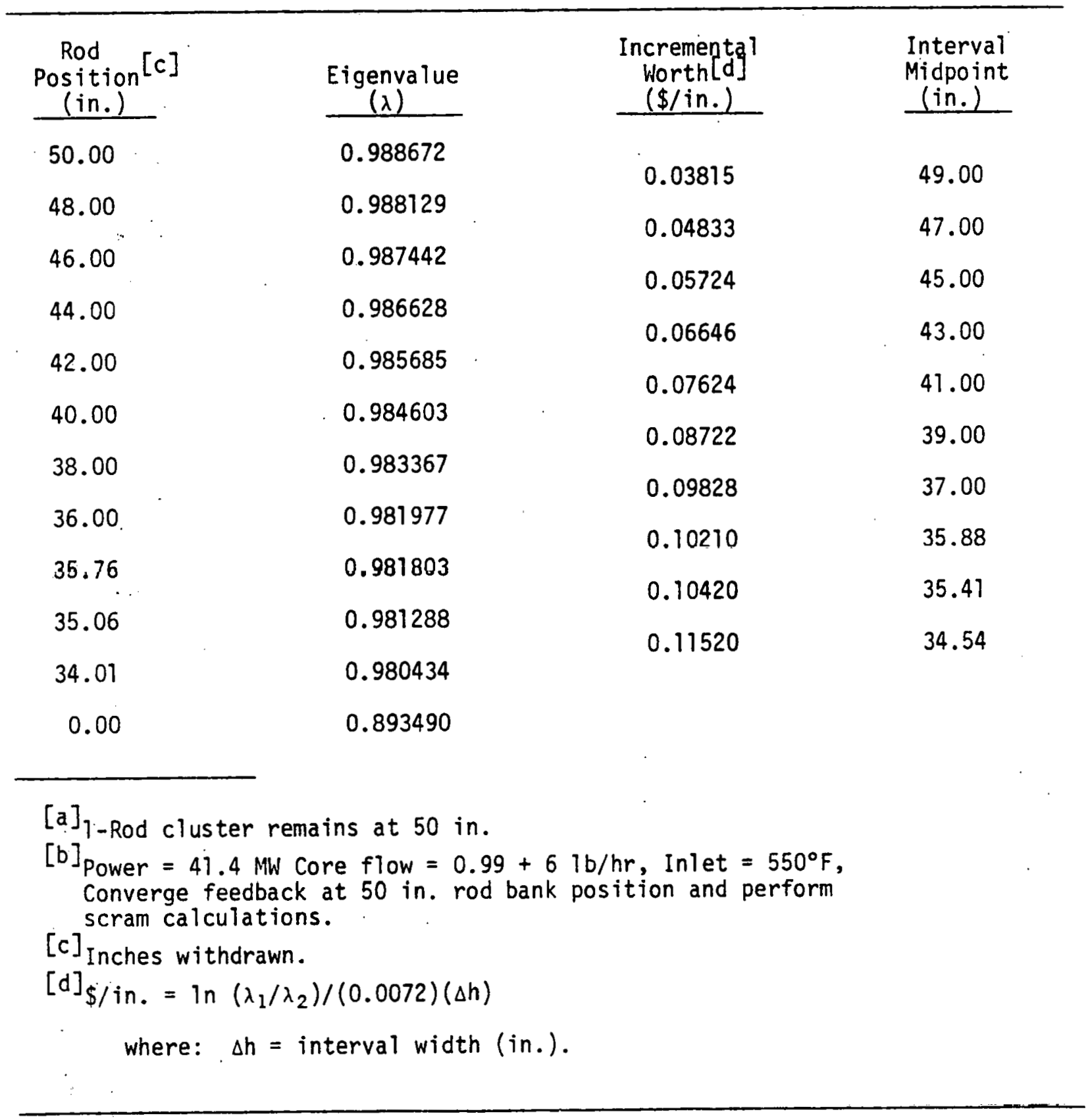




\title{
INTEROFFICE CORRESPONDENCE
}

\author{
date April 11, 1979 \\ to W. R. Carpenter \\ from B. L. Rushton B2 \\ sUblect RESULTS OF REQUESTED CALCULATIONS TO PROVIDE SUPPORT FOR \\ LOCE L2-3 - Rush-7-79
}

Additional data for LOCE L2-3 safety analyses have been calculated using the one-dimensional PDQ-7 model with Version II thermal feedback. For your convenient reference, attach this information to Rush-5-79. The calculated results are for the following:

1) Four rod-cluster withdrawal from the 34 in. banked position,

2) The axial power distribution with the four rod-clusters banked at 61 in. withdrawn,

3) Shutdown margins effected by four rod-cluster and three rod-cluster scrams.

Stated rod-bank positions are given relative to the bottom of the active fuel.

\section{Items 1 and 2}

For these analyses, calculations were performed to simulate LOFT operation at the $75 \%$ power level for 100 hours with the control rods banked at 50 inches. The operating parameters are given in Table I.

TABLE I

SPECIFIED OPERATING PARAMETERS

\begin{tabular}{lc}
\hline Core Power (\%) & 75 \\
Core Flow $(\mathrm{lb} / \mathrm{hr})$ & $1.41+6$ \\
Inlet Temperature $\left({ }^{\circ} \mathrm{F}\right)$ & 555 \\
Control Rod Position (in.) $[\mathrm{b}]$ & 50.0 \\
\hline$[\mathrm{a}]_{100 \%}$ Core Power $=48.5 \mathrm{MW}$ & \\
{$[\mathrm{b}]_{\text {in. Withdrawn relative to the bottom of the artive fupl. }}$}
\end{tabular}


Apri1 11, 1979

Rush-7-79

Page 2

At the 100-hour time point, the shutdown transient described in Rush-5-79 was computed and with nuclide concentrations corresponding to the 7.5 hour shutdown interval four-rod withdrawal calculations were performed. Table A-I gives the resulting incremental worths for withdrawal from 34.01 in. (uniform temperature of $555^{\circ} \mathrm{F}$ ). This is an extension of the Table A-III data given in Rush-5-79 which were for withdrawal from $50 \mathrm{in.}$. In the calculational steps that provide the incremental worths, the axial point-to-average power distribution computed for each rod bank position is an output option. As requested, Table A-II gives the computed power distribution for the 61 in. rod bank position (uniform $555^{\circ} \mathrm{F}$ ) and Figure $l$ is a plot of the data.

Item 3

Control rods must compensate for the prompt reactivity increase that would occur if the core were to undergo rapid cooling. Three-rod and four-rod shutdown margins were computed in this study for cooldowns from an at-power case. The thermal-feedback calculations (at-power cases) were made using the specified parameters given in Table II.

TABLE II

OPERATING PARAMETERS BEFORE COOLDOWN

$\begin{array}{lc}\text { Core Power (MW) } & 41.4 \\ \text { Core Flow (1b hr) } & 4.0+6 \\ \left.\text { Inlet Temperature ( }{ }^{\circ} \mathrm{F}\right) & 590 \\ \text { Control Rod Position (in.) } & 50.0\end{array}$

The eigenvalue computed for the at-power case was assumed the just critical value and was used as the base case eigenvalue for computing the reactivity transient on cooldown. The sensitivity of the reactivity transient to ${ }^{135} \mathrm{Xe}$ and boron concentrations was also determined. As requested, the cooldown temperatures used were $535^{\circ} \mathrm{F}$ and $375^{\circ} \mathrm{F}$ for the four-rod and three-rod scrams respectively. The results are given in Tables A-III, IV, V, and VI.

Shutdown criterion were met for each case analyzed in this study. Namely, the four-rod scram provided a shutdown margin greater than $9 \%$ and subcriticality was achieved with the three-rod scrams. 
W. R. Carpenter

LTR 111-127

Appendix 10

April 11, 1979

Rush-7-79

Page 3

$\operatorname{tgs}$

Attachments:

As stated

cc: E. F. Aber

E. C. Anderson

D. R. Cooper

G. S. Gill

D. G. Satterwhite

A. J. Scott aj

G. K. Wachs Leew

B. L. Rushton File Central Files 
TABLE A-I

4-ROD WITHDRAWAL FROM 34 INCHES

LOW FLOW CASE $(1.41+6 \mathrm{lb} / \mathrm{hr})$ [a]

\begin{tabular}{|c|c|c|c|}
\hline $\begin{array}{l}\text { Rod } \\
\text { Position }[b] \\
\text { (in.) } \\
\end{array}$ & $\begin{array}{c}\text { Eigenvalue } \\
(\lambda)\end{array}$ & $\begin{array}{c}\text { Incremeptal } \\
\text { Worth[c] } \\
(\$ / \text { in.) } \\
\end{array}$ & $\begin{array}{c}\text { Interval } \\
\text { Midpoint } \\
\text { (in.) } \\
\end{array}$ \\
\hline $\begin{array}{l}34.01 \\
35.06 \\
35.76 \\
36.00 \\
38.00 \\
40.00 \\
42.00 \\
44.00 \\
46.00 \\
48.00 \\
50.00 \\
50.61 \\
50.96 \\
51.66 \\
52.36 \\
55.00 \\
57.00 \\
59.00 \\
61.00 \\
63.00 \\
66.00\end{array}$ & $\begin{array}{l}0.947576 \\
0.948766 \\
0.949496 \\
0.949745 \\
0.951834 \\
0.953851 \\
0.955809 \\
0.957752 \\
0.959717 \\
0.961735 \\
0.963807 \\
0.964426 \\
0.964765 \\
0.965410 \\
0.966047 \\
0.968699 \\
0.970873 \\
0.973104 \\
0.975263 \\
0.977134 \\
0.979049\end{array}$ & $\begin{array}{l}0.16600 \\
0.06282 \\
0.15140 \\
0.15260 \\
0.14700 \\
0.14240 \\
0.14100 \\
0.14240 \\
0.14590 \\
0.14940 \\
0.14630 \\
0.13950 \\
0.13250 \\
0.12220 \\
0.14430 \\
0.15560 \\
0.15940 \\
0.15390 \\
0.13310 \\
0.09062\end{array}$ & $\begin{array}{l}34.535 \\
35.410 \\
35.880 \\
37.000 \\
39.000 \\
41.000 \\
43.000 \\
45.000 \\
47.000 \\
49.000 \\
50.305 \\
50.785 \\
51.310 \\
52.010 \\
53.680 \\
56.000 \\
58.000 \\
60.000 \\
62.000 \\
64.500\end{array}$ \\
\hline
\end{tabular}

$[a]$ Followed by 7.5 hour shutdown and subsequent calculations at uniform core temperature of $555^{\circ} \mathrm{F}$.

[b] Inches withdrawn (relative to the bottom of the active fuel).

$[c]_{\$ / \text { in. }}=\ln \left(\lambda_{1} / \lambda_{2}\right) /(0.0072)(\Delta h)$

where: $\Delta h=$ interval width (in.). 
TABLE A-II

AXIAL POWER DISTRIBUTION[a]

(Rod Position $=61$ in.; $T=555^{\circ} \mathrm{F}$ uniform)

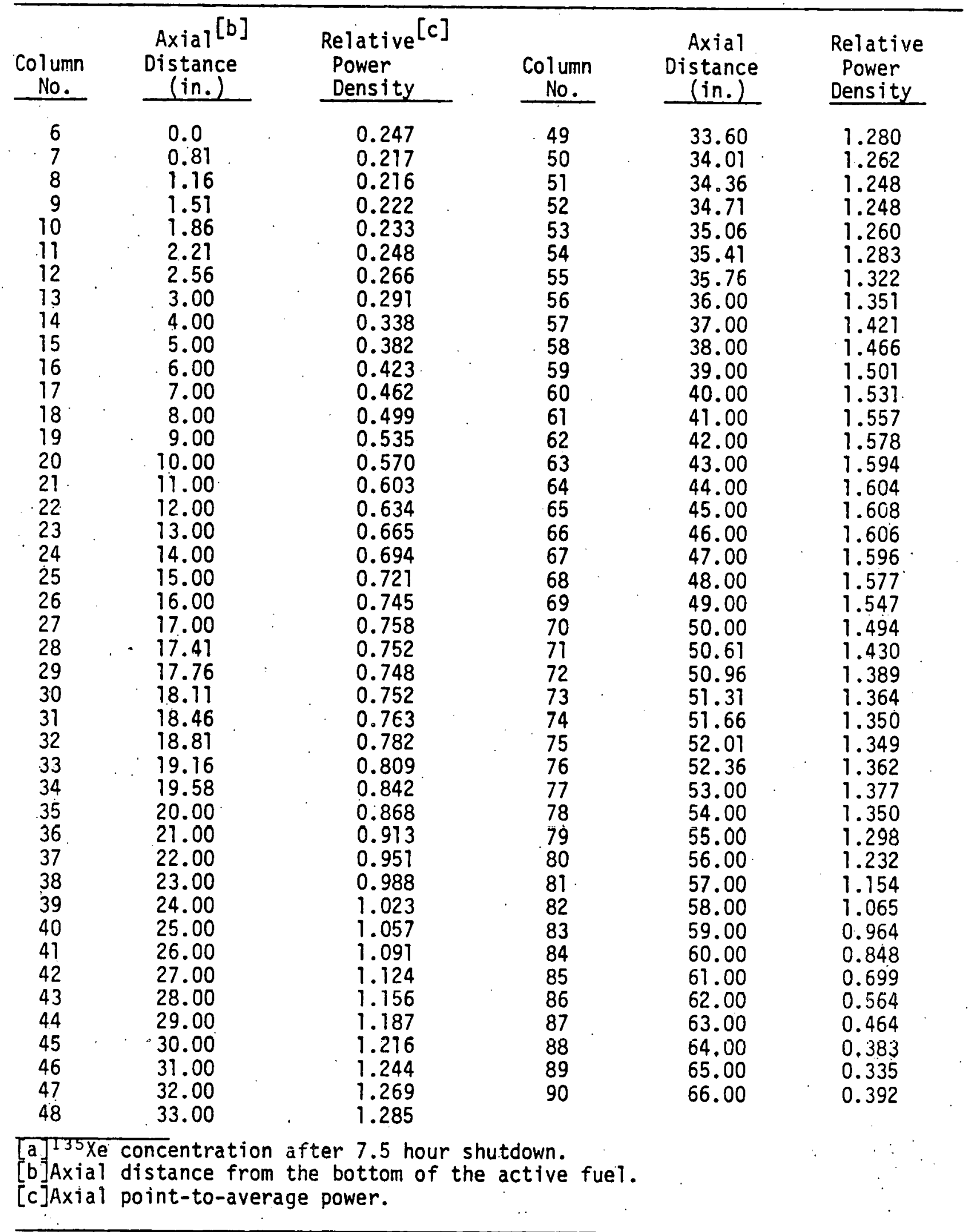


CALCULATED REACTIVITY WORTH EFFECTED BY COOLDOWN FROM $41.4 \mathrm{MW}$ TO $535^{\circ} \mathrm{F}$ AND SHUTDOWN MARGIN FOR 4-ROD SCRAM

At-Power Eigenvalue: $\lambda_{0}=0.992079^{[\mathrm{a}]}$; Uniform $535^{\circ} \mathrm{F}$ Eigenvalue $\lambda_{1}=1.028257$ Overal1 Temperature Worth: in $\frac{\lambda_{1}}{\lambda_{0}}=0.03582$ $535^{\circ} \mathrm{F}$ Scram Worth: $\ln \frac{\lambda(50.00 \text { in. })}{\lambda(0.00 \text { in. })}=0.151369$

Shutdown Margin: In $\frac{\lambda_{0}}{\lambda(0.0 \text { in. })}=0.11555$

Calculated 4-Rod Scram Data Uniform $535^{\circ} \mathrm{F}$

\begin{tabular}{l}
$\begin{array}{c}\text { Rod } \\
\text { Position [b] } \\
\text { (in.) }\end{array}$ \\
\hline 50.00 \\
48.00 \\
46.00 \\
44.00 \\
42.00 \\
40.00 \\
38.00 \\
36.00 \\
35.76 \\
35.06 \\
34.01 \\
00.00
\end{tabular}

\begin{tabular}{c}
$\begin{array}{c}\text { Eigenvalue } \\
(\lambda)\end{array}$ \\
\hline 1.028257 \\
1.026906 \\
1.025412 \\
1.023786 \\
1.022021 \\
1.020097 \\
1.017984 \\
1.015684 \\
1.015404 \\
1.014576 \\
1.013199 \\
0.8838185
\end{tabular}

Incremental

Worthlc]

(\$/in.)

0.09130

0.10111

0.11021

0.11983

0.13086

0.14399

0.15708

0.15956

0.16186

0.17965
Interval

Midpoint (in.)

49.00

47.00

45.00

43.00

41.00

39.00

37.00

35.88

35.41

34.535

$[\mathrm{a}]_{\text {Power }}=41.4 \mathrm{MW}$, Core flow $=4.0+6 \mathrm{lb} / \mathrm{hr}$, Inlet $=590^{\circ} \mathrm{F}$, Converge feedback at 50 in. rod-bank position.

[b] Inches withdrawn (relative to the bottom of the active fuel).

$[c]_{\$ / \text { in. }}=\ln \left(\lambda_{1} / \lambda_{2}\right) /(0.0072)(\Delta h)$ where: $\Delta h=$ interval width (in.). 
TABLE A-IV

CALCULATED REACTIVITY WORTH EFFECTED BY COOLDOWN FROM $41.4 \mathrm{MW}$ TO $375^{\circ} \mathrm{F}$ AND SHUTDOWN MARGIN FOR 3-ROD SCRAM[a]

( $135 \mathrm{Xe}$-free; $1232 \mathrm{ppm}$ )

At-Power Eigenvalue: $\lambda_{0}=0.992079^{[\mathrm{b}]}$; Uniform $375^{\circ} \mathrm{F}$ Eigenvalue: $\lambda_{1}=1.052609$

Overall Temperature Worth: $\ln \frac{\lambda_{1}}{\lambda_{0}}=0.05922$

$375^{\circ} \mathrm{F}$ Scram Worth: In $\frac{\lambda(50.0 \text { in. })}{\lambda(0.0 \text { in. })}=0.086652$

Shutdown Margin: $\ln \frac{\lambda_{g}}{\lambda(0.0 \text { in. })}=0.0274$

Calculated 3-Rod Scram Data Uniform $375^{\circ} \mathrm{F}$

Rosition [c]

(in.)

50.00

48.00

46.00

44.00

42.00

40.00

38.00

36.00

35.76

35.06

34.01

00.00 $\underset{(\lambda)}{\text { Eigenvalue }}$

1.052609

1.051808

1.050798

1.049620

1.048291

1.046815

1.045184

1.043411

1.043198

1.042576

1.041554

0.9652381
Incrementa]

Worth [d]

(\$/in.)

0.05286

0.06672

0.07789

0.08798

0.09785

0.10828

0.11790

0.11815

0.11834

0.12973
Interval

Midpoint

(in.)

49.00

47.00

45.00

43.00

41.00

39.00

37.00

35.88

35.41

34.535

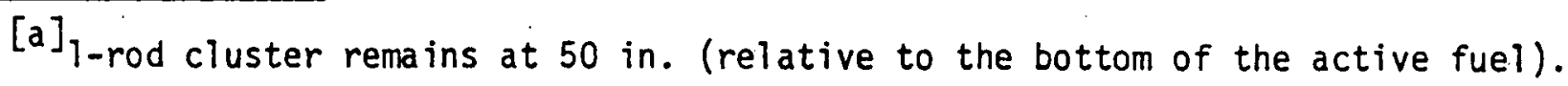
$[\mathrm{b}]_{\text {Power }}=41.4 \mathrm{MW}$, Core flow $=4.0+6 \mathrm{ib} / \mathrm{hr}$, Inlet $=590^{\circ} \mathrm{F}$, Converge feedback at 50 in. rod-bank position.

$[c]$ Inches withdrawn (relative to the bottom of the active fuel).

$[d]_{\$ / \text { in. }}=\ln \left(\lambda_{1} / \lambda_{2}\right) /(0.0072)(\Delta h)$

where: $\Delta h=$ interval width (in.). 
TABLE $A-V$

CALCULATED REACTIVITY WORTH EFFECTED BY COOLDOWN FROM $41.4 \mathrm{MW}$ TO $375^{\circ} \mathrm{F}$.

AND SHUTDOWN MARGIN FOR 3-ROD SCRAM[a]

(Equilibrium $135 \mathrm{Xe} ; 1232 \mathrm{ppm}$ )

At-Power Eigenvalue: $\lambda_{0}=0.9633739^{[\mathrm{b}]}$; Uniform $375^{\circ} \mathrm{F}$ Eigenvalue $\lambda_{1}=1.020917$

Overall Temperature Worth: In $\frac{\lambda_{1}}{\lambda_{0}}=0.058015$

Scram Worth: In $\frac{\lambda(50.0 \text { in. })}{\lambda(0.0 \text { in. })}=0.087069$

Shutdown Margin: $\ln \frac{\lambda_{0}}{\lambda(0.0 \text { in. })}=0.02905$

Calculated 3-Rod Scram Data Uniform $375^{\circ} \mathrm{F}$

Rod
Positjon $[c]$
(in.)

50.00

48.00

46.00

44.00

42.00

40.00

38.00

36.00

35.76

35.06

34.01

00.00 $\underset{(\lambda)}{\text { Eigenvalue }}$

1.020917

1.020044

1.018984

1.017784

1.016467

1.015018

1.013443

1.011751

1.011547

1.010957

1.009989

0.935787

Incremental
Worth $[\mathrm{d}]$
$(\$ /$ in. $)$

Interval

Midpoint

(in.)

0.05941

0.07220

0.08182

0.09033

0.09866

0.10784

0.11604

0.11670

0.11576

0.12671
49.00

47.00

45.00

43.00

41.00

39.00

37.00

35.88

35.41

34.535

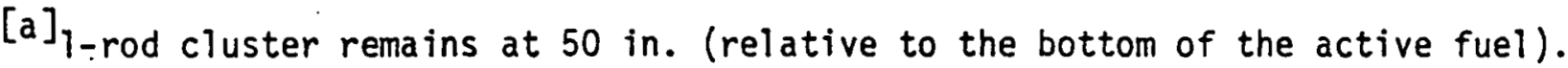

$[\mathrm{b}]_{\text {Power }}=41.4 \mathrm{MW}$, Core flow $=4.0+61 \mathrm{~b} / \mathrm{hr}$, Inlet $=590^{\circ} \mathrm{F}$, Converge feedback at $50 \mathrm{in}$. rod-bank position and perform $135 \mathrm{Xe}$ search.

$[c]$ Inches withdrawn (relative to the bottom of the active fuel).

$[d]_{\$ / \text { in. }}=\ln \left(\lambda_{1} / \lambda_{1}\right) /(0.0072)(\Delta h)$

where $\Delta h=$ interval width (in.). 
TABLE A-VI

CALCULATED REACTIVITY WORTH EFFECTED BY COOLDOWN FROM $41.4 \mathrm{MW}$ TO $375^{\circ} \mathrm{F}$ AND SHUTDOWN MARGIN FOR 3-ROD SCRAM[a]

( $135 \mathrm{Xe}$ free; $100 \mathrm{ppm})$

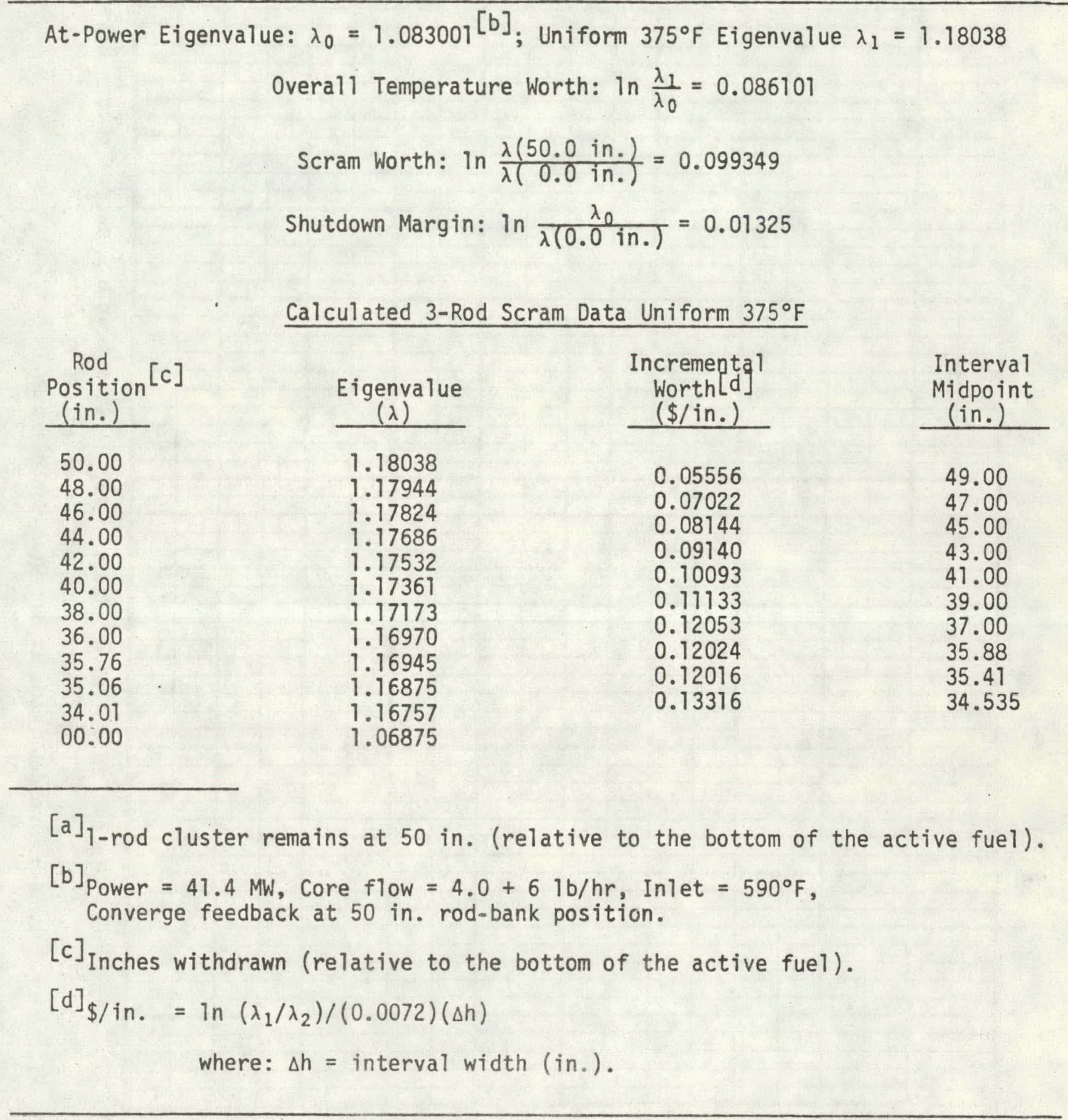




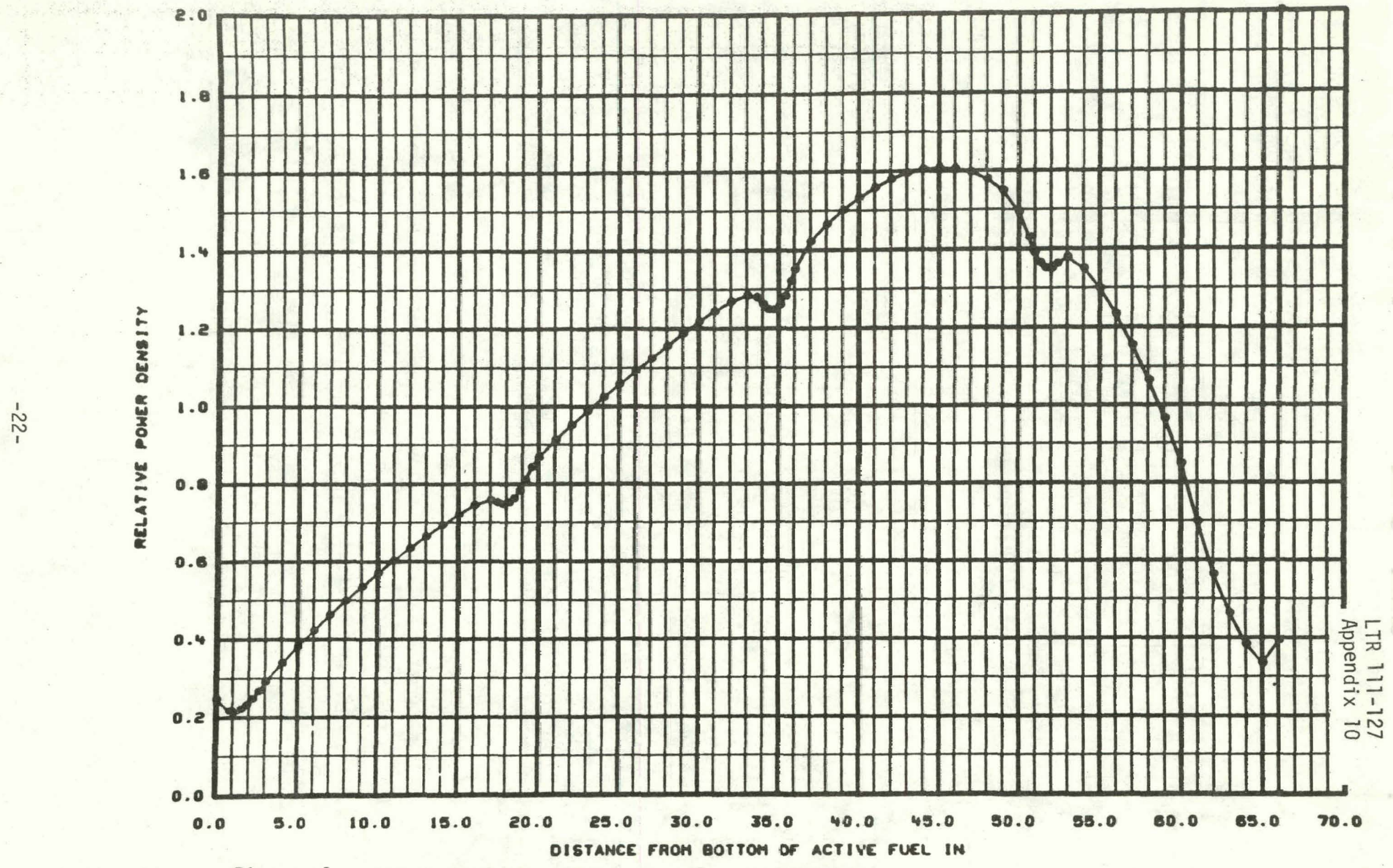

Figure 1. FROM 7.5 HR DOH ROOS AT OIIIN) TES5B UNIFORM 
APPENDIX $B$

ANALYSIS RESULTS 
APPENDIX $B-1$

L2-3 MODE \& STEADY-STATE

ANALYSIS RESULTS 


\title{
INTEROFFICE CORRESPONDENCE
}

\author{
date $\quad$ March 23, 1979 \\ to S. A. Atkinson \\ Irom B. S. Anderson BSA \\ subject L2-3 MODE 8 STEADY-STATE LIMITS - BSA-4-79
}

Steady-state safety limits have been established for core power, hot leg temperature, high core pressure, and low loop flow during L2-3 Mode 8 operation. To establish the limits a series of COERA runs which bound the 1 imit were made for each parameter. One series for a peak-to-average power ratio of 2.55 and one for a peak-to-average of 2.60. Off nominal values were used for all parameters except the parameter being varied. The off-nominal values used are listed in Table I. The three to five cases run in each series were then plotted and the safety limit was then interpolated from the plots. The large core COBRA model used for this analysis is shown in Figure 1.

For core power the limiting factor is the MDNBR which must be $>1.14$ to insure a 95\% chance. that the core will not be in DNB. Figure $\overline{2}$ shows a plot of the core power versus MCNBR. From this plot the high core power safety limit is $42 \mathrm{MiW}$ for the series with a peak-to-average of 2.55 and $41 \mathrm{MW}$ for the series with a peak-to-average of 2.60 .

The hot leg temperature is limited by hitting saturation conditions in the hot leg before the MDNBR drops to 1.14. The cases made for this report used a low off-nominal pressure of 2088. The low-off-nominal pressure has since been lowered to 2050 psia which implies a saturation temperature of $639.3^{\circ} \mathrm{F}$ and therefore, is the limiting hot leg temperature. The range of tenperatures run using 2088 psia covers this temperature, and from a MDNBR standpoint the higher pressure will be more conservative, so the cases were not rerun using the lower pressure. Figure 3 shows the hot leg temperature plotted against the NDKBR. Two extra cases however, were run to determine the MDNBR assuming a hot leg temperature of $639.3^{\circ} \mathrm{F}$ with a core pressure of 2257 psia which very conservatively bounds the MDNBR for the limiting hot leg temperature. Results for the case with a peak-toaverage of 2.55 indicated that MIDNBR $=1.189$ and for the case with a peakto-average of 2.60 the MDNBR $=1.187$.

Like the core power the limiting factor for the high pressure safety limit is a MDNBR of $\geq 1.14$. Figure 4 shows a plot of the core pressure versus MDNBR. From this plot the high core pressure safety limit is 2500 psia for the series with a peak-to-average of 2.55 and 2490 psia for the series with a peak-to average of 2.60. Since the design pressure of the reactor vessel is 2500 psia the core should not go into DNB up to the limits of the reactor vessel. 
The LOFT-3 DNB correlation has a lower limit on mass flux of $0.4 \mathrm{Ml} \mathrm{bm} / \mathrm{hr}-\mathrm{ft}^{2}$. For the low loop flow rate safety limit the lower limit on the LOFT-3 DNB correlation was assumed to be the lower limit on mass flux at the point of MDNBR. This 7 imit was reached before a MDNBR of 1.14. Figure 5 shows a plot of loop mass flow rate versus the mass flux at the point of MDNBR. From this plot a low loop flow rate safety limit of $0.69 \mathrm{Mlbm} / \mathrm{hr}$ was found for both the 2.55 and 2.60 peak-to-average cases. At this point the MDNBR is 27.23 . This analys is however, assumes that the steam generator will cool the loop flow to the low core inlet temperatures necessary to maintain steady-state loop flows this low.

Table II summarizes the steady-state safety limits found in this study.

u1

Attachments :

As stated

cc: B. S. Anderson

D. F. Elger

J. E. Fisher

D. G. Satterwhite

R. P. Wadkins

Central File

TAB File 3.5 


\section{TABLE I}

OFF-NOMINAL PARAMETER VALUES

$\begin{array}{lcc}\text { Parameter } & P / A=2.60 & P / A=2.55 \\ \text { High Off-Nominal Power (MW) } & 37.2 & 37.9 \\ \begin{array}{l}\text { High Off-Nominal Hot } \\ \left.\text { Leg Temperature ( }{ }^{\circ} \mathrm{F}\right)\end{array} & 613 \\ \begin{array}{l}\text { High Off-Nominal Pressure } \\ \text { (psia) }\end{array} & 613 & 2257^{\star} \\ \quad 2257^{\star} \\ \text { Low Off-Nominal Loop Mass } \\ \text { Flow (Mlbm/hr) }\end{array}$

*An off-nominal low pressure was used for determining the safety limit for the hot leg temperature. 
L2-3 MODE 8 STEADY-STATE SAFETY LIMITS

\begin{tabular}{|c|c|c|}
\hline & $\begin{array}{l}P / A=2.60 \\
W=1.15 \times 10^{6} \mathrm{ib} / \mathrm{hr}\end{array}$ & $\begin{array}{l}P / A=2.55 \\
W=1.18 \times 10^{6} \mathrm{lb} / \mathrm{hr}\end{array}$ \\
\hline Power at which MDNBR $=1.14$ & $41 \mathrm{MW}$ & $42 \mathrm{MW}$ \\
\hline $\begin{array}{l}\text { Thot at which saturation is } \\
\text { reached in the hot leg }\end{array}$ & $\begin{array}{c}639^{\circ} \mathrm{F} \\
(\mathrm{MDNBR}=1.31)\end{array}$ & $\begin{array}{c}639^{\circ} \mathrm{F} \\
(\mathrm{MDNBR}=1.31)\end{array}$ \\
\hline $\begin{array}{l}\text { Core pressure at which } \\
\text { MDNBR }=1.14\end{array}$ & 2490 psia* & 2500 psia* \\
\hline $\begin{array}{l}\text { Loop flux a which channel } \\
15 \text { flux }=.4 \times 10^{6} \mathrm{ib} / \mathrm{hr}\end{array}$ & $\begin{array}{l}.69 \mathrm{MLM} / \mathrm{hr} \\
\text { (MDNER }=1.24)\end{array}$ & $\begin{array}{l}.69 \mathrm{MLM} / \mathrm{hr} \\
(\mathrm{MDNBR}=1.23) .\end{array}$ \\
\hline : & & . \\
\hline
\end{tabular}

*Design pressure is 2500 psia. 


\section{LTR 111.127 APPENDIX B-I}

Center of Core

(3) Exlernol T/C

Fuel Rod

I $\left.15 I_{14} I_{13}{ }_{12}\right]_{11}$ CRA Guide Tube

(21) (20) (19) (18) (17) I21]20I19I18 I17 I16

(28) (27) (26) (23) (22)

I28 I27 I 26 I 25 I 24 I 23 I 22

(36) (35) (34)-(33)-(32)-(31)-(30)-(29)

Subchannel Number (Typ.)

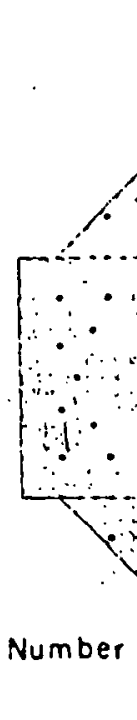

if

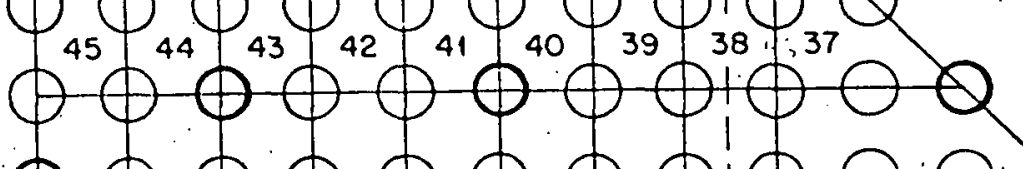

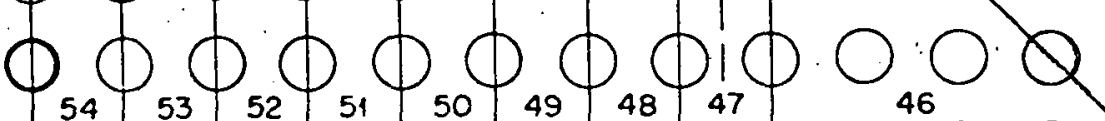

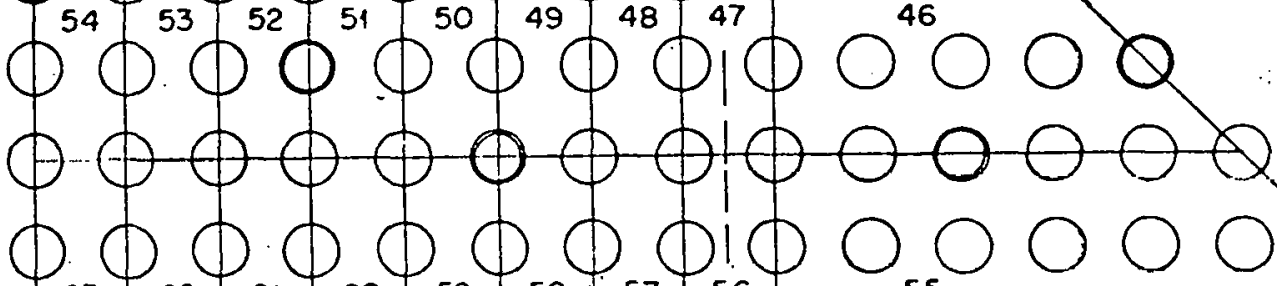

${ }_{63}{ }_{62}{ }_{61}{ }_{60}{ }_{59}{ }_{58}{ }_{57}{ }_{56}$

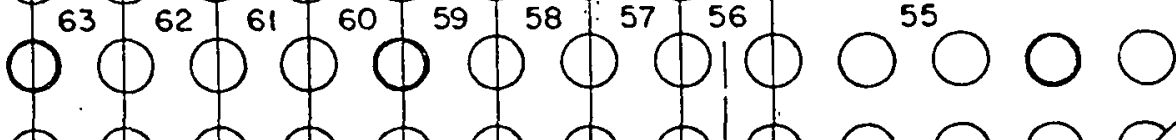

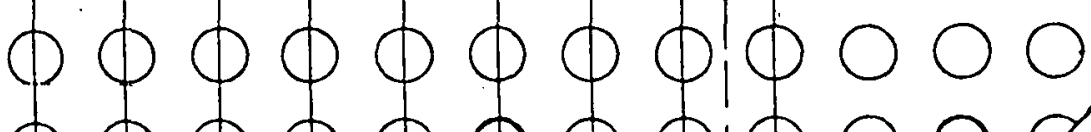

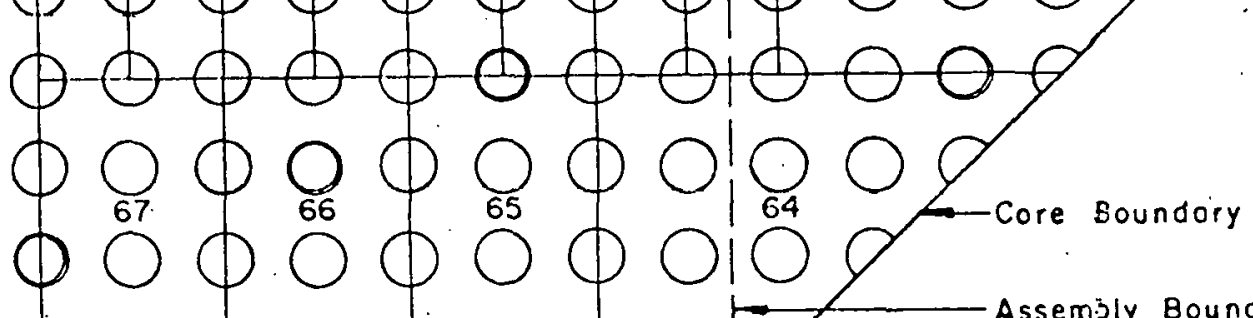

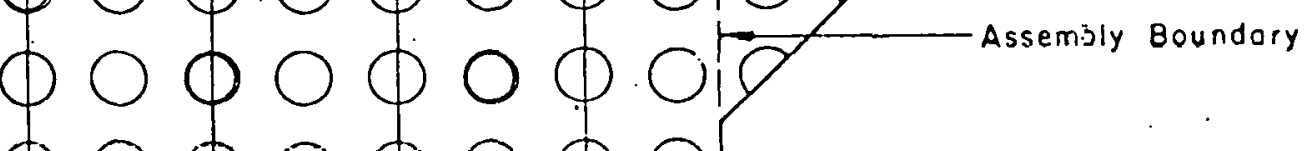

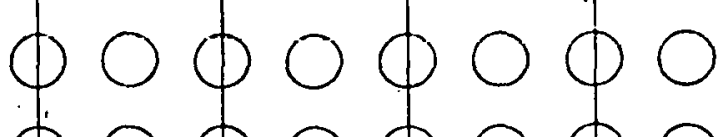

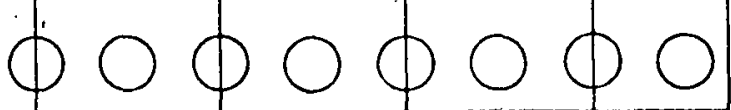

FIG. 1 COBRA $\|$ MODEL OF $1 / 8$ SEGMENI UH LOF 1 CUAE FOR STEADY STATE DNB ANALYSIS 


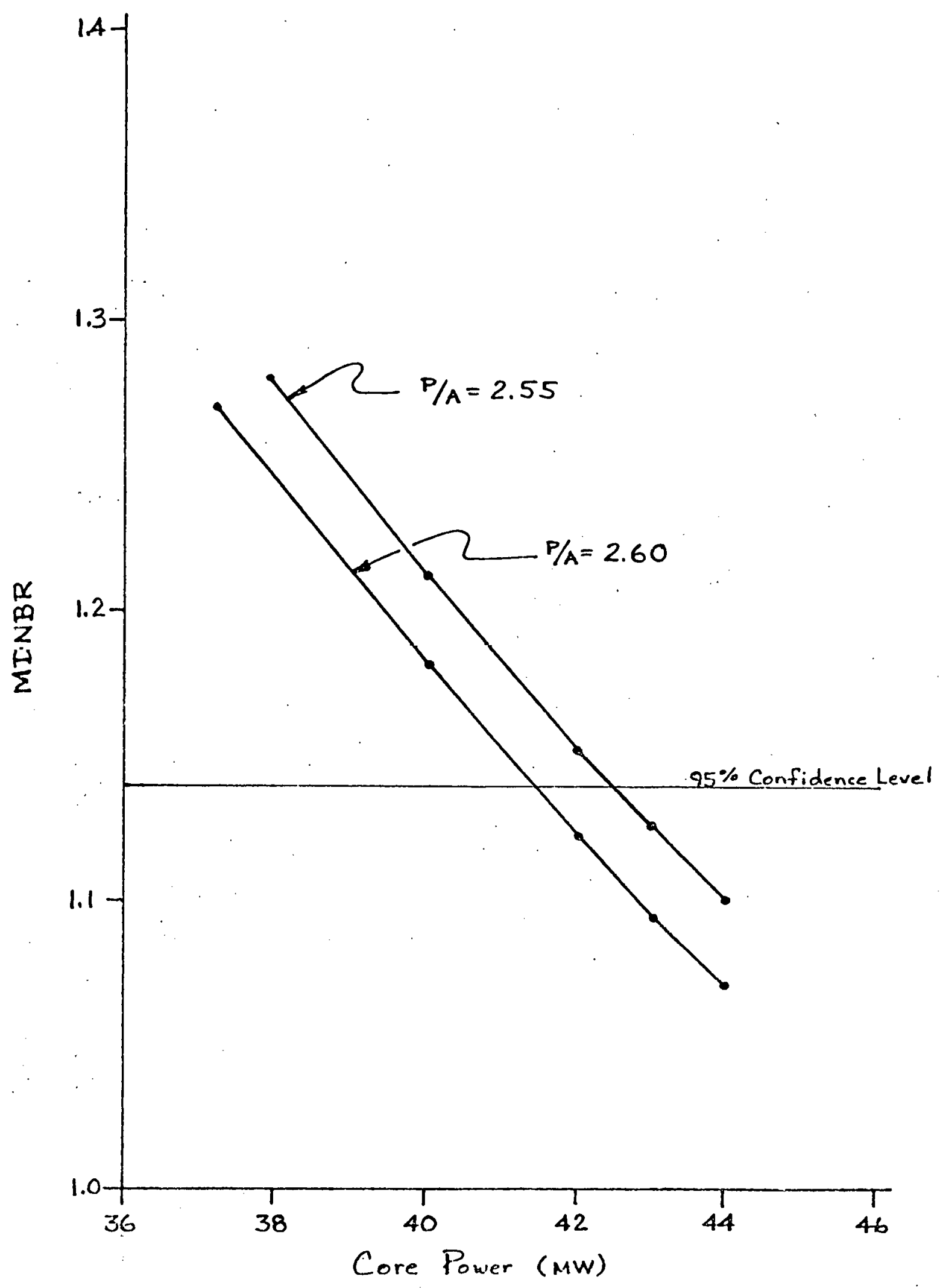

Pigure 2-Core Power versus MDNER 6 


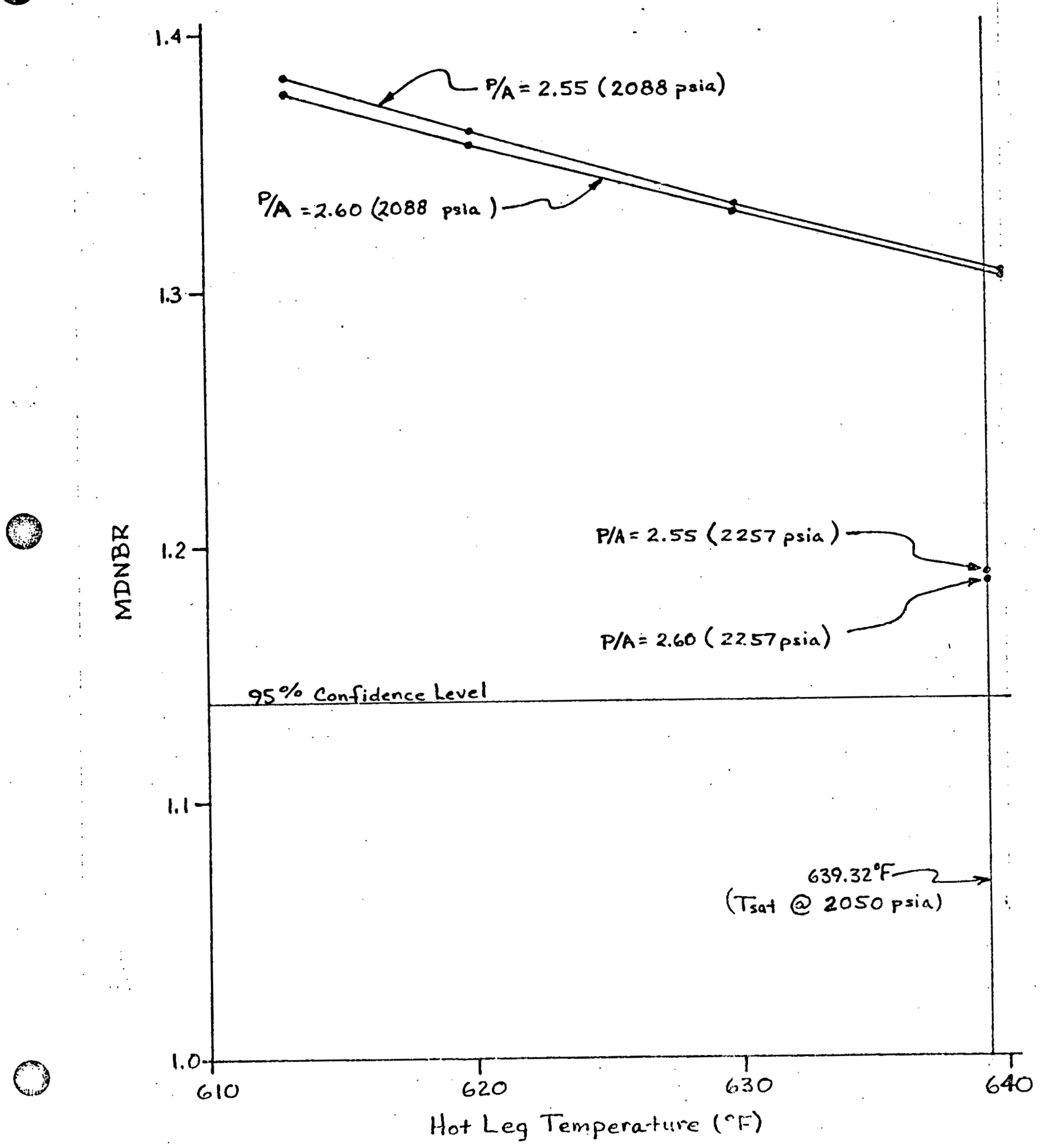

Figure 3- Hot Leg Temperature versus MDNBR 

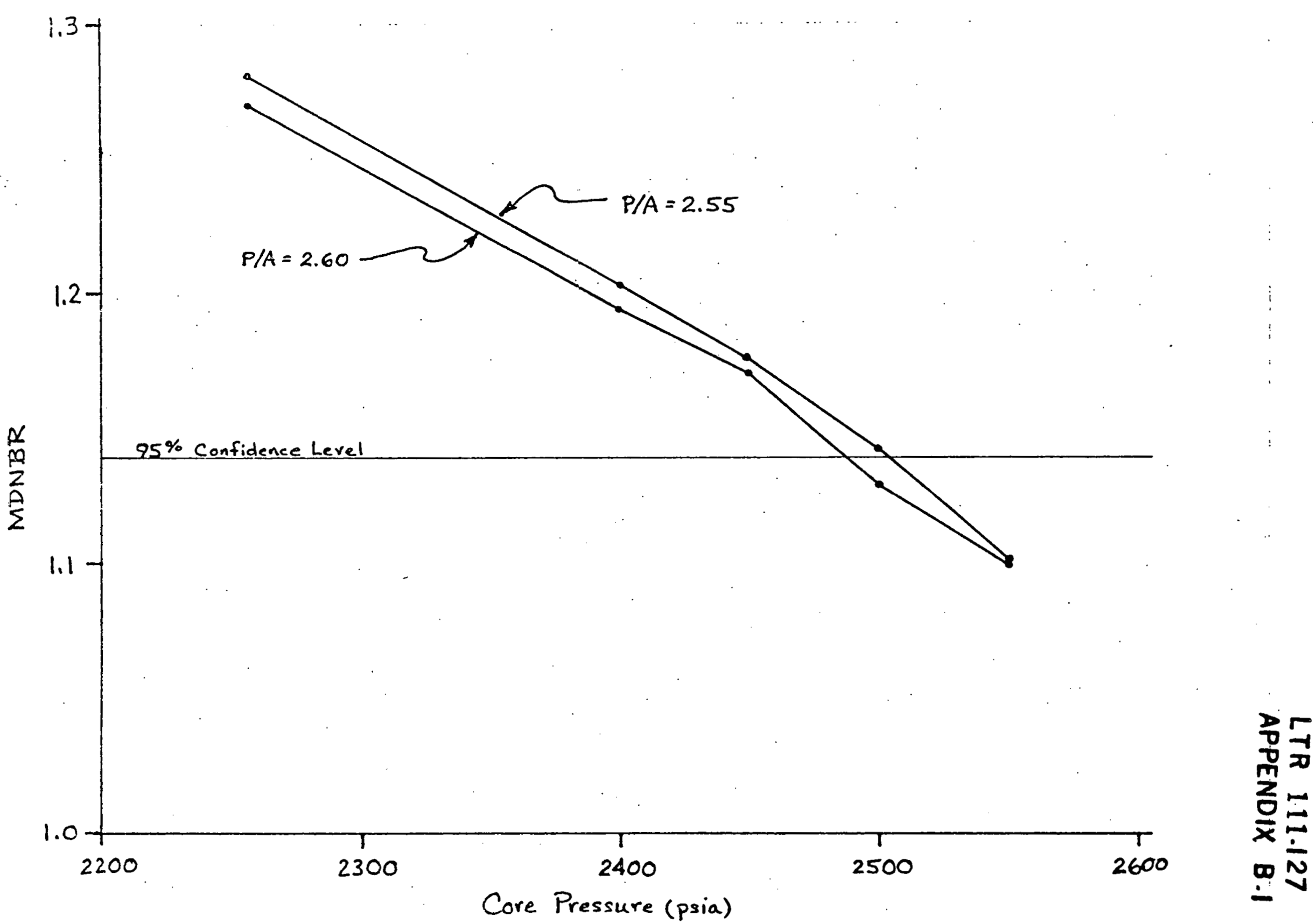

Figure 4 - Core Pressure versus MDNBR 
8

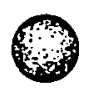

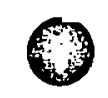

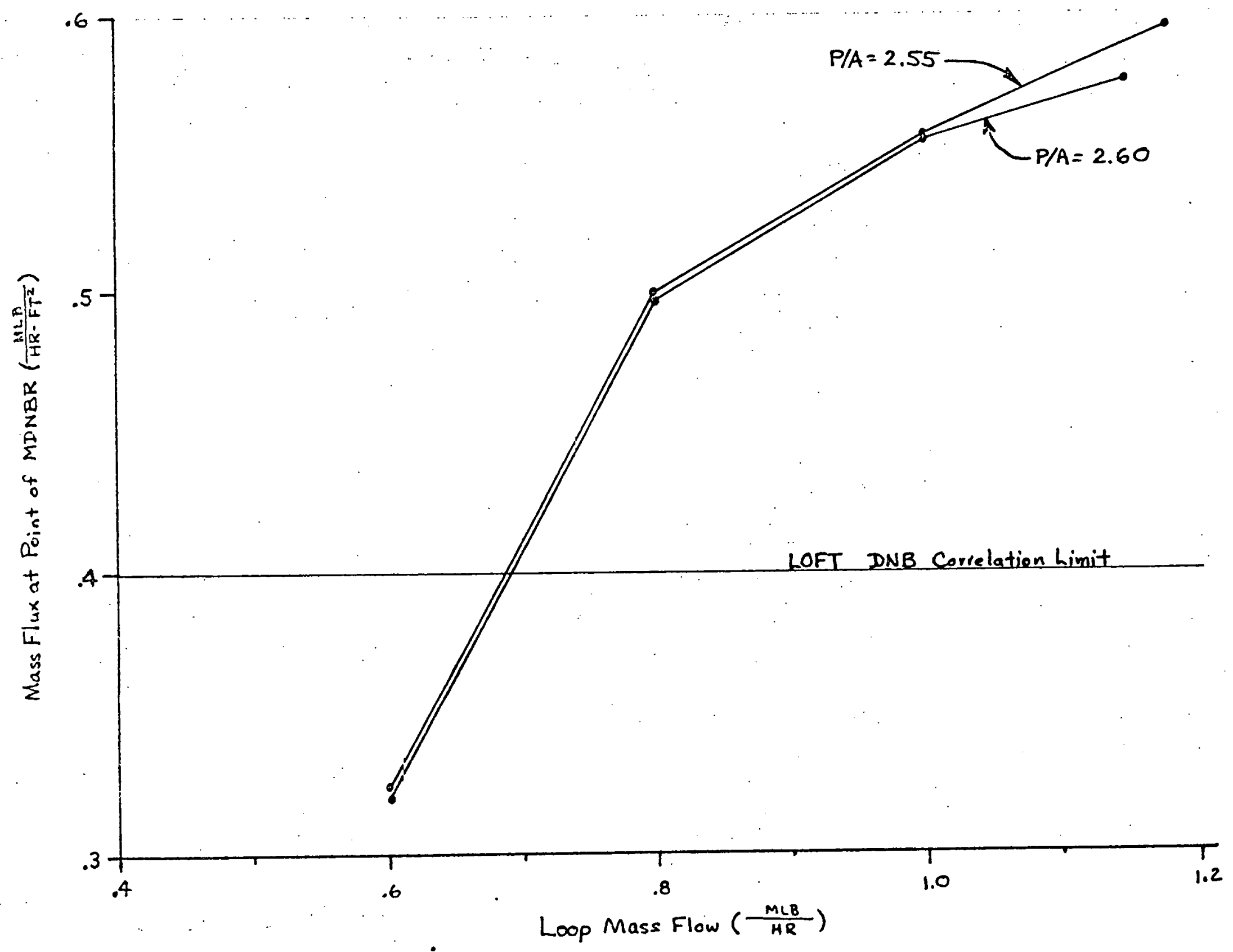

Fiqure 5- Loop Mass Flow versus Mass Fluxat Point of MDNBR 


\title{
$=385$ Idaho
}

\section{INTEROFFICE CORRESPONDENCE}

\author{
dale February 22, 1979 \\ 10 E. C. Anderson

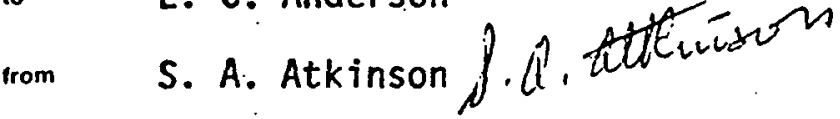 \\ subject STEADY-STATE (SAFETY) LIMITS FOR L2-3 MODE 8 - Atki-4-79
}

The limits for which Damage Criteria $A$ is satisfied for steady-state operation in operating Mode 8 for the L2-3 test have been determined. The Damage Criteria A consequence limit of interest is that MDNBR is greater than or equal to 1.14 using the LOFT-3 DNB correlation. Calculations were done using the LOFT large core model (1/8th of the LOFT core) with the COERA IIIC computer code for thermal-hydraulic analysis in a nuclear fuel rod bundle. The limit analys is method was to set all the sensitive thermal-hydraulic parameters except one to their off-nominal or more severe values (more severe for determining DNBR), then to either:

(a) vary the remaining parameter until MDNBR $=1.14$ or,

(b) determine if MDNBR $\geq 1.14$ at the worst-case trip value of the remaining parameter.

The parameter limits defined in this manner satisfy the intent of 10 CFR 50.36 for safety limits as illustrated in the 1968 Guide to the Content of Technical Specifications.

The resulting steady-state (safety) limits determined according to the above analysis method are:

Parameter Safety Limit

Reactor Power $116 \%$ of nominal

PCS Loop Flow $1.01 \times 10^{6} 1 \mathrm{bm} / \mathrm{hr}$

\section{Comments}

Nominal power is a function of measured peak to average power ratio $(P / A)$ as defined in the $L 2$ EOS. The maximum value of $P / A$ was 2.60 for this analysis. The limit corresponds to MONBR $=1.14$.

The limit corresponds to the maximum flow worst-case trip (WCT) for $P / A=2.66$. However, MDNBR is $>1.14$ for lower $P / A$ 's as well. Minimum mass velocity is greater than the lower limit for the LOFT-3 correlation 
February 22, 1979

\section{LTR. 111.127 \\ APPENDIX B 1}

E. C. Anderson

Atki-4-79

Page 2

Parameter Safety Limit

PCS Temperature $626^{\circ} \mathrm{F}$

(controlled by hot

leg coolant temperature)

PCS Pressure 2400 psia
(Reactor hot 1eg)

\section{Comments}

MDNBR > 1.14 for operation with a $P / A$ up to 2.60 at this hot leg temperature and at a power above the minimum WCT power.

MDNBR $=1 . \$ 44$ for $P / A=2.66$.

The values of all the sensitive parameters for each of the limiting steadystate cases are in Table I attached. The most limiting off-nominal parameter values used for these analyses were:

\author{
Parameter \\ Reactor Power \\ PCS Loop Flow \\ Hot Leg Temperature \\ Pressure
}

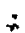

u?.

Attachment:

As stated

cc:

S. A. Atkinson
Off-Nominal Value

Nominal $+2.5 \mathrm{MW}$

$3.327 /(P / A)-(0.125) \mathrm{Mlbm} / \mathrm{h}$

$627^{\circ} \mathrm{F}$

2257 psia (off-nominal high)

D. F. Elger

J. E: Fisher

J. L. Liebenthal $a^{\ell}$

D. G. Satterwhite

R. P. Wadkins papew

TAB File 3.6

Central File 
TABLE I

\section{LIMITING STEADY-STATE CASES FOR L2-3}

\begin{tabular}{|c|c|c|c|c|c|c|}
\hline Case No. & $P / A$ & $\begin{array}{l}\text { Power*t } \\
\text { NWW } \\
\end{array}$ & $\begin{array}{l}\text { Loop Flow } \\
M 1 \mathrm{bm} / \mathrm{h}\end{array}$ & $\begin{array}{c}\text { Pressure } \\
\text { psia } \\
\end{array}$ & $\begin{array}{c}T_{\text {hot }} \\
{ }^{\circ} \mathrm{F} \\
\end{array}$ & MDNBR \\
\hline L2-3. 13 & 2.66 & 36.4 & $1.01 *$ & 2350 & 621 & 1.161 \\
\hline$L 2-3.20$ & 2.66 & 36.4 & 1.12 & $2400^{\star}$ & 621 & 1.144 \\
\hline$L 2-3.46$ & 2.60 & $40.2^{*}$ & 1.15 & 2257 & 621. & 1.142 \\
\hline$L 2-3.48$ & 2.60 & 38.7 & 1.15 & 2257 & $626^{*}$ & 1.172 \\
\hline$\llcorner 2-3.50$ & 2.37 & 40.6 & $1.01 *$ & 2350 & 621 & 1.157 \\
\hline
\end{tabular}

*Parameter for which the limit is being determined or tested.

$\star *$ For $P / A=2.66$, Off-nominal high power $=36.4 \mathrm{M} !$.

For $P / A=2.60$, Off-nominal high power $=37.2 \mathrm{MW}$.

Nominal power $=34.7 \mathrm{MH}$.

Minimum WCT power $=38.2 \mathrm{NW}$.

For $P / A^{i}=2.37$, Off-nominal high power $=40.6 \mathrm{MW}$. 


\section{INTEROFFICE CORRESPONDENCE}

date April 18, 1978

10 T. M. Howe

from S. A. Atkinson

sublect MDNBR VS MLHGR PLOT FOR L2-3 CONDITIONS Atki-12-78

Attached is the results of the COBRA analysis done to generate a plot of MDNBR VS MLHGR for L2-3 nominal and worst-case pre-LOCE operating conditions, as was requested of you by Chuck Solbrig. The worse-case conditions assumed for the analys is may be extra conservative but not by a significant amount. Also, the effect of slightly changing some of the worse-case assumptions is not significant. For instance, if worse-case power is assumed to be only 2.5 MW greater than nominal, instead of $3.5 \mathrm{MW}$ greater, the resulting worse-case MDNBR's would only increase by 2 to $3 \%$ (a MDNBR of 0.96 instead of 0.94 for. MLHGR = $12 \mathrm{~kW} / \mathrm{ft}$ ).

This. study indicates that transient analyses for L2-3 pre-LOCE conditions may not be expected to have consequences that fall under Damage Criteria $A$ in the LOFT Technical Specifications. Whether or not Damage Criteria $B$ can be complied with (as is required by the LOFT Technical Specifications) is not discernable from the results of this study.

prk

.cc: W/attachment

E. C. Anderson

C. H. Cooper

R. A. Dimenna

G. A. Uinneen

D. F. Elger

N. F. Fausz

C. W. Solbrig

R. P. Wadkins

S. A. Atkinson.

Central File 


\section{LTR 111.127 \\ APPENDIX B.2}

SUMMARY: It was requested that work te done to generate a plot of MDNBR as a function of PLHGR for two sets of conditions. One set of conditions used worst case values of flow, THOT, power and power profile uncertainties. The input conditions are summarized below. ( $S C M)$

WORST CASE CONDITIONS

$$
\text { FLOW }_{\ell}^{\prime}=\frac{(37.13 \mathrm{MW}) 3.413 \times 10^{6} \frac{\mathrm{BTU}}{\mathrm{m}-\mathrm{MW}}}{88.08 \frac{\mathrm{BTU}}{1 \mathrm{bm}}}-\left[.395 \times 10^{6}\right]
$$

$=1.04 \times 10^{6} .1 \mathrm{bm} / \mathrm{hr}$

POWER $=\frac{\text { PLHGR }}{.3232}+3.5 \quad 40.6 \mathrm{mw}$ for $1-2-3$

$T_{\text {HOT }}=625^{\circ} \mathrm{F}$

PROFILE: $\quad$ L1057 $: F_{Q}=2.43$ FLAT RADIAL ASSUMPTION

$$
\begin{array}{ll}
F_{Q}{ }^{U}=7 \% & F_{\Delta H}{ }^{U}=7 \% \quad F_{\Delta H}{ }^{E}=1.032 \% \\
F_{Q}{ }^{E}=3.2 \% & F_{Q}{ }^{D}=1.1 \% F_{\Delta H} \text { Dens. }=1.1 \%
\end{array}
$$

$$
\underline{\text { PRESSURE }}=2440 \mathrm{psia}
$$

NOMINAL CONDITIONS

$$
\begin{aligned}
& \mathrm{FLOW}_{\ell}=1.44 \times 10^{6} \mathrm{lbm} / \mathrm{hr} \text { (No } 5 \% \text { penalty to hot assembly) } \\
& \underline{\text { POWER }}=\frac{\text { PLHGR }}{.3232} \quad 37.1,414 \therefore \therefore \% 3 \\
& \underline{T_{\text {HOT }}}=617^{\circ} \mathrm{F}
\end{aligned}
$$

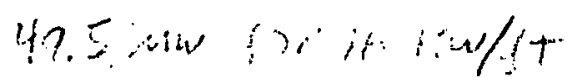

$$
\begin{aligned}
\text { PROFILE }= & \text { L1057 } F_{Q}=2.43 \text { NORMAL RADIAL DISTRIBUTION } \\
& \begin{array}{l}
\text { No uncertainties, "HOT" pin is not placed in subchannel } \\
\text { number } 15 .
\end{array} \\
\text { PRESSURE }= & 2262 \text { psia }
\end{aligned}
$$

\section{RESULTS}

\begin{tabular}{c|c|c}
$\begin{array}{c}\text { PLHGR } \\
(\mathrm{kW} / \mathrm{ft} \text { ) }\end{array}$ & $\begin{array}{c}\text { MDNBR } \\
\text { (worst case) }\end{array}$ & $\begin{array}{c}\text { MDNBR } \\
\text { (nominal) }\end{array}$ \\
\hline 8 & 1.40 & 2.295 \\
12 & .9375 & 1.549 \\
16 & .6431 & 1.134 \\
\hline
\end{tabular}




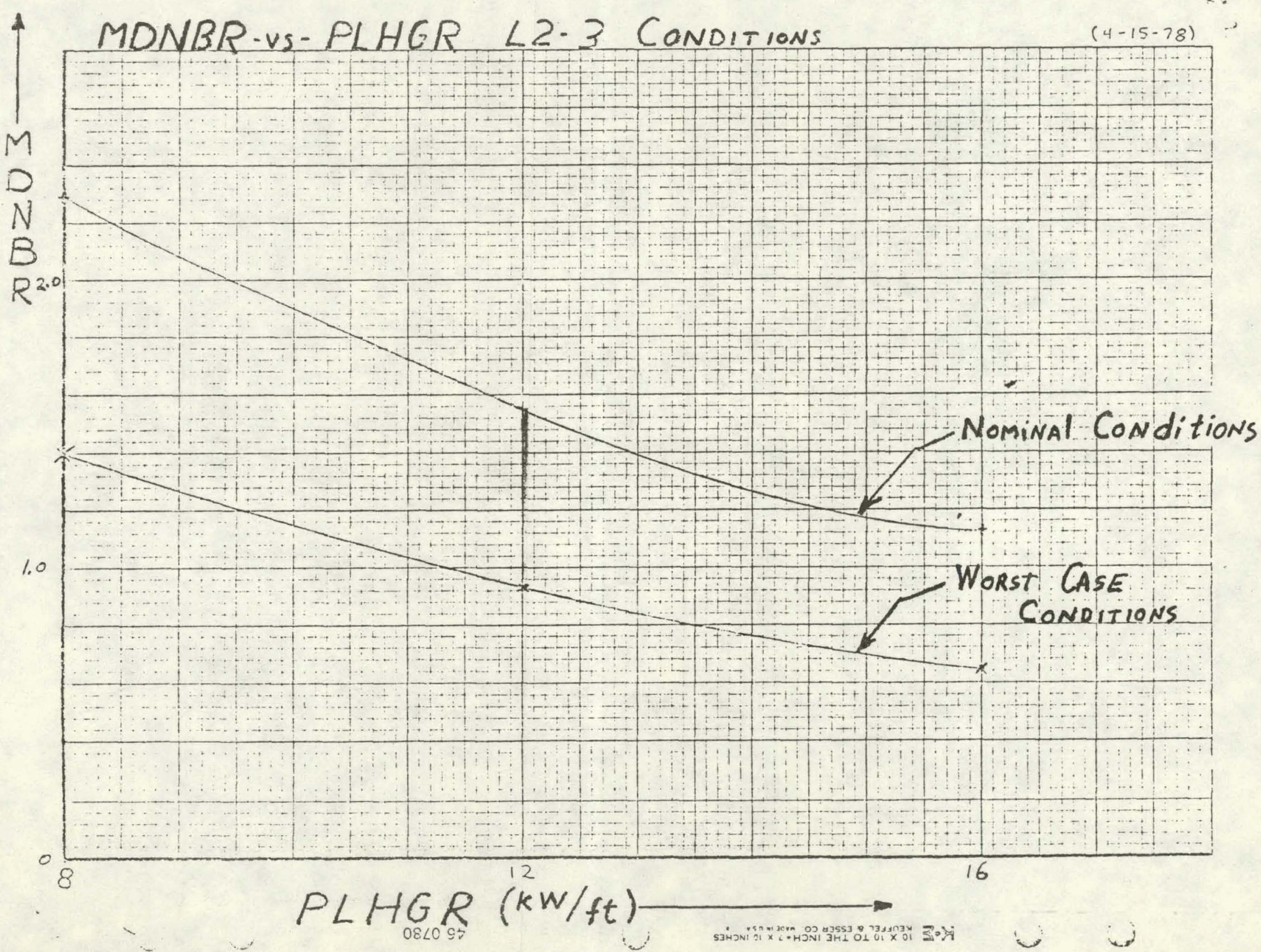


APPENDIX B-3

COBRA ANALYSIS FOR L2-3 MODE 7

OPERATION WITH MAXIMUM

XENON BUILDIN 


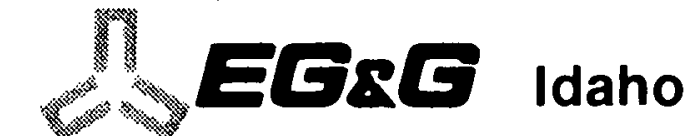

LTR 111.127

APPENDI: B.3

\section{INTEROFFICE CORRESPONDENCE}

\author{
date Apri1 3, 1979 \\ to S. A. Atkinson

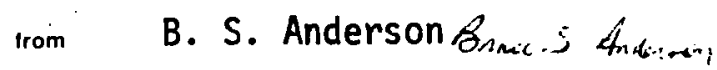 \\ subject MDNBR's FOR LOFT L2-3 OPERATION WITH A XENON PERTURBATED \\ AXIAL POWER PROFILE - BSA-5-79 \\ Refs: (a) Letter B. S. Anderson to S. A. Atkinson, "L2-3 Mode 8 \\ Steady-State Limits -BSA-4-79" (March 23, 1979). \\ (b) Letter S. A. Atkinson to T. M. Howe, "LOFT Ful1 Power \\ Safety Margins with Xenon Peaking Perturbation - Atki-32-78" \\ (September 21, 1978).
}

Two COBRA IIIC cases have been run to determine steady-state MDNBR while operating at $39 \mathrm{MW}$ and $50 \mathrm{MW}$ with a xenon perturbated axial profile with a radial peaking factor of 1.60 . Initial conditions for both cases are listed in Table I. Xenon buildin was generated by assuming that the reactor operated at 75 percent of full power for 100 hours to buildin equilibrium xenon, and then was shut down for 7.5 hours to allow the xenon concentration to reach a peak. The profile was then calculated using peak xenon at zero power, a coolant temperature of $555^{\circ} \mathrm{F}$, and the CRA's withdrawn 59 inches. Using these assumptions the peak $P / A$ is moved further downstream in the core (further from the bottom of the core). Figure 1 shows the axial profile. The reactor was then assumed to be brought up to power while this profile existed.

The MDNBR is 1.841 for the $39 \mathrm{MW}$ case and 1.381 for the $50 \mathrm{MW}$ case. The highest power which could occur in L2-3 is the worst case trip power of $42.7 \mathrm{MW}$. By linear interpolation between the $39 \mathrm{MW}$ case and the $50 \mathrm{MW}$ case the MDNBR will be 1.686 at a power of $42.7 \mathrm{MW}$. Linear interpolation was used based on Figure 2 which is a plot of power versus MDNBR from Reference (a). As can be seen the core power versus MDNBR is almost linear. A MDNBR of 1.686 compares favorably with case $\times 50-2(b)$ which is a $50 \mathrm{MW}$ case with the CRA's 56 inches withdrawn, and a xenon perturbated axial profile. Steady-state MDNBR for case $\times 50-2$ is 1.553 , and was shown to have a safety margin over case $\times 50-1$ (b). Case $\times 50-1$ is a $50 \mathrm{MW}$ case with CRA's withdrawn 48 inches, a BOL axial power profile, and is the limiting case for steady-state MDNBR (1.402) reported in the FSAR. Since the highest power expected in LOFT during the L2-3 experiment will be less than 42.7 MW (MDNBR $=1.686$ ) the safety margin with the xenon perturbed axial power profile shown in Figure 1 should be even greater than the margin for case $\times 50-2$. The xenon profile of Figure 1 should, therefore, be acceptable for any power level expected during normal L2-3 operation at high loop flow rate. 


\section{LTR 111.127 \\ APPENDIX B.3}

S. A. Atkinson

Apri] 3, 1979

BSA-5-79

Page 2

NOTE: To obtain position of CRA above fuel bottom, add two inches to withdrawn value.

$u 1$

Attachments

As stated

CC: D. F. Elger

J. E. Fisher

B. L. Rushton

D. G. Satterwhite

R. P. Wadkins

B. S. Anderson File

Central File

TAB File 3.5 


\section{LTR 111.127 \\ APPENDI: B.3}

TABLE I

THERMAL-HYDRAULIC CONDITIONS FOR XENON PERTURBED

AXIAL PROFILE MDNBR STUDY CASES

\begin{tabular}{lll} 
Parameters & $\frac{\text { Case 1 }}{39}$ & $\frac{\text { Case 2 }}{50}$ \\
Power (MW) & \multicolumn{1}{c}{ (M67.8 } & 559.3 \\
Inlet Temperature $\left({ }^{\circ} \mathrm{F}\right)$ & 2262 & 2262 \\
Pressure (psia) & $3.42 \times 10^{6}$ & $3.42 \times 10^{6}$
\end{tabular}




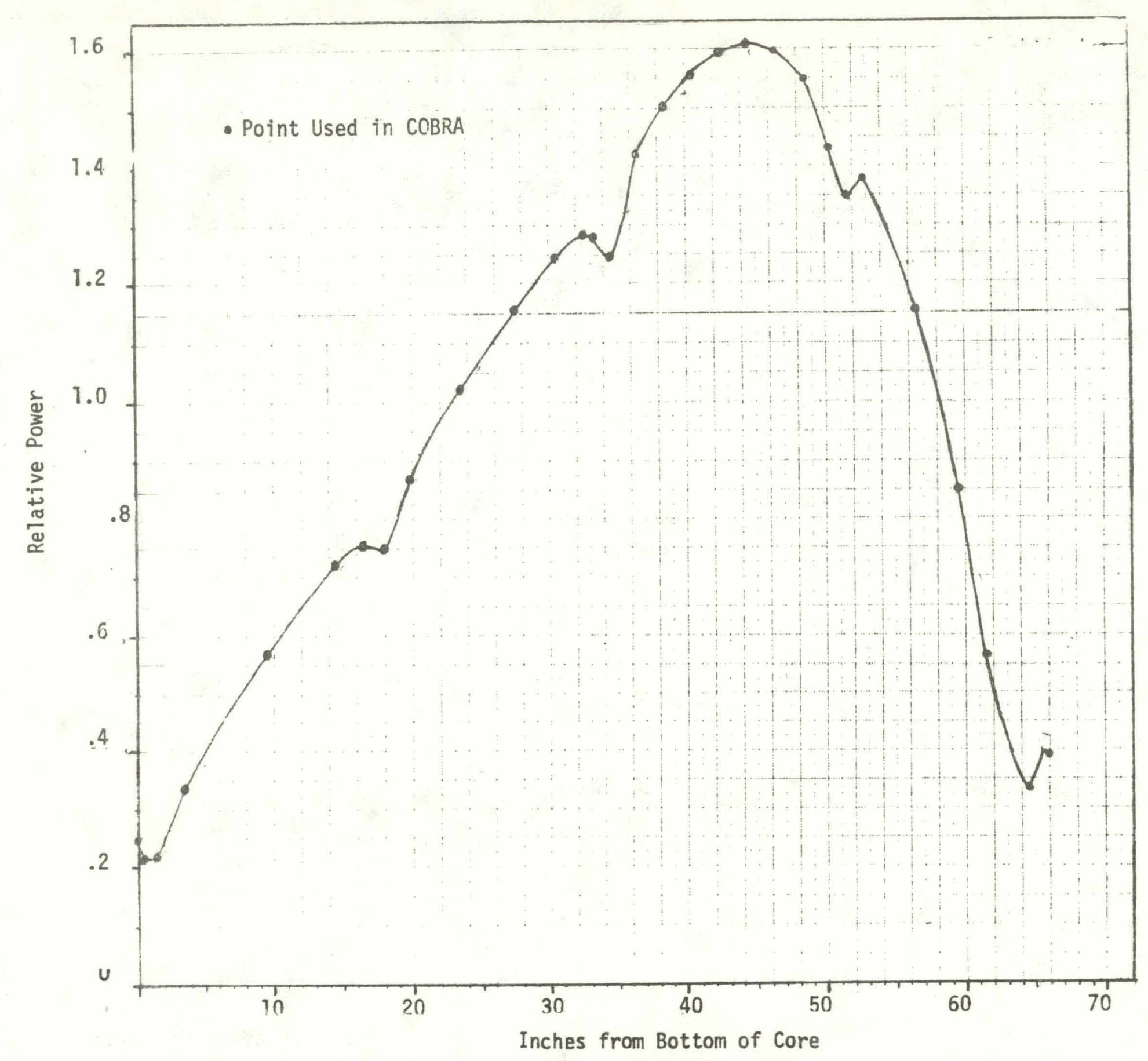

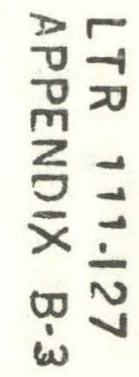

Fiqure 1 - Xenon Perturbated Axfal Profile 


\section{LTR 111.127 \\ APPENDIX B.3}

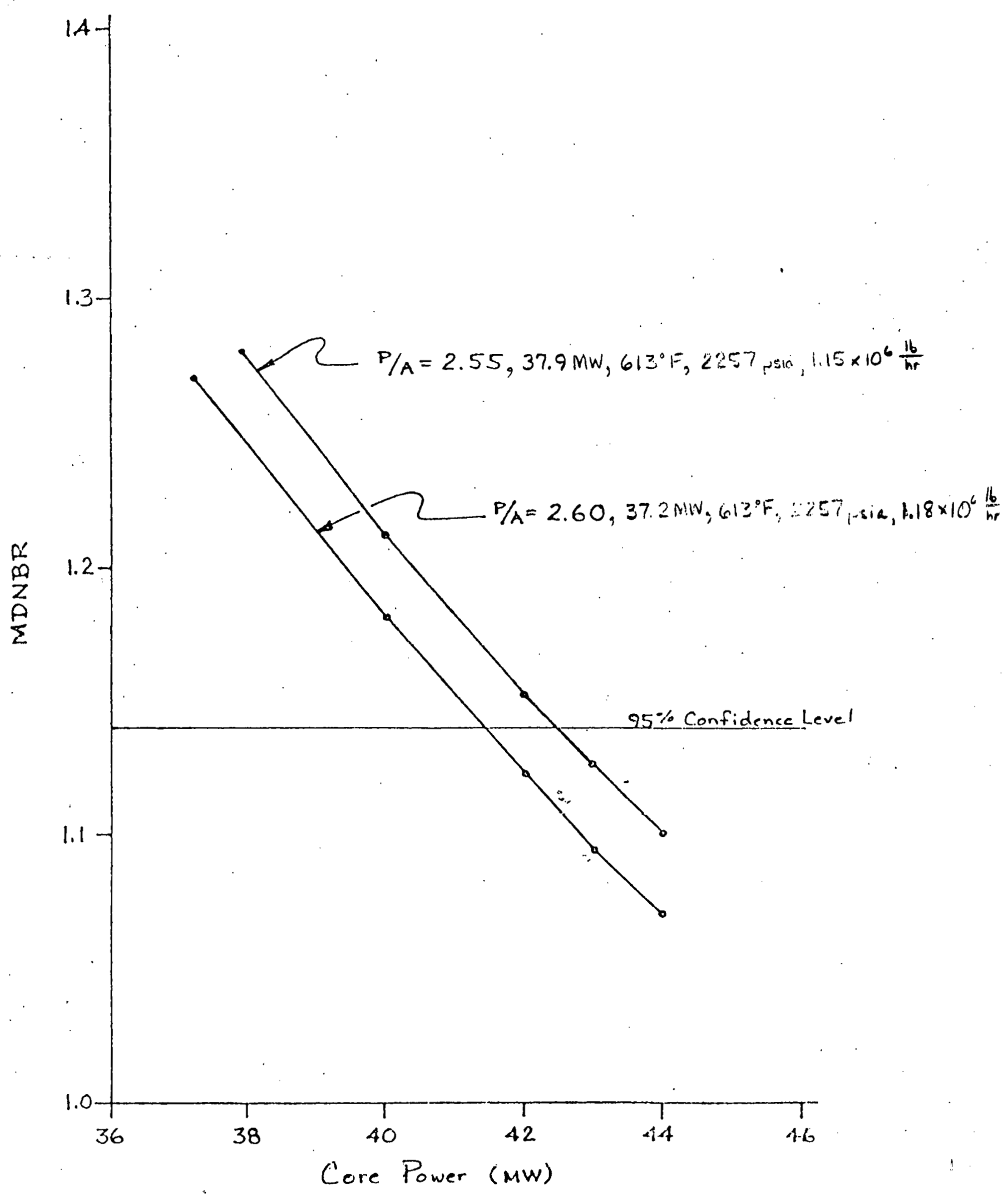

Figure 2-Core Power versus MDNBR 
APPENDIX B-4

MODE 8 TRANSIENT

ANALYSIS RESULTS 


\title{
INTEROFFICE CORRESPONDENCE
}

\author{
date $\quad$ March 15, 1979 \\ to E. C. Anderson \\ rom S. A. Atkinson $f . Q$. tettivisis \\ subject LOFT L2-3 MODE 8 SAFETY ANALYSIS RESULTS WITH COBRA IIIC \\ CORRECTION - Atki-9-79 \\ Refs: (a) S. A. Atkinson 1 tr to E. C. Anderson, Atki-7-79, \\ "L2-3. Mode 8 Transient Analysis Results", March 13, 1979 \\ (b) S. A. Atkinson 1tr to E. C. Anderson, Atki-8-79, "COBRA IIIC \\ - COBRA IV-I Comparison and Spacer Grid Loss Calculation \\ Error", March 14, 1979 \\ (c) S. A. Atkinson 1 tr to E. C. Anderson, Atki-4-79, "Stecidy- \\ State (Safety) Limits for L2-3 Mode 8", February 22, 1979.
}

The analysis results (consequences) for the limiting transients are changed by the correction of the error in the computer coding for the LOFT spacer grids loss coefficient equation as discussed in Reference (b). Therefore, the limiting transients (those for which LOFT-3 MDNBR < 1.14) have been re-analyzed with the COBRA IIIC LOFT large core model and the spacer grid loss coefficient equation corrected as indicated in Reference (b). As indicated in Reference (b), the loss coefficient equation error results in a conservative calculation for MDNBR. Therefore, all other (non-limiting) transients, including the rod ejection accident, were not re-analyzed. The results of analysis for these other transients remains as transmitted by Reference (a), recognizing that the results are somewhat conservative.

The results of the analyses for the limiting transients with the corrected loss coefficient equation are:

Accident.

Boron Dilution

$$
R \leq 0.1 \times 10^{-4} \Delta \rho / \mathrm{s}
$$

Boron Dilution or Slow CRWA

$$
R \leq 0.7 \times 10^{-4} \Delta \rho / \mathrm{s}
$$

CRWA

$$
\begin{aligned}
& R>0.7 \times 10^{-4} \Delta \rho / s \\
& \left(R=2.0 \times 10^{-4} \Delta \rho / s\right)
\end{aligned}
$$

Loss of Steam Load

$17 \mathrm{~s}$ stroke time on SFCV
MDNBR

1.162

1.156 


\section{Atki-9-79}

Page 2

The limits on operating conditions and worst-case trips remain the same as transmitted by Reference (a).

In conclusion, the transient analyses demonstrate that the LOFT Damage Criteria for mode 8 operation can be met for operation within the bounds described in Reference (a) using the LOFT-3 correlation. Reference (a) indicated that additional safety margins may exist if the LOFT low-flow (ANC-6) data is used to define the 95-95 bound for DNB. But, COBRA calculations with the corrected spacer grid loss coefficient equation indicate that the mass fluxes at the point of MDNBR are at the upper bound of the ANC-6 data. Therefore, it would not be appropriate to use the ANC-6 95-95 bound without including LOFT DNB data for higher mass fluxes $\left(G>0.6 \mathrm{Mlbm} / \mathrm{h}-\mathrm{ft}^{2}\right)$.

Steady-state COBRA IIIC calculations have also been done, with the corrected spacer grid loss coefficient equation, for a high off-nominal hot leg temperature of $613^{\circ} \mathrm{F}$. The results reported in Reference (c) vere for a $621^{\circ} \mathrm{F}$ high off-nominal hot leg temperature. Also, these steady-state calculations defined the safety limit for each parameter in terms of the limit of Damage Criteria A (MDNBR $>1.14$ ), or physical or data limits. The resulting safety 1 imits for a $\bar{E} 73^{\circ} \mathrm{F}$ high off-nominal hot leg temperature are:

$\begin{array}{ll}\text { Parameter } & \text { Safety Limit } \\ \text { Reactor Power Nominal power } & \begin{array}{l}\text { Nom } \\ +6 \mathrm{Mh}^{\prime}\end{array}\end{array}$

Hot Leg

Temperature. $639^{\circ} \mathrm{F}$

PCS Loop

Flow

$<0.8 \times 10^{6} 1 \mathrm{bm} / \mathrm{h}$

PCS pressure 2490 psia

(high)

(Reactor Outlet)

u1

cc:
B. S. Anderson
S. A. Atkinson (2)
D. F. Elger
N. F. Fausz
J. E. Fisher

\author{
Limiting Condition Cominents \\ MONBR $>1.14$ \\ Limit was $41 \mathrm{MW}$ \\ for $P / A=2.60$
}

Reactor outlet saturation MONBR > 1.14 for low off-nominal pressure $=2050$ psia

Lower limit of LOFT-3 correlation (mass flux

MDNBR > 1.14

MDNBR $\geq 1.14$
J. L. Liebenthal
D. G. Satterwhite
R. P. Wadkins for
Central Files
TAB File 3.5 
F. K. Hyer

J. L. Liebenthat

D. G. Satterwhite

\author{
date $\quad$ March 13, 1979 \\ E. C. Anderson
trom S. A. Atkinson f. $d$. teli-iitim \\ súbject L2-3 MODE 8 TRANSIENT ANALYSIS RESULTS - Atki-7-79
}

Transient analyses for accidents and operational transients have been completed for mode 8 (LOCE pre-blowdown) operation for the L2-3 test. The applicable damage criteria can be met for all transients for the following limitations on operating conditions:

$$
\begin{aligned}
& \text { Measured peak-to-core average } \leq 2.60 \\
& \text { Power ratio }(P / A) \\
& \text { Reactor power (MW) } \\
& P_{O N}-4.5 \text { to } P_{O N}+2.5 \\
& P_{O N} \equiv \text { nominal power }=90.23 /(P / A) \\
& \text { PCS loop flow }(M 1 b m / h) \quad \geq[3.327 /(P / A)]-0.125 \\
& \text { Pressure (reactor outlet) (psia) } 2050 \text { to } 2257 \\
& \text { Hot leg temperature } \quad \leq 613^{\circ} \mathrm{F}
\end{aligned}
$$

For the transient analyses, the following worst-case trippoints and trip time constants were assumed:

\section{Trip Parameter}

Reactor power (MW)

$P / A>2.55$

$2.50 \leq P / A \leq 2.55$

$$
P / A \leq 2.50
$$

PCS loop flow $(1 \mathrm{bm} / \mathrm{h})$

Pressure (psia)

low

high

Hot leg temperature $\left({ }^{\circ} \mathrm{F}\right)$

RABV opening

Loss of PSMG field

\section{Worst-Case}

Trippoint

$$
\mathrm{P}_{\mathrm{ON}}+3.5
$$$$
\mathrm{P}_{\mathrm{ON}}+3.8
$$$$
P_{O N}+4.2
$$$$
1.01 \times 10^{6}
$$

2000

2340

$\left(T_{\text {hot }}\right)_{\text {nom }}+8$

$10 \%$ full open

Trip Time

Constant (s)

1.0

1.0

1.0

15

0.10

0.1 s delay 
Page 2

The steam generator main feedwater was assumed to be tripped $1.25 \mathrm{~s}$ after scram is initiated.

The equations for nominal power and initial (off-nominal low) flow were supplied by T. M. Howe on January 4, 1979, and are consistent with the specified conditions in the L2 EOS (a). Because the pressure and temperature conditions found to be acceptable for the L2-3 transients are slightly different from those specified in the $L 2 E O S$, then $\triangle H$ in the flow equation will change. The flow equation is $(a)$ :

$$
\begin{aligned}
\text { Loop flow }=\dot{m}= & \frac{P_{L}}{\Delta_{H}} 3.413 \mathrm{M} 7 \mathrm{bm} / \mathrm{h} \\
& P_{L}=7.519 \frac{M L H G R}{(P / A)} M W=90.23 /(P / A) \\
\dot{m}= & 308 /[(P / A)(\Delta H)]
\end{aligned}
$$

For 2200 psia and $609^{\circ} \mathrm{F} \mathrm{T}_{\text {hot }}$ (nominal), $\Delta H=86.78 \mathrm{Btu} / 1 \mathrm{bm}$ (for $64.5^{\circ} \mathrm{F}$ $\Delta T$ across the core). For hethis condition,

$$
\dot{m}=3.55 /(P / A)
$$

For the mode 8 safety analysis, the assumed off-nominal flows and low flow trips were based on:

$$
\dot{m}=3.502 /(P / A)
$$

Therefore, the assumed flows for the safety analysis are conservative for operation with $T_{\text {hot }}$ (nominal) $\leq 609^{\circ} \mathrm{F}$.

The analyzed transients are 1 isted in the attached Table I, along with the results of the COBRA and/or FRAP analys is for the transients.

A11 the L2-3 transients were analyzed assuming a lowered nominal pressure (lowered from the 2262 psia assumed for previous operation to $2169 \mathrm{psia}$ ). This lowering of the nominal pressure was considered necessary to gain safety margin when transients result in increased pressure to near the high pressure trippoint. Reference (e) discusses the improvement in safety margin obtained by lowering the nominal pressure for L2-3 mode 8 low operating flow.

The transients were analyzed with initial power and pressure adjusted within their control bands such that power and pressure are at their worst-case trip levels simultaneously. The boron dilution and control rod withdrawal accidents were tripped by hot leg temperature with power and pressure at or above their worst-case trip levels.

The MDNBR (calculated using the LOFT-3 ONB correlation ( $f$ )), was compared to the 95-95 DNB bound for the LOFT low flow DNB data (ANC-6 fue 1 bundle data). The 95-95 bound is the bound for which $95 \%$ of the DNB population for the fuel pin being analyzed is enveloped by the bound (a $95 \%$ probability of not having DNB for that fuel pin) with a $95 \%$ confidence level. The determination of the 
95-95 bound for the LOFT low flow DNB data, and the correspording LOFT-3 MDNBR for the transient hot channel mass velocity (near $0.5 \mathrm{M} / \mathrm{bm} / \mathrm{h}-\mathrm{ft}^{2}$ ), is discussed in Reference ( $f)$. This bound is used to test against the intent of Damage Criteria $A$, and for forcing DNB in FRAP calculations for Damage Criteria B.

The analyses for the boron dilution accidents, CRWA's, and the loss of steam load accident used a revised value for the LOFT fuel engineering hot spot factor of 1.026 . This revised factor is based on the 3-standard deviation bound for combined fuel pellet enrichment and fuel pellet density (a $99.9 \%$ probability that the actual value is less than or equal to 1.026 ). Development of the revised engineering hot spot factor is discussed in Reference $(\mathrm{g})$.

Analysis for a measured peak-to-core-average power ratio $(P / A)$ of 2.60 are limiting, even when analyses for lesser values of $P / A$ was done with a larger margin to the worst-case power trip. This result is evident in the comparisons for MDNBR tabulated in Table 2. Table 2 also shows that the LOFT-3 MDNBR is above the ANC-6 95-95 bound (MDNBR > 1.106 for these transients with margins between nominal and WCT power levels of:

$\begin{array}{cc}P / A & \text { WCT margin above nominal (MW) } \\ 2.50 & 4.2 \\ 2.55 & 3.8 \\ 2.60 & 3.5\end{array}$

The maximum reactivity addition ramp rate analyzed for was $8 \times 10^{-4} \Delta \mathrm{p} / \mathrm{s}$. For a maximum differential worth for a 4-CRA withdrawal of $0.141 \% \Delta \mathrm{p} /$ inch (the maximum worth for $L 2-2$ operation) the reactivity addition rate for a 29 inches/min. maximum withdrawal speed is $6.82 \times 10^{-4} \Delta \rho / \mathrm{s}$. The L2-3 maximum differential worth has been calculated to be only $0.127 \% \Delta \rho /$ inch. Therefore, the $8 \times 10^{-4} \Delta p / s$ ramp rate analyzed for envelopes the maximum CRWA for L2-3 mode 8 operation.

In conclusion, the transient analyses demonstrate that the LOFT Damage Criteria for mode 8 operation can be met for operation within the bounds described at the beginning of this correspondence. When MDNBR is compared to the 95-95 bound for the low flow (ANC-6) DNB data, it is seen that there is some extra margin available. Therefore, it may have been possible to meet the Damage Criteria with slightly more severe conditions corresponding more closely to the L2 EOS specifications. An analys is was done for a $0.5 \times 10^{-4} \Delta \rho / s$ ramp rate with an initial off-nominal value for $\mathrm{T}_{\text {hot }}$ of $617^{\circ} \mathrm{F}$. MDNBR $=1.109$, but the ANC-6 95-95 bound for this transient was 1.916 . Therefore, the available margins are sma11. Additionalily, since future tests (such as L2-5 with a changed center fuel bundle and L2-4 at higher power density) will be more severe, it is advisable to take steps now to increase the available safety margin.

u1

Attachments:

As stated 
(a) P. A. Harris, et al, "LOFT Experiment Operating Specification, Volume 2, Power Ascension Test Series L2", July 1978.

(b) S. A. Atkinson 1tr to E. C. Anderson, Atki-5-79, "Pressure Trips for L2-3 Mode 8 with 2169 psia Nominal Pressure," March 2, 1979.

(c) S. A. Atkinson, "L2-2 Pre-LOCE Maneuver Core Safety Analysis," LTR 111-116, November. 17, 1978, Section V.

(d) B. S. Anderson 1tr to E. C. Anderson, BSA-7-79, "Results of L2-3 Rod Ejection Cases," January 19, 1979.

(e) S. A. Atkinson $1 \mathrm{tr}$ to E. C. Anderson, Atki-3-79, "Nominal Pressure Decrease for L2-3 Mode 8," February 2, 1979.

(f) S. A. Atkinson 1tr to E. C. Anderson, Atki-6-7.9, "95\% Probability (at 95\% Confidence) Bound for LOFT Bundle DNB Data at Low Flows," March 7, 1979.

(g) N. F. Fausz Itr to E. C. Anderson, NFF-1-79, "Statistical Evaluation of the LOFT Heat Flux Engineering Hot Spot Factor," February 27, 1979. 
L2-3 MODE 8 TRANSIENT ANALYSIS RESULTS FOR P/A $\leq 2.60$

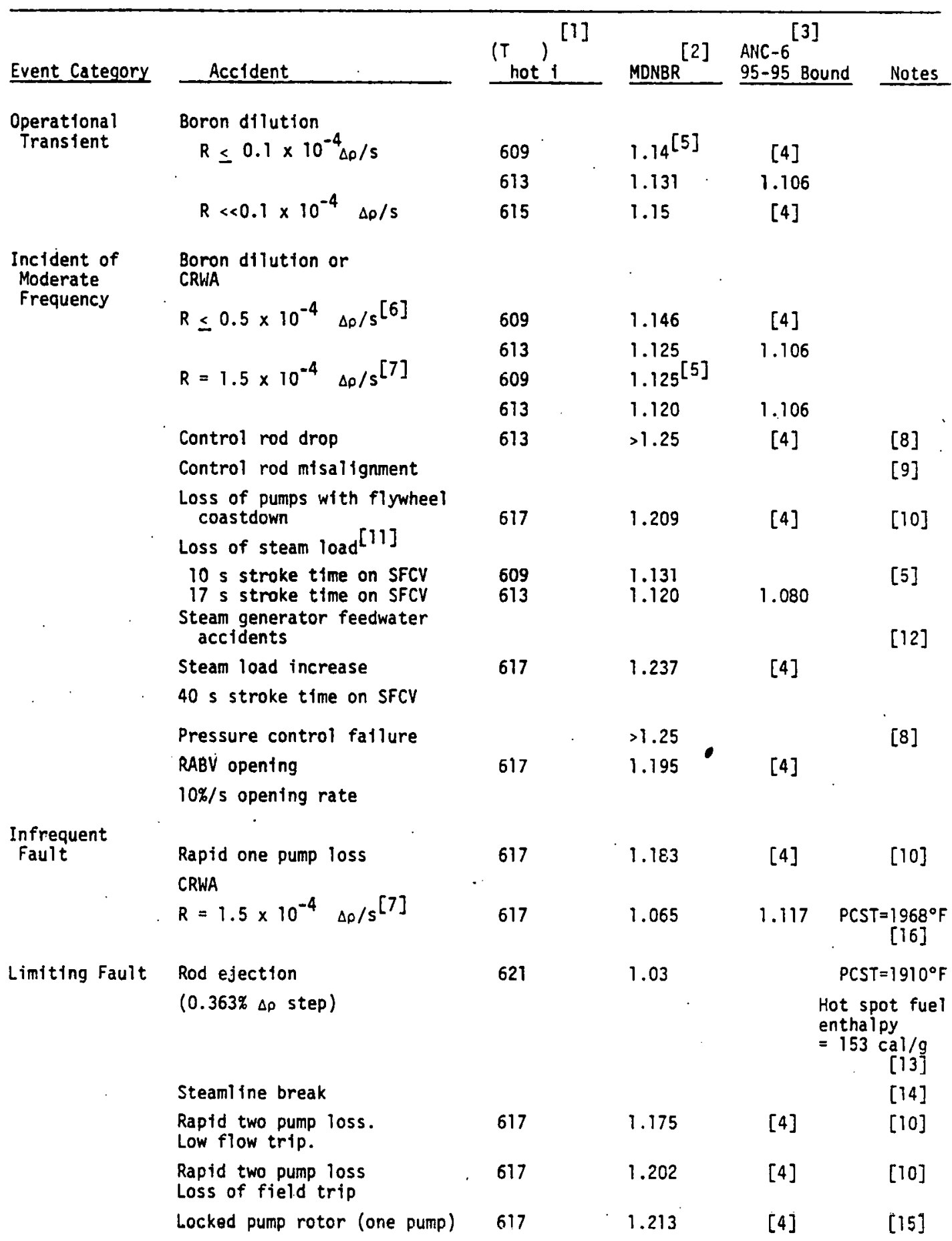


1. High off-nominal hot leg temperature. This temperature is $4^{\circ} \mathrm{F}$ above nominal.

2. Calculated using the LOFT-3 correlation.

3. For a $95 \%$ probability of no DNB with a $95 \%$ confidence for the low flow (ANC-6 test bundle) LOFT DNB data. This number is the LOFT-3 MDNBR which corresponds to the ANC-6 95-95 bound. See Reference (b) for more detail.

4. For the L2-3 mode 8 transients, in which $X<0$ at the point of MDNBR, the LOFT-3 MDNBR corresponding to the ANC- 6 95-95 bound is less than 1.14, the 95-95 bound for the LOFT-3 correlation.

5. For a worst-case power trippoint $3.8 \mathrm{MW}$ above nominal.

6. This is the limiting reactivity ramp rate if control rod withdrawal is inhibited.

7. This is the limiting reactivity ramp rate for all rates up to and including $8 \times 10^{-4} \Delta \rho / \mathrm{s}$. However there is little difference in MDNBR for $0.7 \times 10^{-4} \leq R \leq 2 \times 10^{-4} \Delta p / s$.

8. MDNBR increases throughout this transient. See Reference (b) for a discussion of the results of control rod drop accident analyses.

9. Consequences and protective controls for this accident are no different than for L2-2 mode 8 operation. The analysis and discussion in Reference (c) applies to L2-3 miode 8 operation.

10. A loss of flow accident during the low flow maneuver is not as severe as during low flow operation. This was shown in the L2-2 mode $\&$ safety analys is (c).

11. This accident is the limiting transient for Incidents of Moderate Frequency.

12. The consequences of loss of feedwater or increased feedwater transients are enveloped by the steam load accidents.

13. The results of the L2-3 mode 8 analysis for a maximum control rod ejection accident are discussed in Reference (d). The rod ejection accident analysis assumed a measured $P / A=2.66$, and a power worst-case trippoint of $46.5 \mathrm{MW}$ (a trippoint sufficient to cover any measured P/A down to 2.13). The ejected CRA worth $(0.363 \% \Delta \rho)$ is significantly greater than the maximum calculated worth for L2-3 operation $(0.2 \% \Delta \rho)$. The hot spot fuel enthalpy is significantly less than the Damage Criteria $C$ limit of $280 \mathrm{cal} / \mathrm{g}$, and the maximum cladding temperature is less than $2200^{\circ} \mathrm{F}$. Therefore, the consequences of the rod ejection accident not only meet Damage Criteria $D$ (as required by the Technical Specifications), but also Damage Criteria C. 


\section{LTR 111.127 APPENDIK B.4}

TABLE 1 NOTES

14. The analysis and consequences for the steaml ine break maximum cooldown transient is no different from that analyzed for L2-2 mode 8 operation, as discussed in Reference (c). As discussed in Reference (c), the MDNBR increases throughout this transient, even if initiated from high off-nominal power.

15. The event category for a locked pump rotor has not been established, other than it is at least an infrequent fault. This transient is conservatively simulated as a step loss of flow to $50 \%$ of the original flow. In actuality, flow will decrease as a rapid ramp to a flow rate greater than $50 \%$. One pump alone, with a high flow resistance (due to the locked rotor) in the other pump, will pump more than $50 \%$ of the two-pump flow rate. This transient was analyzed using COBRA IV-I with. its improved solution routine, since COBRA IIIC was not able to solve for the effects of such a rapid flow decrease.

16." The consequences for this transient for lower values of off-nominal hot leg temperature are listed under the Incidents of Moderate Frequency. The indicated peak clad surface temperature was calculated by forcing regions of the hot fuel pin into film boiling when the LOFT-3 MDNBR $\leq 1.12$, above the ANC-6 95-95 bound value of the LOFT-3 MDNBR. When the transient was analyzed forcing film boiling when MDNBR $\leq 1.14$, the peak clad surface temperature was $2052^{\circ} \mathrm{F}$. Additional conservatisms for this case were a loop flow corresporiding to a $P / A=2.66$, and use of the conservative FSAR engineering hot spot factor (1.032). The consequences of this transient case meet the limits of Damage Criteria C. 
TABLE 2

TRANSIENT ANALYSIS COMPARISONS FOR BORON DILUTION

OR CRWA'S WITH DIFFERENT MEASURED P/A

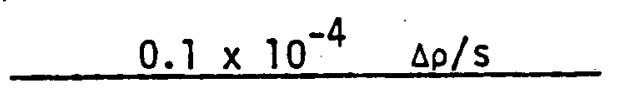

Measured P/A

Initial Thot

$$
\text { Power }
$$

Power WCT Margin above Nominal (MW)

$\begin{array}{llllllllll}\text { Pressure (psia) } & 2369 & 2370 & 2340 & 2340 & 2379 & 2379 & 2340 & 2340 & 2340\end{array}$ when MDNBR

$\begin{array}{llllllllll}\text { Engineering Hot } & 1.026 & 1.026 & 1.026 & 1.026 & 1.032 & 1.032 & 1.026 & 1.026 & 1.026\end{array}$ Spot Factor

MDNBR

$\begin{array}{llll}2.50 & 2.60 & 2.55 & 2.60\end{array}$

$673 \quad 613$

3.5

3.5

4.2

4.0

3.8

3.5

3.5

2369

$1.196 \quad 1.14 \quad 1.143$

$1.131 \quad 1.110 \quad 1.080 \cdot 1.150$

$1.133 \cdot 1.125$ 


\section{EG\&E Idaho}

\section{INTEROFFICE CORRESPONDENCE}

date $\quad$ March 13, 1979

10 S. A. Atkinson

from

D. F. Elger

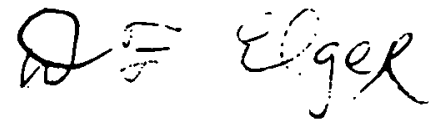

subject THERMAL SAFETY ANALYSIS OF LOFT REACTOR PLANT ACCIDENT CONDITIONS OCCURRING DURING THE L2-3 TEST MODE 8 OPERATION - DFE-4-79

Refs: (a) S. A. Atkinson Itr to F. K. Hyer, "Initial Hybrid Analysis for L2-3 Safety Analys is Support" Atki-38-78 (November 20, 1978)

(b) S. A. Atkinson Itr to E. C. Anderson, "Pressure Trips for L2-3 Mode 8 with 2169 psia Nominal Pressure," Atki-5-79 (March 2, 1979)

(c) R. A. Dimenna/G. L. Hunt 1 tr to S. A. Atkinson, "PPS Trip Setpoints and Time Constants for L2-2 Safety Analyses" RAD-2-78 (May 16, 1978)

(d) S. A. Atkinson 1 tr to E. C. Anderson, "Nominal Pressure Decrease for L2-3 Mode 8," Atki-3-79 (February 2, 1979)

This letter presents analysis results for the LOFT plant transients described in reference (a), with the exception of the control rod withdrawal accident. The LOFT reactor hybrid computer model combined with a COBRA IIIC/IV-I LOFT core model was used to show that the minimum predicted DNBR (LOFT-3 DNB correlation) was above 1.14 (this represents a $95 \%$ probability at a $95 \%$ confidence level of not reaching DNB) for all cases. Therefore, all plant transients satisfied the LOFT FSAR Section 15 allowable consequence levels and the applicable damage criteria in the LOFT Technical Specifications (since Damage Criteria A was met for all these transients).

The results are:

Run ID

Description

MDNBR

ESAL231C

2 pump failure with flywheel coastdown

1.209 low flow trip

ESAL232C7 Loss of steam load-high pressure trip $\quad 1.156$

ESAL233C Steam load increase - high power trip $\quad 1.237$

ESAL234C1 5\%/sec inadvertent RABV openting-trip at 1.205 10\% RABV opening

ESAL234C2 Same as above except opening rate $=10 \% / \mathrm{sec} \quad 1.195$ 
March 13, 1979

LTR 111.127

S. A. Atkinson

DFE-4-79

Page 2

Run ID

ESAL235C1

ESAL236C1

ESAL236C2

ESAL237C

ESAL238C
Description

one pump failure without flywheel coastdown low flow trip

two pump failure without flywheel coastdown field current loss trip

two pump failure without flywheel coastdown low flow trip

one control rod drop. Worth $=\$ 2.90$

low pressure trip

locked pump rotor - $50 \%$ step flow reduction low flow trip
MDNBR

1.183

1.202

1.175

No DNBR calculated see reference (b)

1.213

In general each plant transient was assumed to start from off-nominal reactor conditions and to trip at worst case values. The initial conditions were defined by the L2-3 desired test conditions corresponding to a $P / A=2.60$. For a given transient, these conditions produce a slightly lower MDNBR than conditions corresponding to a lower $P / A$ ratio.

Two important chanqes were made during the course nf the analysis: (1) It was discovered that the scram curve being used, the "10/26 LF scram curve", was incorrect and a new scram curve, the "2/13 L2-3 worst case scram curve", was developed, (2) an error was found and corrected in COBRA IIIC and COBRA IV-I.

The new scram curve, the "2/13 L2-3 worst case scram curve," was developed after most of the analysis was completed and rather than redo all the computer runs, only the plant transients most sensitive to the scram assumption were rerun. DNBR's were not significantly effected $(<0.5 \%)$. Figure 1 is a plot of the two scram curves.

The COBRA error was a coding error in a modification of the fuel bundle grid spacer loss coefficient calculation for the LOFT versions. The error tends to decrease the local coolant mass flux at the point of MONBR and consequently added extra conservatism to the COBRA model. Only the steam load loss, the limiting accident studied, was run using the corrected version of COBRA. This increased the predicted MDNBR by $3.1 \%$. The error effects and correction will be documented in a forthcoming letter by J. E. Fisher.

Table 1 is a listing of reactivity coefficients and scram setpoints used in the analysis. Table 2 is a detailed listing of the plant transient initial conditions and results. 
March 13, 1979

S. A. Atkinson

DFE-4-79

Page 3

The ultimate result of these calculations is to define L2-3 mode 8 operation as follows

$$
\begin{aligned}
& F_{Q} \text { (measured) } \leq 2.60 \\
& \text { Nominal power }(M W) \leq 90.228 / F_{Q} \text { (measured) } \\
& \text { Nominal loop flow }(M 7 \mathrm{bm} / \mathrm{hr}) \geq \frac{\text { Nominal reactor power (MW) }}{.0387} \\
& \text { Nominal hot leg temperature }\left({ }^{\circ} \mathrm{F}\right) \leq 609^{\circ} \mathrm{F} \\
& \text { Nominal pressure (psia) } \leq 2169 \text { psia. }
\end{aligned}
$$

Additionally reactor scram setpoints must be defined by the measured $F_{0}$ using the scenario in reference (c) for hot leg temperature, power and loop flow and reference (d) for pressure. Note: other analyses not considered in this letter (reactivity addition transients) could impose more limiting conditions for reactor operation than the above limits.

41

Attachments:

As stated

cc: B. S. Anderson

D. F. Elger

N. F. Fausz

J. E. Fisher

F. K. Hyer

D. G. Satterwhite

R. P. Wadkins

Central File

TAB File 3.5 


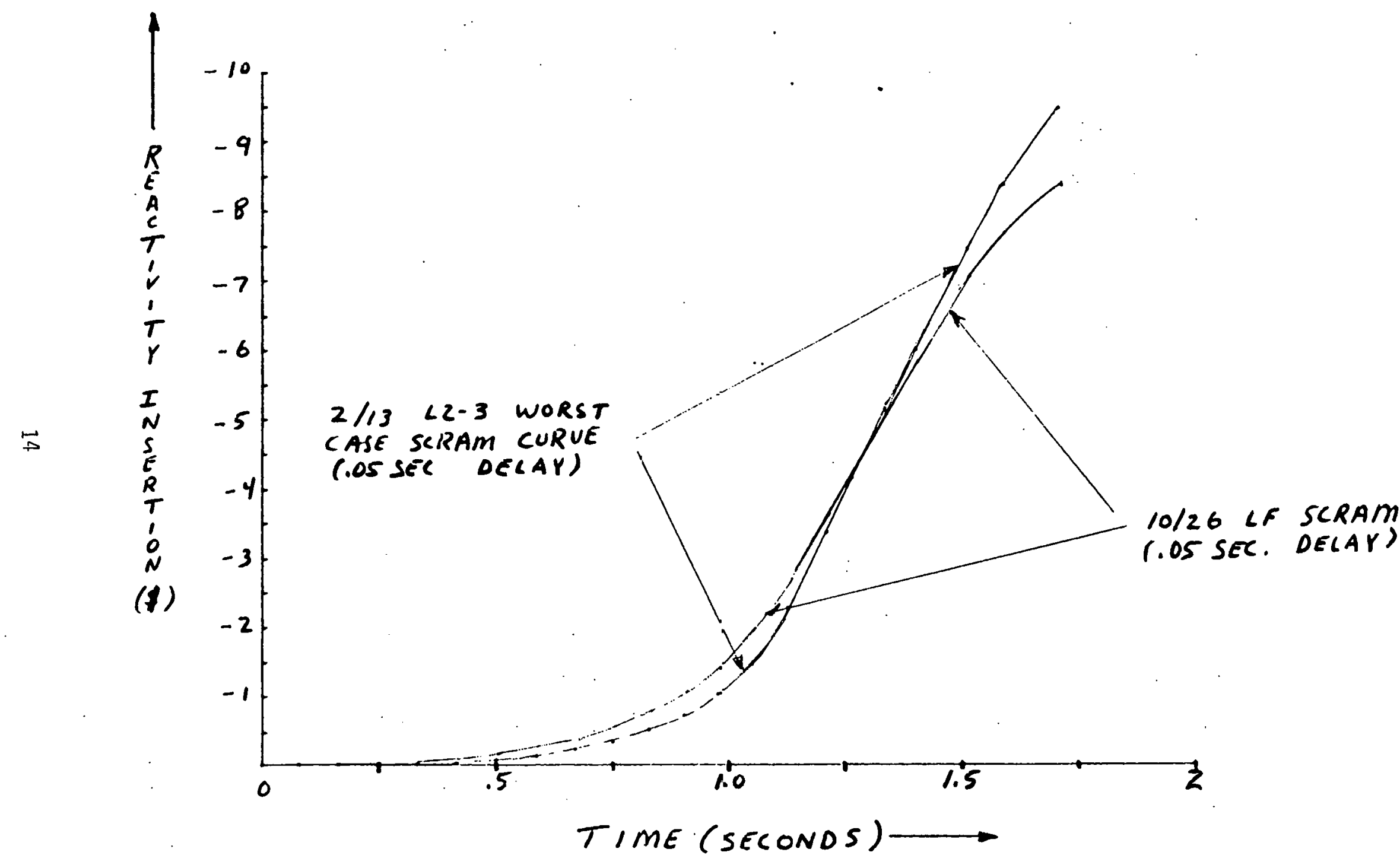

Figure 1: SCRAM CURVES USED IN THE ANALYSES 
TABLE 1

\section{REACTIVITY COEFFICIENTS AND SCRAM SETPOINTS}

\section{$\underline{\text { Reactivity Coefficients }}^{[1]}$}

Doppler

$$
\begin{aligned}
& \text { High (HD) }-1.08 \times 10^{-5} \Delta \rho /^{\circ} \mathrm{F} \\
& \text { Low (LD) }-0.44 \times 10^{-5} \Delta \rho /^{\circ} \mathrm{F}
\end{aligned}
$$

Moderator

$$
\begin{aligned}
& \text { High (HM) } 6.5 \times 10^{-3} \Delta \mathrm{o} / 1 \mathrm{bm} / \mathrm{ft}^{3} \\
& \text { Low (LM) } \quad 2.6 \times 10^{-3} \Delta \rho / 1 \mathrm{bm} / \mathrm{ft}^{3}
\end{aligned}
$$

\section{Scram Setpoints}

Power

$38.2 \mathrm{MW}$ (3.5 MW above nominal)

Loop Flow ${ }^{[2]} 1.01 \mathrm{Mlbm} / \mathrm{hr}$ (see Figure 1, Ref. (c))

Hot leg temperature $617^{\circ} \mathrm{F} \quad\left(4^{\circ}\right.$ above a nominal $613^{\circ} \mathrm{F}$ )

$621^{\circ} \mathrm{F} \quad\left(4^{\circ}\right.$ above a nominal $\left.617^{\circ} \mathrm{F}\right)$

High pressure 2340 psia (171 psia above nominal)

Low pressure 2000 psia (169 psia below nominal)

$[1]$ For a given transient, reactivity coefficients are chosen to maximize the severity.

[2] The actual low flow trip point was $\sim .98 \mathrm{Mlbm} / \mathrm{hr}$. The correct value

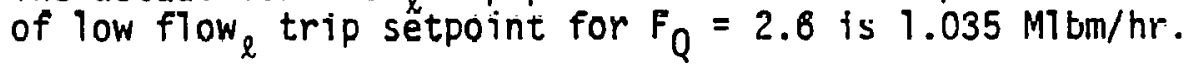


TABLE 2

SUMMARY OF L.2-3 ACCIDENT ANALYSIS

\begin{tabular}{|c|c|c|c|}
\hline Run ID & Transient & $\begin{array}{l}\text { Inftiai } \\
\text { Conditions } \\
\end{array}$ & MDNBR \\
\hline ESAL231C & $\begin{array}{l}2 \text { pump failure with flywheel } \\
\text { coastdown }\end{array}$ & $\begin{array}{l}37.2 \mathrm{MN} \\
1.15 \mathrm{MI} \mathrm{bm} / \mathrm{hr}\end{array}$ & $\begin{array}{l}1.209 \\
3 \mathrm{sec}\end{array}$ \\
\hline & $\begin{array}{l}\text { Low flow trip HD/LM } \\
10 / 26 \text { LF scram curve } \\
\text { Small core model - COBRA IIIC }\end{array}$ & $\begin{array}{l}2257 \text { psia } \\
617^{\circ} \mathrm{F} \\
F_{Q}=2.60 \\
h g=750 \text { BTU/hr-ft }{ }^{2}-{ }^{\circ} \mathrm{F}\end{array}$ & \\
\hline
\end{tabular}

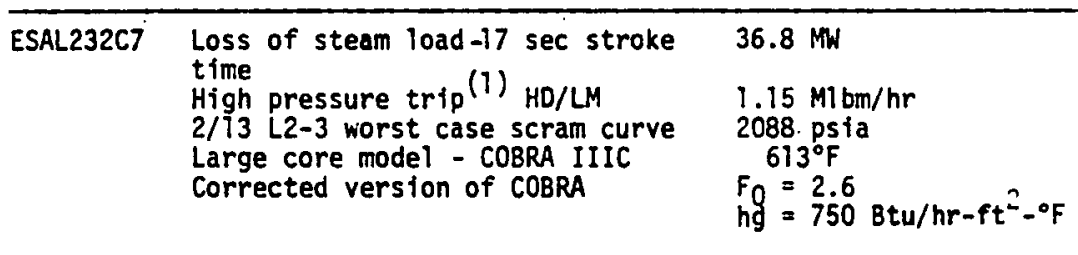

\begin{tabular}{|c|c|c|c|}
\hline ESAL232C7A & $\begin{array}{l}\text { Same as above except used } \\
\text { version of COBRA with error }\end{array}$ & Same as above & $1.120014 \mathrm{sec}$ \\
\hline ESAL233C & $\begin{array}{l}\text { Steamload increase - } 40 \text { sec stroke } \\
\text { time } \\
\text { Power trip LD/HM } \\
10 / 26 \text { LF scram curve } \\
\text { Small core model - COBRA IIIC }\end{array}$ & $\begin{array}{l}37.2 \mathrm{MH} \\
1.15 \mathrm{Mrbm} / \mathrm{hr} \\
2257 \mathrm{psta} \\
617^{\circ} \mathrm{F} \\
\mathrm{F}_{0}=2.60 \\
\mathrm{hg}=10000 \mathrm{Btu} / \mathrm{hr}-\mathrm{ft}^{2}-{ }^{\circ} \mathrm{F}\end{array}$ & $1.237014 .2 \mathrm{sec}$ \\
\hline
\end{tabular}

\begin{tabular}{llll}
\hline ESAL234CI & $\begin{array}{l}\text { Inadvertent RABV opening accident } \\
\text { Opening rate }=5 \% / \mathrm{sec}\end{array}$ & $37.2 \mathrm{MW}$ & $1.20501 .3 \mathrm{sec}$ \\
& Tr1p 0 10\% RABV openting LD/LM & $2257 \mathrm{psia}$ & \\
& $10 / 26$ LF scram curve & $\mathrm{Fg}=2.60$ \\
& Small core model - COBRA IIIC & $\mathrm{hg}=750 \mathrm{Btu} / \mathrm{hr}-\mathrm{ft}^{2}-{ }^{\circ} \mathrm{F}$ \\
\hline
\end{tabular}

$\begin{array}{lll}\text { ESAL234C2 } & \begin{array}{l}\text { Same as above except opening } \\ \text { rate }=10 \% \mathrm{sec}\end{array} & \text { Same as above }\end{array}$

\begin{tabular}{|c|c|c|c|}
\hline ESAL235C & $\begin{array}{l}1 \text { pump fallure without flywheel } \\
\text { coastdown } \\
\text { Low flow trfp HD/LM } \\
\text { 10/26 LF Scram curve } \\
\text { Small core model - COBRA IIIC }\end{array}$ & Same as above & $1.18801 .4 \mathrm{sec}$ \\
\hline
\end{tabular}

\begin{tabular}{llll}
\hline ESAL235C1 & $\begin{array}{l}\text { Same as above except used } 2 / 13 \\
\text { L2-3 worst case scram curve }\end{array}$ & Same as above & $1.183 \mathrm{01.4 \textrm {sec }}$ \\
\hline
\end{tabular}

\begin{tabular}{|c|c|c|c|}
\hline ESAL236CI & $\begin{array}{l}2 \text { pump fallure without flywheel } \\
\text { coastdown. } \\
\text { Loss of field current trip HO/LM } \\
10 / 26 \text { LF scram curve } \\
\text { Small core model - COBRA IIIC }\end{array}$ & Same as above & $1.2020 .8 \mathrm{sec}$ \\
\hline
\end{tabular}

ESAL236C2 Same as above except low flow trip. Same as above

$1.17501 .4 \mathrm{sec}$

1: The initial reactor power was scaled such that the reactor power setpoint was reached at the same time as the reactor high pressure scram occurred. 


\section{LTR 111.127 \\ APPENDIX B.4}

TABLE 2 (continued

\begin{tabular}{|c|c|c|c|}
\hline Run ID & Transient & $\begin{array}{l}\text { Initial } \\
\text { Conditions } \\
\end{array}$ & MDNBR \\
\hline ESAL236C3 & $\begin{array}{l}\text { Same as above except used } 2 / 13 \\
\text { L2-3 worst case scram curve }\end{array}$ & Same as above & $1.17801 .4 \mathrm{sec}$ \\
\hline ESAL237C & $\begin{array}{l}\text { Control rod drop - one rod } \\
\text { worth } \$ 2.90 \\
\text { Low pressure scram HD/HM } \\
10 / 26 \text { LF scram curve } \\
\text { No COBRA run }\end{array}$ & Same as above & $\begin{array}{l}\text { No DNBR } \\
\text { calculation } \\
\text { See Ref. (b) }\end{array}$ \\
\hline ESAL238C & $\begin{array}{l}\text { Locked pump rotor - } 50 \% \text { step } \\
\text { flow reduction } \\
\text { Low flow trip LD/LM } \\
10 / 26 \text { LF scram curve } \\
\text { COBRA IV-I }(2)^{-} \text {- small core }\end{array}$ & Same as above & $1.2530 .7 \mathrm{sec}$ \\
\hline
\end{tabular}

2: COBRA IV-I with its improved solution routine was able to perform the transient analysis for this rapid flow loss accident, whereas COBRA IIIC could not. 
Cc: B. S. Anderson

D. F. Elger

N. F. Fausz

J. E. Fisher

F. K. Hyer

J. L. Liebenthal
D. E. Satterwhite (2)

R. P. Wadkins Rpel

S. A. Atkinson File (2)

Central File

TAB File 3.5
date
March 2, 1979
10
E. C. Anderson
from
s. A. Atkinson \&.d allinsors
subject
3
PRESSURE TRIPS FOR L2- $\$$ MODE 8 WITH 2169 PSIA NOMINAL PRESSURE - Atki-5-79
Ref: (a) S. A. Atkinson Itr to E. C. Anderson, Atki-3-79, "Nominal Pressure Decrease for L2-3 Mode 8," February 2, 1979
(b) S. A. Atkinson, "L2-2 Pre-LOCE Maneuver Core Safety Analys is," LTR 111-116 (RE-A-78-257) November 17, 1978
(c) "LOFT Integral Test System Final Safety Analysis Report," Revision 1, August 1977

Reference (a) suggested that LOFT nominal operating pressure be reduced by 93 to 100 psi for L2-3 Mode 9 operation to gain safety margin for potential transients during Mode 8 operation. Operation with such a reduced nominal pressure would result in a reduction in the low-pressure worst-case trippoint (WCT) below the 2076 psia WCT for the power range and L2-2 Mode 8 safety analyses. The L2-2 Mode 8 safety analyses concluded (Ref. (b), Section II), "The L2-2 pre-LOCE analyses did not establish any limitation on operation at a low pressure, other than what might be implied by the 2000 psia lower limit for the LOFT-3 DNB data." Therefore, a 2000 psia WCT was assumed for the L2-3 Mode 8 safety anaiyses. The L2-3 Mode 8 safety analyses assumed a 2169 psia nominal pressure, at the reactor outlet.

The L2-3 Mode 8 transients were evaluated for a 2000 psia WCT, and the consequences were found to be satisfactory with this WCT. In addition, the control rod drop accident, which is the controlling transient for the low-pressure WCT, was evaluated for both Mode 8 low flow and Mode 7 full flow operation. The 2000 psia WCT was found to be satisfactory for either flow rate. The evaluation of the $2000 \mathrm{psia}$ WCT is discussed in more detail in Attachment 2.

A decrease in nominal pressure can also allow a decrease in the highpressure WCT. This decrease (a decrease of 100 psi to a 2340 psia WCT) has been found to be necessary for mitigation of the loss of steam load transient and the boron-dilution or slow control rod withdrawal accidents. These accidents will be discussed in more detail in the L2-3 Mode 8 core safety analysis report (LTR 111-127).

The pressure assumptions used and found acceptable for the L2-3 Mode 8 core safety analyses are as indicated in the attached Table I.

jj

Attachments 
TABLE I

L2-3 MODE 8 CORE SAFETY ANALYSIS

PRESSURE ASSUMPTIONS

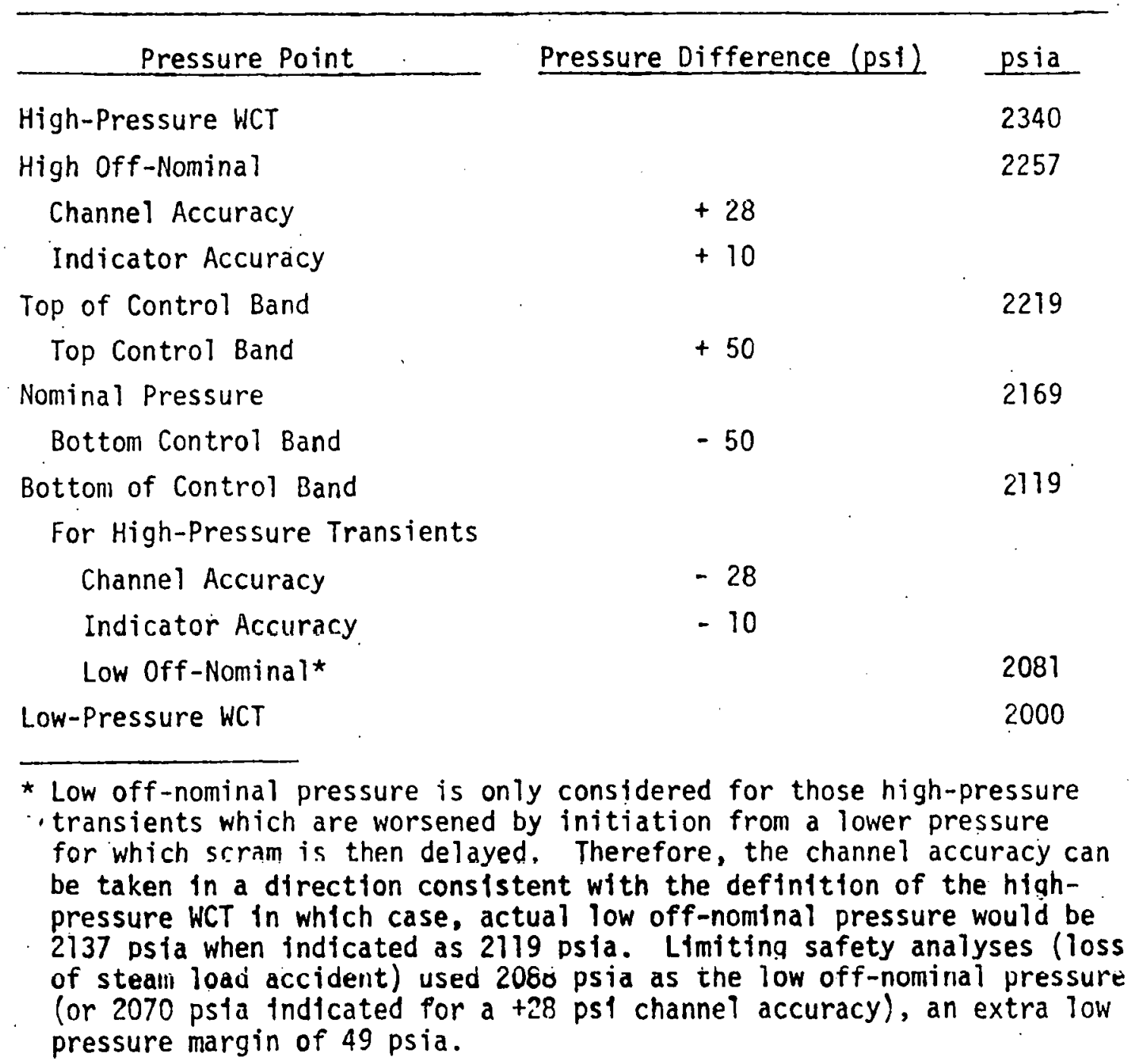




\section{EVALUATION OF TRANSIENTS FOR A LOW-PRESSURE TRIP}

The LOFT transients which are tripped by low pressure are:

1) The steamline break accident at low power.

2) An automatic pressure control system failure.

3) The control rod drop accident.

4) LOCA (trips on low pressurizer pressure coincident with low pressurizer level).

The steam line break accident at low power is a cooldown transient which is worsened by a higher low-pressure trip (a quicker trip will result in slightly greater cooldown). However, the analysis for the steamline break was done assuming an instant trip (a). Therefore, the low-pressure WCT is not a. consideration for this transient.

The MDNBR increases throughout the transient for an automatic pressure control system failure (FSAR ${ }^{(e)}$, Section 15.2.12, and LTR $111-116^{(b)}$ ) as the power and temperature decrease in addition to the pressure decrease. Pressure will continue to decrease and the reactor will be scrammed by the low-pressure WCT. This transient, therefore, does not define any limit or lower bound for the low-pressure WCT.

The ECCS trippoint for a LOCA is 1850 psia. As long as the low-pressure WCT is above this, then the low-pressure WCT is not a consideration for a LOCA unless the time to reactor trip is important. However, upon the initiation of the LOCA, pressure very rapidly drops to saturation ( 1700 psia). Therefore, a slight difference in the low pressure trip or the initial operating pressure will not significantly effect the LOCA transient.

The MDNBR also increases throughout the transient for a control rod drop accident. However, pressure does not continually decrease for this transient. If the reactor is to be automatically shutdown in response to a dropped control rod assembly (CRA), then some limiting (low bound) value for the lowpressure WCT needs to be defined which will result in a reactor trip for this transient. For the Mode 8 core safety analysis for the L2-2 test, it was concluded $(c)$, "The L2-2 pre-LOCE analyses did not establish any limitation on 


\section{LTR 111.127 \\ APPENDI' B.4}

operation at a low pressure, other than what might be implied by the 2000 psia lower limit for the LOFT-3 DNB data". Therefore, a 2000 psia low-pressure WCT was evaluated for a control rod drop accident during L2-3 Mode 8 operation.

\section{L2-3 CONTROL ROD DROP ACCIDENT}

The control rod drop accident was simulated on the Hybrid computer for a low worth CRA $(2.1 \% \Delta \rho)$. The drop of a low worth CRA results in a greater power recovery and less pressure decrease, as was shown for the L2-2 core safety analysis ${ }^{(d)}$. The Hybrid computer results show:

1) The reactor is tripped by a 2000 psia low-pressure WCT.

2) At the time of maximum power recovery:

- power is only recovered to $49 \%$ of initial power.

- core average temperature has decreased $26^{\circ} \mathrm{F}$.

- core flow has increased by $8 \%$.

A dropped CRA causes a radial flux tilt in the core which results in an increased core peak-to-average power ratio and increased integrated rod power for the hot rod. This effect was discussed in LTR 111-116 for the control rod drop accident ${ }^{(d)}$. As indicated in LTR $111-116$, the hot rod power is expected to increase by $10 \%$ due to the radial flux tilt. This result is based on power distribution calculations given in Reference $(g)$. The results in Reference $(g)$ also indicates that the axial power shape is essentially unchanged by the dropped rod. The change in MDNBR can be estimated based only on the change in power level, at maximum power recovery, and the radial power distribution increase by ${ }^{(d)}$ :

$$
\triangle M D N B R=\left[(1-.10) \frac{\text { Inital Pwr }}{\text { Max Recovery Pwr }}-1\right]
$$

This estimate assumes that the change in MDNBR is linear with power. Analysis experience with COBRA has shown that the MDNBR will change by more than the power change, that is:

$$
\triangle M D N B R=C \frac{\text { Initial Pwr }}{\text { Final Pwr }}
$$

where $\mathrm{C}>\mathrm{I}$. 

The above estimate (Equation $A-1$ ) also neglects the effects of 10 W
temperature and increased flow which will improve (increase) the MDNBR. Using Equation $(A-1)$, for the L2-3 Mode 8 control rod drop, MDNBR will increase by:

$$
\triangle M D N B R=\frac{(0.90)}{(0.49)}-1=84 \%
$$

The following Figure $A .1$ shows the transient power change for the control rod drop during L2-3 Mode 8 operation.

A control rod drop was also simulated for L2-3 power level, but with full (Mode 7) reactor flow $\left(3.42 \times 10^{6} \mathrm{lbm} / \mathrm{h}\right)$. The Hybrid computer results show:

1) The reactor is tripped by a 2000 psia low-pressure WCT.

2) At the time of maximum power recovery: (see the following Figure A.2 for the transient power)

- power only recovers to $34 \%$ of initial power.

- core average temperature has decreased $28^{\circ} \mathrm{F}$.

- core flow has increased by $6 \%$.

- the estimated increase in MDNBR is:

$$
\triangle M D N B R=\frac{(0.90)}{(0.34)}-1=165 \%
$$

Fö this simulation at full flow, the moderator and Doppler feedback coefficients were also increased above the high values being assumed for the L2-3 core safety analysis. The coefficients used were increased 7 to $10 \%$ above those in LTR $111-52^{(h)}$ for a hot reactor $\left(T_{\text {ave }}=584^{\circ} \mathrm{F}\right)$ and only $100 \mathrm{ppm}$ boron concentration in the primary coolant system. The corresponding coefficients used are:

\begin{tabular}{llll} 
& \multicolumn{1}{c}{$\begin{array}{c}\text { L2-3 Mode } 8 \\
\text { Low Flow }\end{array}$} & $\frac{\begin{array}{c}\text { L2 }=3 \text { Power } \\
\text { Ful1 Flow }\end{array}}{\text { Moderator Coefficient }}$ \\
\cline { 2 - 3 } & $6.5 \times 10^{-3} \Delta \rho / 1 \mathrm{bm} / \mathrm{ft}^{3}$ & $8 \times 10^{-3} \Delta \rho / 1 \mathrm{bm} / \mathrm{ft}^{3}$ \\
Doppler Coefficient & $1.08 \times 10^{-5} \Delta \rho /{ }^{\circ} \mathrm{F}$ & $1.1 \times 10^{-5} \Delta \rho /{ }^{\circ} \mathrm{F}$
\end{tabular}

As seen by the simulation results, the safety margin is greater for a dropped CRA for full flow operation. Therefore, for L2-3 operation, a 2000 psia lowpressure WCT is suitable for any flow rate within the operating bounds, Mode 8 low off-nominal flow to $4 \times 10^{6} 1 \mathrm{bm} / \mathrm{h}$. 


\section{FULL POWER MODE 7 CONTROL ROD DROP ACCIDENT}

Hybrid computer simulation was also done for a control rod drop accident during full power (Mode 7) operation with a 2000 psia low-pressure WCT. The original analysis for this case in the FSAR $^{(f)}$ assumed an initial pressure near nominal (2259 psia) and a dropped CRA worth $2.39 \% \Delta p$. Two reanalyses were done. One with the FSAR maximum values for moderator and Doppler feedback coefficients $\left(9.1 \times 10^{-3} \Delta p / 1 \mathrm{bm} / \mathrm{ft}^{3}\right.$ and $-1.5 \times 10^{-5} \Delta \mathrm{p} /{ }^{\circ} \mathrm{F}$, respectfully), and another with the high values used for the full flow, L2-3 power case discussed above. The results for the control rod drop from full power (53 MW off-nominal power) are:

1) The reactor is tripped by a 2000 psia low pressure WCT.

2) At the time of maximum power recovery:

FSAR Max. LTR $171-52$

Feedback Max Feedback

Power Recovery

$\%$ of Initial

(see Figures A.3 and A.4)

Core Average Temp

Decrease ( ${ }^{\circ} \mathrm{F}$ )

Core Flow Increase

(q)

Increase in MONBR

with 10\% Flux Tilt (\%)
74

29

5.5

22
50

29

6

78

Since the FSAR assumption of initiation from near nominal pressure (2259 psia) is above the high off-nominal pressure for an assumed decrease in nominal pressure for 12-3 operation (2257 psia high off-nominal), then the above results apply to operation with reduced nominal pressure as we11. Therefore, the control rod drop accidents analyzed above demonstrate that a 2000 psia lowpressure WCT is suitable for Mode 7 or Mode 8 operation with the nominal pressure reduced to $2169 \mathrm{psia}$. The following Table A.I tabulates the results and assumptions for all of the control rod drop accidents analyzed. These results do not, however, imply that it is acceptable to operate at full power in Mode 7 with reduced nominal pressure, as other transients or safety analysis assumptions may have to be more fully considered. 


\section{REFERENCES}

\section{LTR 111.127 \\ APPENDI: B. 4}

(a) S. A. Atkinson, "L2-2 Pre-LOCE Maneuver Core Safety Analys is," LTR 111-116 (RE-A-78-257), November 17, 1978, Section V.4.2.2.

(b) Ibid, Section V.2.10.

(c) Ibid, Section II.

(d) Ibid, Section V.2.3.

(e) "LOFT Integral Test System Final Safety Analysis Report," Revision 1 , August 1977, Section 15.2.12.

(f) Ibid, Section 15.2.3.

(g) E. F. Aber, "Power Distributions from XYZ Synthesis Calculations to Support LOFT Low-Power Reactor Physics Measurements, "LIR 117-76, Apri1 9, 1976.

(h) A. J. Scott, "Temperature Coefficients and Boron Worth for LOFT I at Beginning of Life," LTR 111-52, August 31, 1973. 
FIGURE A.l

LZSPCDAT FOWER MW LE-3 CONTROL ROD DROP O6-FEB-79 14:58:57

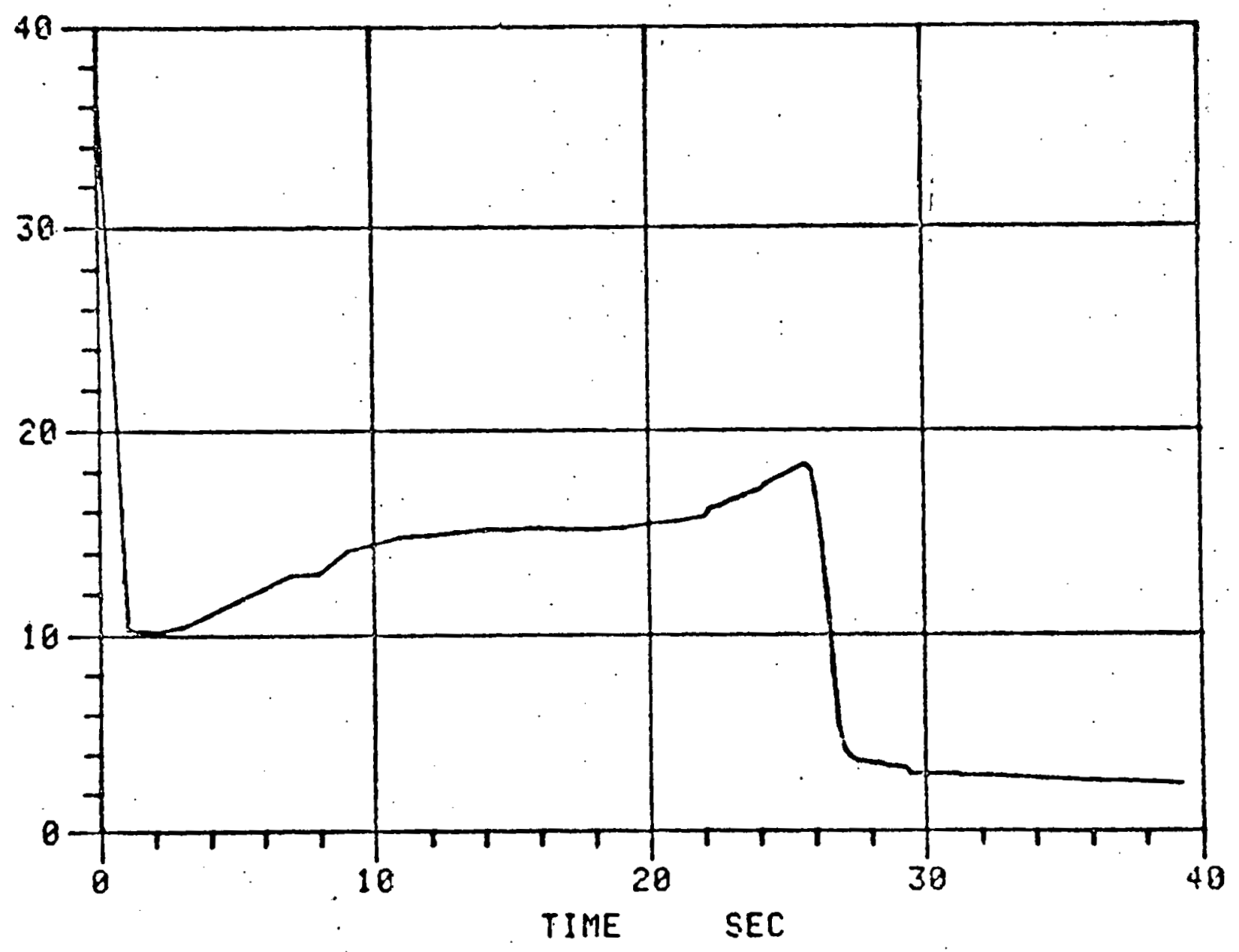

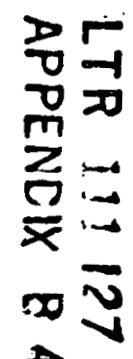


FIGURE A.2

L2-3 POWER, FULL MODE? FLOW
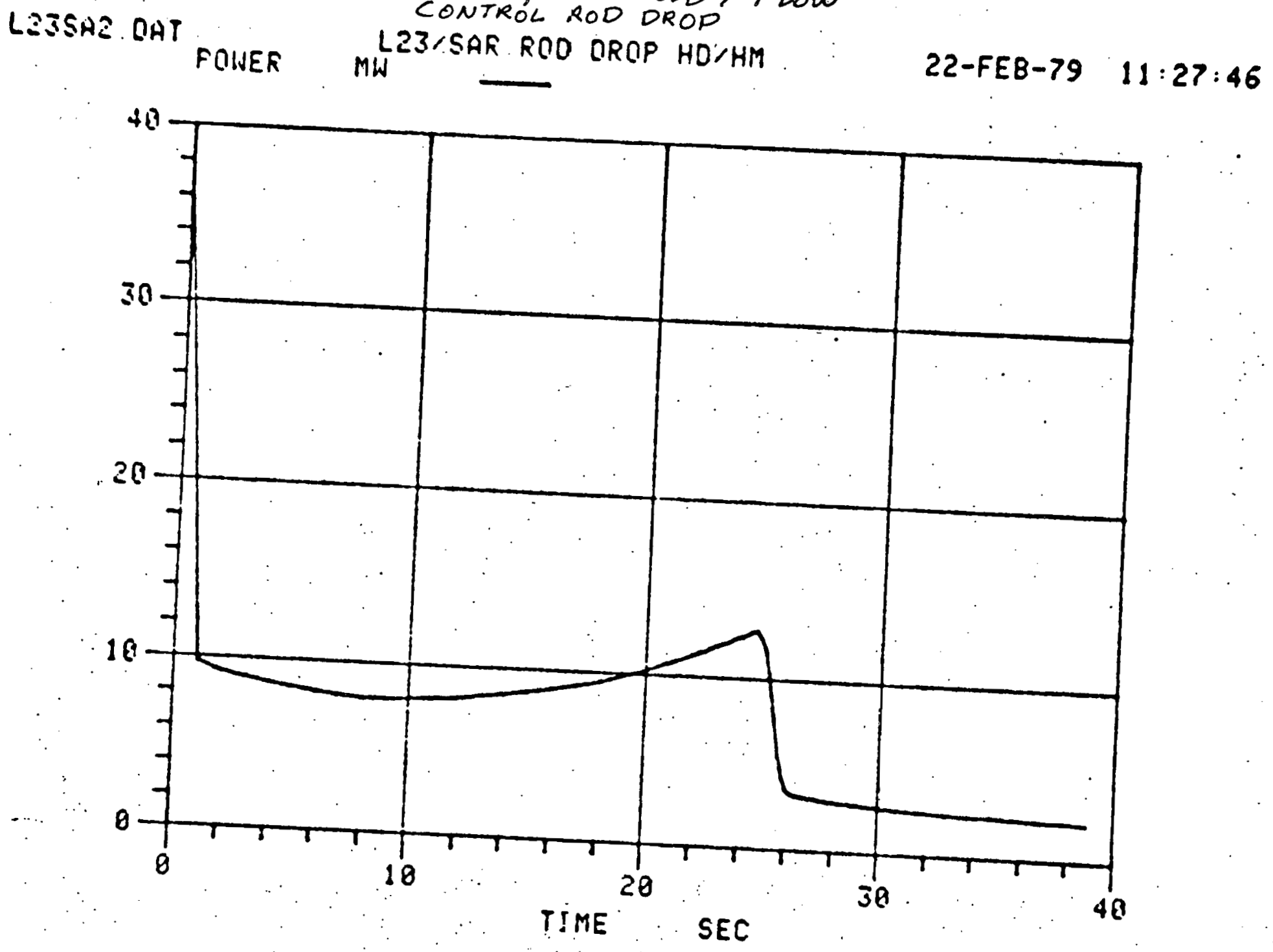

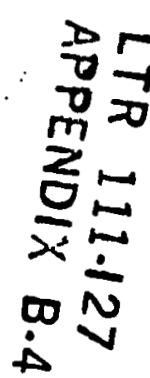


FIGURE A.3 FULL POWER

LEJSAR. DAT FOWER: HWT-3/SAR CONTROL ROD DROP 68-FEB-79 09:60:35

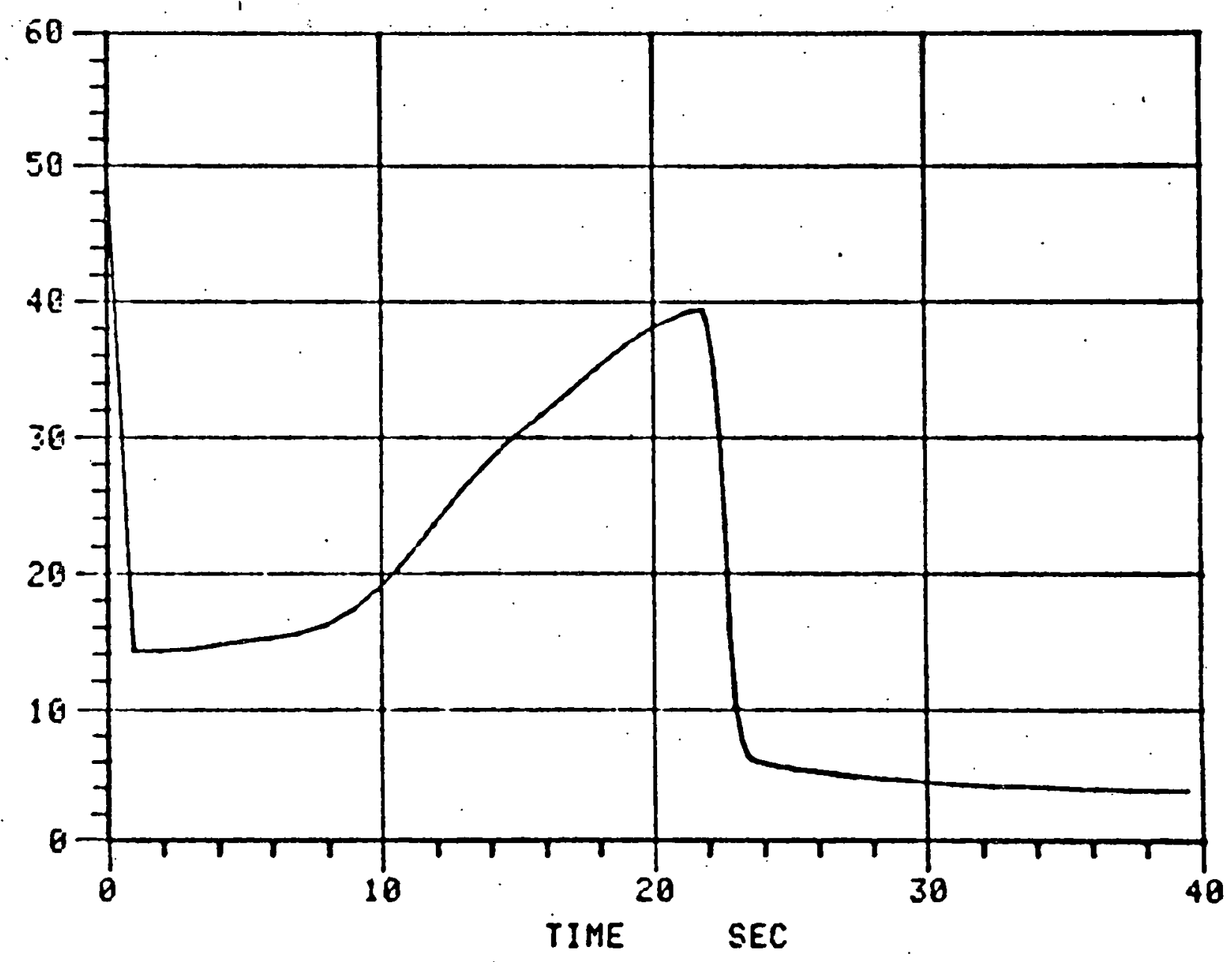


FIgURE A.4

FULL POWER-FULL FLOW

LTR $\|-52$ MAX FEEDBACH COEFFICIENTS
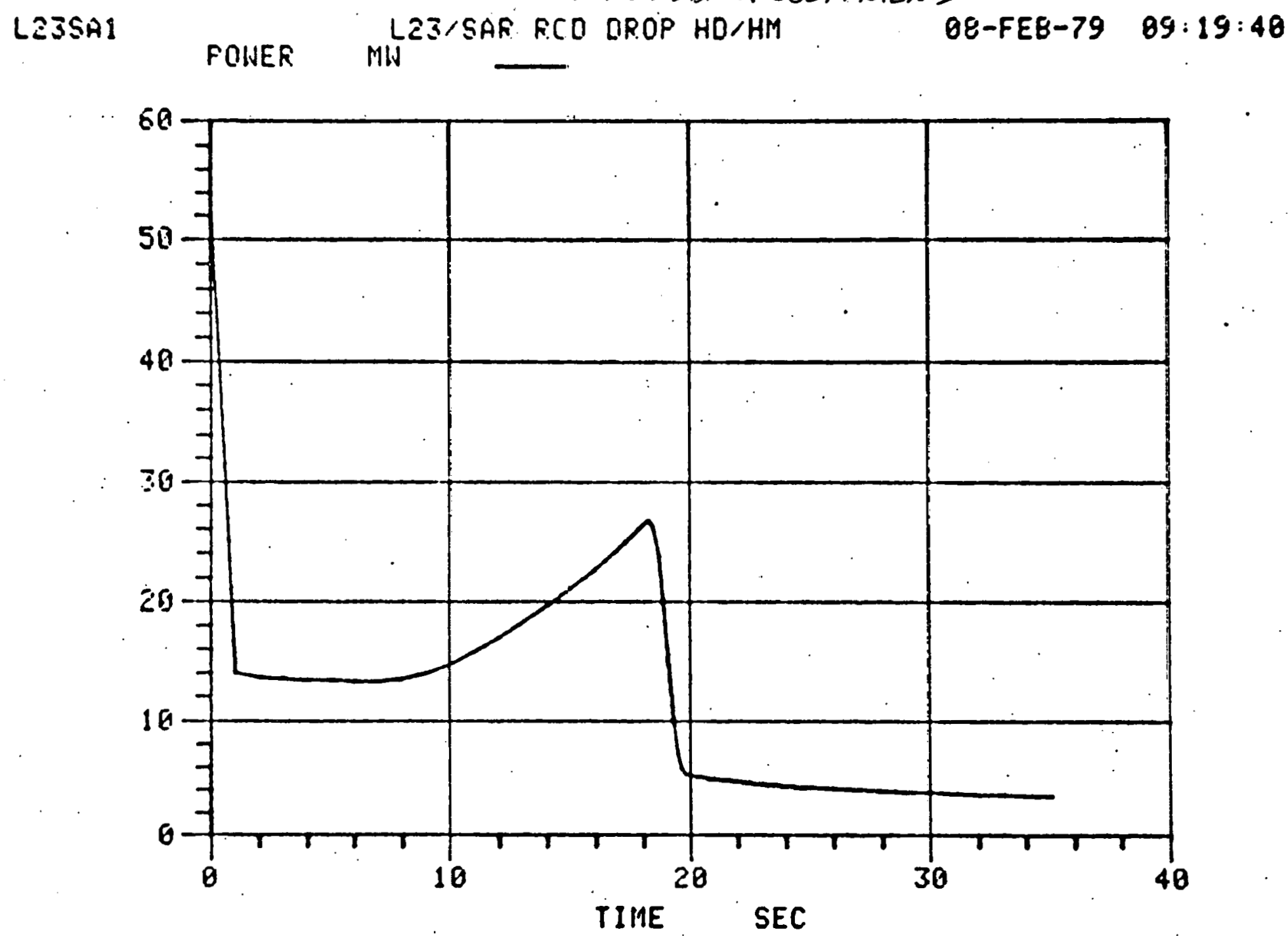

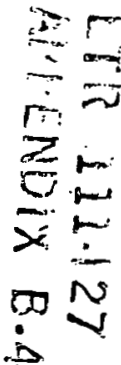


TABLEAu CONTROL ROD DROP ACCIDENT ANALYSIS RESULTS

FOAM INES -656

(Rev. 2-76)
IDAHO NATIONAL ENGINEERING LABORATORY

IMOOE 8 ! $22-3$ I FULL POWER! FULL Pouts 'LOW FLOW' FuLL FLow, FULL FLow, FUL FLOW!

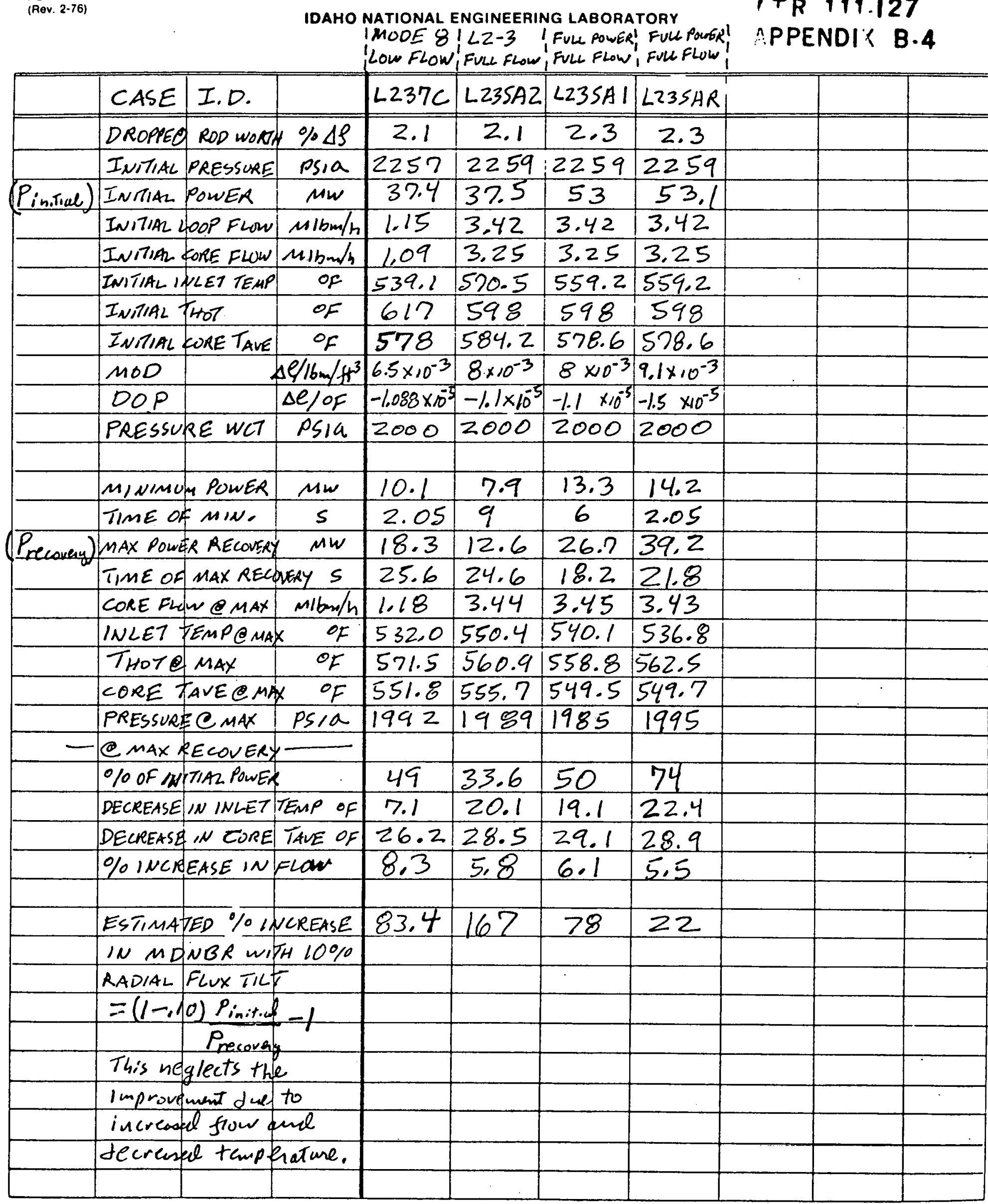

29
TR 111.127
APPENDIX B.4 
CC:

B. S. Anderson fiv
S. A. Atkinson/f
J. E. Fisher

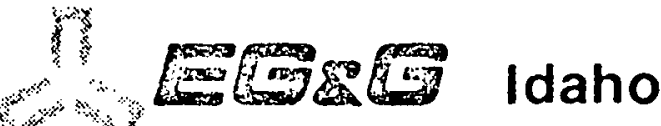

LTR 111.127
APPENDIK B.4

J. L. Liebenthal

D. G. Satterwhite

R. P. Wadkinspow

Central File

TAB File 3.7

INTEROFFICE CORRESPONDENCE

date January 19, 1979

10 E. C. Anderson

Irom B. S. Anderson Buxi S. Andezzan

subjec1 RESULTS OF L2-3 ROD EJECTION CASES - BSA-1-79

Refs: (a) B. S. Anderson and R. A. Dimenna, LOFT Core I-Rod Ejection Accident Analys is, LTR 111-65, Rev. T, July 6, 1977.

(b) R. A. Dimenna, Zero Power Physics Testing Safety Analys is, LTR 111-88, Rev. D, June 16, 1978

(c) Letter, B. S. Anderson to S. A. Atkinson "Comparison of TIP Power Measurements to PDQ Predictions - BSA-4-78", (November 30, 1978)

RELAP4, COBRA-IIIC, and FRAP calculations have been completed for the rod ejection accident study in support of the LOFT L2-3 test. The analytical technique is the same as described in References (a) and (b). Minimum Doppler reactivity feedback (Table II, Reference b), hot moderator reactivity feedback (Table III, Reference $b$ ), and the 10/26 LF scram curve were used for these analyses. The axial power distribution used in RELAPI was based on the TIP measurements taken with the control rods withdrawn 54 inches and the reactor operating at a power of $38.2 \mathrm{MW}$ (Reference c). Table I lists the initial conditions used in the two cases examined.

The calculations show no problems in meeting Damage Criteria $C$. COBRA IIIC results for both cases indicate that DNB will occur, but the resulting heatup is well within acceptable limits. Since DNB occurs the average fuel enthalpy at the hot spot was calculated assuming adiabatic heating for five seconds, and FRAP was used to calculate the maximum fuel ceriterline temperature and maximum cladding surface temperature. A peak power of $78 \mathrm{MWl}$ was calculated for case $A$ and 70 MW was calculated for case $B$. In both cases the transient is turned around by negative Doppler and moderator feedback. The scram, which was delayed 0.25 seconds after the high power setpoint was reached, brought the power to $\sim 7 \mathrm{MW}$ two seconds into the transient. Figures 1 and 2 show the power versus time plots for case $A$ and $B$. The resulting pressure transients are shown in Figures 3 and 4 . Results for these two cases are summarized in Table II.

u1

Attachments:

As stated 
TABLE I

LTR 111127
APPENDIK $B .4$

INITIAL CONDITIONS FOR THE L2-3 ROD EJECTION CASES

$\begin{array}{lcc} & \text { Case A } & \text { Case B } \\ \text { Power (MW) } & 40.6 & 36.4 \\ \text { Loop Flow (1.b/hr) } & 1.28 \times 10^{6} & 1.12 \times 10^{6} \\ \left.\text { Hot Leg Temperature ( }{ }^{\circ} \mathrm{F}\right) & 609 & 609 \\ \text { Pressure (psia) } & 2257 & 2257 \\ \text { High Power Scram (MW) } & 46.5 & 46.5\end{array}$


RESULTS OF THE L2-3 ROD EJECTION CASES

Case A Case B

Peak Power (MW)

Minimum DNER @ Time(sec)

Average Fuel Enthalpy at the Hot Spot (ca1/cm)

Peak $\&$ Fuet Temperature ( $\left.{ }^{\circ} \mathrm{F}\right)$ o Time (sec)

78

70

$1.00 @ 0.8$

$1.06 \div 0.9$

$(1.0300 .9)^{*}$

158

153

$4320 @ 1.0$

$4670 @ 1.2$

$(4670 @ 1.2) *$

Peak Cladding Surface

Temperature $\left({ }^{\circ} \mathrm{F}\right)$

(o) Time (sec)

$1800 @ 2.1$

186002.4

$(191002.3)^{*}$

Time When Scram Setpoint was Reached (sec)

0.004

0.005

Change in Pressure Due to

the Power Transient (psia)

13

15

* COBRA-IIIC and FRAP were rerun assuming a hot leg temperature of $621^{\circ} \mathrm{F}$. 


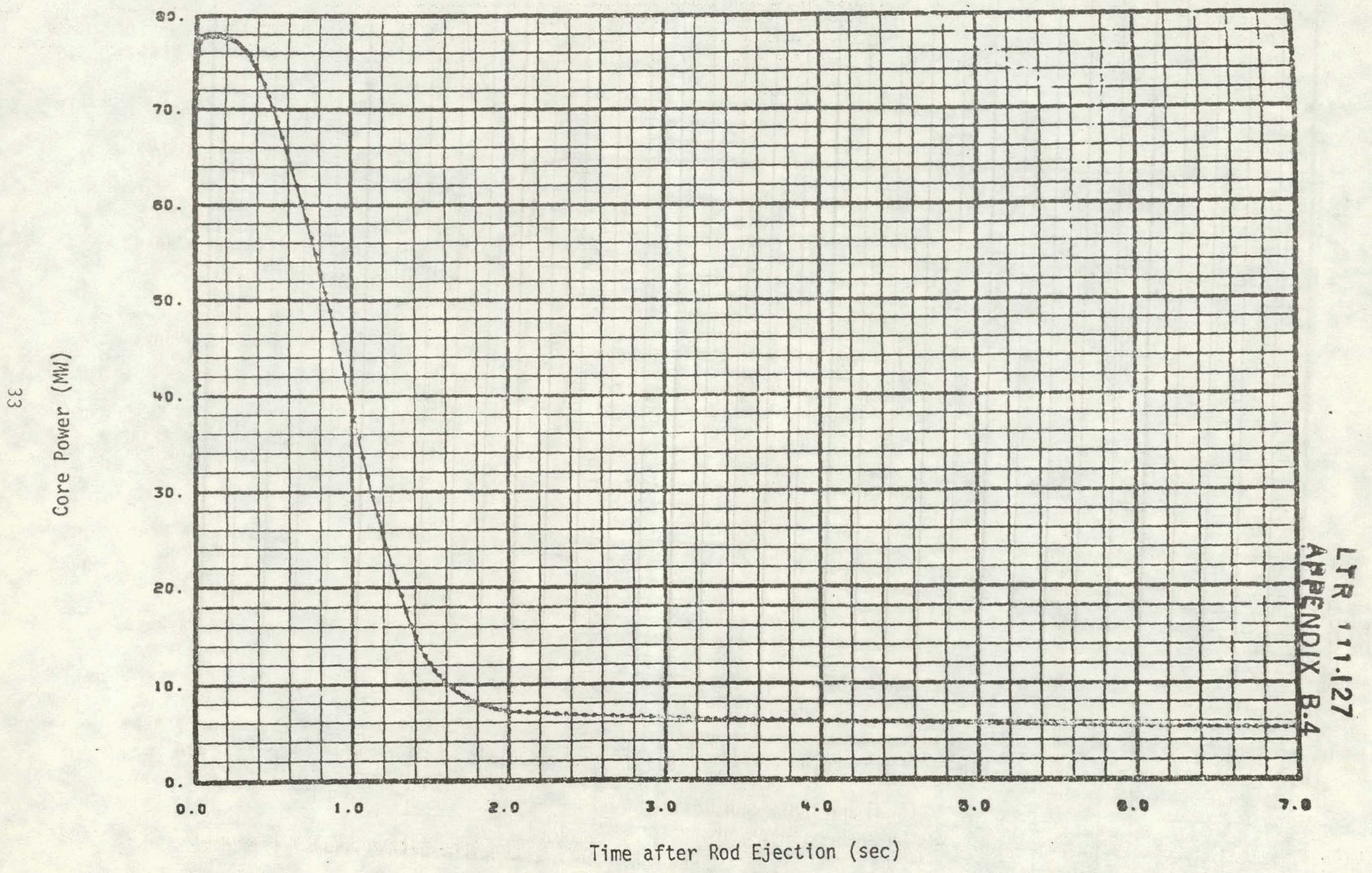

Figure 1 - Core Power for L2-3, 40.6 MW Case 


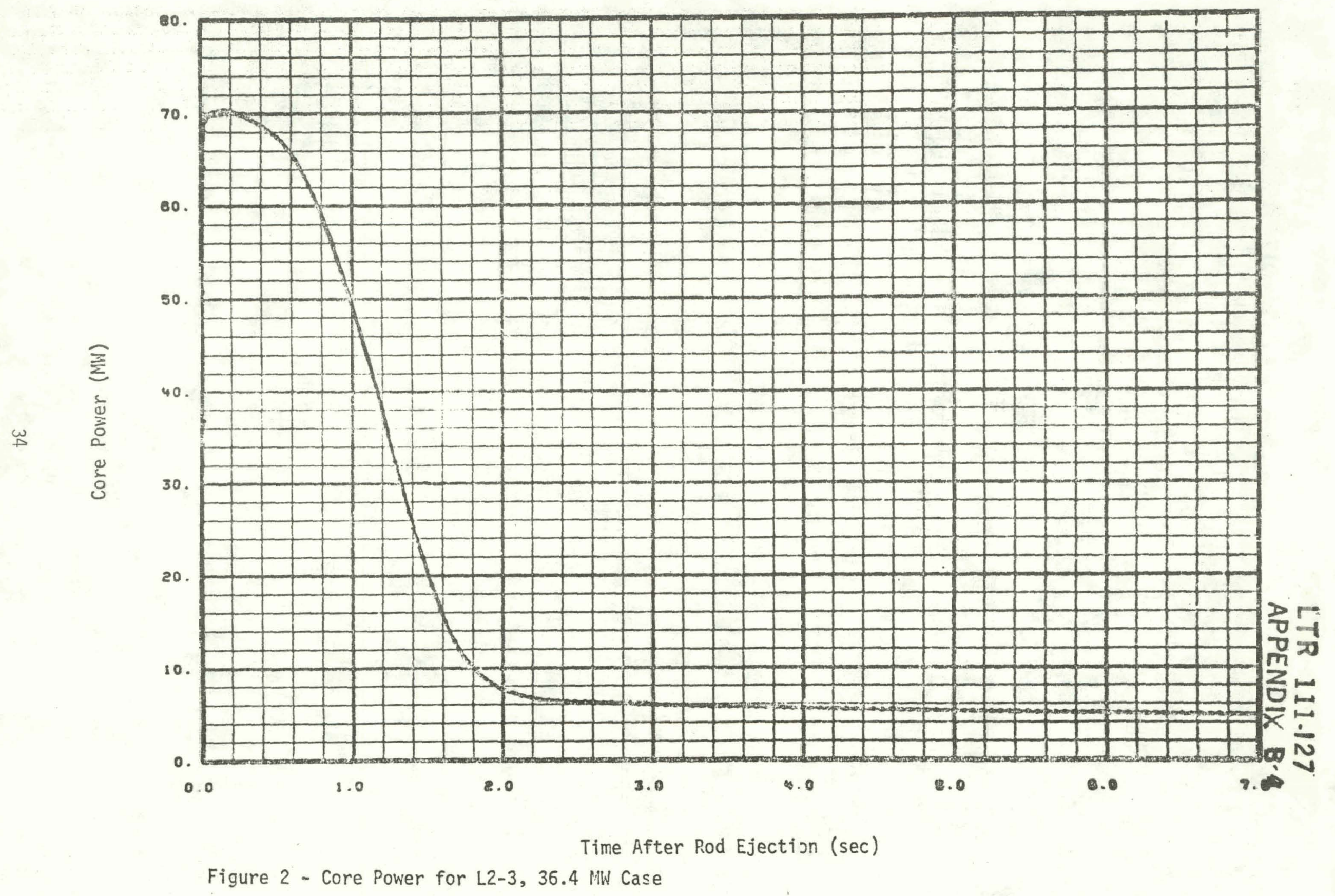




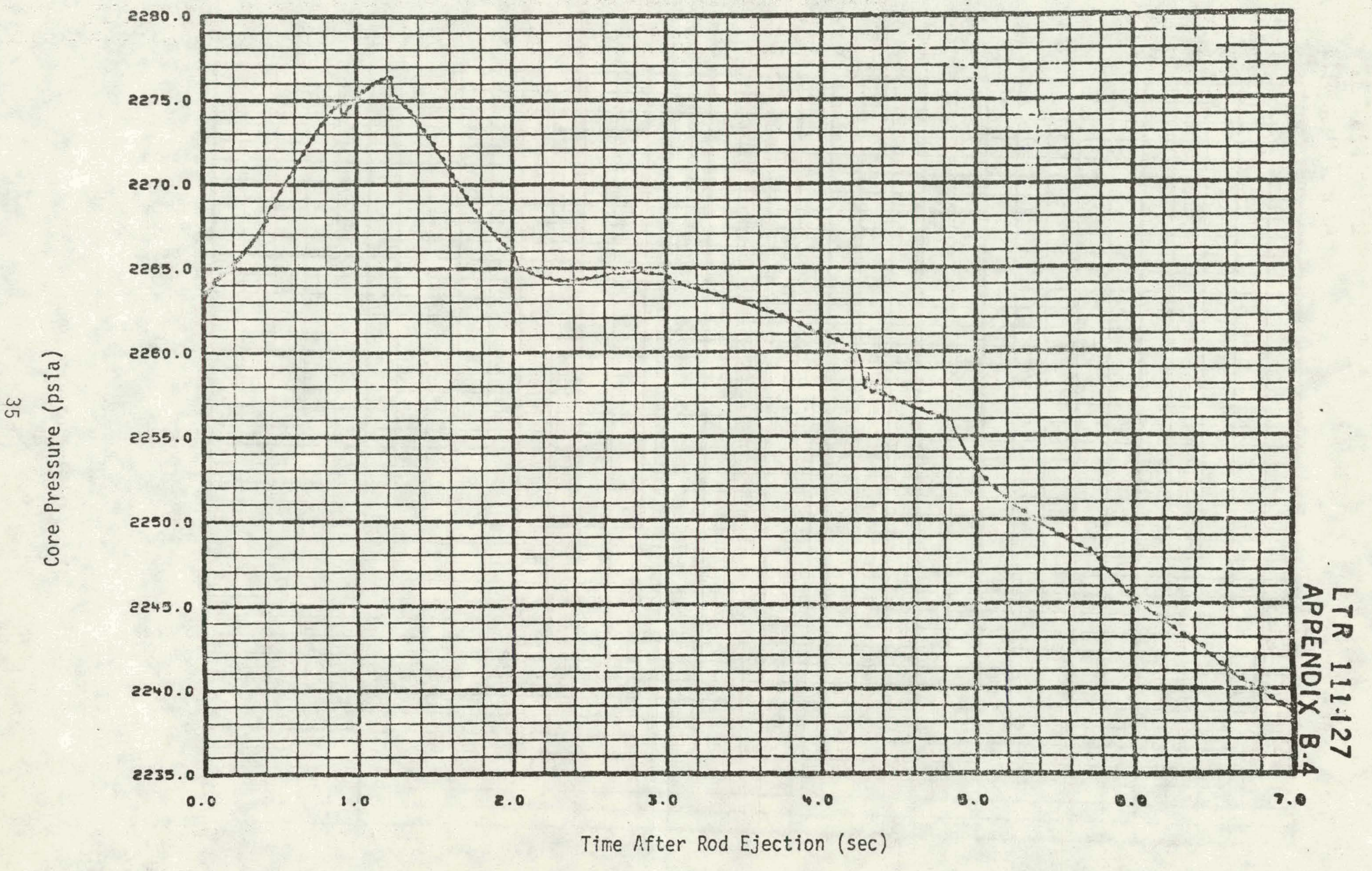

Figure 3 - Core Pressure for L2-3, 40.6 MW Case 


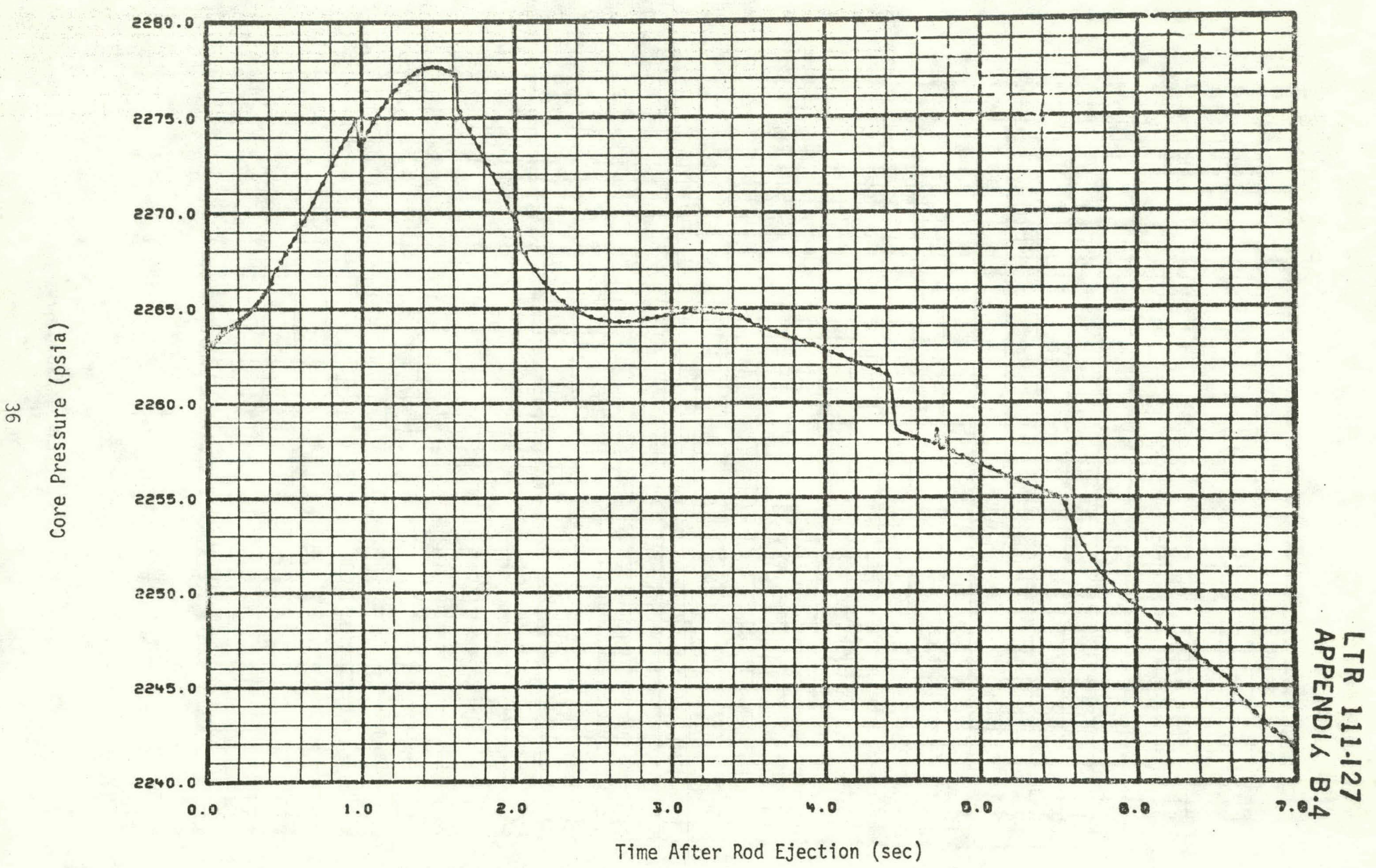

Figure 4 - Core Pressure for L2-3, 36.4 MW Case 


\title{
INTEROFFICE CORRESPONDENCE
}

\author{
date March 22, 1979 \\ to S. A. Atkinson \\ trom B. S. Anderson Bance S. Andiosare \\ subject COMPARISON OF PARAMETERS USED IN THE L2-3 ROD EUECTION CASES \\ TO PARAMETERS USED FOR OTHER L2-3 ANALYSES - BSA-3-79
}

Ref: (a) Letter B.S. Anderson to E. C. Anderson, "Results of L2-3

Rod Ejection Cases - BSA-1-79" (January 19, 1979)

Concern has been expressed that the parameters used in the L2-3 rod ejection accident cases (reference a) may not be conservative when compared to parameters used for present L2-3 analyses. This letter presents a comparison of parameters used in the L2-3 rod ejection cases against those presently being used. Table I lists the comparison of parameters. As can be seen, the hot leg temperature is conservative, while pressure and scram delay time are the same in a 11 analyses. Although the P/A power ratio and loop flow rate for the $40.6 \mathrm{MW!}$ case may appear to be nonconservative the values are comparable since they were calculated in a consistent manner with present $1.2-3$ analysis (based on power profile and allowable $\Delta$ h through the core). A conservative constant value was used in the L2-3 rod ejection cases for the high power trip.

Moderator and Doppler feedbacks are input as tables in the L2-3 rod ejection cases while many of the present $L 2-3$ analyses use a constant value within the range specified in Table I. Over the range of fuel temperatures experienced during the L2-3 rod eject transients the average reactivity change per degree Fahrenheit was calculated and this is the number which appears in Table $I$ and, as can be seen, lies within the range used in present $L 2-3$ studies. The moderator feedback was found to be conservative. When the density begins to drop below steady-state density, negative reactivity is inserted at the rate of $-.334 \$ / 7 \mathrm{bm} / \mathrm{ft}^{3}$ and when the density goes above steady-ștate density positive reactivity is inserted at a rate of $1.135 \$ / 1 \mathrm{bm} / \mathrm{ft}^{3}$.

Calculations for 12 -3 rod ejection worth determined a ramped reactivity insertion for rod ejection which adds .274 \$ in .054 seconds as conpared to a . 5 \$ step insertion used in the $1.2-3$ rod ejection cases reported in reference (a). The reference (a) rod ejects have a conservative reactivity insertion, but this may be offset by non-conservatisms in the 10/26 LF scram curve used for the L2-3 rod ejects. A typical total reactivity curve for the $40.6 \mathrm{WW}$ rod eject case is shown in Figure 1. Superimposed on this curve is a 


\section{LTR 111.127 \\ APPENDIX B 4}

curve generated by adding the difference in reactivity between the L.2-3 rod ejection and analyses using the calculated L2-3 rod eject worth and the L2-3 worst case scram as calculated by Equation 1.

$$
\begin{aligned}
\Delta \$= & \{(.5 \$)-\text { (Reactivity from the } 10 / 26 \text { LF scram curve) }\} \\
- & \{\text { (Reactivity from rod ejection versus time ramp) } \\
& - \text { (Reactivity from the new worst case scram curve) }\} \quad \text { Eq. } 1
\end{aligned}
$$

This new curve is an attempt to show the difference which might be expected using present rod eject worth and scram data. The new curve assumes that the scram occurs at the same time, and that the moderator and Doppler reactivity feedbacks remain essentially the same. From these curves it can be seen that the original analysis was conservative except from .82 seconds to 1.22 seconds. DNB occurred prior to this time, and the fuel rod is in $f i 1 \mathrm{~m}$ boiling well before $0.8 \mathrm{~s}$. As seen in Figure 1 , the L.2-3 rod eject analysis predicts more reactivity insertion and therefore higher power during this critical time period. The peak clad temperature is reached shortly after 2.0 seconds in the L2-3 rod eject cases $(a)$. Again, over the whole 2 second period, the L2-3 reactivity assumptions are conservative. Therefore, it can be concluded that the L2-3 rod eject analyses using the 0.5 \$ step insertion assumption and 10/26 LF scram are conservative compared to reactivity worth for the $L 2-30.274$ \$ rod eject ramp with lhe L2 -3 worst case scram.

The above comparisons and discussion show that the 1.2-3 rod eject analyses as reported in reference (a) are conservative, and do not need to be rerun for final L2-3 analysis conditions.

u1

Attachments :

As stated

CC: B. S. Anderson

E. C. Anderson

S. A. Atkinson

J. E. Fisher

D. G. Satterwhite

Central File

TAB File 3.5 
TABLE I

Parameter
L2-3 Rod Ejection Cases 40.6 M!! Case

621

46.5

2.66

1.12

2257

$.5 \$$ step

$10 / 26$ LF

.25

$\sim-.00106$
Scram delay time (sec)
Hot leg temperature $\left({ }^{\circ} \mathrm{F}\right)$

Power trip (Mk')

$P / A$

Loop flow rate $(M 1 \mathrm{bm} / \mathrm{hr}$ )

Pressure (psia)

Rod eject reactivity (\$)

Scram curve

Doppler feedback reactivity

\section{1}

46.5

2.37

1.28

2257

$.5 \$$ step

10/26 LF

.25

$\sim-.00100$

Moderator feedback when density

is less than at steady-state

$$
\left(\frac{\$}{\mathrm{bm} / \mathrm{ft}}\right)
$$

36.4 MW Case

$-.334$

-.36 to -.90

Moderator feedback when density is greater than at steady-state

$$
\left(\frac{\$}{1 \mathrm{bm} / \mathrm{ft}^{3}}\right)
$$

1.135

.36 to .90

\section{LTR 111.127 \\ APPENDIK B.4}

Present L2-3 Analyses
613

38.5

2.60

1.15

2257

$.054 \mathrm{sec}$ Ramp to $.274 \$$

L2-3 worst case

.25

$\sim-.00061$ to -.0015 


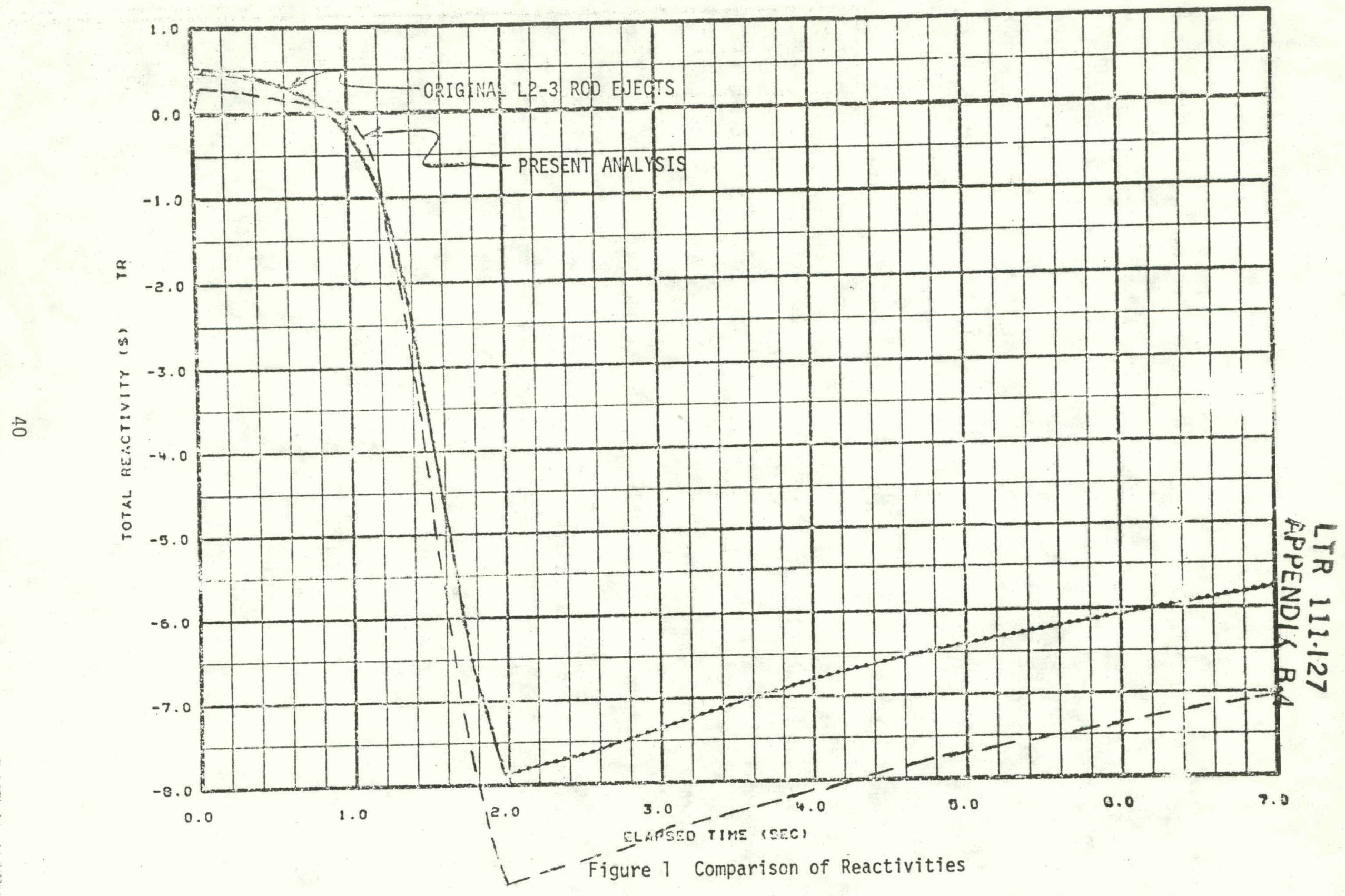


APPENDIX B-2

MDNBR VS MLHGR PLOT

FOR L2-3 CONDITIONS 
APPENDIX B-5

L2-3 MODE 7 TRANSIENT AND MISCELLANEOUS ANALYSIS RESULTS 
APPENDIX B-5: ANALYSIS FOR REVISED MODE 7 SCRAM CURVE EFFECTS

This appendix discusses the effect of using the "214 HF" instead of "817" scram curve for analysis of these two LOFT plant accidents: (1) A one pump failure without flywheel assisted coastdown; trip on low flow (2) A two pump failure without flywheel assisted coastdown; trip on loss of field current. LTR 111-104[a] identifies these accidents as the two being the closest to their allowable damage limits (Damage Criteria B and C, respectively, as defined in Section 15 of the LOFT FSAR) for those accidents which are sensitive to changes in the scram curve. The results of this analysis and the Reference[a] analysis are compared in Table B-5-1.

The accidents are assumed to occur during LOFT Mode 7 operation and are initiated from off nominal high power, high average coolant temperature, low loop flow, low control rod position and nominal pressure. The initial conditions are:

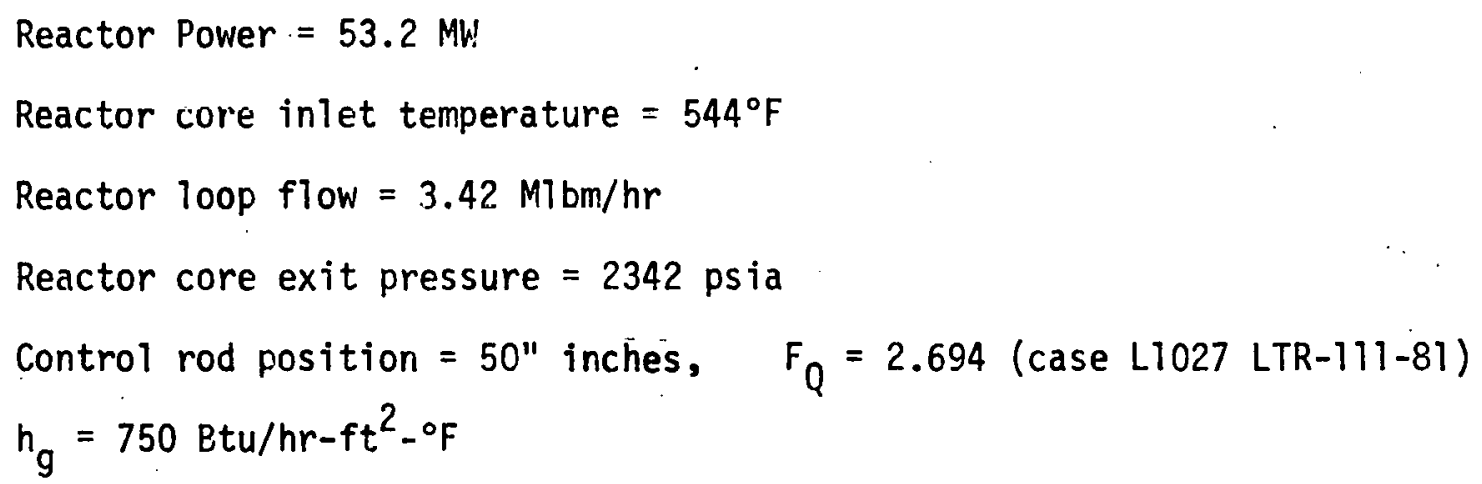

The analysis consisted of three steps: (1) model the accident using a hybrid computer simulation of the LOFT reactor. The scram curve model is used in this step. (2) use the hybrid computer results as input to the reactor core subchanncl analysis code COBRA IIIC. (INFL. Conde Configuration Control Numbers C0031005 and C0031006; for the small and large core models respectively) to predict local fluid conditions which are used with the LOFT-1 DNB correlation 
to calculate a DNBR (3) use the COBRA IIIC results as input to FRAP-T4, (INEL Code Configuration Control Number H0034IB) which uses a detailed single fuel pin model to calculate peak fuel rod thermal behavior.

The methodology and assumptions used are identical to those in Referencelia]except: (1) This analysis applied the full engineering hot spot factor, $F_{Q}{ }^{E}=1.026$, (instead of only the off-nominal enrichment contribution to $F_{Q}{ }^{E} ; 1.0125$ ) to the FRAP-T4 power history table and (2) In the time between the two analyses, an error was identified and corrected in COBRA IIIC. As discussed in Reference[b] the existance of this error tended to decrease the predicted MDNBR.

As shown in Table B-5-1, onty the one pump loss with rapid coastdown was significantiy effected by the different scram curve. The most important change is the $39^{\circ} \mathrm{F}$ increase in predicted peak clad temperature to a temperature of $1669^{\circ} \mathrm{F}$. Consequently, the FSAR Section 15 allowable damage criteria for this accident (infrequent incident, damage criteria $B$ ) was not met because the peak clad temperature exceeded the $1650^{\circ} \mathrm{F}$ limit. A second attempt was made to show that the damage criteria could be met by using the COBRA IIIC large core model and decreasing the engineering factor, $F_{Q}{ }_{Q}$, from 1.032 to $1.026^{[c]}$. However, as seen in Table B-5-1 the time to DNB only increased by .1 second and so it was not expected that FRAP-T4 results would change more than a few degrees and no FRAP-T4 calculation was performed.

Table B-5-1 shows that the consequences of the two pump loss with rapid coastdown are less severe than the Reference[a]consequences. All the COBRA III variables which are used as input to FRAP-T4 were in a direction which would decrease the peak temperature prediction. These variables are local mass flux time when DNBR goes below 1.13, and the axial spread of regions where DMBR $<1.13$ on the hot fuel pin. 
One pump failure without fiywheel

Results

ts

\begin{tabular}{l|l} 
Run ID & Results \\
\hline
\end{tabular}

coastdown - low flow trip Small core model

\section{Same as above except \\ (2) $F_{Q}{ }^{E}$ changed to 1.026 from 1.032 in COBRA IIIC. \\ (3) $2.5 \%$ decrease in the $5 \%$ inlet flow conservatism is not used}

Two pump failure without flywheel coastdown - loss of field current trip

Small core COBRA IIIC model Run ID

Flow $.4 \mathrm{~F}$

MDNBR $=1.082$

Flow .40

$$
\text { MDNBR }=1.115
$$

$t_{\text {DNB }}=1.25 \mathrm{sec}$

$\left.t \notin\right|_{\max }=5002^{\circ} \mathrm{F}$

$\left.\mathrm{tc}\right|_{\max }=1638^{\circ} \mathrm{F}$

\begin{tabular}{|l|l|l|l} 
& $\left.t c\right|_{\max }=1669^{\circ} \mathrm{F}$ & & $\left.t c\right|_{\max }=1638^{\circ} \mathrm{F}$ \\
\hline Same & $M D N B R=1.092$ & Same & Same as above \\
& $t_{D N B}=1.14 \mathrm{sec}$ & as & \\
& & above &
\end{tabular}

(1) $t_{\text {DNB }}=$ time when DMBR $($ LOFT-1) $=1.13$

$\left.t \notin\right|_{\text {max }}=$ maximum fuel pellet centerline temperature

$\left.t c\right|_{\max }=$ maximum fuel pin clad temperature

(2) Mo FRAP-T4 run made because it was not expected that the FRAP-T4 results would change by more than $5^{\circ} \mathrm{F}$.

(3) Mo FRAP. T4 run made because the COBRA IIIC results (as compared to flow .6K) were all in a direction

MDNBR $=1.009$

$t_{\text {DNB }}=1.00$

$\left.t \notin\right|_{\text {max }}=5002^{\circ} \mathrm{F}$

$\left.\mathrm{tc}\right|_{\max }=2010^{\circ} \mathrm{F}$

which would decrease the FRAP T4 temperature predictions. 
(a) S. A. Atkinson, R. A. Dimenna, T. M. Howe, Power Range Testing Core Safety Analysis, LTR 111-104, p. 29-37. (Decemler 4, 1978).

(b)* S. A. Atkinson letter to E. C. Anderson, COBRA IIIC- COBRA IV-I Comparison and Spacer Grid Loss Calculation Error," Atki-8-79 (March 14, 1979)

(c)* N. F. Fausz letter to E. C. Anderson, "Statistical Evaluation of the LOFT Heat Flux Engineering Hot Spot Factor" NFF-1-79 (February 27, 1979).

*Reference (b) is in Appendix $A-9$.

Reference $(c)$ is in Appendix A-7. 


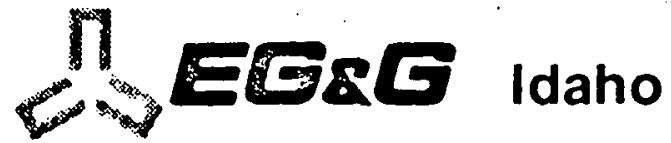

INTEROFFICE CORRESPONDENCE

Hale March 13, 1979

to S. A. Atkinson

irom B. S. Anderson BSA

sublect RESULTS OF BOL-EOL MDNBR COMPARISON STUDY - BSA-2-79

Refs: (a) B. L. Rushton, LOFT-I Results from Three-Dimensional PDQ Calculation with Thermal Feedback and Depletion to 2000 , EFPH, LTR-111-60, Rev. B (November 12, 1976)

(b) E. F. Aber, LOFT-I High-Flow Power Distributions as a Function of Control Rod Position, Core Power Level, and Full Power Operating History, LTR-117-83, Rev. A (November 1976)

Calculations have been completed to determine the effect of fuel burnup on the minimum DNB ratio for high flow steady-state conditions at power levels of 33 and 53 megawatts. CCBRA IIIC was used to calculate the MDNBR assuming power profiles from BOL to $2000 \mathrm{EFPH}$. Figure 1 shows the small core model used in COBRA IIIC for the calculations, and Table I describes the seven cases and the initial conditions for each. Axial and radial power profiles were taken from references (a) and (b). The axial power profiles are plotted in Figures 2 through 5 . The power profiles available for CRA's withdrawn 36 inches were calculated using a core power of $49.4 \mathrm{MW}$ instead of $33 \mathrm{MW}$. The higher power will affect the profiles slightly, but all three of the $33 \mathrm{MW}$ cases have the same error, and for comparative purposes should not present a problem.

The results of the study are tabulated in Table II and a plot of MDNBR versus EFPH is presented in Figure 6. As can be seen, increasing EFPH results in higher MDNBR's, therefore from a MDNBR standpoint, BOL is the limiting case for steady-state operation. From Figure 6 it can al so be seen that increasing EFPH has more effect on the MDNBR for the 53 MW cases than for the 33 MW cases. For the $53 \mathrm{MW}$ cases the. MONBR always occurred 33 irches from the core inlet in channe1 15. For the $33 \mathrm{MW}$ cases however, increasing EFPH lowers the point at which the MDNBR occurs and shifts it to channel 21 . This can be attributed to the fact that channel 21 has a lower inlet mass flux than channel 15; and fluid is redistributed from channel to channel as flow proceeds up the core. In the $53 \mathrm{MW}$ cases, for example, the axial power profile peaks 25.5 inches: from the botton of the core and flow redistribution near the spacer grid at 35 inches up the channel reduces the flow in channel 15 such that the MDMER occurs at 33 inches. For the $33 \mathrm{MW}$ cases the axial power peak is at 17.4 inches from the bottcm, significantly closer to the core inlet. Although mass flux increases in channel 21 as a result of flow redistribution, the 
March 13, 1979

S. A. Atkinson

BSA-2-79

Page 2

highly peaked power profile results in the occurrence of MDNBR before flow redistribution significantly raises the flow in channel 21 or lowers the flow in channel 15. With significant burnups MDNBR does not occur in channel 15 even though the mass flux is decreasing, because the axial power profile drops rapidiy at levels above 25 inches from the bottom.

47

Attachments :

As stated

cc: B. S. Anderson

D. F. Elger

N. F. Fausz

J. E. Fisher

D. G. Satterwhit

R. P. Wadkins P $^{2}$

Central File

TAB File 3.4 
TABLE I

INITIAL CONDITIONS FOR BOL-EOL MDNBR COMPARISON CASES

\begin{tabular}{|c|c|c|c|c|c|c|}
\hline $\begin{array}{l}\text { Case } \\
\text { Number }\end{array}$ & $\begin{array}{l}\text { Core Power } \\
(M W)\end{array}$ & $\begin{array}{l}\text { Loop Flow } \\
\text { (Mib/hr) }\end{array}$ & $\begin{array}{l}\text { Pressure } \\
\text { (psia) }\end{array}$ & $\begin{array}{l}\text { Average Core } \\
\text { Temperature }\left({ }^{\circ} \mathrm{F}\right)\end{array}$ & $\begin{array}{l}\text { Core Burnup } \\
\text { (EFPH) }\end{array}$ & $\begin{array}{l}\text { CRA } \\
\text { Position } \\
\text { (in) }\end{array}$ \\
\hline 1 & 53 & 3.42 & 2262 & 580 & 0 & 54 \\
\hline 2 & 53 & 3.42 & 2262 & 580 & 200 & 54 \\
\hline 3 & 53 & 3.42 & 2262 & 580 & 1000 & 54 \\
\hline 4 & 53 & 3.42 & 2262 & 580 & 2000 & 54 \\
\hline 5 & 33 & 3.42 & 2262 & 566 & 0 & 36 \\
\hline 6 & 33 & 3.42 & 2262 & 566 & 1000 & 36 \\
\hline 7 & 33 & 3.42 & 2262 & 566 & 2000 & 36 \\
\hline
\end{tabular}

\section{TABLE II}

RESULTS OF BOL-EOL MDNBR COMPARISON STUDY

\begin{tabular}{|c|c|c|c|}
\hline Case Number & MDNBR & $\begin{array}{l}\text { Axial Location } \\
\text { of MDNBR } \\
\text { (in) }\end{array}$ & $\begin{array}{l}\text { Channel where } \\
\text { DNB DCcurs }\end{array}$ \\
\hline 1 & 1.43 & 33 & 15 \\
\hline 2 & 1.53 & 33 & 15 \\
\hline 3 & 1.59 & 33 & 15 \\
\hline 4 & 1.72 & 33 & 15 \\
\hline 5 & 2.06 & 27 & 15 \\
\hline 6 & 2.07 & 18 & 21 \\
\hline 7 & 2.09 & 16.5 & 21 \\
\hline
\end{tabular}




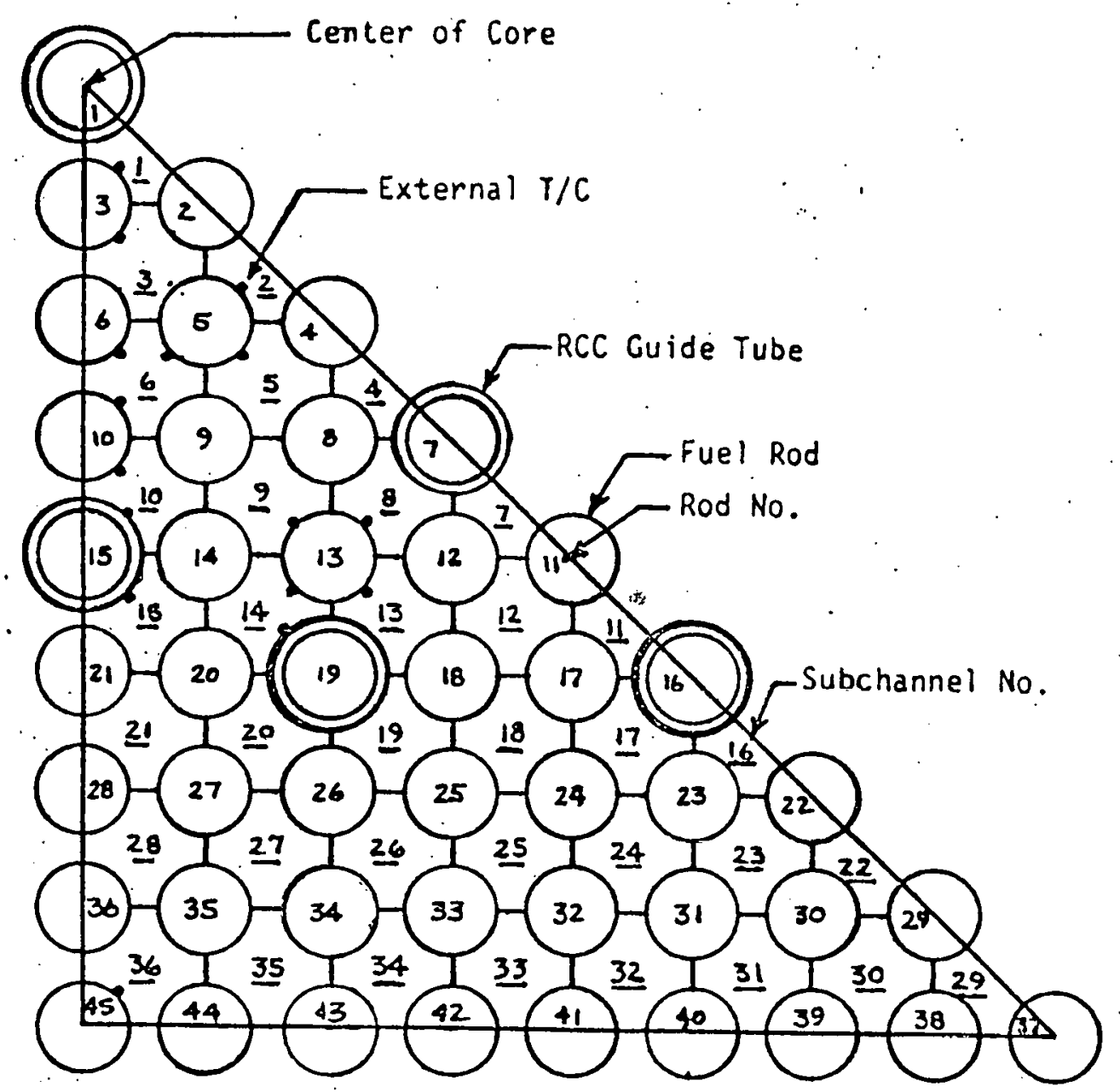

Figure 1-Diagram of COBRA IIIC Model 
o

o

ND. $341.10 \%$ DIETZEEN GRAPH PAPER

IO $\times$ IO PER HALF INEH

o

DIETZEEN CORPORATION

(3)

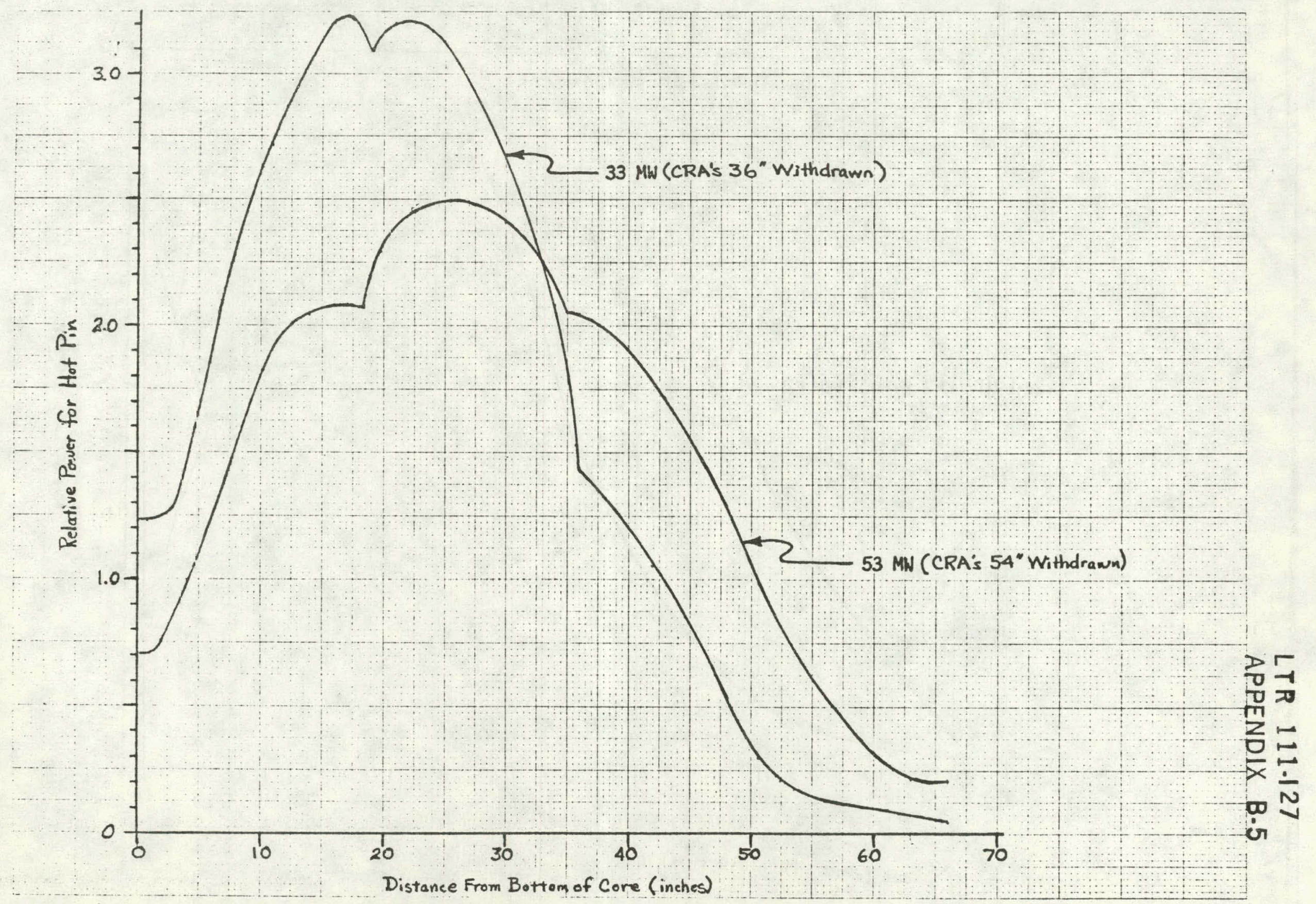

Figure 2 - BOL Axial Profiles 


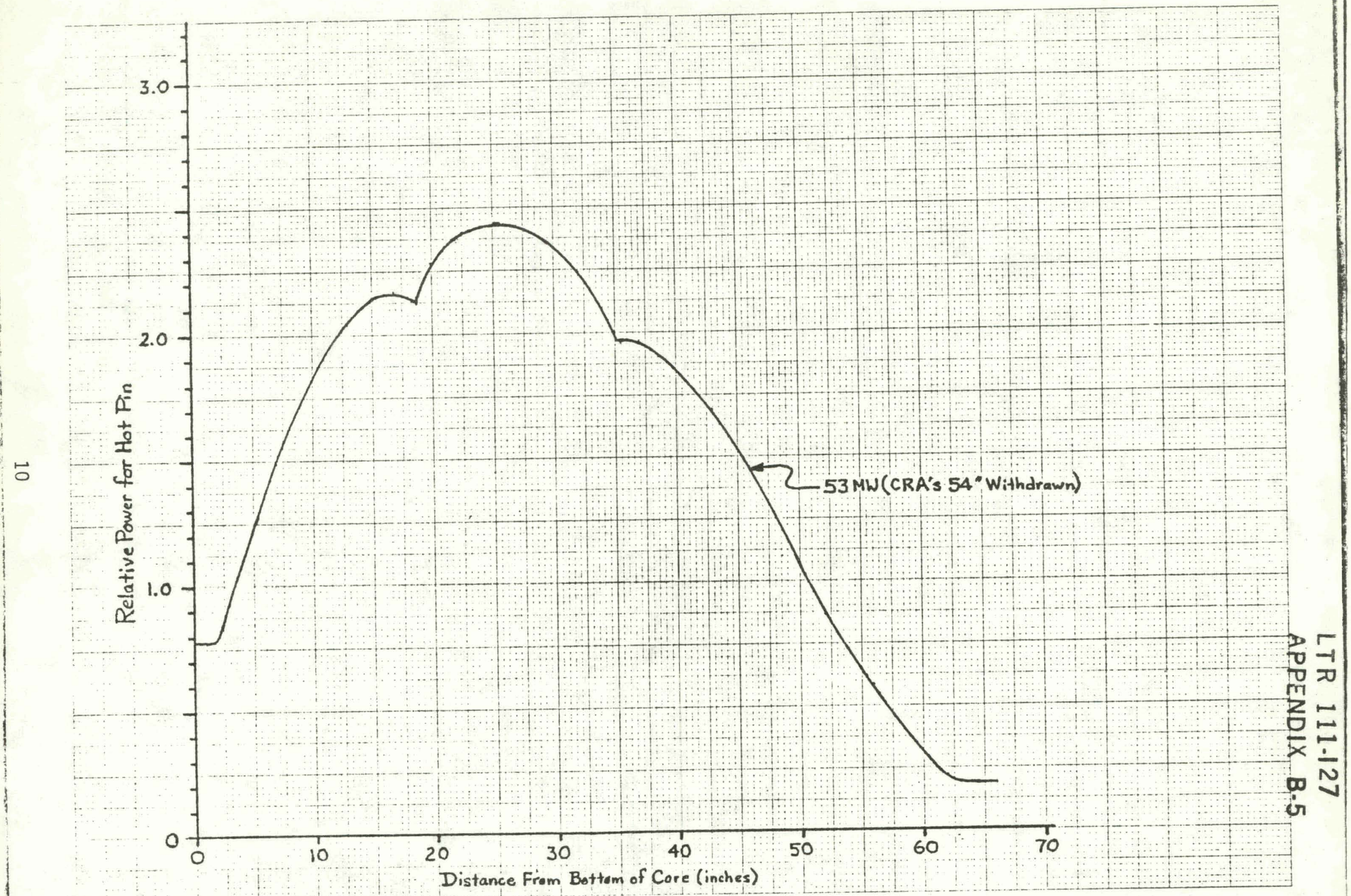

Figure 3 - 200 EFPH Axial Profile 
o

6 NO. 3H.19\% DIETZGEN GRAPH PAPER

(3)

DIETZEEN CORPDRATION

6.

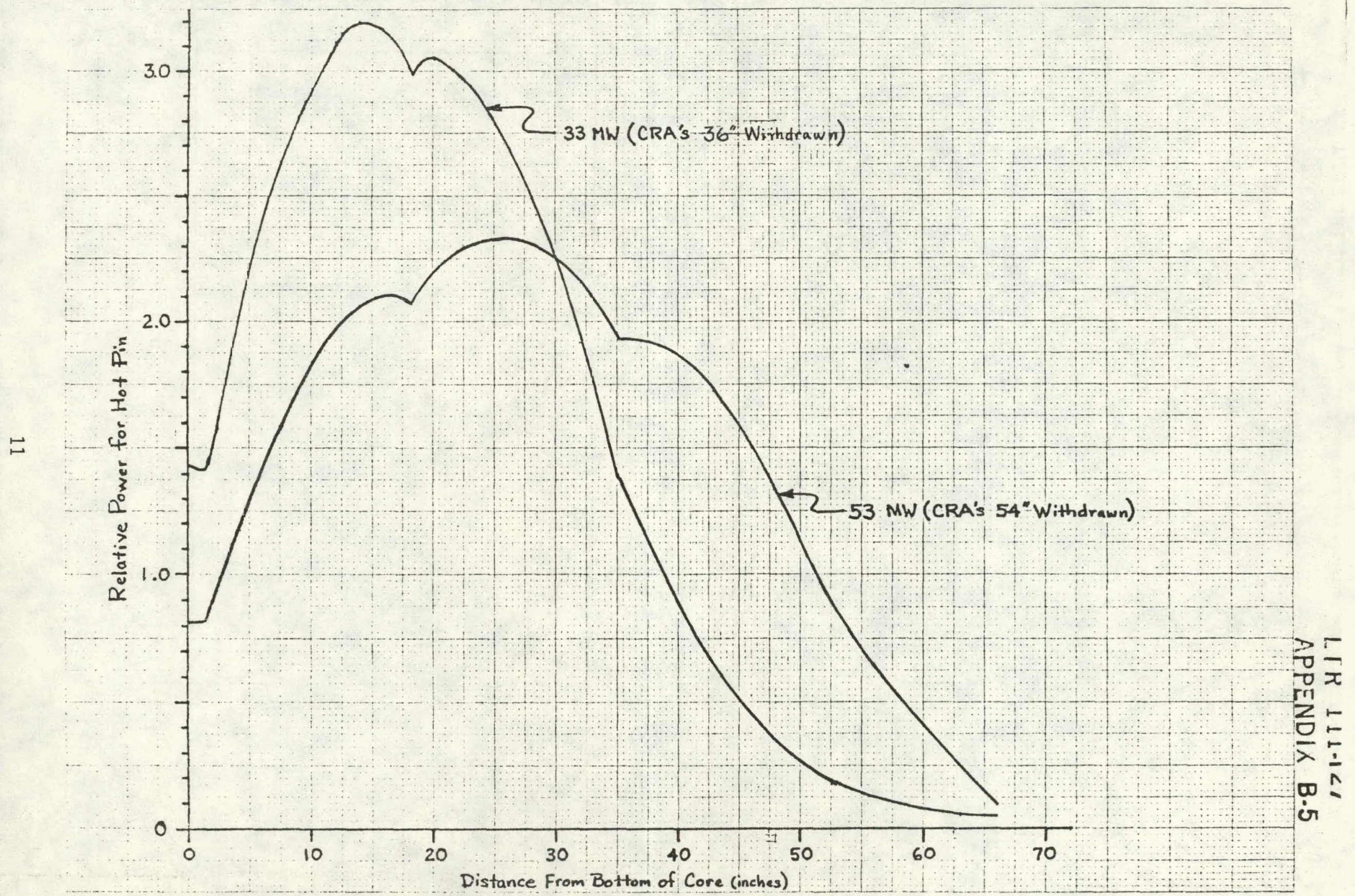

Figure 4 - 1000 EFPH Axial Profiles 


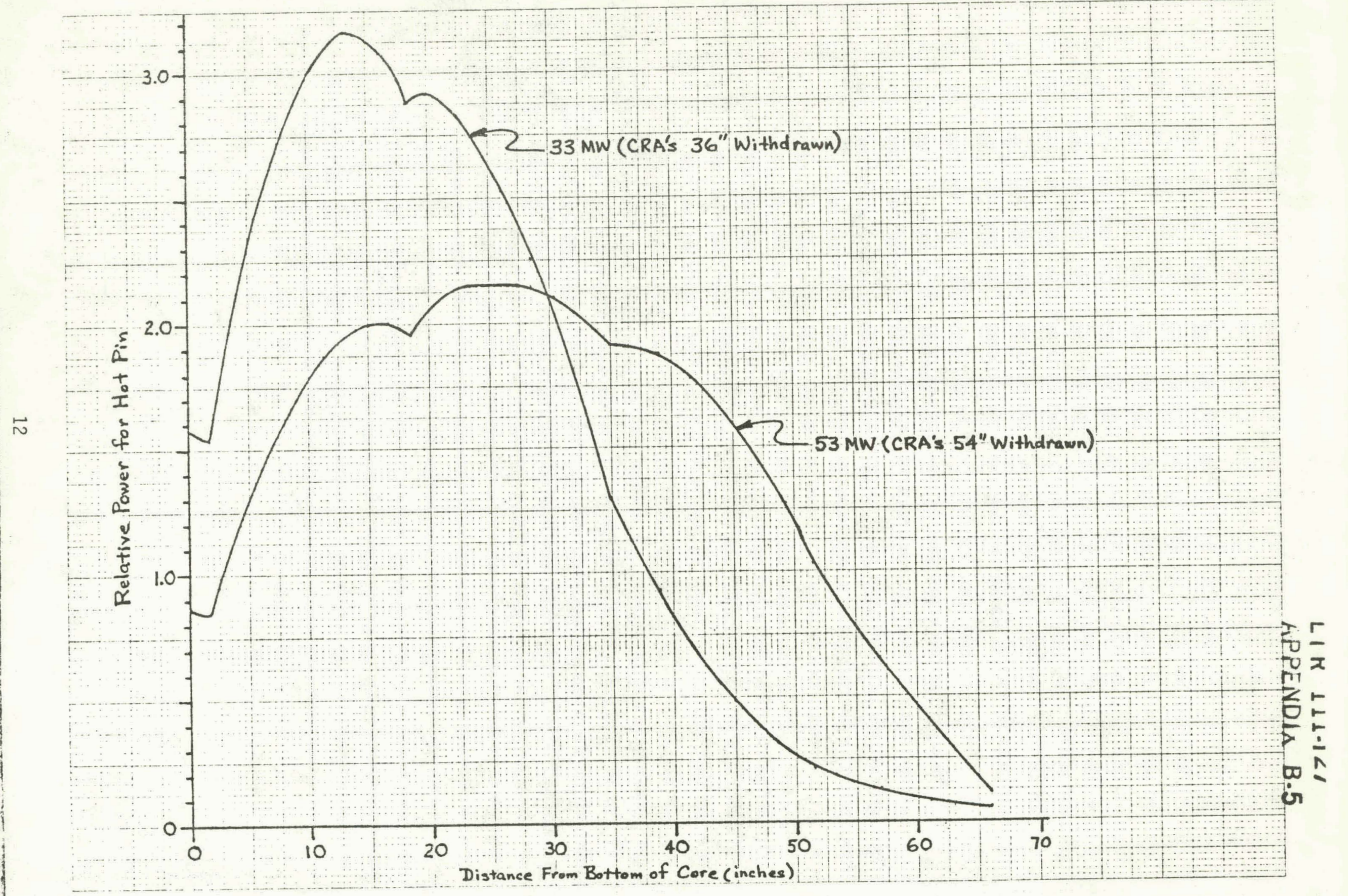

Figure 5 - 2000 EFPH Axial Profiles 
O

2.2

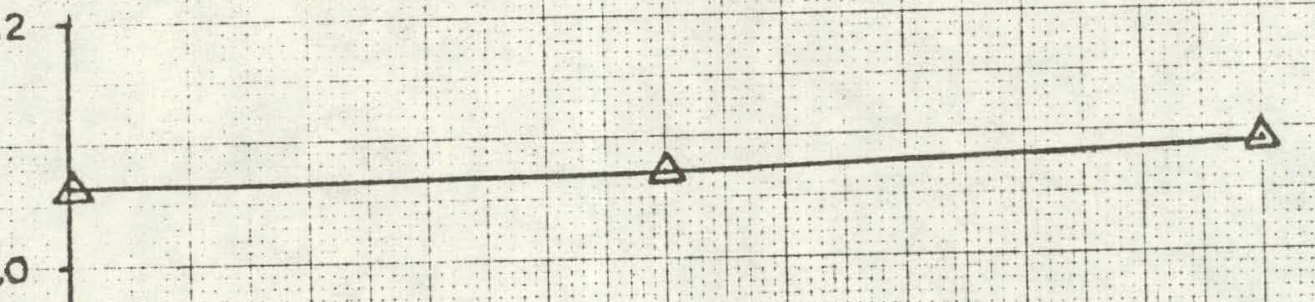

2.0

1.8

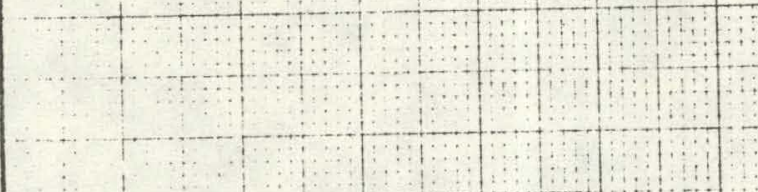

(
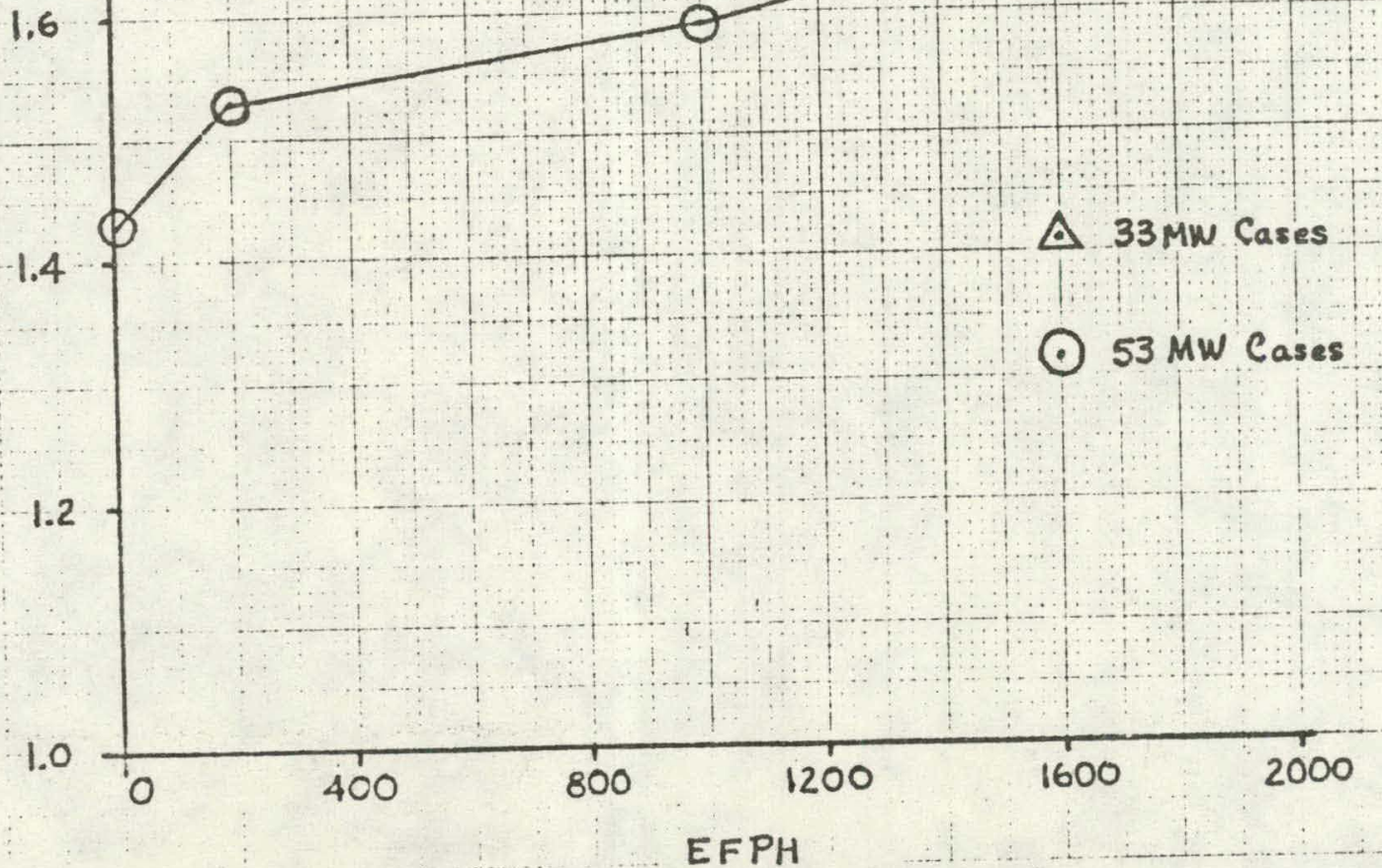

$\triangle 33$ mw Cases

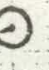

Figure 6 - Results of BOL-EOL MDNBR Comparison Study 